\title{
IntechOpen
}

\section{Advanced Ceramic Processing}

Edited by Adel Mohamed

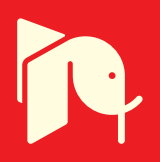





\section{ADVANCED CERAMIC PROCESSING}

Edited by Adel Mohamed 


\section{Advanced Ceramic Processing}

http://dx.doi.org/10.5772/59892

Edited by Adel Mohamed

\section{Contributors}

Sumana Ghosh, Ik Jin Kim, Naboneeta Sarkar, Teresa Golden, Hiroshi Maiwa, Penchal Reddy Matli, Huang Qing, Ramakrishna Reddy R, Adel Mohamed, Maria Aparecida Zaghete, Glauco Meireles Mascarenhas Morandi Lustosa Lustosa, Natalia Jacomaci, João Costa, Leinig Perazolli, Gisane Gasparoto

\section{(c) The Editor(s) and the Author(s) 2015}

The moral rights of the and the author(s) have been asserted.

All rights to the book as a whole are reserved by INTECH. The book as a whole (compilation) cannot be reproduced, distributed or used for commercial or non-commercial purposes without INTECH's written permission. Enquiries concerning the use of the book should be directed to INTECH rights and permissions department (permissions@intechopen.com).

Violations are liable to prosecution under the governing Copyright Law.

\section{(cc) BY}

Individual chapters of this publication are distributed under the terms of the Creative Commons Attribution 3.0 Unported License which permits commercial use, distribution and reproduction of the individual chapters, provided the original author(s) and source publication are appropriately acknowledged. If so indicated, certain images may not be included under the Creative Commons license. In such cases users will need to obtain permission from the license holder to reproduce the material. More details and guidelines concerning content reuse and adaptation can be foundat http://www.intechopen.com/copyright-policy.html.

\section{Notice}

Statements and opinions expressed in the chapters are these of the individual contributors and not necessarily those of the editors or publisher. No responsibility is accepted for the accuracy of information contained in the published chapters. The publisher assumes no responsibility for any damage or injury to persons or property arising out of the use of any materials, instructions, methods or ideas contained in the book.

First published in Croatia, 2015 by INTECH d.o.o.

eBook (PDF) Published by IN TECH d.o.o.

Place and year of publication of eBook (PDF): Rijeka, 2019.

IntechOpen is the global imprint of IN TECH d.o.o.

Printed in Croatia

Legal deposit, Croatia: National and University Library in Zagreb

Additional hard and PDF copies can be obtained from orders@intechopen.com

Advanced Ceramic Processing

Edited by Adel Mohamed

p. cm.

ISBN 978-953-51-2203-6

eBook (PDF) ISBN 978-953-51-6397-8 


\section{We are IntechOpen, \\ the world's leading publisher of Open Access books}

Built by scientists, for scientists

\section{$3,800+$}

Open access books available

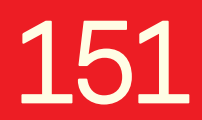

Countries delivered to

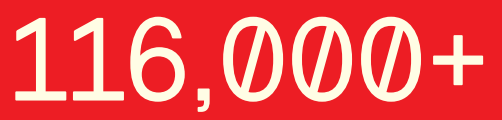

International authors and editors
$120 \mathrm{M}+$

Downloads

Our authors are among the

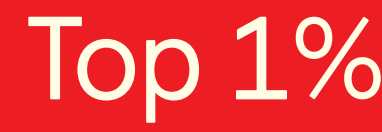

most cited scientists

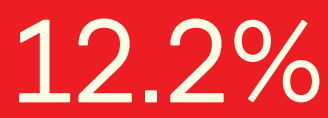

Contributors from top 500 universities

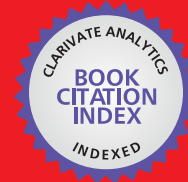

WEB OF SCIENCE ${ }^{\mathrm{TM}}$

Selection of our books indexed in the Book Citation Index in Web of Science ${ }^{\mathrm{TM}}$ Core Collection (BKCI)

Interested in publishing with us?

Contact book.department@intechopen.com

Numbers displayed above are based on latest data collected.

For more information visit www.intechopen.com

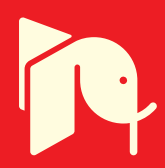





\section{Meet the editor}

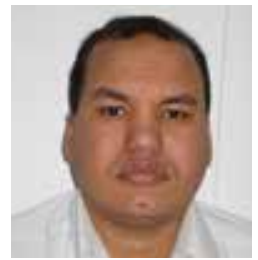

Dr Adel Mohamed holds a PhD degree in metallurgical engineering from Université du Québec à Chicoutimi (UQAC), Quebec, Canada, and MSc and BSc degrees in metallurgical engineering and materials from the Suez Canal University (SCU), Suez, Egypt. He has also completed postdoctoral studies at UQAC. He is working as Associate Professor at Faculty of Petroleum and Mining Engineering, SU, Egypt. He is also working as Research Professor at the University of North Texas (UNT), Texas, USA. His research focuses on development of light metals for automotive applications, and production of ceramic materials and nanotechnology of composite coatings for industrial applications. His accomplishments include around 70 publications in various international journals and conferences, and he has been Editor-in-Chief of a journal, Associate Editor of a journal, and a Reviewer for many international journals. 



\section{Contents}

Preface XI

Chapter 1 Microwave Fast Sintering of Double Perovskite Ceramic Materials 1

Penchal Reddy Matli, Adel Mohamed Amer Mohamed and Ramakrishna Reddy Rajuru

Chapter 2 New Approaches to Preparation of SnO2-Based Varistors Chemical Synthesis, Dopants, and Microwave Sintering 25 Glauco M.M.M. Lustosa, Natalia Jacomaci, João P.C. Costa, Gisane Gasparotto, Leinig A. Perazolli and Maria A. Zaghete

Chapter 3 Porous Ceramics 55

Naboneeta Sarkar and Ik Jin Kim

Chapter 4 Electrochemical Synthesis of Rare Earth Ceramic Oxide Coatings 85

Teresa D. Golden, Yajuan Shang, Qi Wang and Ting Zhou

Chapter 5 Thermal Barrier Ceramic Coatings - A Review 111

Sumana Ghosh

Chapter 6 Electrocaloric Properties of $(\mathrm{Pb}, \mathrm{La})(\mathrm{Zr}, \mathrm{Ti}) \mathrm{O} 3$ and $\mathrm{BaTiO} 3$ Ceramics 139

Hiroshi Maiwa 



\section{Preface}

The primary classes of solid materials are ceramics, metals, and polymers. Ceramics are nonmetallic materials and can be divided into two classes: traditional and advanced. Traditional ceramics include clay products, silicate glass, and cement, while advanced ceramics consist of carbides $(\mathrm{SiC})$, pure oxides $\left(\mathrm{SnO}_{2}\right)$, rare earth oxides (REOs), and many others. Ceramic materials display a wide range of properties, which facilitate their use in many different product areas compared with other materials. Ceramic oxides can also be used as protection coatings because of their interesting corrosion-inhibiting properties. This book is a compilation of laboratory experiences in the sequential phases of advanced ceramic processing and analysis. Although not in the style of a handbook, in a real sense, it is a guide and manual to some practical aspects excluded from other available sources. Researchers from several disciplines across the continents share their expertise and research knowledge about advanced preparation techniques for ceramic oxides.

In Chapter 1, Microwave Fast Sintering of Double Perovskite Ceramic Materials, Adel A.M. Mohamed's team focused on fabrication of the double perovskite $\operatorname{La}_{2} \mathrm{MMnO}_{6}(\mathrm{M}=\mathrm{Ni}$, Co) ceramics using the microwave sintering technique, in order to further improve their magnetic and dielectric properties for practical spintronic applications. As a result, the microwave sintering approach shows obviously better promise over the conventional heating method, in terms of higher efficiency of heating, significantly shorter reaction time, smaller and more regular size, and stronger magnetization of the products. IR, XRD, and SEM-EDX analyses confirmed the formation of single phase for $\mathrm{La}_{2} \mathrm{MMnO}_{6}(\mathrm{M}=\mathrm{Ni}, \mathrm{Co})$ double perovskites.

In Chapter 2, New Approaches to Preparation of $\mathrm{SnO}_{2}$-Based Varistors: Chemical Synthesis, Dopants, and Microwave Sintering, Maria A. Zaghete's team provided a review on new processing steps for the production of $\mathrm{SnO}_{2}$ varistors and showed the possibility to get electrical properties with nonohmic characteristics for technological applications. The new approaches for the chemical synthesis of ceramic powder promote the homogeneous distribution of dopants into the ceramic matrix and reduce segregation and the formation of secondary phases, which are harmful factors on the electrical properties of the varistor and facilitate the integration of the material in today's electronic devices for electrical protection. As a result, the use of microwave oven is a new processing step aiming to reduce the time and temperature of the sintering step and can be considered a promising procedure for varistor production. The preparation of varistors as film emerges as a new possibility in order to facilitate the integration of this material in electronic circuits.

In Chapter 3, Porous Ceramics, Naboneeta Sarkar and Ik Jin Kim used a foaming method, a simple and versatile approach, as fabrication techniques for porous ceramics with tailored 
microstructure, along with distinctive properties. The effects of foam precursor suspensions - bubble size, distribution, contact angle, and surface tension - on the resultant porous ceramics' mechanical and physical properties are assessed in this chapter. Control of these parameters can allow the tailoring of the microstructures of porous ceramics produced by direct foaming.

In Chapter 4, Electrochemical Synthesis of Rare Earth Ceramic Oxide Coatings, Teresa D. Golden's team discussed in detail the electrolytic and direct electrodeposition for the production of rare earth oxide coatings, such as gadolinium, terbium, samarium, neodymium, europium, and dysprosium oxides. Direct electrodeposition occurs when there is a direct oxidation or reduction (exchange of electrons) between the metal ion or metal ion complex and electrode to produce the metal oxide on the surface. The physical and chemical properties of the electrodeposited oxides were characterized by XRD, SEM, and XPS techniques. The mechanisms of electrodeposition for rare earth oxides are discussed in detail. As a result, a variety of morphologies have been obtained for the REO films, such as nanocrystalline films, nanorods, nanotubes, nanosheets, as well as flower-like and coral-like nanostructures.

In Chapter 5, Thermal Barrier Coatings: An Overview, Sumana Ghosh provided an overview on the thermal barrier coating (TBC) requirement, application of TBCs, degradation mechanisms, different processing techniques used for preparation of TBCs, and their thermal properties. As a result, TBCs are required to be more suitably designed for the thermal protection of gas turbine engine components to increase engine operating temperatures, fuel efficiency, and engine reliability significantly. However, coating durability is a vital factor to increase the engine operating temperature. Therefore, the coating behavior and failure modes under high temperature and high thermal gradient cyclic conditions should be properly understood to develop next-generation advanced TBCs.

In Chapter 6, Electrocaloric Properties of PLZT and $\mathrm{BaTiO}_{3}$ Ceramics, Hiroshi Maiwa studied the electrocaloric temperature change of the PLZT ceramics and $\mathrm{BaTiO}_{3}$ ceramics using direct measurements. The electrocaloric effect (ECE) is a phenomenon in which a material shows a reversible temperature change under an applied electric field. He concluded that the possibility of the approximately twice temperature change was obtained by introducing 9.1\% La components in PZT ceramics.

Adel Mohamed 
Chapter 1

\title{
Microwave Fast Sintering of Double Perovskite Ceramic Materials
}

\author{
Penchal Reddy Matli, Adel Mohamed Amer Mohamed and \\ Ramakrishna Reddy Rajuru
}

Additional information is available at the end of the chapter

http://dx.doi.org/10.5772/61026

\begin{abstract}
The book chapter mainly deals with the microwave sintering of high quality crystals of $\mathrm{La}_{2} \mathrm{MMnO}_{6}(\mathrm{M}=\mathrm{Ni}$ or $\mathrm{Co})$ ceramics. Double perovskite $\mathrm{La}_{2} \mathrm{MMnO}_{6}(\mathrm{M}=\mathrm{Ni}$ or $\mathrm{Co})$ ceramics with average particle size of $\sim 65 \mathrm{~nm}$ were manufactured using microwave sintering at $90^{\circ} \mathrm{C}$ for $10 \mathrm{~min}$ in $\mathrm{N}_{2}$ atmosphere for the first time. The morphology, structure, composition, and magnetic properties of the prepared compacts were characterized using X-ray diffraction (XRD), scanning electron microscopy (SEM), transmission electron microscopy (TEM), energy-dispersive X-ray spectroscopy (EDX), infrared spectroscopy (IR and FTIR), and physical properties measurement system (PPMS). The corresponding dielectric property was tested in the frequency range of $1 \mathrm{kHz}-1 \mathrm{MHz}$ and in the temperature range of 300-600 K, and the ceramics exhibited a relaxation-like dielectric behavior.
\end{abstract}

Keywords: ceramics, microwave sintering, microstructures, XPS, multiferroic properties

\section{Introduction}

Microwave sintering (MWS) is emerging and an innovative sintering technology for processing of ceramic materials and is commonly related with volumetric and uniform heating. MWS is one of the exciting new fields in material science with vast potential for preparation of novel and/or nanostructured ceramics/materials. Microwave heating has some important benefits 
over normal heating for ceramic processing, including reduced processing time, higher energy efficiency, selective and controlled heating, environmental friendliness, and improved product uniformity and yields. Microwave processing of materials is a relatively new technology that can be used in wide range of different materials such as ceramics, ferroelectrics, oxides, metals, and composites [1-10].

The effect of microwave radiation on the processing of several ceramic materials such as magnetic materials, superconducting materials, dielectric materials, metals, polymers, ceramics, and composite materials offers numerous benefits over conventional heating techniques. These benefits include time and energy savings, volumetric and uniform heating, considerably reduced processing time and temperature, improved product yield, fine microstructures, improved mechanical properties, lower environmental impact, reduction in manufacturing cost, and synthesis of new materials [11].

Microwave sintering has developed in recent years as a promising technology for faster, cheapest and most environmental-friendly processing of a wide variety of materials, which are regarded as significant advantages over conventional sintering procedures. Microwave radiation/heating for sintering of ceramic constituents has recently appeared as a newly motivated scientific approach [5].

Microwave sintering approach has unique advantages over conventional sintering methods in many respects. The essential difference in the conventional and microwave sintering processes is in the heating mechanism (Figure 1). In microwave heating, the materials themselves absorb microwave energy and then transform it into heat within the sample volume and sintering can be completed in shorter times. In microwave sintering, the heat is generated internally within the test sample due to the rapid oscillation of dipoles at microwave frequencies [12]. The contribution of diffusion from external sources is lesser. The internal and volumetric heating makes the sintering rapidly and uniformly. The heat generated through conventional heating is generally transferred to the sample via radiation, conduction, and convention [13]. This process takes longer duration for sintering the materials and causes some of the constituents to evaporate. This may lead to modify the desired stoichiometry and grain.

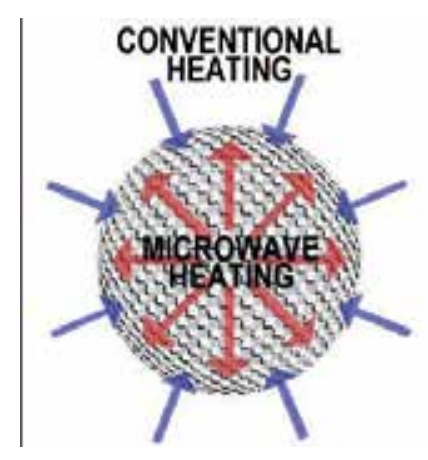

Figure 1. Comparison of heating mechanism in microwave and conventional sintering methods. 
In contrast, microwave energy is transferred directly to the material through molecular interaction with an electromagnetic field. Microwave heating is more effective than conventional methods in terms of the usage of energy, produces higher temperature homogeneity, and is considerably faster than conventional heat sources. In the last 8 years, we have successfully sintered various ferrites/ferroelectrics, oxides, ceramics, mullite fiber, composites, and even powdered metals to full density using microwave processing $[4,5,14-16]$.

Due to the energy efficient nature of microwave heating, there is a great opportunity for the application of microwaves to process metal based materials to couple the many gains of microwave heating. Recently, microwaves energy has been successfully used in different composites, metal, ceramics, melting of metals and metal ores, joining or brazing of metals, and heat treatment of metals [17].

The microwave energy is highly versatile in its application in the field of communication, and it still dominates almost all communications in space and mobile or cordless phone technology involves microwave frequencies. However, other than this communication, microwave energy has found its use for a variety of applications including rubber products industry, food processing, wood/paper/textile/ceramic drying, pharmaceuticals, polymers, printing materials, and biomedical fields over the past 50 years. These applications involve low temperature $\left(<500^{\circ} \mathrm{C}\right)$ utilization of microwaves. The high temperature $\left(>800^{\circ} \mathrm{C}\right)$ applications of microwaves are a rather recent phenomenon.

Many researchers have reported that microwave heating is relatively faster than the conventional heating processes. This faster speed is manifested as a reduction in the densification time of ceramic powder compacts, often allied to lower sintering temperatures [7]. Generally, the synthesis kinetics and sintering materials are apparently upgraded by two or three orders of magnitude or even more when conventional heating is switched for microwave heating [18].

\subsection{Interaction of microwaves with ceramic materials: theoretical aspects}

Microwaves are electromagnetic waves with the electromagnetic radiations in the frequency band of $300 \mathrm{MHz}$ to $300 \mathrm{GHz}$, and their corresponding wavelength between $1 \mathrm{~m}$ and $1 \mathrm{~mm}$ can be used successfully to heat many ceramic materials. Since most of the microwave band is used for communication purpose, the Federal Communications Commission has allocated only very few specific frequencies for industrial, scientific, and medical applications. A major portion of these microwave used in the communication sector and only certain frequencies, viz., $0.915,2.45,5.85$, and $21.2 \mathrm{GHz}$, are chosen for medical and industrial applications. Among these allowed frequencies, $2.45 \mathrm{GHz}$ is the most common microwave frequency used for industrial and scientific applications. The interaction and heating generation of ceramics under microwave field depends on the dielectric, magnetic, and conductive loss of the material and temperature dependent parameters.

The ability of a material to be heated in microwave field depends on its dielectric properties, characterized by the dielectric complex constant $\varepsilon^{*}$ : 


$$
\varepsilon^{*}=\varepsilon^{\prime}-j \varepsilon^{\prime \prime}
$$

Dielectric permittivity $\varepsilon^{\prime}$ represents the material capacity to store electromagnetic energy and loss factor $\varepsilon^{\prime \prime}$ to dissipate it.

The dielectric constant of a material varies with its temperature, frequency, and composition. The power $\mathrm{P}$ absorbed in the material is proportional to the loss factor $\varepsilon^{\prime \prime}$, the frequency $f[\mathrm{~Hz}]$, and the electric field intensity $E[\mathrm{~V} / \mathrm{m}]$ :

$$
P=2 \Pi f \varepsilon^{0} \varepsilon^{\prime \prime} E^{2}
$$

(or)

$$
P=55.63 \times 10^{-2} f \varepsilon^{\prime} \tan \delta E^{2}
$$

where the dielectric loss angle (loss tangent) is

$$
\tan \delta=\frac{\varepsilon^{\prime \prime}}{\varepsilon^{\prime}}
$$

Eq. (3) shows that for a fixed value of electric field (E), the power in microwave absorbed in the material mass is proportional to the frequency (f) (which is practically $2.45 \mathrm{GHz}$ ), the dielectric permittivity $\left(\varepsilon^{\prime}\right)$, and loss factor $\left(\varepsilon^{\prime \prime}\right)$ (through the loss tangent tan $\delta$ ), which vary with the materials temperature and humidity in their turn.

The diffusion of electromagnetic power into the absorber is characterized by skin depth $(D)$ and expressed as

$$
D=(\pi f \mu \sigma)^{-1 / 2}
$$

where $\mu$ and $\sigma$ are magnetic permeability and electrical conductivity and $f$ is the frequency, respectively.

The effective penetration depth decreases with increase in frequency which in turn causes less heating. Hence, a suitable combination of parameters in Eqs. (2) and (4) is required for achieving optimum coupling. It can be inferred from this discussion that low dielectric loss materials take longer time and high dielectric loss materials take shorter duration in the microwave sintering.

On a microscopic scale, the phenomenon of dielectric heating is the effect of impurity dipolar relaxation in the microwave frequency region. When the vacancy jumps around the impurity 
ion to align its dipole moment with the electric field the internal friction of the rapidly oscillating dipole cause a homogeneous (volumetric) heating. Where the maximum absorption of microwave energy at the frequency or temperature at which the loss factor $(\tan \delta)$ attains its maximum. This is equivalent to an elastic relaxation resulting in damping of mechanical vibrations in solids.

The efficiency of the microwave dielectric heating is dependent on the ability of a specific material (powder, solvent, or reagent or anything else) to absorb microwave energy and convert it into heat. The heat is generated by the electric component of the electromagnetic field through two main mechanisms, i.e., dipolar polarization and ionic contribution [19]. According to the electromagnetism, the effect of a material upon heat transfer rates is often expressed as

$$
\frac{\Delta T}{t}=\frac{0.56 \times 10^{-10} \varepsilon_{e f f}^{\prime \prime} f E^{2}}{\rho C_{p}}
$$

where $\varepsilon_{\text {eff }}^{\prime \prime}$ is the effective relative dielectric loss factor, $f$ is the frequency of microwave, $E$ is the magnetic fields of microwave within the material, $\rho$ is the mass density of the sample, and $C_{\mathrm{P}}$ is the isotonic specific heat capacity [19]. In this case, the energy efficiency can easily reach 80 $90 \%$ utilization and higher than the conventional heating methods [20, 21]. However, the essential nature of the interaction between microwaves and reactant molecules during the preparation of materials is fairly uncertain and speculative.

\subsection{Benefits of microwave sintering comparison to conventional sintering method}

In recent years, microwave sintering has shown significant advantages against conventional sintering for the synthesis of ceramic materials. Microwave sintering has attained worldwide attention due to its major advantages against conventional sintering methods, especially in ceramic materials.

Microwave sintering can significantly shorten the sintering time leading to consume much lower energy than conventional sintering.

There are major potential and real advantages using microwave energy for material processing over conventional heating. These include the following:

- Time and energy savings

- Reduced processing time and temperature

- Rapid, volumetric, and selective heating

- Fine microstructures

- Improved physical and functional properties

- Lower environmental impact 
- Controllable electric field distribution

\subsection{Applications of microwave sintering of ceramic materials}

Now microwave processing has been found that this technique can also be applied as efficiently and effectively to powdered metals as to many ceramics. Finally, The MWS operational expenses are less than $50-80 \%$ to the conventional sintering techniques. The MWS technique works 20 times faster than the conventional sintering method and takes only few minutes for processing than the conventional ones (takes hours).

\subsection{Brief introduction of multiferroics}

Multiferroic materials exhibits both ferroelectric and magnetic in nature and have much attracted research interest due to their potential application in multistate data storage and electric field controlled spintronics. Among all the studies related to the materials, transition metal oxides with perovskite structure are noteworthy $[22,26]$.

Multiferroic materials with double-perovskite structure $\left(A A^{\prime} B B^{\prime} O_{6}\right)$ are solid solutions of two perovskites: $\left(A B O_{3}\right)$ and $\left(A^{\prime} B^{\prime} O_{3}\right)$. In $\left(A A^{\prime} B B^{\prime} O_{6}\right)$, $A$ and $A^{\prime}$ represent alkaline rare earth cations (La, $\mathrm{Y}$, and $\mathrm{Ce}$ ), while $\mathrm{B}$ and $\mathrm{B}^{\prime}$ are transition metal cations ( $\mathrm{Ni}$ and $\mathrm{Co}$ ). If $\mathrm{A}$ and $\mathrm{A}^{\prime}$ represent the same chemical element, the double perovskite has the general formula $\left(A_{2} B B^{\prime} O_{6}\right)$ and the crystal structure of $\mathrm{A}_{2} \mathrm{BB}^{\prime} \mathrm{O}_{6}$-type perovskite, as shown in Figure 2. Alkali-earth and lanthanide (smaller ion) ions are alone usually occupied in the A site [27, 28]. If the $\mathrm{A}$ ion is too small, the common expected distortions are cation displacement with $\mathrm{BO}_{6}$ and octahedral ones [29].

The most representative $\left(A_{2} B^{\prime} \mathrm{O}_{6}\right)$ ferromagnetic double perovskites are $\mathrm{La}_{2} \mathrm{NiMnO}_{6}$ [30-33], $\mathrm{La}_{2} \mathrm{CoMnO}_{6}[5,34,35], \mathrm{La}_{2} \mathrm{BMnO}_{6}[36-48]$, and $\mathrm{La}_{2} \mathrm{FeMnO}_{6}[41,42]$.

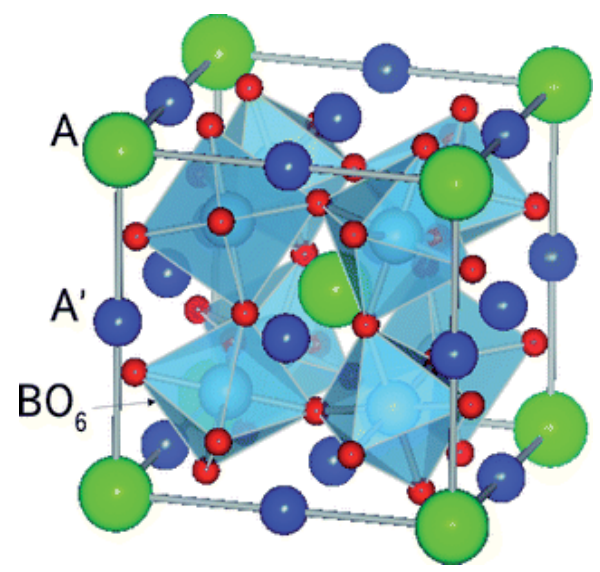

Figure 2. Crystal structure of $\mathrm{A}_{2} \mathrm{BB}^{\prime} \mathrm{O}_{6}$ type perovskite. The spheres at $\mathrm{A}$ and $\mathrm{A}^{\prime}$-site are for $\mathrm{La}$ and at $\mathrm{B}^{\prime}$-site are for $\mathrm{Ni}$, Co. The network of corner-sharing $\mathrm{BO}_{6}$ octahedra isare shown where oxygen atoms are in the corner of octahedra. 
$\mathrm{La}_{2} \mathrm{NiMnO}_{6}(\mathrm{LNMO})$ has gained more attention as a rare example of a single-material platform with multiple functions, such as ferromagnetic (FM) semiconducting properties up to room temperature, magnetocapacitance, and magnetoresistance effects. The spin lattice coupling characteristics of LNMO exhibits a larger magnetodielectric (MD) effect close to room temperature. It has been well documented that the spins, electric charge, and dielectric functions in LNMO are turned by magnetic or electric fields. LNMO is considered as an FM semiconductor and shows Curie transition temperature $\left(T_{c}\right)$ very close to room temperature. This property in LNMO makes the $\mathrm{Ni}^{2+}$ and $\mathrm{Mn}^{4}$ ions ordered and occupied the centers of $\mathrm{BO}_{6}$ (corner shared) and $\mathrm{B}^{\prime} \mathrm{O}_{6}$ structures respectively. This arrangement leads to the distribution of ideal double perovskite.

LNMO's structural system, $\mathrm{La}_{2} \mathrm{CoMnO}_{6}(\mathrm{LCMO})$, possesses an $\mathrm{FM} T_{\mathrm{c}} \sim 225 \mathrm{~K}$ with an insulating behavior. The magnetic properties of the LCMO are strongly depending on the cation ordering, valences, defects, and synthetic conditions.

Among them, double perovskite $\mathrm{La}_{2} \mathrm{NiMnO}_{6}(\mathrm{LNMO})$ and $\mathrm{La}_{2} \mathrm{CoMnO}_{6}(\mathrm{LCMO})$ ceramics are attractive due to their impressive properties and potential on industrial applications [30-33, $42,43]$. LNMO is a ferromagnetic semiconductor with high critical temperature of $T_{c} \sim 280 \mathrm{~K}$, which may be used in commercial solid-state thermoelectric (Peltier) coolers [42]. LCMO is also a ferromagnetic semiconductor with critical temperature of $T_{\mathrm{c}} \sim 230 \mathrm{~K}$ [35-37]. Several crystal structures have been identified, and it is confirmed that the ferromagnetic semiconductors LNMO and LCMO with high $T_{\mathrm{c}}$ are $P_{1 / n}^{2}$ monoclinic structure, in which octahedra with $\mathrm{Ni}$ (or Co) and Mn centers alternately stacking along (111). Recent reports indicate LNMO and LCMO have considerable magnetodielectric effects at room temperature, which is very useful for future electronic device $[29,35,44,45]$.

The double perovskites $\mathrm{La}_{2} \mathrm{MMnO}_{6}(\mathrm{M}=\mathrm{Co}$ and $\mathrm{Ni})$ are one of the most commonly occurring and important in all of materials science because they can exhibit novel magnetic, electric, and optical properties [28-44]. $\mathrm{La}_{2} \mathrm{MMnO}_{6}$ crystallizes in a double perovskite structure with rock salt configuration of $\mathrm{MO}_{6}$ and $\mathrm{MnO}_{6}$ octahedra. The ordering of $\mathrm{M}^{2+}$ and $\mathrm{Mn}^{4+}$ gives rise to $180^{\circ}$ super exchange interactions based on Goodenough-Kanamori rules and consequently high ferromagnetic Curie transition temperature [43].

It is familiar that the properties of double perovskite compounds are strongly influenced by the materials composition and microstructure, which are sensitive to the preparation technique employed for their synthesis [46]. Various synthesis techniques such as sol-gel [30, 32, 35], coprecipitation [31], solid-state reaction method [33, 34], microwave sintering process [5], molten-salt synthetic process [26, 27] sol-gel autocombustion [41], and chemical solution deposition method [47] have been reported in the preparation of double perovskite compounds. Each of the techniques has its own merits and limitations. For instance, conventional sintering is a simple and relatively cheap method with a long holding time (several hours), formation of lots of undesirable intermetallic compounds, and nonhomogeneous pore-size distribution. In the recent years, microwave sintering has emerged as a new sintering method for ceramics, semiconductors, metals, and composites. 
Microwave sintering (MWS) technique has gained a lot of significance in recent times for materials (metals, composites, ceramics/nanoparticles) synthesis and sintering mainly because of its intrinsic advantages [5] such as rapid heating rates, reduced processing times, substantial energy savings novel and improved properties, finer microstructures, and being environmentally more clean. Therefore, it is viewed as one of the most advanced sintering techniques in material processing $[5,48]$ and improved physical and mechanical properties [7]. It has been shown that microwave sintering technique may provide enhanced densification in sintering of metal, oxides and non-oxide ceramics $[5,48,49,50]$.

However, to the best of our knowledge in the open literature, there have been only a few reports so far on the fabrication of double perovskite nanoparticles by microwave sintering approach $[5,51]$. The purpose of the current chapter will focus on fabrication of the double perovskite $\mathrm{La}_{2} \mathrm{MMnO}_{6}(\mathrm{M}=\mathrm{Ni}, \mathrm{Co})$ ceramics and in order to further improve their magnetic and dielectric properties for practical spintronic applications through microwave sintering approach.

\section{Experimental procedure}

\subsection{Materials}

All the chemical reagents were of analytical pure grade $(99.99 \%)$ and used without further purification. The versatile chemical coprecipitation-microwave sintering process [15] employed in present investigation is two-step process which consists of coprecipitation method is the first step of synthesis followed by microwave sintering in second half of experiment. High-purity $\mathrm{La}\left(\mathrm{NO}_{3}\right)_{3} \cdot 5 \mathrm{H}_{2} \mathrm{O}$ (Merck), $\mathrm{Ni}\left(\mathrm{NO}_{3}\right)_{2} \cdot 6 \mathrm{H}_{2} \mathrm{O}$ (Sigma-Aldrich), $\mathrm{Co}\left(\mathrm{NO}_{3}\right)_{2} \cdot 6 \mathrm{H}_{2} \mathrm{O}$ (Sigma-Aldrich), and $\mathrm{Mn}\left(\mathrm{NO}_{3}\right)_{3} \cdot 4 \mathrm{H}_{2} \mathrm{O}$ (Sigma-Aldrich) were used as starting materials. In a typical experimental process, the high purity stoichiometric amounts of $\mathrm{La}\left(\mathrm{NO}_{3}\right)_{3} \cdot 5 \mathrm{H}_{2} \mathrm{O}, \mathrm{Ni} /$ $\mathrm{CO}\left(\mathrm{NO}_{3}\right)_{2} \cdot 6 \mathrm{H}_{2} \mathrm{O}$, and $\mathrm{Mn}\left(\mathrm{NO}_{3}\right)_{3} \cdot 4 \mathrm{H}_{2} \mathrm{O}$ were dissolved in appropriate amounts of deionized water and magnetically stared vigorously for $2 \mathrm{~h}$ at $80^{\circ} \mathrm{C}$. The ammonia solution was used until to get $8.5 \mathrm{PH}$ value. The stirring will continue for about $30 \mathrm{~min}$, and the suspension was ball milled for about $24 \mathrm{~h}$ with ethanol as a milling media. The reactants were to be mixed well and then dried at $80^{\circ} \mathrm{C}$ in a cabinet drier for $24 \mathrm{~h}$ to obtain precursor powder sample. Then the powder was subjected to microwave sintering under uniform heating to get dense ceramics.

\subsection{Microwave sintering setup}

Microwave processing systems usually consist of a microwave source, for generation of microwaves, a circulator, an applicator to deliver the power to the load, and systems to control the heating and the experimental diagram of the microwave sintering set up used is shown in Figure 3. Most applicators are multimode, where different field patterns are excited simultaneously.

Further, In order to achieve pure double perovskite phases, the precursor samples were put into $2.45 \mathrm{GHz}, 6 \mathrm{~kW}$ continuously adjustable microwave equipment (HAMiLab-HV3, SynoTherm), the maximum operating temperature up to $1400^{\circ} \mathrm{C}$, and $0.5-3 \mathrm{~kW}$. The multimode 
microwave furnace consists of a cubical stainless steel chamber with a side of $30 \mathrm{~cm}$. Two magnetrons (microwave source), each with a maximum rated power of $1100 \mathrm{watts}$, are situated opposite to each other. A box made of alumina, zirconia, and silica mixed cardboard is used as a thermal insulator. The material is positioned in the center of box and is surrounded by silicon carbide (susceptor) plates.

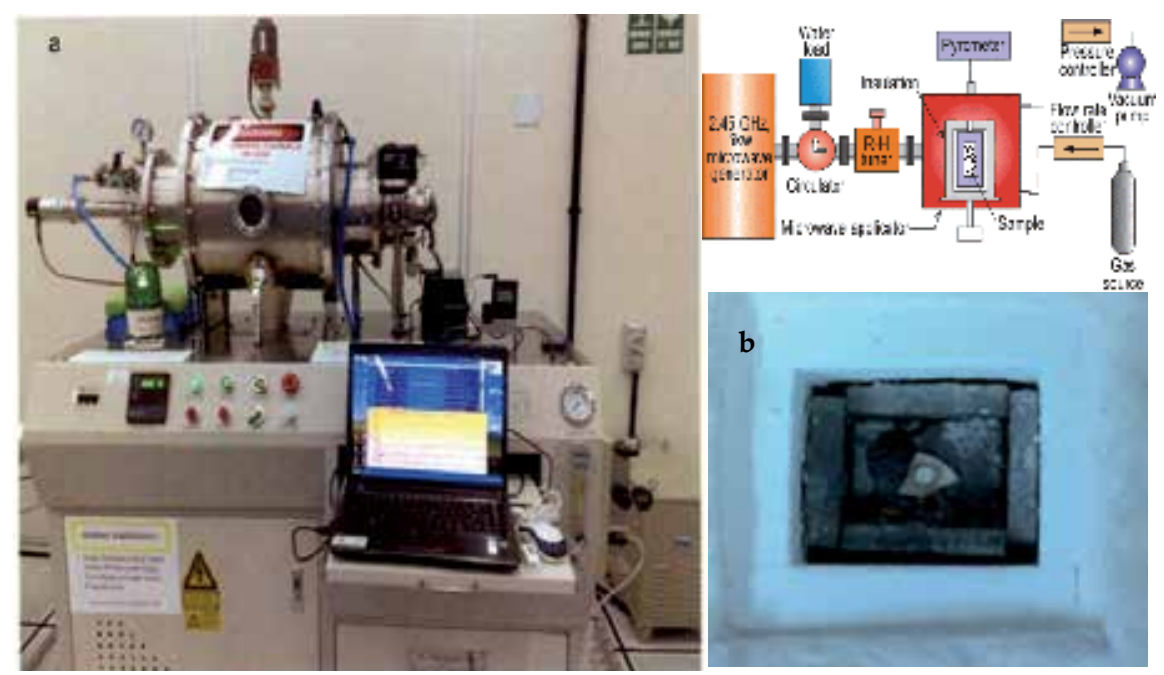

Figure 3. Experimental setup of multimode microwave furnace [3] (a) and Ssusceptor (b).

During the sintering process, the microwave sintering chamber was filled with high purity nitrogen gas flow (99.999\%). An adjustable programmed electrical control system was used to deliver the required energy to the sample. The employed heating chamber was made up with stainless steel double walled tubular cavity with water-cooled facility, and the maintained processing temperature is about $1400^{\circ} \mathrm{C}$. A high purity quartz crystal cylinder arrangement is available inside the chamber, where the samples were loaded for processing; the temperature of the sample was measured using infrared pyrometer during the MW sintering. The SiC plates surrounded in the crucible were served as susceptors and provide initial heating to be compact disc samples. Once the materials received absorb sufficient MW heat including the core and will get uniform heating. The secondary purpose of $\mathrm{SiC}$ is to maintain the surface temperature. The crucible was positioned at the center of the furnace so it provides strong MW radiation. The green compacted disks for heated at $900^{\circ} \mathrm{C}$ for $10 \mathrm{~min}$ in atmospheric $\mathrm{N}_{2}$ ambient temperature and heating rate of $20^{\circ} \mathrm{C} / \mathrm{min}$ is maintained by varying magnetron power between 1000 and $2500 \mathrm{~W}$ followed by normal frequency cooling.

\subsection{Characterization and property measurements of $\mathrm{La}_{2} \mathrm{MMnO} 6(\mathrm{M}=\mathrm{Ni}$, Co $)$ ceramics}

The crystal structure of the microwave sintered products was characterized by X-ray diffraction (XRD) using a Shimadzu X-ray diffractometer with $\mathrm{Cu}-\mathrm{K}_{\alpha}$ radiation $2 \theta$ range of 20 to $80^{\circ}$. Raman spectra were carried out on an RM-1000 micro-Raman spectrometer with the 514.53 
$\mathrm{nm}$ line of an argon laser under ambient conditions. The composition, morphology, and microstructures of the products were characterized by transmission electron microscope (TEM FEI Tecnai F20 microscope, Japan) and field emission scanning electron microscope (FESEM, Hitachi S-4800, Japan) equipped with an energy-dispersive X-ray spectrometer (EDS). Fourier transform infrared spectroscopy (FTIR) was performed on a Nicolet 5700 spectrometer in the wave number range of $400-4000 \mathrm{~cm}^{-1}$. The spectroscopic grade $\mathrm{KBr}$ pellets were used for collecting the spectra with a resolution of $4 \mathrm{~cm}^{-1}$ performing 32 scans. X-ray photoelectron spectroscopy (XPS) was performed on an ESCA-UK XPS system with an $\mathrm{Mg} \mathrm{K}_{\alpha}$ excitation source $(\mathrm{h} v=1486.6 \mathrm{eV})$, where the binding energies were referenced to the C1s peak at 284.6 $\mathrm{eV}$ of the surface adventitious carbon. The magnetic properties were measured using a physical property measurement system (PPMS-9, Quantum Design, Inc., San Diego, CA, USA) at room temperature under a maximum field of $20 \mathrm{kOe}$. Silver paste was applied on both sides of the pellet for the electrical measurements. The variation of dielectric constant and dielectric loss as a function of frequency at room temperature and as a function of temperature at different frequencies was measured using computer interfaced HIOKI 3532-50 LCR-HITESTER.

\section{Microwave-sintering of engineered double perovskite ceramic materials}

\subsection{Crystal structure of $\mathrm{La}_{2} \mathrm{MMnO}(\mathrm{M}=\mathrm{Ni}$, Co) ceramics}

The phase structure of the microwave sintered LNMO and LCMO nanoparticles was characterized by X-ray diffraction (XRD). As shown in Figure 4, no extra reflection peaks other than those of pure perovskite phase are detected, indicating the high purity of nanoparticles can be obtained in $10 \mathrm{~min}$ by this microwave sintering approach, which confirms the formation of single phase compositions of LNMO and LCMO double perovskites [30].

The crystallite size was calculated from XRD patterns using the Debye-Scherrer formula [7], described by the Eq. (7):

$$
D=\frac{0.94 \times \lambda}{\beta_{1 / 2} \times \cos \theta}
$$

where $D=$ crystallite size, $\lambda$ = radiation wavelength $(1.5405 \AA), \beta_{1 / 2}=$ half-width of diffraction profile, and $\theta=$ diffraction angle.

The average crystal size was found to be $23 \mathrm{~nm}$ for LNMO and $28 \mathrm{~nm}$ for LCMO, which are 2-3 times smaller than the particle/grain sizes measured by TEM as shown in below section.

Raman spectroscopy is one of the most important tools to attain the information about the structure of the samples. The Raman spectra of microwave sintered LNMO and LCMO ceramics are shown in Figure 5. The Raman spectra display two characteristics peaks at around $514,653 \mathrm{~cm}^{-1}$ for LNMO and 488, $670 \mathrm{~cm}^{-1}$ for LCMO ceramics, corresponding to the welldocumented A band and B band, respectively. Martín-Carron et al. have assign the two peaks 


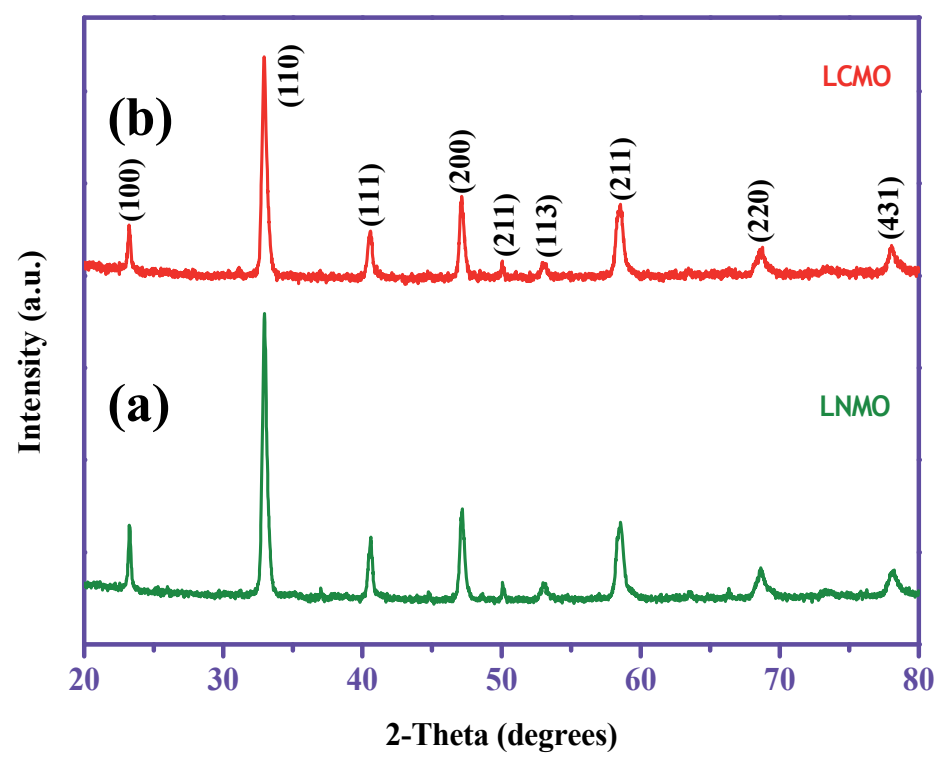

Figure 4. XRD patterns of the microwave sintered (a) LNMO and (b) LCMO ceramics.

to the $A_{g}$ antisymmetric stretching (or Jahn-Teller stretching mode) and $B_{g}$ symmetric stretching vibrations of the $\mathrm{MnO}_{6}$ octahedra, respectively [34-36, 52-54]. It is well known that the $A_{g}$ band is usually assigned to antisymmetric stretching (or Jahn-Teller stretching mode), while the $B_{g}$ band distributed to symmetric stretching vibrations. A noticeable difference is seen between our LNMO/LCMO ceramics and the bulk sample: the $A_{g}$ and $B_{g}$ peaks for the nanoparticles shift to higher binding energy, 13 and $25 \mathrm{~cm}^{-1}$, respectively, when compared to the bulk crystal. The shifting may occur due to surface strain of the crystal structure [55].

The microstructure and morphology of microwave sintered LNMO and LCMO ceramics were investigated by FESEM and TEM techniques. Typical SEM images of $\mathrm{La}_{2} \mathrm{MMnO}_{6}(\mathrm{M}=\mathrm{Ni}, \mathrm{Co})$ nanoparticles are shown in Figure 6, the average grain size is about $52 \mathrm{~nm}$ and $58 \mathrm{~nm}$ for $\mathrm{La}_{2} \mathrm{NiMnO}_{6}$ and $\mathrm{La}_{2} \mathrm{CoMnO}_{6}$, respectively. The grain size of $\mathrm{La}_{2} \mathrm{CoMnO}_{6}$ is bigger than that of $\mathrm{La}_{2} \mathrm{NiMnO}_{6}$, which obeys the rule that relatively large ionic radius id benefit to the diffusion in the microwave sintering process.

From the morphologies of both samples, the grains seem to be homogeneous and form a group of cluster phenomenon. The perovskite material has better microwave absorption capability $[5,51]$ and leads to fine grain growth during the sintering process.

The EDX spectra (inset of $6 \mathrm{a}$ and $6 \mathrm{~b}$ ) and their corresponding tables confirm the presence of the constituent elements ( $\mathrm{La}, \mathrm{Ni}, \mathrm{Co}, \mathrm{Mn}$, and $\mathrm{O}$ ), the composition being nearly the same as that of stoichiometric $\mathrm{La}_{2} \mathrm{NiMnO}_{6}$ and $\mathrm{La}_{2} \mathrm{CoMnO}_{6}$, respectively.

As shown in Figures 7a and 7b, transmission electron microscopy (TEM) was applied for all samples to determine particle size and confirmed that the particle sizes are about $53 \pm 12$ and $60 \pm 15 \mathrm{~nm}$ for LNMO and LCMO, respectively, which agrees good agreement with the SEM 


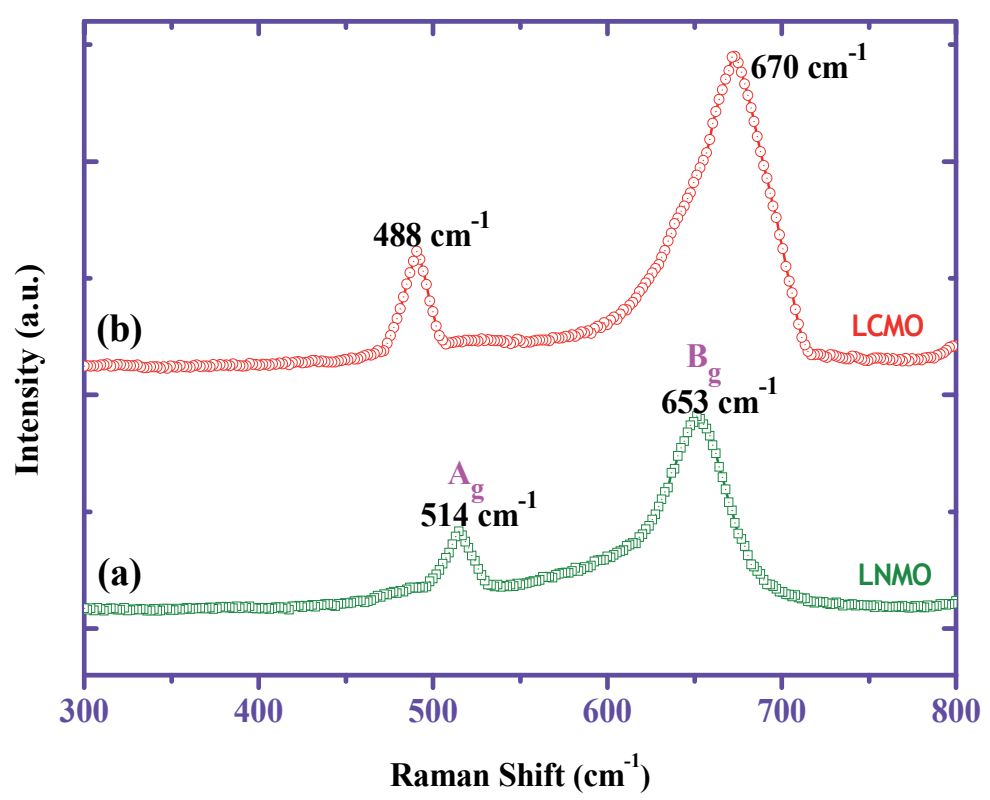

Figure 5. Raman of the microwave sintered (a) LNMO and (b) LCMO ceramics.

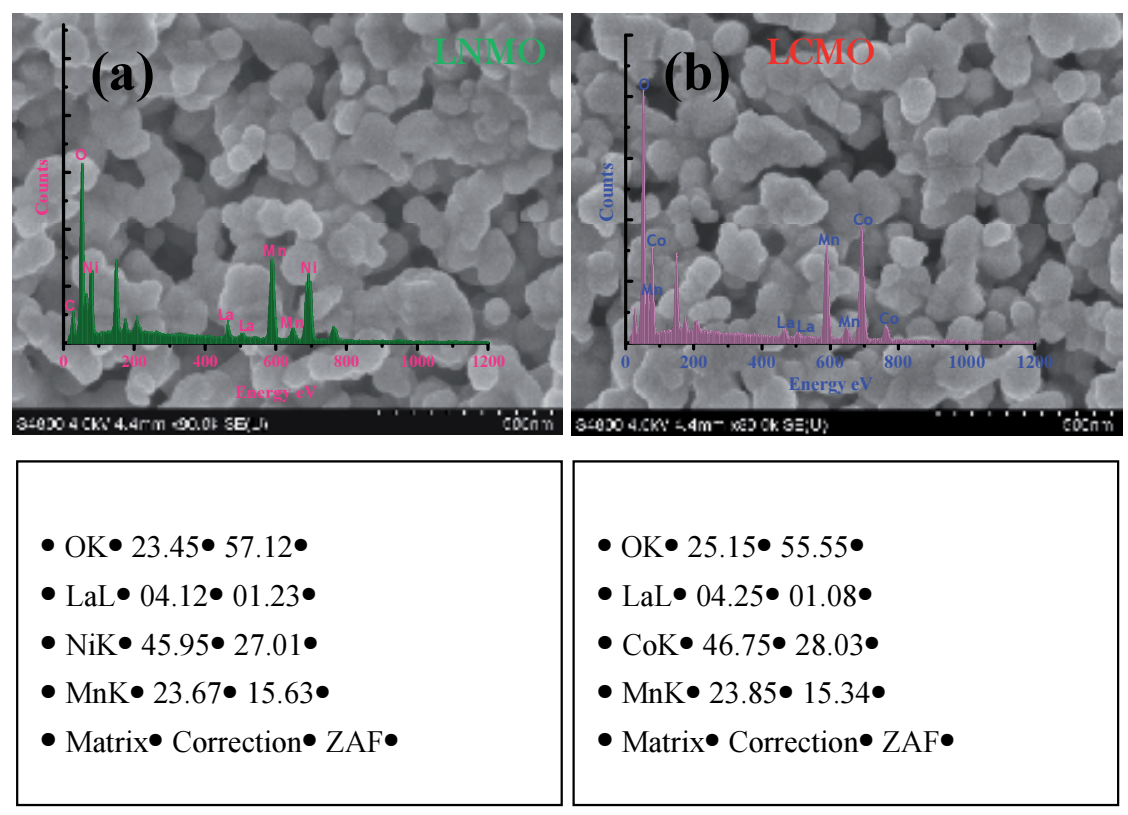

Figure 6. FESEM images, EDX spectra (inset) and elemental data of the microwave sintered (a) LNMO and (b) LCMO ceramics. 

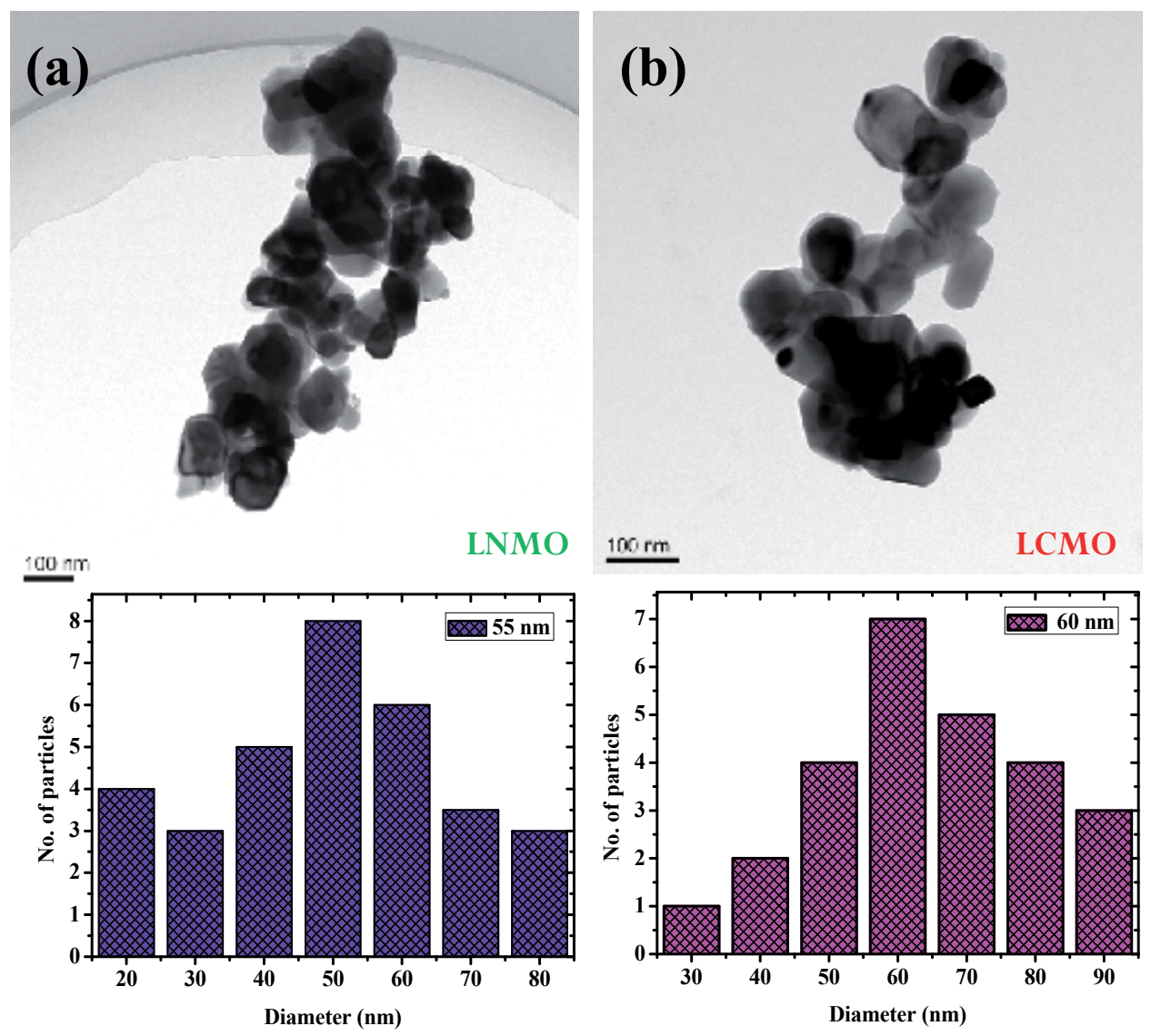

Figure 7. TEM images and particle size distributions of the microwave sintered (a) LNMO and (b) LCMO ceramics.

results. From the TEM micrograph, nanosized grains with quasi spherical shape can be observed.

The formation mechanism of the perovskite type structure in the microwave sintered LNMO and LCMO ceramics is further supported by FT-IR spectrum shown in Figure 8. The FTIR spectrum is used to characterize the phase composition and purity of the prepared samples. The intense peak around $3423 \mathrm{~cm}^{-1}$ is referring to the stretching vibration of hydroxyl group. In addition, the bands at about $1629 \mathrm{~cm}^{-1}$ can be ascribed to the asymmetric $\mathrm{COO}^{-}$stretching vibrations. The bands at 1450 and $1357 \mathrm{~cm}^{-1}$ attributed to the asymmetric stretching of $\mathrm{CO}_{3}^{2-}$. The intensive absorption band observed at $597 \mathrm{~cm}^{-1}$ can be assigned to Fe-O stretching vibrations formed by the octahedral $\mathrm{MnO}_{6}$ group.

The chemical states of elements of Ni, Mn in LNMO, and Co, Mn in LCMO ceramics was further investigated by X-ray photoelectron spectroscopy. The XPS core level spectra of Ni 2p, Co 2p, and $\mathrm{Mn} 2 \mathrm{p}$ of $\mathrm{La}_{2} \mathrm{MMnO}_{6}(\mathrm{M}=\mathrm{Ni}, \mathrm{Co})$ are presented in Figure 9. A Ni $2 \mathrm{P}_{3 / 2}$ signal was observed at $851.3 \mathrm{eV}$ along with a satellite peak at $858.5 \mathrm{eV}$. Another peak was noticed at $869.5 \mathrm{eV}$ and 


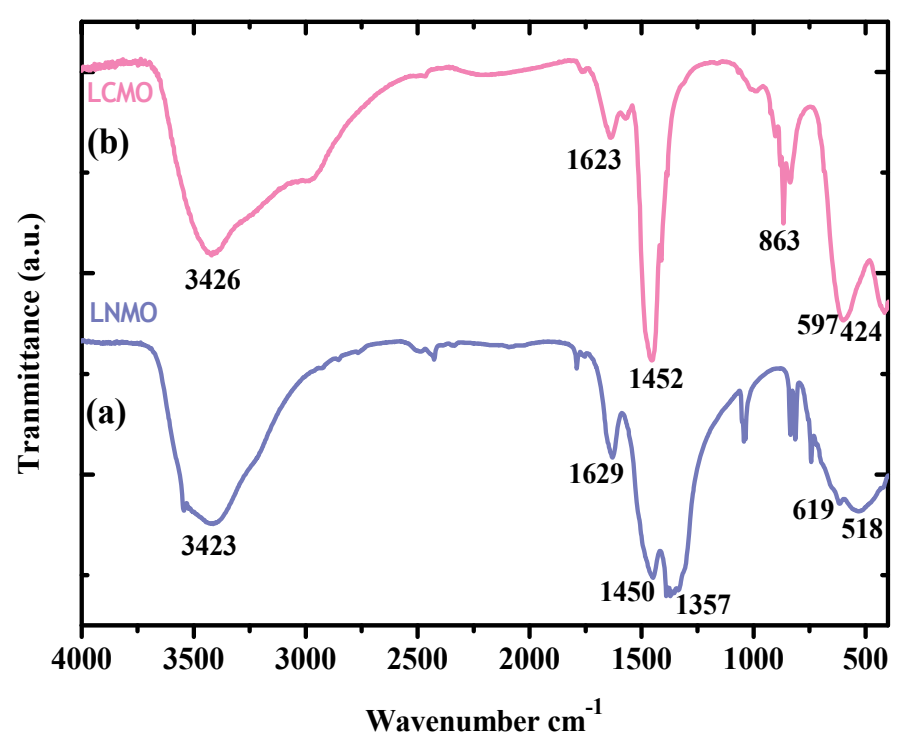

Figure 8. FTIR of the microwave sintered (a) LNMO and (b) LCMO ceramics.

ascribed to the $\mathrm{Ni} 2 \mathrm{P}_{1 / 2}$ level. Auger electron peak of Ni of [Figure 9a] explains the presence of +2 oxidation state of the nickel in LNMO ceramics. The Mn $2 \mathrm{p}_{3 / 2}$ peak of LNMO is at $638.4 \mathrm{eV}$, while the same $\mathrm{Mn} 2 \mathrm{p}_{3 / 2}$ peak is at $641.5 \mathrm{eV}$ for $\mathrm{Mn}_{2} \mathrm{O}_{3}$ [56]. In the spectrum of $\mathrm{Co} 2 \mathrm{p}$ (Figure $6 \mathrm{c})$, the peaks of Co $2 \mathrm{p}_{3 / 2}$ and Co $2 \mathrm{p}_{1 / 2}$ states were located at 777.3 and $782.7 \mathrm{eV}$, respectively [57]. The Mn $2 \mathrm{p}_{3 / 2}$ peak of LCMO shown in Figures $6 \mathrm{~b}$ and $6 \mathrm{~d}$ is found at $637.6 \mathrm{eV}$, close to that in $\mathrm{Mn}_{2} \mathrm{O}_{3}$ [56].

\subsubsection{Magnetic analysis of $\mathrm{La}_{2} \mathrm{MMnO}_{6}(\mathrm{M}=\mathrm{Ni}, \mathrm{Co})$ ceramics}

The magnetization characteristics were measure both as a function of applied magnetic field at fixed temperatures and as a function of temperature at fixed fields. The room temperature hysteresis loops of the microwave sintered $\mathrm{La}_{2} \mathrm{MMnO}_{6}(\mathrm{M}=\mathrm{Ni}, \mathrm{Co})$ ceramics were measured using physical property measurement system (PPMS). The magnetization curves, as shown in Figures 10a and 10c, display relatively high saturation magnetization. The magnetic saturation $\left(M_{s}\right)$ values of LNMO and LCMO are 42.9 and $65.4 \mathrm{emu} / \mathrm{g}$, respectively, which is lower their theoretical values of 47.5 and $71.21 \mathrm{emu} / \mathrm{g}$ reported in the literature [40]. One can note that MWS products saturation magnetization was higher than for the conventionally sintering products [36], indicating that MWS method is efficient to fabricated high quality double perovskite material.

The frequency dependence of saturation magnetization hysteresis curves was recorded at room temperature for the LNMO ceramics as shown in Figure 10a. A hysteresis loop has been observed at $5 \mathrm{~K}$ with a coercive field of $\sim 282$ Oe and remnant magnetization of $\sim 7.7 \mathrm{emu} / \mathrm{g}$, which show that the LNMO sample exhibit typical ferromagnetic behavior. Figure 10c shows the variation of magnetization as a function of magnetic field for LCMO ceramics. A hysteresis 

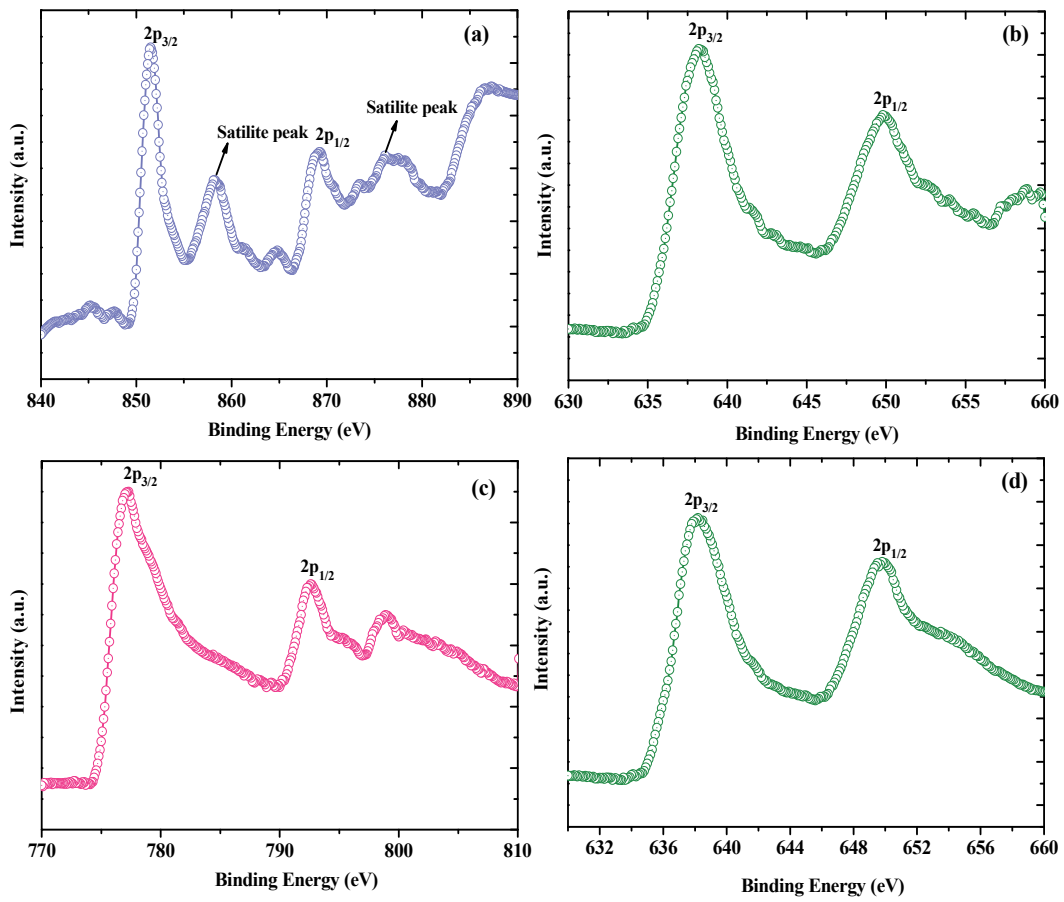

Figure 9. High-resolution XPS spectra's of (a) Ni 2p peaks, (b) Mn 2p peaks for LNMO and (c) Co 2p peaks, (d) Mn 2p peaks for LCMO ceramics.

loop has been observed at $5 \mathrm{~K}$ with a coercive field of $\sim 972$ Oe and remnant magnetization of $\sim 8.14 \mathrm{emu} / \mathrm{g}$, which show that the LCMO sample exhibit typical super paramagnetic behavior. Apart from the magnetic characteristics presented here, detailed examination is in progress and the extensive and expected results will be reported elsewhere shortly.

Figures $10 \mathrm{~b}$ and $10 \mathrm{~d}$ show the temperature dependence of magnetization measurements for LNMO and LCMO under an applied field was carried out by field-cooled (FC) and zero-fieldcooled (ZFC) processes at an applied magnetic field of 100 Oe in the temperature range of 5$400 \mathrm{~K}$. For the LNMO, It could be observed from ZFC as well as FC magnetization that the material shows two ferromagnetic transitions around $270 \mathrm{~K}$ and $240 \mathrm{~K}$, which is reliable with the presence of two phases as showed by the X-ray diffraction studies. As the ferromagnetic transition temperature in the pure monoclinic phase is found to be near $255 \mathrm{~K}$, we attribute the ferromagnetic transition at $240 \mathrm{~K}$ to the rhombohedral phase. FC magnetization reaches a maximum value of $\sim 3.2 \mathrm{emu} / \mathrm{g}$ at $5 \mathrm{~K}$. The magnetic transition at $\sim 255 \mathrm{~K}$ indicates the onset of FE long-range ordering, very close to the magnetic transition temperature $\left(T_{\mathrm{c}}=\sim 280 \mathrm{~K}\right)$ reported earlier in the literature [41]. It is pertinent to maintain that there is a divergence between ZFC and FC magnetization curves below $220 \mathrm{~K}$ for the LCMO. Noticeable difference has also been observed in the case of low field ZFC and FC magnetization for LNMO particles. These LCMO nanoparticles possess a single magnetic transition at about $225 \mathrm{~K}$ under $100 \mathrm{Oe}$ 

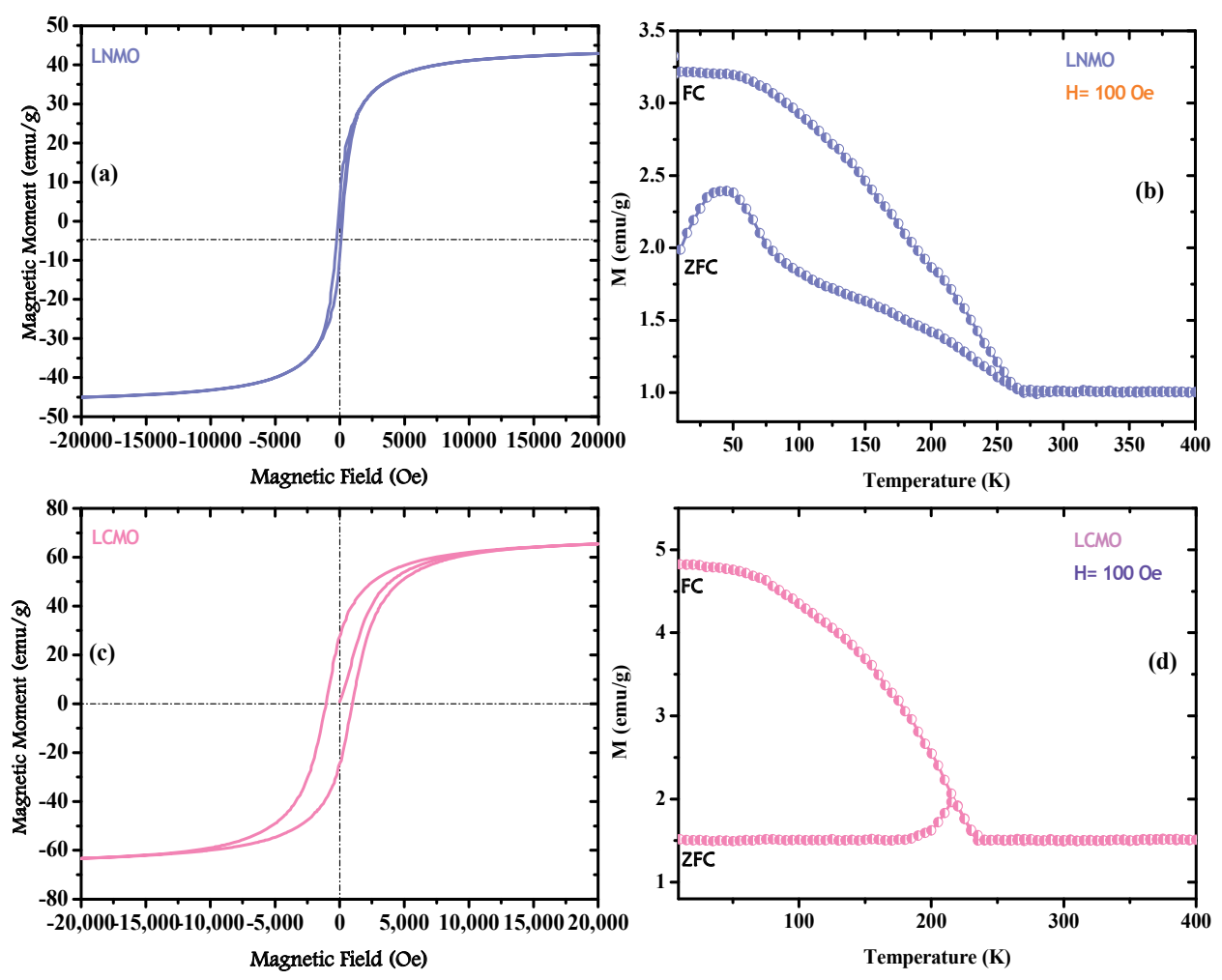

Figure 10. Magnetic field dependent magnetization data at $5 \mathrm{~K}$ (a and c), zZero-Ffield-Ccooled (ZFC) and FfieldCcooled (FC) magnetization as a function of temperature (b and d) the microwave sintered LNMO and LCMO ceramics.

field. This observation is very close to the behavior of bulk LCMO ceramics [58]. The maximum FC magnetization is noticed about $4.8 \mathrm{emu} / \mathrm{g}$ at $5 \mathrm{~K}$.

\subsection{Dielectric properties of $\mathrm{La}_{2} \mathrm{MMnO}_{6}(\mathrm{M}=\mathrm{Ni}$, Co) ceramics}

The temperature variation of dielectric constant $\left(\varepsilon^{\prime}\right)$ and loss tangent $(\tan \delta)$ at different frequencies ranging from $1 \mathrm{kHz}$ to $1 \mathrm{MHz}$ for the microwave sintered $\mathrm{La}_{2} \mathrm{MMnO}_{6}(\mathrm{M}=\mathrm{Ni}, \mathrm{Co})$ ceramics is shown in Figures 11a-11d. Noticeably, the dielectric constant $\left(\varepsilon^{\prime}\right)$ decreases significantly with increasing frequency. An interesting Maxwell-Wager relaxation [59]-type dielectric behavior (at high dielectric constant) has been noticed around $450 \mathrm{~K}$ in these materials and also strong dispersion in the relaxation spectra. The dielectric constant is gradually increased first along with the increase in temperature and attains significant growth at a critical temperature. The critical temperature value shifts toward higher side as and when the measuring frequency increases. These features indicate the thermally activated process [59]. This phenomenon has been most widely described in various earlier reports [24, 59-61]. 
Such dielectric performance could be attributed to the cationic disorder prompted by the exchange of $\mathrm{B}$ sites [62]. In the present systems, $\mathrm{Ni}^{3+} / \mathrm{Co}^{3+}$ and $\mathrm{Mn}^{4+}$ ions instantly exist in $\mathrm{B}$ sites, which results in two kinds of $\mathrm{BO}_{6}$ octahedra in the structure of $\mathrm{La}_{2} \mathrm{MMnO}_{6}$. Therefore, the ion disorder in the unit cell should be one of the causes for this behavior.
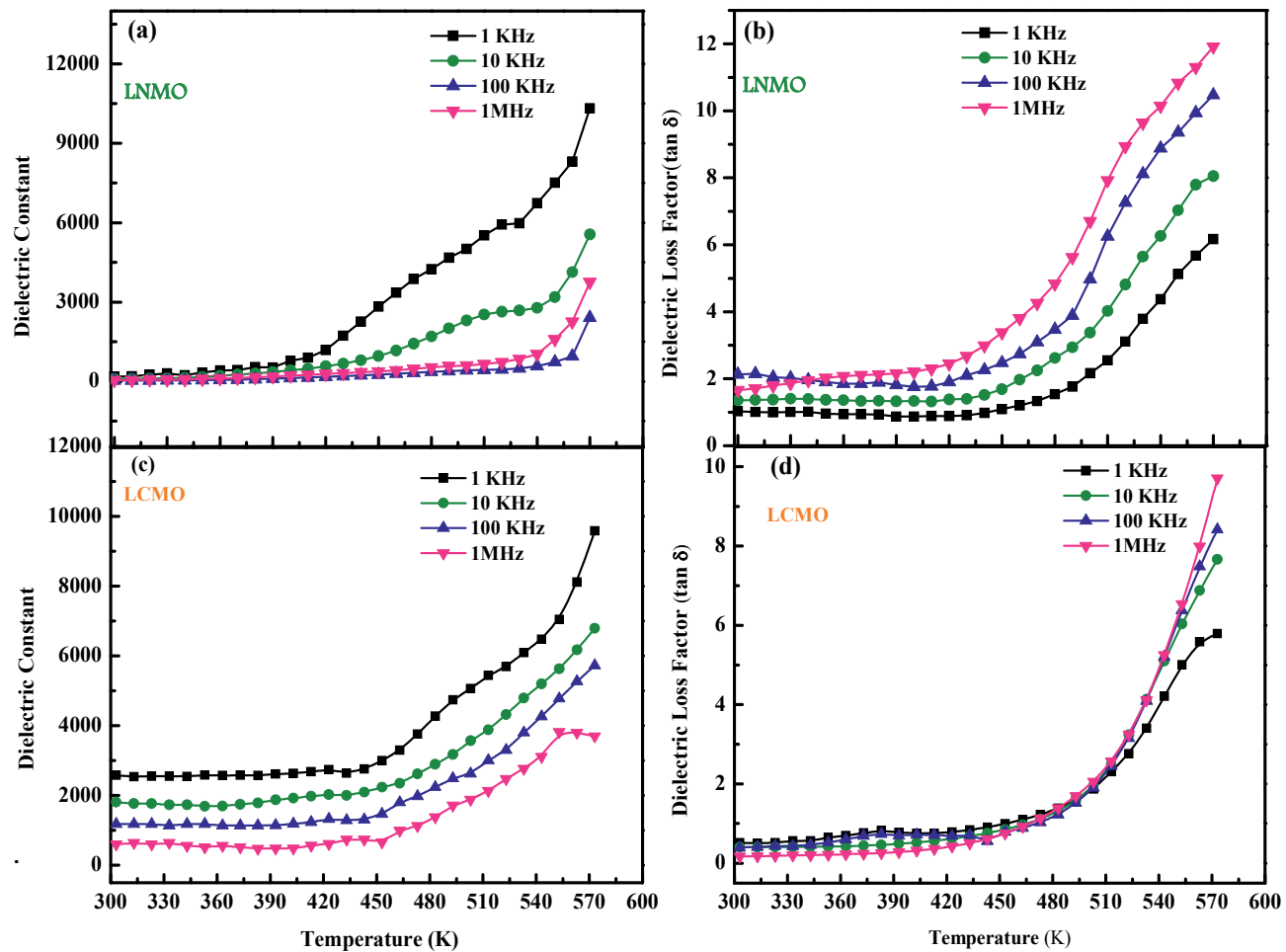

Figure 11. Temperature dependence of dielectric constant and dielectric loss of the microwave sintered (a \& b) LNMO and $(c \& d)$ LCMO ceramics at various frequencies.

Figures $12 \mathrm{a}$ and $12 \mathrm{~b}$ show the dielectric constant $\left(\varepsilon^{\prime}\right)$ as a function of frequency of LNMO and LCMO ceramics at different temperatures. It can be observed that the dielectric constant of both ceramics decreases as frequency increases. The decrease in the dielectric constant with increase in frequency can be explained by the behavior on the basis of electron happing from $\mathrm{Fe}^{2+}$ to $\mathrm{Fe}^{3+}$ ions or on basis of decrease in polarization with the increase in frequency. Polarization of a dielectric material is the quantity of the contributions of ionic, electronic, dipolar, and interfacial polarizations [63]. At low frequencies, polarization mechanism is keenly observed at low frequencies to the time varying electric fields. As the frequency of the electric field increases, different polarization contributions are filter out under leads to the decrement in net polarization under dielectric constant. Similar behavior has also been reported by different investigators earlier in the literature [60,64]. The physical, magnetic, and dielectric properties of LMNO and LCMO are summarized in Table 1. 


\begin{tabular}{lll}
\hline Parameters & LNMO & LCMO \\
\hline$d_{\text {XRD }}(\mathrm{nm})$ & 23 & 28 \\
\hline$d_{\text {TEM }}(\mathrm{nm})$ & 53 & 60 \\
\hline$A_{\mathrm{g}}\left(\mathrm{cm}^{-1}\right)$ & 514 & 653 \\
\hline$B_{\mathrm{g}}\left(\mathrm{cm}^{-1}\right)$ & 488 & 670 \\
\hline$M_{\mathrm{s}}(\mathrm{emu} / \mathrm{g})$ & 42.9 & 65.4 \\
\hline$M_{\mathrm{r}}(\mathrm{emu} / \mathrm{g})$ & 7.7 & 8.14 \\
\hline$H_{\mathrm{c}}(\mathrm{Oe})$ & 272 & 972 \\
\hline$T_{\mathrm{N}}(\mathrm{K})$ & 225 & 240 \\
\hline $\mathrm{DC}(1 \mathrm{MHz})$ & 161 & 19.7 \\
\hline $\mathrm{DL}(1 \mathrm{MHz})$ & 1.235 & 0.172 \\
\hline
\end{tabular}

Table 1. Physical and multiferroic characteristics of the microwave sintered LNMO and LCMO nanoparticles

\section{Conclusions and scope of the future work}

In this chapter, double perovskite $\mathrm{La}_{2} \mathrm{MMnO}_{6}(\mathrm{M}=\mathrm{Ni}, \mathrm{Co})$ ceramics were successfully prepared using microwave sintering technique. The microwave sintering approach shows obviously better promise over the conventional heating method, in terms of higher efficiency of heating, significantly shorter reaction time, smaller and more regular size, and stronger magnetization of the products. IR, XRD, and SEM-EDX analysis confirmed the formation of single phase for $\mathrm{La}_{2} \mathrm{MMnO}_{6}(\mathrm{M}=\mathrm{Ni}, \mathrm{Co})$ double perovskites. XPS gives information about the oxidation state and chemical stoichiometric composition of the perovskite samples. The oxidation states of transition metals are $\mathrm{Ni}^{2+}$ and $\mathrm{Mn}^{4+}$ in the samples. The variation with temperature of a sample's magnetization can give Neel temperatures of about $240 \mathrm{~K}$ for LNMO and $225 \mathrm{~K}$ for LCMO. Multiferroic properties of microwave sintered ceramics were found to be higher than that of the values reported for conventionally sintered samples. Microwave processing greatly reduced the processing time and improved the magnetic and dielectric properties, which hinted its superiority over conventional processing. Hence, the microwave sintering technique is more facile approach for the preparation of the industrially important perovskite-type ceramics.

Furthermore, one can study the correlation between different magnetic and electric order parameter for this material, to use as a potential candidate for multiferroics. The magnetization dynamics can be studied to know the spin-spin interactions. Low temperature dielectric spectroscopy can also be studied to know whether this material undergoes any transition or not and if so what is the inside story of this transition and much more work can be done related to this material. 


\section{Author details}

Penchal Reddy Matli ${ }^{1 *}$, Adel Mohamed Amer Mohamed ${ }^{1,2}$ and Ramakrishna Reddy Rajuru ${ }^{3}$

*Address all correspondence to: drlpenchal@gmail.com

1 Center for Advanced Materials, Qatar University, Doha, Qatar

2 Department of Metallurgical and Materials Engineering, Faculty of Petroleum and Mining Engineering, Suez University, Suez, Egypt

3 Department of Physics, Sri Krishnadevaraya University, Anantapur, India

\section{References}

[1] Vasylkiv O, Demirskyi D, Sakka Y, Ragulya A, Borodianska H. Densification kinetics of nanocrystalline zirconia powder using microwave and spark plasma sintering -a comparative study. Journal of Nanoscience and Nanotechnology 2012;12: 4577-82.

[2] Demirskyi D, Borodianska H, Grasso S, Sakka Y, Vasylkiv O. Microstructure evolution during field-assisted sintering of zirconia spheres. Scripta Materialia 2011;65: 683-6.

[3] Shannigrahi SR, Pramoda KP, Nugroho FAA. Synthesis and characterizations of microwave sintered ferrite powders and their composite films for practical applications. Journal of Magnetism and Magnetic Materials 2012;324: 140-145.

[4] Penchal Reddy M, Madhuri W, Balakrishnaiah G, Ramamanohar Reddy N, Siva Kumar KV, Murthy VRK, Ramakrishna Reddy, R. Microwave sintering of iron deficient $\mathrm{Ni}-\mathrm{Cu}-\mathrm{Zn}$ ferrites for multilayer chip inductors. Current Applied Physics 2011;11: 191-8.

[5] Penchal Reddy M, Zhou XB, Jing L, Huang Q. Microwave sintering, characterization and magnetic properties of doubleperovskiteLa ${ }_{2} \mathrm{CoMnO}_{6}$ nanoparticles. Material Letters 2014;132: 55-8.

[6] Demirskyi D, Agrawal D, Ragulya A. Neck growth kinetics during microwave sintering of copper. Scripta Materialia 2010;62: 552-5.

[7] Roy R, Agrawal D, Cheng J, Gedevanishvili S. Full Sintering of powdered-metal bodies in a microwave field. Nature 1999;399: 668-70.

[8] Oghbaei M, Mirzaee O. Microwave versus conventional sintering: a review of fundamentals, advantages and applications. Journal of Alloys and Compounds 2010;494:175-89. 
[9] Demirskyi D, Ragulya A, Agrawal D. Initial stage sintering of binderless tungsten carbide powder under microwave radiation. Ceramics International 2011;37: 505-12.

[10] Demirskyi D, Borodianska H, Agrawal D, Ragulya A, Sakka Y, Vasylkiv O. Peculiarities of the neck growth process during initial stage of spark-plasma, microwave and conventional sintering of WC spheres. Journal of Alloys and Compounds 2012;523: $1-10$.

[11] Plapcianu C, Agostino A, Badica P, Aldica GV, Bonometti E, Ieluzzi G, Popa S, Truccato M, Cagliero S, Sakka Y, Vasylkiv O, Vidu R. Microwave synthesis of fullerenedoped $\mathrm{MgB}_{2}$. Industrial and Engineering Chemistry Research 2012;51: 11005-10.

[12] Borrell A, Salvador MD, Rayon E, Penaranda-Foix FL. Improvement of microstructural properties of $3 \mathrm{Y}$-TZP materials by conventional and nonconventional sintering techniques. Ceramics International 2012;38: 39-43.

[13] Costa ACFM, Tortella E, Morelli MR, Kiminami RHGA. Microstructure and magnetic properties of $\mathrm{Ni}-\mathrm{Zn}$ ferrites. Journal of Magnetism and Magnetic Materials 2003;256: 174-82.

[14] Phani AR, Santucci S. Evaluation of structural and mechanical properties of aluminum oxide thin films deposited by a sol-gel process: comparison of microwave to conventional anneal. Journal of Non-Crystalline Solids 2006;352: 4093-100.

[15] Zhou XB, Qiu F, Penchal Reddy M, Han YH, Lee J, Huang Q. Comparative study of conventional and microwave sintered mullite fibers: a structural study. Advances in Applied Ceramics: Structural, Functional and Bioceramics 2015;114: 139-43.

[16] Penchal Reddy M, Madhuri W, Venkata Ramana, M, Ramamanohar Reddy N, Siva Kumar KV, Murthy VRK, Ramakrishna Reddy R. Effect of sintering temperature on structural and magnetic properties of $\mathrm{NiCuZn}$ and $\mathrm{MgCuZn}$ ferrites. Journal of Magnetism and Magnetic Materials 2010;322: 281923.

[17] Praveena K, Bououdina M, Penchal Reddy M, Srinath S, Sandhya R, Sadhana K. Structural, magnetic, and electrical properties of microwave sintered $\mathrm{Cr}^{3+}$ doped $\mathrm{Sr}$ hexa ferrites. Journal of Electronic Materials 2012;44: 1-7.

[18] Gupta M, Wong WLE. Microwaves and Metals. Singapore: John Wiley \& Sons; 2007.

[19] Upadhya DD, Ram Prasad. DAE-BRNS Symposium, IT-03, 9. Shivaji University, Kolhapur.

[20] Jin Q. Microwave Chemistry. Beijing: China Science Press; 1999.

[21] Berteaud AJ, Badet JC. High temperature microwave heating in refractory materials. Journal of Microwave Power Electromagnetic Energy 1976;11: 315-20.

[22] Liu P, Wang H, Cheng X, Shui A, Zeng L. China Ceramics 2005;41(4): 12-15. 
[23] Kimura T, Goto T, Shintani H, Ishizaka K, Arima T, Tokura Y, Magnetic control of ferroelectric polarization. Nature 2004;26: 55-58.

[24] Ishiwata S, Tokunaga Y, Taguchi Y, Tokura Y. High-pressure hydrothermal crystal growth and multiferroic properties of a perovskite $\mathrm{YMnO}_{3}$. Journal of American Chemical Society 2011;133: 13818-13820.

[25] Chai YS, Oh YS, Wang LJ, Manivannan N, Feng SM, Yang YS, Yan YQ, Jin CQ, Kim $\mathrm{KH}$. Intrinsic ferroelectric polarizations of orthorhombic manganites with E-type spin order. Physical Review B 2012;85: 184406.

[26] Lee JH, Jeong YK, Park JH, Oak MA, Jang HM, Son JY, Scott JF. Spin-canting-induced improper ferroelectricity and spontaneous magnetization reversal in $\mathrm{SmFeO}_{3}$. Physical Review Letters 2011;107: 117201.

[27] Weber MC, Kreisel J, Thomas PA, Newton M, Sardar K, Walton RI. Phonon Raman scattering of $\mathrm{RCrO}_{3}$ perovskites $(\mathrm{R}=\mathrm{Y}, \mathrm{La}, \mathrm{Pr}, \mathrm{Sm}, \mathrm{Gd}, \mathrm{Dy}, \mathrm{Ho}, \mathrm{Yb}, \mathrm{Lu})$. Physical Review B 2012;85: 054303.

[28] Retuerto M, Lope MJM, Hernandez GM, Munoz A, Diaz MTF, Alonso JA. Crystal and magnetic study of the disordered perovskites $\mathrm{Ca}\left(\mathrm{Mn}_{0.5} \mathrm{Sb}_{0.5}\right) \mathrm{O}_{3}$ and $\mathrm{Ca}\left(\mathrm{Fe}_{0.5} \mathrm{Sb}_{0.5}\right) \mathrm{O}_{3}$. Materials Research Bulletin 2010; 45: 1449-1454.

[29] Ivanov SA, Nordblad P, Tellgren R, Hewat A, Temperature evolution of structure and magnetic properties in the perovskite $\mathrm{Sr}_{2} \mathrm{MnSbO}_{6}$. Materials Research Bulletin 2009;44: 822-830.

[30] Lufaso MW, Barnes PW, Woodward PW. Structure prediction of ordered and disordered multiple octahedral cation perovskites using SPuDS. Acta Crystallographica Section B: Structural Science 2006;62: 397-410.

[31] Zhao S, Shi L, Zhou S, Zhao J, Yang H, Guo Y. Journal of Applied Physics 2009;106:123901.

[32] Wu ZY, Ma CB, Tang XG, Li R, Liu QX, Chen BT, Double-perovskite magnetic $\mathrm{La}_{2} \mathrm{NiMnO}_{6}$ nanoparticles for adsorption of bovine serum albumin applications. Nanoscale Research Letters 2013;8: 207-211.

[33] Li C, Liu B, He Y, Lv C, He H and Y. Xu. Preparation, characterization and dielectric tunability of $\mathrm{La}_{2} \mathrm{NiMnO}_{6}$ ceramics. Journal of Alloys and Compounds 2014;590: 541545.

[34] Kumar P, Ghara S, Rajeswaran B, Muthu DVS, Sundaresan A, Sood AK. Temperature dependent magnetic, dielectric and Raman studies of partially disordered $\mathrm{La}_{2} \mathrm{NiMnO}_{6}$. Solid State Communications 2014;184: 47-51.

[35] Lin $Y Q$, Chen XM. Local structure evolution in Ba-substituted $\mathrm{Pb}\left(\mathrm{Fe}_{1 / 2} \mathrm{Nb}_{1 / 2}\right) \mathrm{O}_{3}$ ceramics. Journal of American Society 2011;94(3): 782-787. 
[36] Murthy JK, Chandrasekhar KD, Murugavel S, Venimadhav A. Investigation of intrinsic magnetodielectric effect in $\mathrm{La}_{2} \mathrm{CoMnO}_{6}$ : role of magnetic disorder. Journal of Material Chemistry C 2015; 3, 836-843.

[37] Mao Y, Facile molten-salt synthesis of double perovskite $\mathrm{La}_{2} \mathrm{BMnO}_{6}$ nanoparticles. RSC Advances 2012;2: 12675-12678.

[38] Mao Y, Parsons J, McCloy JS. Magnetic properties of double perovskite $\mathrm{La}_{2} \mathrm{BMnO}_{6}$ (B=Ni or Co) nanoparticles. Nanoscale 2013;5: 4720-4728.

[39] Zhu M, Lin Y, Lo EWC, Wang Q, Zhao Z, Xie W. Electronic and magnetic properties of $\mathrm{La}_{2} \mathrm{NiMnO}_{6}$ and $\mathrm{La}_{2} \mathrm{CoMnO}_{6}$ with cationic ordering. Applied Physics Letters 2012;100: 062406.

[40] Barrozo P, Moreno NO, Aguiar JA. Ferromagnetic cluster on $\mathrm{La}_{2} \mathrm{FeMnO}_{6}$. Advanced Materials Research 2014;975: 122-127.

[41] Qian Y, Wu H, Kan E, Lu J, Lu R, Liu Y, Tan W, Xiao C, Deng K. Biaxial strain effect on the electronic and magnetic phase transitions in double perovskite $\mathrm{La}_{2} \mathrm{FeMnO}_{6}$ : a first-principles study. Journal of Applied Physics 2013;114: 063713.

[42] Rogado NS, Li J, Sleight AW, Subramanian MA. Magnetocapacitance and magnetoresistance near room temperature in a ferromagnetic semiconductor: $\mathrm{La}_{2} \mathrm{NiMnO}_{6}$. Advanced Materials 2005;17: 2225-2227.

[43] Lufaso MW, Woodward PM. Jahn-Teller distortions, cation ordering and octahedral tilting in perovskites. Acta Crystallographica Section B: Structural Science 2004;60: $10-20$.

[44] Dass RI, Goodenough JB. Multiple magnetic phases of $\mathrm{La}_{2} \mathrm{CoMnO}_{6}$. Physical Review B 2003;67: 014401.

[45] Wolf SA, Awschalom DD, Buhrman RA, Daughton JM, Molnar S, Roukes ML, Chtchelkanova AY, Treger DM. Spintronics: a spin-based electronics vision for the future. Science 2001;294:1484-88.

[46] Awschalom DD, Flatte ME, Samarth N. Scientific American. 2002, 286, 66-73.

[47] Prasatkhetragarn A, Kaowphong S, Yimnirun R. Synthesis, structural and electrical properties of double perovskite $\mathrm{Sr}_{2} \mathrm{NiMoO}_{6}$ ceramics. Applied Physics A: Materials Science and Processing 2012;107(1): 117-121.

[48] Gu Y, Wang Y, Wang T, Shi W. Structure and current-induced effect on the resistivity of $\mathrm{La}_{2} \mathrm{CoMnO}_{6}$ thin films. Materials Chemistry and Physics 2012;132: 466-70.

[49] Agrawal D. Microwave sintering of ceramics, composite, metals, and transparent materials. Journal of Material Education 1999;19: 49-58.

[50] Agrawal DK, Microwave processing of ceramics: a review. Current Opinion in Solid State Material Science 1998;3: 480-486. 
[51] Penchal Reddy M, Madhuri W, Ramamanohar Reddy N, Siva Kumar KV, Murthy VRK, Ramakrishna Reddy R. Influence of copper substitution on magnetic and electrical properties of $\mathrm{MgCuZn}$ ferrite prepared by microwave sintering method. Materials Science and Engineering: C 2010;30: 1094-1099.

[52] Uvarov U, Popov I. Metrological characterization of X-ray diffraction methods for nanocrystallite size determination. Material Characterization 2007;58: 883-91.

[53] Carron LM, Andres A, Lopez MJM, Casais MT, Alonso JA. Raman phonons as a probe of disorder, fluctuations, and local structure in doped and undoped orthorhombic and rhombohedral manganites. Physical Review B 2002;66: 174303.

[54] Carron LM, Andres A. Excitations of the orbital order in $\mathrm{RnMnO}_{3}$ manganites: light scattering experiments. Physical Review Letters 2004;92: 175501.

[55] Guo H, Burgess J, Street S, Gupta A, Calvarese TG, Subramanian MA. Structural and magnetic properties of epitaxial thin films of the ordered double perovskite $\mathrm{La}_{2} \mathrm{CoM}$ $\mathrm{nO}_{6}$. Applied Physics Letters 2006;89: 022509.

[56] Burgess J, Guo H, Gupta A, Street S. Raman spectroscopy of $\mathrm{La}_{2} \mathrm{NiMnO}_{6}$ films on $\mathrm{SrTiO}_{3}(100)$ and $\mathrm{LaAlO}_{3}(100)$ substrates: observation of epitaxial strain. Vibrational Spectroscopy 2008;48: 113-117.

[57] Kim KJ, Lee HJ, Park. Cationic behavior and the related magnetic and magnetotransport properties of manganese ferrite thin films. Journal of Magnetism and Magnetic Materials 2009;321: 3706-3711.

[58] Zhou G, Lee DK, Kim YH, Kim CW, Kang YS. Preparation and spectroscopic characterization of Ilmenite-Type $\mathrm{CoTiO}_{3}$ nanoparticles. Bulletin of Korean Chemical Society 2006;27: 368-372.

[59] Schnorr JM, Swager TM. Emerging applications of carbon nanotubes. Chemical Materials 2011;23: 646-657.

[60] Zhang Z, Jian H, Tang X, Yang J, Zhu X, Sun Y. Synthesis and characterization of ordered and disordered polycrystalline $\mathrm{La}_{2} \mathrm{NiMnO}_{6}$ thin films by sol-gel. Dalton Transaction 2012;41: 11836-11840.

[61] Qing TY, Meng Y, Mei HY. Structure and colossal dielectric permittivity of $\mathrm{Ca}_{2} \mathrm{Ti}^{-}$ $\mathrm{CrO}_{6}$ ceramics. Journal of Physics D: Applied Physics 2013;46: 015303.

[62] Liu F, Li J, Li Q, Wang Y, Zhao X, Hu Y, Wang C, Liu X. High pressure synthesis, structure, and multiferroic properties of two perovskite compounds $\mathrm{Y}_{2} \mathrm{FeMnO}_{6}$ and $\mathrm{Y}_{2} \mathrm{CrMnO}_{6}$. Dalton Transaction 2014;43: 1691-1698.

[63] Subramanian MA, Li D, Duan N, Reisner BA, Sleight AW. High dielectric constant in $\mathrm{ACu}_{3} \mathrm{Ti}_{4} \mathrm{O}_{12}$ and $\mathrm{ACu}_{3} \mathrm{Ti}_{3} \mathrm{FeO}_{12}$ phases. Journal of Solid State Chemistry 2000;151: 323325. 
[64] Singh AK, Goel TC, Mendiratta RG., Thakur OP, Prakash C. Dielectric properties of Mn-substituted Ni-Zn ferrites. Journal of Applied Physics 2002;91: 6626-6630.

[65] Singh AK, Choudhary RNP. Structural, dielectric and electrical properties of $\mathrm{Pb}_{5-\mathrm{x}} \mathrm{La}_{1+\mathrm{x}} \mathrm{Ti}_{3+\mathrm{x}} \mathrm{Nb}_{7-\mathrm{x}} \mathrm{O}_{30}(x=0,1$ and 2$)$ ceramics. Journal of Physics and Chemistry of Solids, 2003;64: 1185-1193. 
Chapter 2

\title{
New Approaches to Preparation of $\mathrm{SnO}_{2}$-Based Varistors - Chemical Synthesis, Dopants, and Microwave Sintering
}

\author{
Glauco M.M.M. Lustosa, Natalia Jacomaci, João P.C. Costa, \\ Gisane Gasparotto, Leinig A. Perazolli and Maria A. Zaghete
}

Additional information is available at the end of the chapter

http://dx.doi.org/10.5772/61206

\begin{abstract}
Tin oxides have applications such as sensors, solar cells, transistors, and varistors, which are being studied to replace $\mathrm{ZnO}$ varistors due to similar electrical properties, simpler microstructure, no formation of secondary phases, and lower concentration of agent modifiers to promote the varistor characteristics and densification. Varistors are ceramic with a high concentration of structural and electronics defects. The type and the amount of defects are related with agent modifiers and processing steps employed. The study in materials processing aims to improve the ceramics properties. Chemical synthesis ensures the homogeneous distribution of dopants used to promote electrical and structural properties. Microwave sintering appears as processing to optimize time and sintering temperature. Varistor application is linked to its breakdown voltage, which should be larger than the operating voltage. In an operating range of $1 \mathrm{kV}$ to $1 \mathrm{MV}$, the varistors are used in electricity transmission networks. In a range of 24-1000 V, the application occurs in electronics and appliances and in a range smaller than $24 \mathrm{~V}$, as protective of automotive electronics and computers. This chapter aims to provide information on new processing steps for the production of $\mathrm{SnO}_{2}$ varistors and to show the possibility to get electrical properties with non-ohmic characteristic for technological applications.
\end{abstract}

Keywords: Tin dioxide varistor, chemical synthesis, microwave sintering, dopants, low voltage 


\section{Introduction}

\subsection{Varistors}

Varistor is an electrical device based on semiconductor materials used for protection against voltage spikes in the electric network, against overvoltage in electronic circuits of low voltage and electrical power systems [1,2].

Due to the high energy absorption, the ceramic varistors become many helpful in protecting electrical circuits, and their electrical properties are highly dependent on their microstructure. The development of devices ever more technological and brings the need for electrical protection due to the sensitivity equipment. The use of varistors as voltage protectors in electronic equipment is very simple: the varistor is directly connected in parallel to the power line of equipment, and in case of an increase in the electrical current on energy network, the varistor rapidly increases the conductivity, allowing the current flow toward the ground. For electrical appliances operating with few voltages, the varistors ceramics are called low-voltage varistors [1-3].

The first varistor ceramics were developed in 1930. They were constituted from compact silicon carbide $(\mathrm{SiC})$ partially sintered and were designed by the System Bell Labs to replace selenium rectifiers that were used in the protection of telephone systems [4]. Over time, the processing of varistors has undergone successive improvements, and in 1968, Matsuoka [3] developed varistors based on zinc oxide with manganese and cobalt as a dopant to improve the electrical properties. One of the disadvantages of using $\mathrm{ZnO}$-based varistors are the large amount of dopant added to ceramic matrix for its electric modification and consequently to its high chemical instability that leads to degradation of the varistor. Castro et al. [5] reported that the trapping of electrons, ion migration and oxygen adsorption are included as $\mathrm{ZnO}$ varistor degradation mechanisms. The exposure of $\mathrm{ZnO}$ varistors to high temperatures and oxidizing atmospheres leads to excess interstitial ions $D_{Z n}$ and $D_{Z n} \ddot{t}$ that migrate through the depletion layer and chemically interact with species that are in the grain boundary, causing decrease and enlargement of the potential barrier, and facilitate the electronic conduction, destroying its varistor property $[5,6]$.

The $\mathrm{SnO}_{2}$-based varistors were introduced by Pianaro et al. [7] as an alternative to the $\mathrm{ZnO}$ varistors commercial, presenting nonlinear electrical characteristics similar to $\mathrm{ZnO}$ varistors. The $\mathrm{SnO}_{2}$-based system shows more advantages, for example, their simpler microstructure and no formation of secondary phases require a lower concentration of agents modifiers to promote the varistor characteristics and densification and higher chemical and thermal resistances. The use of $\mathrm{M}^{2+}$ ion as dopant improved significantly the densification of the varistor, the addition of $\mathrm{M}^{5+}$ ion promoted electrical conductivity, and the $\mathrm{M}^{3+}$ ion influenced on nonlinearity coefficient.

\subsection{Electrical properties}

The electrical properties of varistor ceramics are governed by potential barriers located in the grain boundaries. Potential barriers were formed by the addition of dopants elements to 
generate defects on crystal network, which segregate to the grain boundary region by diffusion during sintering. The presence of these barriers promotes the large-capacity power absorption and its flow when subjected to electrical overvoltage $[4,8]$.

In denominated "smart ceramics," the ceramic varistor acts as variable resistors, with resistive behavior at low voltages and conductive behavior starting from a specific voltage value, known as the breakdown voltage $\left(V_{\mathrm{R}}\right)$ or breakdown electric field $\left(E_{\mathrm{R}}\right)[9,10]$.

These electrical responses featuring the varistor ceramics as main elements in the manufacture of devices for electrical protection equipment subjected to both low and medium voltages apply directly as of the electro-electronics components (telephony system, computers, medical devices, automotive electronics, industrial automation systems, alarms, transformers, etc.) and for the high voltages used as part of lightning protection devices installed in the terminals of the power substations [11].

The varistor characteristic associated to quality is the nonlinear coefficient $(\alpha)$. The higher their value, the greater the varistor efficiency. This coefficient can be obtained through empirical relationships current $\times$ voltage (Eq. 1) or current density versus electric field (Eq. 2) and expresses how much the material deviates from ohmic response when required, and it can be explained by a graphic representation (Figure 1) with distinct regions [12-15].

$$
\begin{aligned}
& I=C V^{\alpha} \\
& J=C E^{\alpha}
\end{aligned}
$$

where $C$ is a constant related to the microstructure.

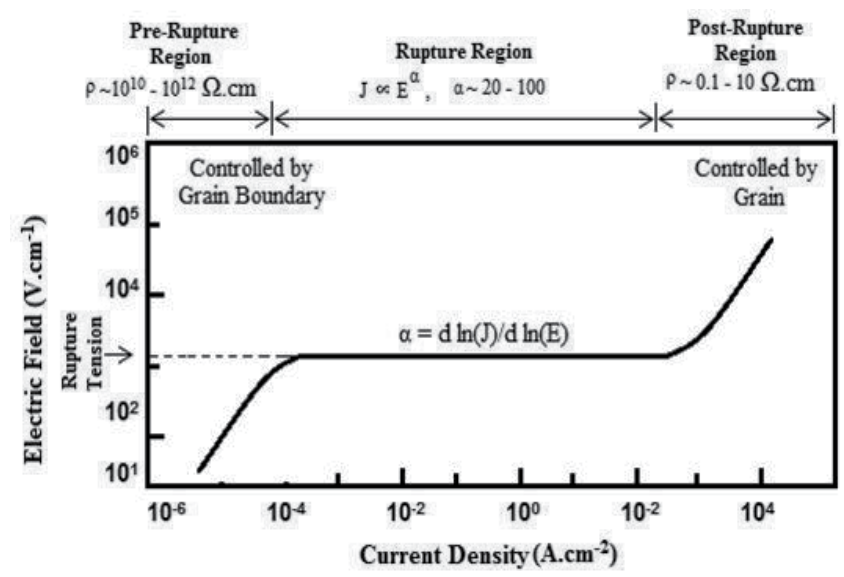

Figure 1. Electric field $(E)$ versus current density $(J)$ curves of a varistor [16]. 
The pre rupture region is also named as linear region and has an ohmic behavior when the material is under operation normal tension. The varistor acts as a resistor in this case with a small amount of current (known as leakage current) passing through the material due to the action of the potential barrier formed at grain boundary and preventing the electronic conduction between the grains. The conductivity in this region is of thermionic emission type, i.e., the electrical conduction is strongly dependent of temperature, thus being possible to retrieve information about the resistivity of the material $[8,16,17]$.

The rupture region showed nonlinear behavior, i.e., non-ohmic behavior between the applied voltage and the current that the material is submitted. The conductivity of the material increases with a small variation in the applied voltage, indicating the varistor efficiency that starts to act as a conductor from a specific breakdown electric field $\left(E_{\mathrm{R}}\right)$. Recombination of electron-hole pair at grain boundary interfaces, thermionic emission, and electron tunneling are suggested as electric conduction mechanisms of this region $[8,16]$.

In the post rupture region, the ohmic behavior between the current and the applied voltage is observed once again and is characterized by high current density. The electric conduction in this region is controlled by the impedance of the grains $[2,8]$.

The $V_{\mathrm{R}}$ value provides the varistor voltage application, and it is a function of a grain size of sintered material. If the composition is fixed, the microstructure becomes strongly dependent on the processing conditions $[12,15]$.

The varistor efficiency determined by the breakdown region can be evaluated by the $\alpha$ nonlinear coefficient of the curve in Figure 1, which is used in Eq. 6, derived from Eq. 3, which allows the calculation of the value of $\alpha$ by the field data electric $(E)$ and current density $(J)[18,19]$ :

$$
\alpha=\left(\log J_{2}-\log J_{1}\right) /\left(\log E_{2}-\log E_{1}\right)
$$

The electric field and the current density are obtained from the measurements of the electric current (I) generated when the sample is submitted to a potential difference $(\mathrm{V})$, according to Eqs. 4 and $5[18,19]$ :

$$
\begin{aligned}
& E=V / d \\
& J=I / A
\end{aligned}
$$

$d$ is the thickness of the sample and $A$ is the electrode area deposited on the film surface. For $\alpha$ calculation, the interval of 1 and $10 \mathrm{~mA} / \mathrm{cm}^{2}$ of current density was used, i.e., $J_{1}=1$ and $J_{2}=$ $10[18,19]$ :

$$
\alpha=\left(\log E_{2}-\log E_{1}\right)^{-1}
$$




\subsection{Mechanisms for electrical conduction}

The potential barrier is the determining factor on the electrical properties of varistors. Several models have been proposed to better understand the potential barrier formed in the grain boundary region $[20,21]$.

Gupta et al. [22] proposed the first potential barrier model for ZnO-based varistor of the Schottky-type with an intergranular layer acting as insulator between the grains. In this model, negative charge densities (formed by $\mathrm{Zn}$ vacancies) were trapped between the grain boundary being balanced by two depletion layers that are positively charged. Leite et al. [23] proposed the accumulation of oxygen species adsorbed as new origin of negative defects $[22,23]$.

Based on the $\mathrm{ZnO}$ potential barriers model, Bueno et al. [14] suggested a modification for formation of potential barrier in $\mathrm{SnO}_{2}$ varistors systems, whereas the sides of the barrier are in contact since there is no precipitated phase in the grain boundary, as observed Figure 2. In this model, the oxygen adsorbed species in the grain boundary region generate the negative charges defects, counterbalanced by the positive defects in the depletion layer. Pianaro et al. [1] proposed a potential barrier model, which has a large presence of negative charges on the $\mathrm{SnO}_{2}$ surface generated by tin vacancies $\left(V_{s n}^{\prime \prime}\right)$, adsorbed oxygen atoms and substitutional cobalt ions $\left(\mathrm{Co}_{S_{n}}\right)$, and positive defects in the depletion layer formed by interstitial tin $\left(\mathrm{Sn}_{n} \cdots \cdot\right.$, $S n \cdot)$, oxygen vacancies $\left(V_{O} \ddot{*}, V_{O}^{\bullet}\right)$, and niobium taking place of tin on the crystal lattice $\left(N b_{S n}^{\bullet}\right)[1,14]$.
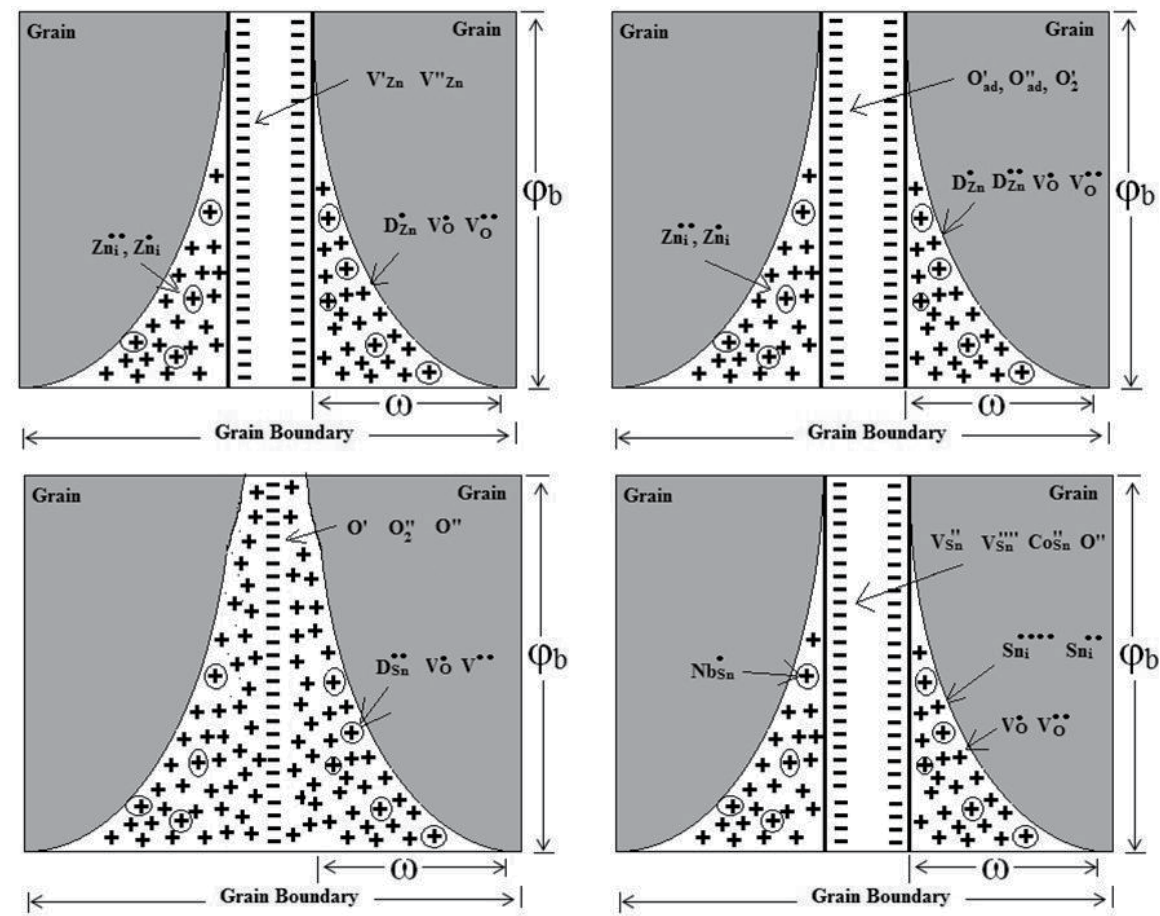

Figure 2. Potential barrier model to $\mathrm{ZnO}$ varistors proposed by Gutpa et al. [22] and Leite et al. [23] and to $\mathrm{SnO}_{2}$ varistors base proposed by Bueno et al. [14] and Pianaro et al. [1]. 


\subsubsection{Schottky type}

In this model, the electrons are emitted and pass through the potential barriers particularly due to the action of temperature distorting the energy band diagram, near the interface. This distortion modifies the potential barrier favoring the thermal emission. The equation that describes this behavior is $[24,25]$

$$
J_{S}=A^{*} \cdot T_{2} \cdot \exp \left[-\frac{\phi_{b}-\beta E_{1 / 2}}{k T}\right]
$$

where $A^{*}$ is the Richardson constant, $\varphi_{\mathrm{b}}$ is the potential barrier height, $E$ represents the electric field, $T$ is the ambient temperature in Kelvin, and $\beta$ is a constant related to the width of the potential barrier in accordance with the following equation [25]:

$$
\beta=(n \omega)^{-1 / 2}
$$

where $n$ is the grain number per unit length and $\omega$ is the width of the barrier.

\subsubsection{Poole-Frenkel type}

The emission of the Poole-Frenkel type assumes the formation of coulombian centers in the grain-intergranular layer interface region. The relationship that describes this type of emission is on Equation 9, where the external electric field variations are more relevant than for issue of Schottky type [26]:

$$
J_{P}=c . E \cdot \exp \left[-\frac{\phi_{b}-2 \beta E_{1 / 2}}{k T}\right]
$$

where $c$ is a constant of the material, $T$ is the room temperature, $E$ is the electric field, $k$ is the Boltzmann constant, and $\varphi_{\mathrm{b}}$ is the height of the potential barrier. The thermionic emission cannot explain the high nonlinear coefficients observed in varistors. In the post rupture zone with the presence of high electric fields, the possibility that distortion of the energy levels and, therefore, the possibility that electrons pass through the potential barrier by tunneling must be considered [27].

\section{Influence of synthesis methods on $\mathrm{SnO}_{2}$ electrical properties}

The processing by mixing oxides is widely used at the industrial scale for the production of varistor ceramics mainly due to its low cost, consisting basically of an initial powder mix and wet milling followed by drying, deagglomeration of powder, forming pellets/bulks, and 
sintering. The varistor synthesis with large amounts of chemical additives and/or impurities resulting from the process can lead to non-densifying sintering mechanisms. This mean that impurities may accumulate on the material surface and increase the mass flow on the surface or forming more unstable compounds that can evaporate and condense on the surface, favoring grain growth without decreasing pore size. The advancement in ceramic materials process technology aims to find low-cost methods and the viability of the process on an industrial scale. Among the processes available in the literature for the production of ceramics, techniques can be cited as coprecipitation, sol-gel, dehydration by rapid cooling (freeze drying), combustion method, and polymeric precursor method known as the Pechini method [28-31].

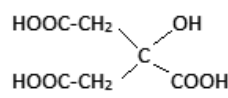

Citric Acid

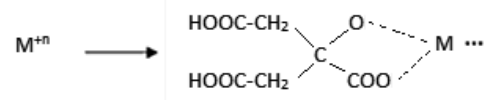

Metal Citrate

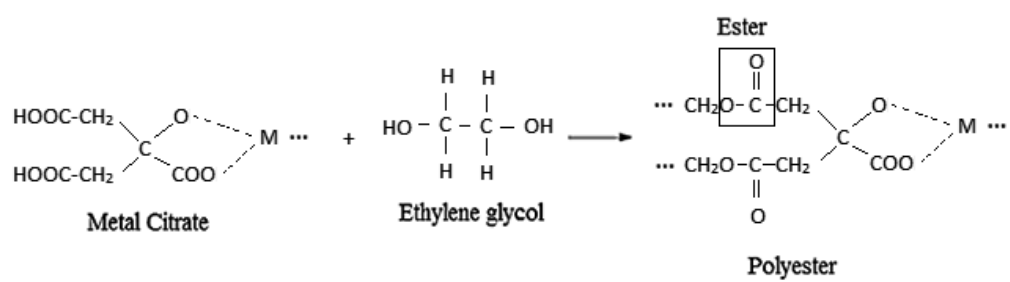

Figure 3. Schematic representation of reactions developed in the polymeric precursor method (Pechini method) [31].

The polymeric precursor method involves a complexation reaction of metal ions by an organic complexing agent as carboxylic acid. The metal ions are complexed into carboxylic sites forming a metal carboxylate, which is sequentially polymerized with ethylene glycol, as shown in Figure 3, citric acid is often used as the complexing agent. This process shows advantages such as low temperature of synthesis and high control of stoichiometry, and allows the obtention of powder with nanometric particles. The immobilization of metal ion in organic matrix reduces the segregation of the metal during the decomposition of the polymer at high temperatures, thus ensuring a homogeneous composition [31]. The ceramic powders are obtained by controlled calcination of the resin until total oxide formation.

Another method widely used for controlled synthesis of multifunctional ceramics is the solgel, that is used for the synthesis of a colloidal suspension where the dispersed phase is a solid and the dispersion medium is liquid, and is called sol. Therefore, there is the formation of a dual phase material: a solid body that is occupied by a solvent, i.e., moist gel. The initiator compounds, commonly called precursors, consist of a metal surrounded by many connections and typically are inorganic salts or organic compounds. The two precursors undergo two chemical reactions at sol preparation: hydrolysis and condensation, which resulted from the addition of an acid or base catalyst to form small solid particles or clusters in a liquid (aqueous solvent) [32,33]. The sol-gel method provides homogenous mixtures of cations on an atomic 
scale and also allows the preparation of ceramic powders with high surface area and films or gels fibers, which have high technological importance. The method has advantages over other conventional methods such as high purity, resin calcination at low temperatures, and synthesis of oxides with defined and controlled properties [32-34].

Also, the controlled precipitation method (CPM) can be used to prepare precursor powders. In this case, the solution containing the cation of interest is added to another solution containing a precipitating agent that can be a base or anion (ammonia, urea, and oxalic acid). In this way, the final product precipitate is separated by filtration, washed, dried, and calcined to obtain the oxide. The precipitation process has a complex mechanism, which is dependent on the degree of saturation of the ion to be used. The process starts by formation of cluster from chemical species in the solution, known as nucleation process. Reaching the ion solubility limits the growth stage of formed centers and finally the formation of precipitates [35].

To check the influence of the chemical synthesis route the electrical properties of the $\mathrm{SnO}_{2}$ based varistors, Mosquera et al. [36] carried out the synthesis of tin oxide by controlled precipitation and polymeric precursor (Pechini) methods that's offering the strict control of the chemical purity and the particle size of the raw material. The system $\mathrm{SnO}_{2} \cdot \mathrm{Co}_{3} \mathrm{O}_{4} \cdot \mathrm{Nb}_{2} \mathrm{O}_{5} \cdot \mathrm{TiO} \cdot \mathrm{Al}_{2} \mathrm{O}_{3}$, with $1 \mathrm{~mol} \% \mathrm{Co}_{3} \mathrm{O}_{4}, 0.05 \mathrm{~mol} \% \mathrm{Nb}_{2} \mathrm{O}_{5}$, and $1 \mathrm{~mol} \% \mathrm{TiO}_{2}$ and variations of 0.05 (named SCNT05A), 0.1 (named SCNT1A), and $0.2 \mathrm{~mol} \%$ (named SCNT2A) of $\mathrm{Al}_{2} \mathrm{O}_{3}$ were prepared. Following synthesis, the materials were submitted to heat treatment at $600^{\circ} \mathrm{C} / 1 \mathrm{~h}$ (controlled precipitation method, CPM) and $600^{\circ} \mathrm{C} / 2 \mathrm{~h}$ (Pechini method, $\mathrm{PCH}$ ) to eliminate organic matter and obtain the full formation of the oxide. The use of dopants in both methods resulted in no change in the $\mathrm{SnO}_{2}$-crystal structure or formation of secondary phases due to have been added small amounts of dopants (Figure 4). The SEM micrographs indicated the influence of the addition of the aluminum grain growth control. The Pechini method showed smaller grains and more porous samples.
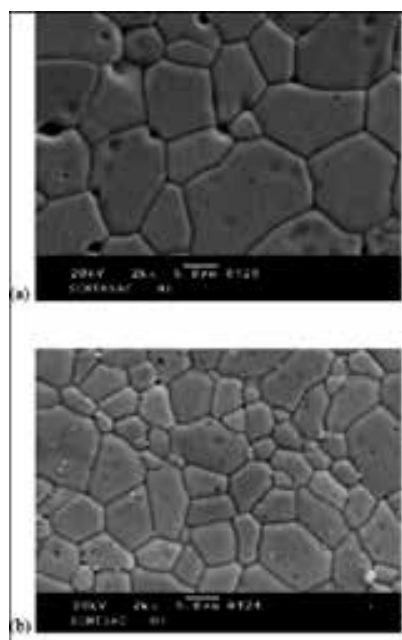

CPM
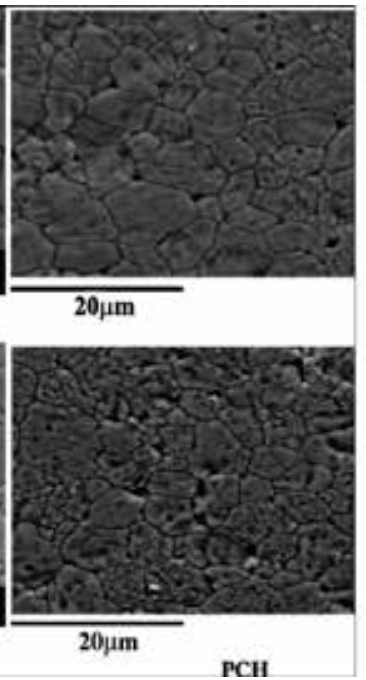

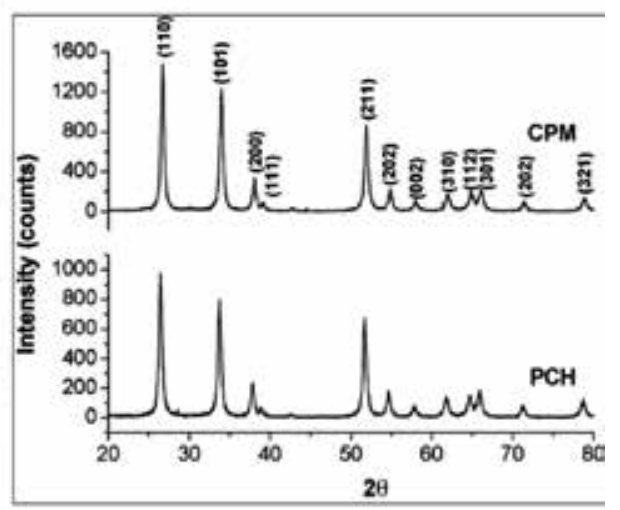

Figure 4. SEM for sintered samples at $1350^{\circ} \mathrm{C}$, obtained by CPM and $\mathrm{PCH}$ (a) $0.05 \% \mathrm{Al}_{2} \mathrm{O}_{3}$ and (b) $0.1 \% \mathrm{Al}_{2} \mathrm{O}_{3}$. $\mathrm{XRD}$ for varistor system whit $0.2 \% \mathrm{Al}_{2} \mathrm{O}_{3}$ synthesized by $\mathrm{CPM}$ and $\mathrm{PCH}$ [36]. 
The aluminum concentration also influenced on the electrical properties, as shown in Figure 5 , mainly in the breakdown electric field variation that had been related to decreasing of grain size. The samples showed nonlinear coefficient $(\alpha)$ of similar values, but the sample prepared by Pechini method and with $0.2 \% \mathrm{Al}_{2} \mathrm{O}_{3}$ had the highest value for $\alpha$ (21.7) and the breakdown electric field (due to the smaller grain size).

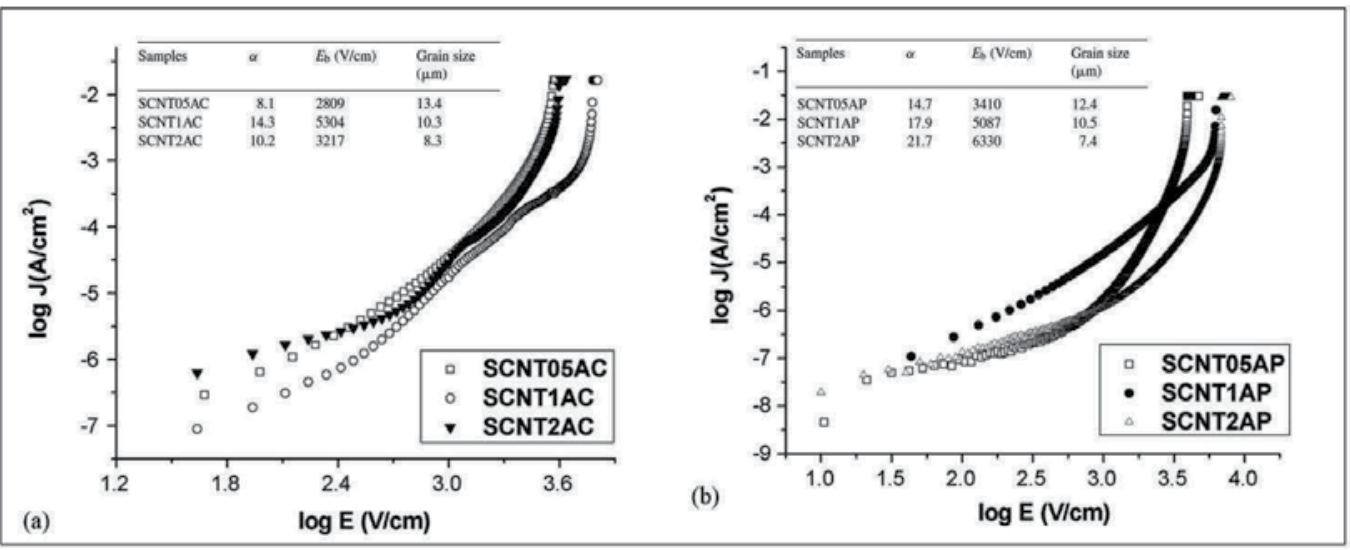

Figure 5. $\log \mathrm{J}$ versus $\log$ E curves of samples synthesized by (a) CPM and (b) $\mathrm{PCH}$, sintered at $1350^{\circ} \mathrm{C}[36]$.

\section{New processing step for varistor ceramics}

\subsection{Microwave sintering}

\subsubsection{Thermodynamics of sintering}

Sintering is the processing step that aims to confer mechanical strength to ceramic or metal powders, shaped by pressing or deposited as films. The process occurs by coalescence of the particles in solid or liquid phase to form a more dense mass. The sintering is an irreversible process and results in decrease of the total free energy of the system. Mathematically, the equation related to total energy of the system is

$$
\Delta G=\Delta G_{s}+\Delta G_{i}<0
$$

where $\Delta G$ is the total free energy, $\Delta G_{\mathrm{s}}$ is the surface free energy, and $\Delta G_{\mathrm{i}}$ is the energy of each particular system [37].

\subsubsection{Driving force}

For the decrease of free energy of the system, there is a force that induces microstructural changes, replacing the contact points between the particles by grain boundaries, closing the pores, densifying, and making the material a hard solid. In addition to the system power 
source, the sintering mechanisms are also a contributing factor induced by driving forces. Figure 6 shows the possible forces involved in the sintering process: surface free energy, applied external pressure, and chemical reaction [38].

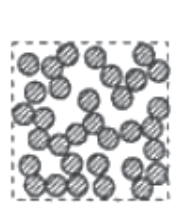

(A)

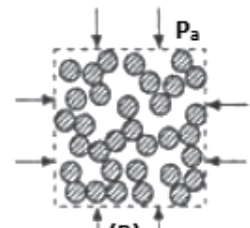

(B)

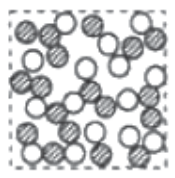

(C)

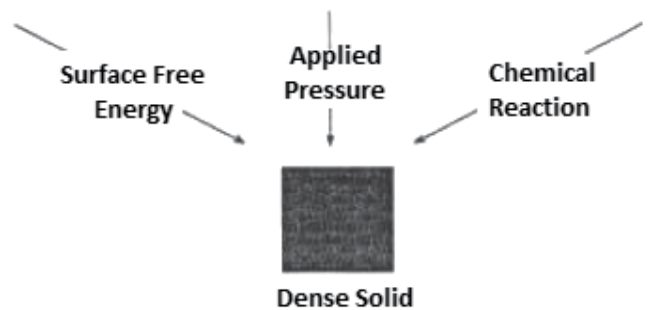

Figure 6. The three main drivers for solid densification: surface free energy, applied pressure, and chemical reaction [38].

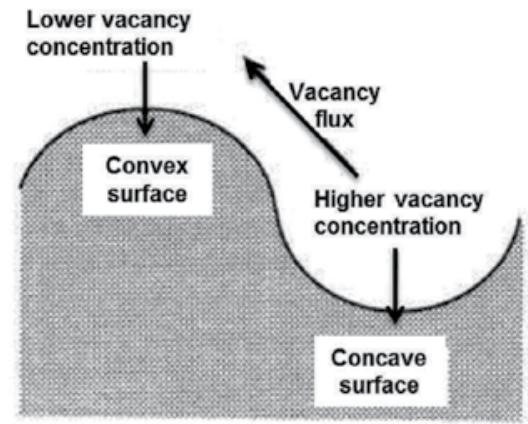

Figure 7. Diagram flow of vacancies on the surface. The atoms flow is opposite to the vacancy [38].

The surface energy is related to the surfaces curve and characterized by vacancies and gaps. The surfaces energy is the main force that sinters the material by mass flow through the region of higher concentration to a lower concentration region where vacancies and gaps, as shown in Figure 7.

The variation of free energy during sintering is represented by Eq. 11:

$$
\delta G=\delta \int \gamma_{S S} d A_{S S}+\delta \int \gamma_{S V} d A_{S V}
$$


where the free energy variation depends on the variation on interfacial energy as a function of the surface area. The surface tension solid-solid $\left(\gamma_{\mathrm{S} / \mathrm{S}}\right)$ is smaller than the surface tension between vapor-solid $\left(\gamma_{\mathrm{S} / \mathrm{V}}\right)$, and the interfacial energy is higher when there are many vacancies in the material, so there is a mass transfer gradient that favors the formation of necks between the particles and the resulting in joint, reducing the solid-vapor area (pore) [37].

\subsubsection{Sintering mechanisms}

In polycrystalline materials, the mass transport ways that are responsible for sintering are diffusion via crystal lattice, surface diffusion, volume diffusion, plastic flow, and evaporationcondensation. Figure 8 shows all mass transport paths arrive at the point of contact between two particles [38].

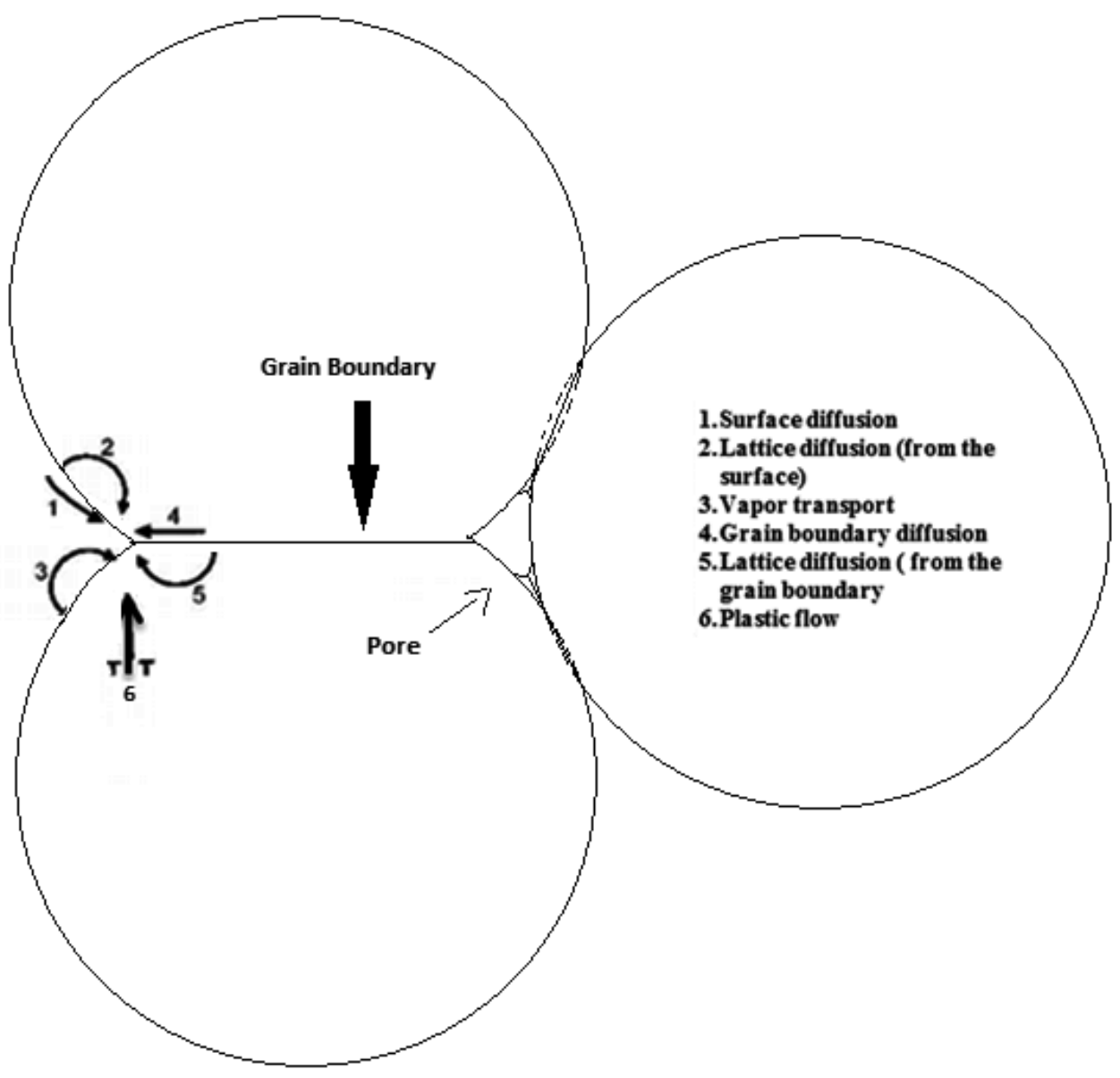

Figure 8. Mass transport mechanism solid and viscous sintering [38]. 
In Figure 8, the first three mechanisms do not lead to an alignment of the mass centers of the particles and therefore are non-densifying mechanisms. Thus, the mechanisms that start on the volume of material to the neck that increase in the neck and decrease the distance between the particles are densifying mechanisms [39].

\subsubsection{Stages of sintering}

The sintering mechanisms occur by three successive or simultaneously stages divided into initial, intermediate, and final stages. In some cases, there is the zero stage, which corresponds to particle rearrangement stage for subsequent joining by spot contact called necks [40]. The initial stage consists of particles rounding, formation of necks with low grain growth, and significant reduction in surface area and porosity. This stage progresses until the point where the necks interfere with each other. This stage corresponds to the point where the dihedral angle of equilibrium is reached. For the system with the green density of $\sim 60 \%$, this corresponds to a linear shrinkage of $3 \%$ to $5 \%$ [36]. It is possible to develop a general equation of the sintering kinetics for the initial stage. The geometric model for the development of this mathematical relationship is illustrated in Figure 9:

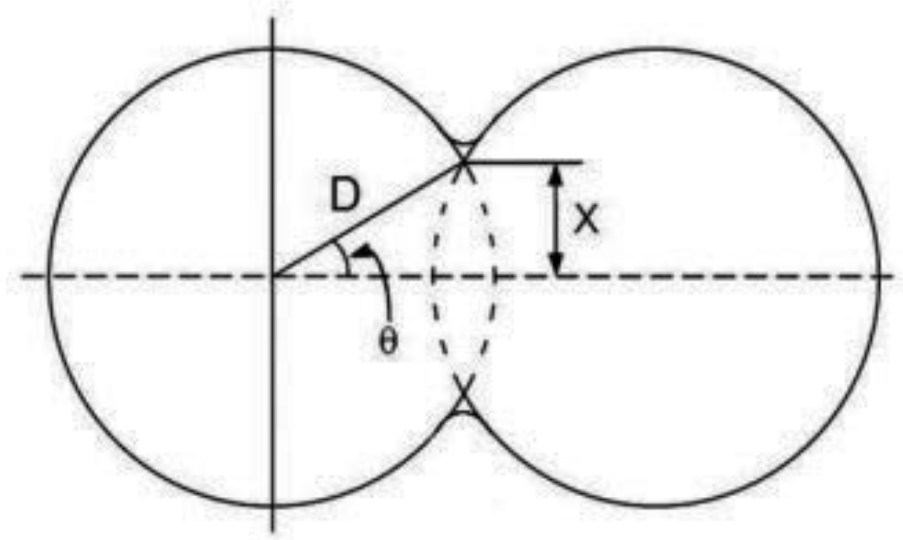

Figure 9. Frenkel's model for early-stage sintering viscous flow [41].

The two spheres of the Frenkel's model use the concept of viscous flow of atoms that relates the vacancy diffusion coefficient $D_{\mathrm{v}}$, the volume of the atom or vacancy $\Omega$, and vacancy concentration gradient per unit area of the material $\left(\mathrm{d} C_{\mathrm{v}} / \mathrm{d} x\right)$, as shown in the following equation [41]:

$$
J_{a}=\frac{D_{v}}{\Omega} \frac{d C_{v}}{d x}
$$

Thus, the transported mass volume as a function of time can be given by [41] 


$$
\frac{d V}{d t}=J_{a} A_{g b} \Omega
$$

were $A_{g b}=2 \pi X \delta_{S V}$ is equal to the cross-sectional area where diffusion occurs, and $X$ is the radius of the neck.

Assuming that the decrease in surface energy of the system is equivalent to the energy dissipated through the material flow, then it is possible to derive several equations relating the radius of the neck and ball as a function of sintering time [38,42]:

$$
\left(\frac{X}{a}\right)^{m}=\frac{H}{a^{n}} t
$$

where $m$ and $n$ are the sintering mechanisms, $H$ is a function that varies with parameters such as diffusion rate, surface tension, atom or vacancy size, and $a$ is the radius of the sphere.

Many aspects can be studied from the kinetic equations, as densification rate, determination of sintering mechanisms, and activation energy. The equation developed by Coble allows to estimate the sintering mechanisms for the initial stage, based on the two spheres Frenkel's model, as indicated in the Eq. 15 [43]:

$$
Y^{n}=k_{0} \exp \left(\frac{-Q}{R T}\right) t
$$

where $n=1,2,3$, or 4 , indicating the predominant mechanism of viscous flow, surface diffusion, and diffusion via grain boundary diffusion and via crystal lattice, and $Y$ is the linear shrinkage of the sample, $Q$ is the activation energy, $R$ is the gas constant real, $T$ is the temperature, and $t$ is time.

The intermediate stage initiates densifying mechanisms as volumetric diffusion by crystal lattice in which there is rapid grain growth, shrinkage pore and increased in the density of the material up to $\sim 90 \%$ of the theoretical density. Whereas there is grain growth, the model for the initial stage does not fit this stage. The final stage is characterized by the elimination of residual pores with little or no densification, but grain growth is observed. For the determination of sintering mechanisms, intermediate and final stages are used in the model-based grain growth [44]:

$$
G^{n}-G_{0}^{n}=k_{0} \exp \left(\frac{-E a_{b}}{R T}\right) t
$$

where $G$ is the average grain size, $E a_{b}$ is the activation energy for moving contour or grain growth, $n$ is the sintering mechanism when valley 3 is spread via reticulum and 4 is broadcast via grain boundary, and $k_{0}$ is a constant that depends on temperature and sintering mechanisms $[41,43,44]$. 


\subsubsection{Sintering model for thick films}

Most of the kinetic studies of $\mathrm{SnO}_{2}$-based ceramic are developed to oxide mixed synthesis compressed into pellets, where significant amounts of mass are used. However, the appearance of thick and thin films makes possible the integration of smaller electric devices, and thus new techniques for the synthesis and deposition of powders on conductive and insulating rigid substrates have been studied.

The sintering of films has been increasingly used for applications in sensors, fuel cells, or photo catalysis that requires porous films [45,46]. This application is based on the fact that sintering occurs on rigid substrates such as viscous flow, wherein the voltage-limiting densification of the material is the force of attraction between the substrate and the deposited material particles $[47,48]$. The model used for understanding the sintering of thin films is based on Scherer and Garino's studies where the rate of densification of the film is delayed by the substrate, as in Eq. 17 [38,41]:

$$
\left(\frac{\dot{\rho}}{\rho}\right)_{c}=-\left[\frac{1+v_{p}}{3\left(1-v_{p}\right)}\right] 3 \dot{\varepsilon}_{f}
$$

The sintering mechanisms remain the same; however, the densification rate is retarded by tension caused by the substrate, like as the system would be sintered followed viscous sintering mechanism, as with glass.

\subsubsection{Microwave $\times$ conventional sintering of $\mathrm{SnO}_{2}$-based ceramic}

One of the ceramic materials that have been very exploited for its great technological and industrial interest is the $\mathrm{SnO}_{2}$. Its applications are widely focused on sensors, solar cells, and catalysts, i.e., requiring high porosity, since its sintering process is limited to nondensifying mechanisms such as surface diffusion at low temperatures and evaporation-condensation at high temperatures [49-51]. Accordingly, what has been done to induce densifying sintering mechanisms is to cause solid substitution reactions that decrease the free energy by the formation of substitutional defects and vacancies that facilitate material transport during sintering [52].

It is possible to increase the densification of $\mathrm{SnO}_{2}$ by the addition of small amounts of lower valence densifying agents that generate substitutional defects and oxygen vacancies, such as $\mathrm{ZnO}, \mathrm{CoO}$, and $\mathrm{MnO}_{2}$, that promote the mass diffusion by solid solution, according to Eqs. 18,19 , and 20 [52,53]:

$$
\begin{aligned}
& \mathrm{ZnO} \stackrel{\mathrm{SnO}_{2}}{\rightarrow} \mathrm{Zn}_{\mathrm{Sn}}^{\prime \prime}+\mathrm{V}_{\mathrm{O}}^{\bullet \bullet}+\mathrm{O}_{\mathrm{O}}^{\mathrm{X}} \\
& \mathrm{CoO} \stackrel{\mathrm{SnO}_{2}}{\rightarrow} \mathrm{Co}_{\mathrm{Sn}}^{\prime \prime}+\mathrm{V}_{\mathrm{O}}^{\cdot \bullet}+\mathrm{O}_{\mathrm{O}}^{\mathrm{X}}
\end{aligned}
$$




$$
\mathrm{MnO}_{2} \stackrel{\mathrm{SnO}_{2}}{\rightarrow} \mathrm{Mn}_{\mathrm{Sn}}^{\prime \prime}+\mathrm{V}_{\mathrm{O}}^{\bullet \bullet}+\mathrm{O}_{O}^{\mathrm{X}}
$$

Also, there is the densification by $\mathrm{CuO}, \mathrm{Fe}_{2} \mathrm{O}_{3}$, and $\mathrm{MnO}$ doping that promotes liquid solution formation [51]. Another way to improve the densification of $\mathrm{SnO}_{2}$-based varistors is to use the microwave as a source of power in the sintering process. According to Hao et al. [53], while conventional sintering occurs as a consequence of surface energy reduction, microwave sintering not only reduces the surface energy but also creates vacancies in the neck [53]. As a consequence of the increase in vacancies in grain necks, the mass flow also enhances in this region, promoting densification. In the case of dielectric materials, the oscillation of the electric field is the only external factor that will cause the internal heating of the material. Thus, the response of the oscillating electric field to the dielectric is determined by $\varepsilon=\varepsilon^{\prime}+i \varepsilon$ ", where $\varepsilon^{\prime}$ is a dielectric constant that depends on the medium, and $\varepsilon^{\prime \prime}$ is the dielectric loss factor; when the material exhibits high dielectric loss, i.e., a high value $\varepsilon^{\prime \prime}$, the microwave energy is absorbed and converted into heat within the material [54]. When a material has high dielectric loss, the microwave can be directly applied to it; however, a susceptor material must be used. The susceptor absorbs microwave radiation and heats up the first piece so that it reaches its critical temperature, which consists of $40 \%$ to $50 \%$ of the melting temperature of the material above which has high dielectric losses.

\section{2. $\mathrm{SnO}_{2}$ microwave sintering}

Sintering mechanisms at Coble initial stage were adjusted to $\mathrm{SnO}_{2}$-based ceramic inserts with $0.95 \mathrm{~mol} \%$ of $\mathrm{ZnO}$ sintered in a microwave oven and compared with results obtained in a conventional oven. The results showed that samples were sintered in a microwave oven to reach $87 \%$ after $30 \mathrm{~min}$ of sintering at $1050^{\circ} \mathrm{C}$ and grain size, while in a conventional oven, the density is $67 \%$. It can be seen in Figure 10 by which the sample (a) is in the initial stage of sintering grain size, while in (b) indicating the morphology of the grains is already in intermediate sintering mechanism.

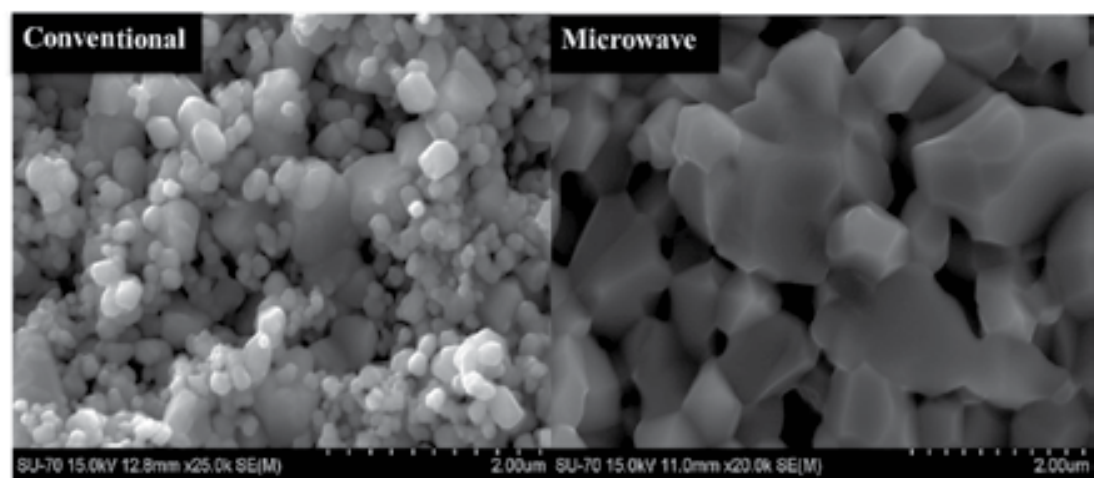

Figure 10. SEM of sintered samples in (a) conventional oven and (b) microwave oven, at $1050^{\circ} \mathrm{C} / 30 \mathrm{~min}$ (by authors). 
The sample sintered in a conventional oven showed a linear shrinkage of $5 \%$ and had an activation energy of $325 \mathrm{~kJ} / \mathrm{mol}$ with predominant mechanisms at this early stage: structural rearrangement of particles, diffusion via crystal lattice, and surface diffusion, while samples sintered in microwave oven showed an activation energy of $111 \mathrm{~kJ} / \mathrm{mol}$ and mechanisms as broadcast via crystalline reticulum. Figure 11 shows that there was a change sintering mechanisms for conventional sintering since there is a rate change in linear shrinkage rate of the material, whereas for microwave sintering the heating rate was rapid and lower temperature which does not inhibit sintering mechanisms densifying.
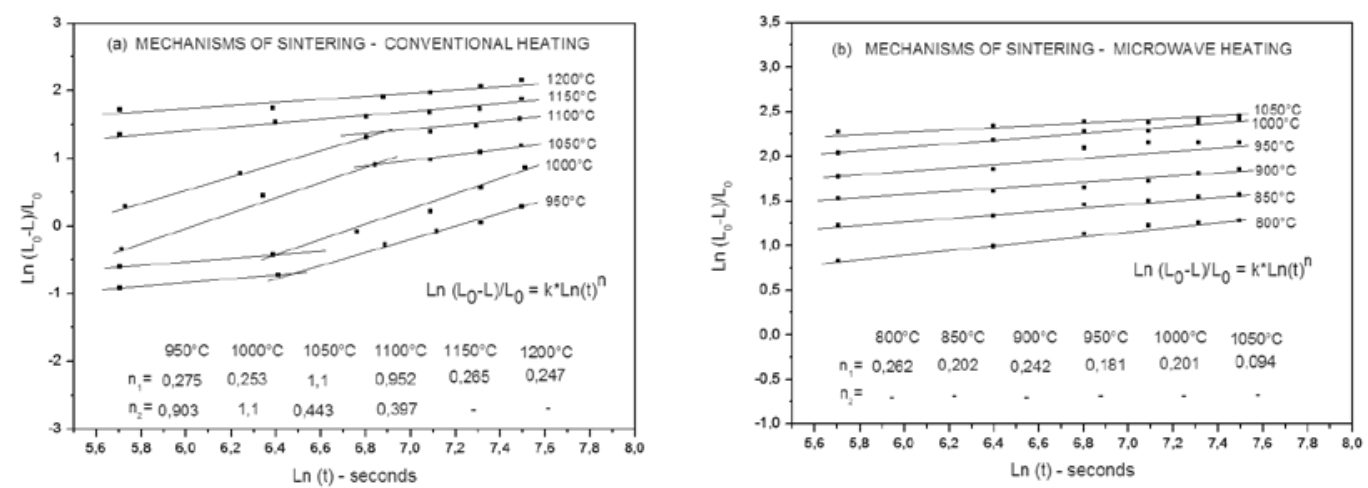

Figure 11. Curves of $\operatorname{Ln}(\mathrm{Y})$ versus $\operatorname{Ln}(\mathrm{t})$ with temperature as a parameter for obtaining the coefficients of sintering at initial stage, for $\mathrm{SnO}_{2}$ samples (doped with $0.95 \mathrm{~mol} \%$ of $\mathrm{ZnO}$ ) sintered in (a) oven conventional and (b) microwave oven (by authors).

The direct relationship between the grain growth and the increasing density for the samples subjected to microwave and conventional heating are shown in Figure 12. With their respective error bars, it may be said that for about the same density of $88 \%$ of the samples, the mean grain size for the sintered sample in a microwave oven at $1050^{\circ} \mathrm{C}$ for $30 \mathrm{~min}$ is $1.2 \mu \mathrm{m}$, while that for the samples sintered in a conventional oven at $1300^{\circ} \mathrm{C} / 30 \mathrm{~min}$ is $1.8 \mu \mathrm{m}$, and this difference increases even more because it enters the final sintering stage, which is when the grains grow more sharply, so the grain size is increased to about $3 \mu \mathrm{m}$. The reduced grain samples sintered in a microwave oven results in more grain boundaries to increase the mechanical strength and modifying the electrical properties of the material.

\subsection{Thick films varistor obtained by electrophoretic deposition}

Lustosa et al. [55] conducted a study on thick films of $\mathrm{SnO}_{2}$-based nanoparticles and their electrical properties. The ceramic powder with composition $98.95 \mathrm{~mol} \% \mathrm{SnO}_{2}+1 \mathrm{~mol} \% \mathrm{ZnO}$ $+0.05 \mathrm{~mol} \% \mathrm{Nb}_{2} \mathrm{O}_{5}$ was synthesized by Pechini method, calcined in a muffle furnace, submitted to milling in the Attritor mill and to the separation of particles by gravimetry. After separation for use of the smaller particles, one ethylic aliquot containing $\mathrm{SnO}_{2}$ powder was taken to an electrophoretic deposition system (Figure 13) for obtain the films. In sequence, the films were submitted to sintering in a microwave oven at $1000^{\circ} \mathrm{C} / 40 \mathrm{~min}$. In order to improve the varistor 


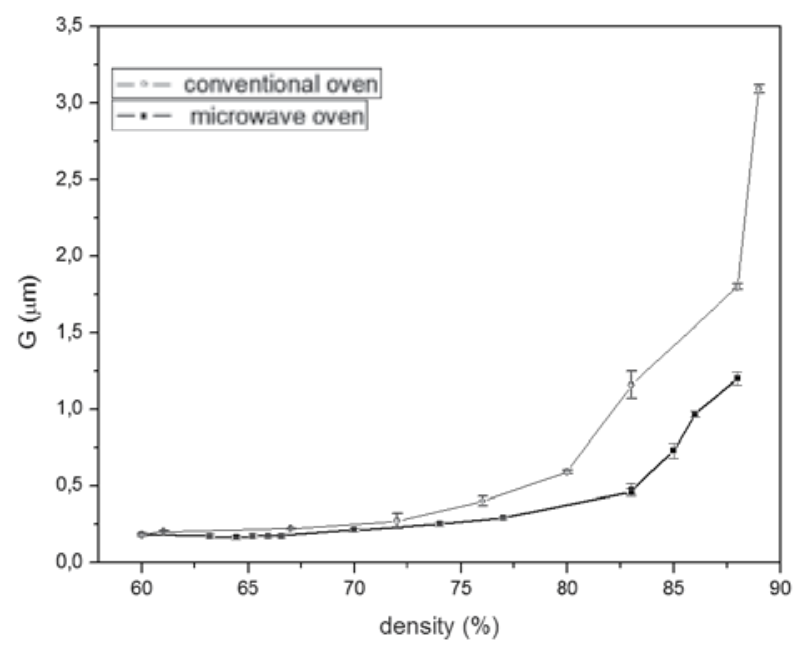

Figure 12. Evolution of grain size as a function of the calculated density of the samples sintered in a conventional oven and a microwave oven at a temperature of $800^{\circ} \mathrm{C}$ to $1050{ }^{\circ} \mathrm{C}$ [by authors].

property, a $\mathrm{Cr}^{3+}$ ion deposition was carried out (also by electrophoresis) on films surface, and then the samples were submitted to different heat treatment for the diffusion of cations in grain boundary region. Figure 14 shows the sintered film, which had a low porosity, homogeneous thickness to the full extent of the film. The chromium addition is known to improve the properties of a varistor system by acting on defect formation at grain boundary region and increase the potential barrier parameter.

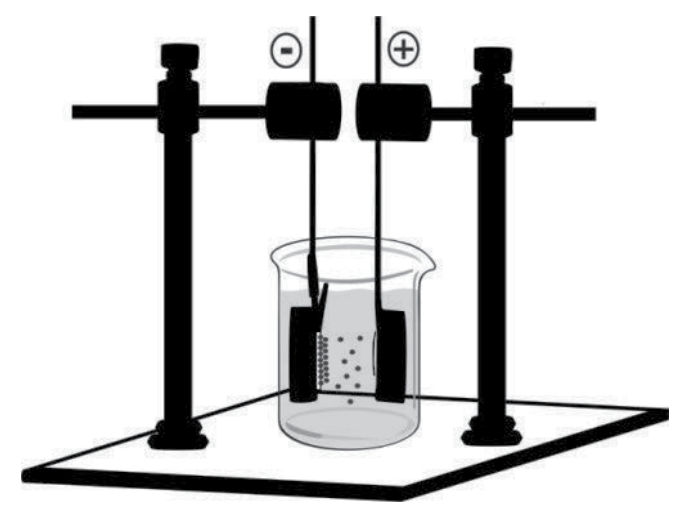

Figure 13. Electrophoretic system for deposition of $\mathrm{SnO}_{2}$-based particles (by authors).

After the heat treatment for $\mathrm{Cr}^{3+}$ diffusion, the films were taken to the electrical characterization. From the varistor responses, shown in Figure 15, it was observed that the heat treatment used after the chromium deposition influenced the improvement of the nonlinear coefficient of the samples. All films had lower rupture voltage less than $65 \mathrm{~V}$ and a low leakage current. 

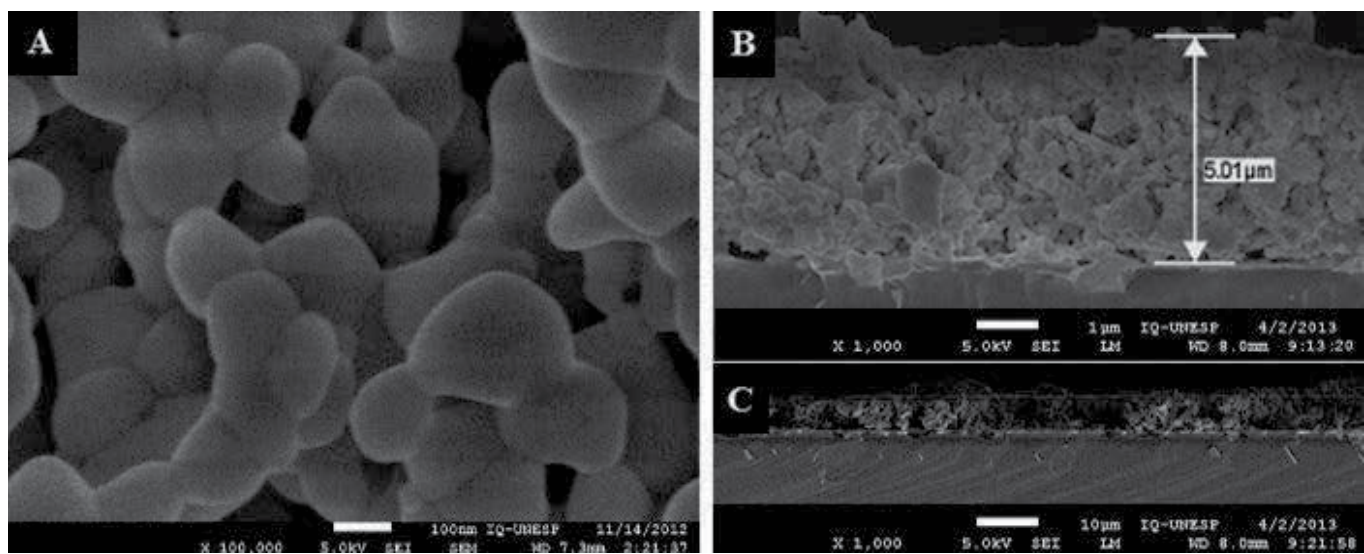

Figure 14. SEM of the film deposited by electrophoresis and sintered at $1000{ }^{\circ} \mathrm{C} / 40 \mathrm{~min}$ : (a) top vision; (b) and (c) different magnifications of cross-sectional vision [55].
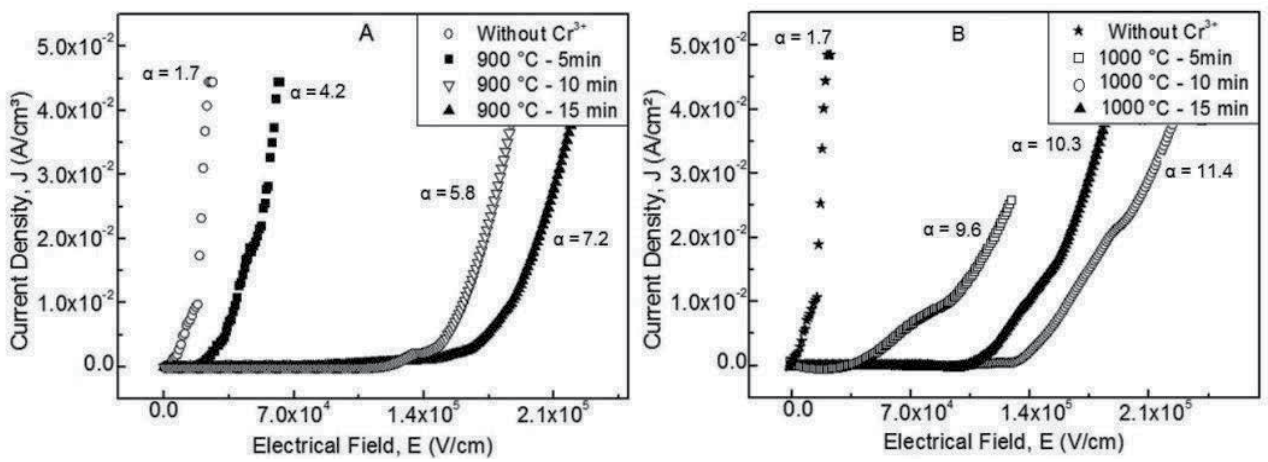

Figure 15. Graphs of current density versus electric field: (a) for films without $\mathrm{Cr}^{3+}$ and films thermally treated at $900{ }^{\circ} \mathrm{C}$ and (b) films thermally treated at $1000{ }^{\circ} \mathrm{C}$ after the $\mathrm{Cr}^{3+}$ deposition [55].

\section{Network modifiers that promote properties of $\mathrm{SnO}_{2}$-based varistor}

The addition of crystal lattice modifiers to $\mathrm{SnO}_{2}$ matrix is required because in the $\mathrm{SnO}_{2}$ sintering process, there is a predominance of mass transport mechanisms (evaporation and condensation), which leads to coalescence and grain growth, which hinder densification. Densification is a precondition to obtain the varistor properties since the phenomena involved in the formulation of non-ohmic properties occur in the grain boundary region. Thus, the studies are carried out to understand the doping effect on the sintering and densification, electrical conductivity, and non-ohmic properties of $\mathrm{SnO}_{2}$-varistor. The defects generated by modifying agents are of Frenkel type (generators of interstitial ion) and Schottky type (generators of vacancies) and are responsible for the formation and modification of the potential barrier in the grain boundaries $[1,56,57]$. 
The addition of bivalent metals such as $\mathrm{CoO}$ [58], $\mathrm{ZnO}$ [59], and $\mathrm{CuO}[60,61]$ is made to enhance the densification because these cations act as acceptors of electrons and replace the tin ions in crystal lattice, creating oxygen vacancy defects that promote mass diffusion in the network and promoting densification, according to Eq. 21 [58]:

$$
M \stackrel{\mathrm{SnO}_{2}}{\rightarrow} \mathrm{M}_{S n}^{\prime \prime}+V_{O}^{\bullet \bullet}+\mathrm{O}_{O}^{X}
$$

The $M_{S n}$ "defect types present in the grain boundary region trap the electrons released by other types of modifiers and create a potential barrier in the grain boundary region.

The electrical conductivity of the varistor system can be improved with the addition of pentavalent ions as $\mathrm{Sb}_{2} \mathrm{O}_{5}$ [62], $\mathrm{Nb}_{2} \mathrm{O}_{5}$ [1], and $\mathrm{V}_{2} \mathrm{O}_{5}$ [63], which act as electron donors to the crystal lattice, resulting in electron concentration and tin vacancies, as demonstrated in Eq. 22 [1,62]:

$$
D_{2} \mathrm{O}_{5} \stackrel{\mathrm{SnO}_{2}}{\rightarrow} 2 D_{\mathrm{Sn}}^{\cdot}+2 e^{\prime}+4 \mathrm{O}_{\mathrm{O}}^{X}+1 / 2 \mathrm{O}_{\mathrm{O}(g)}^{X}
$$

Trivalent cations that act as acceptors of electrons are added to $\mathrm{SnO}_{2}$ crystal lattice, such as chromium [63-65], ytterbium [67], and scandium [68], which were used to improve the varistor properties of the system. The segregation of these ions in the grain boundary potential barrier increases the resistivity values and causes the improvement of nonlinear coefficient due to the higher adsorption of electron acceptor species on the grain boundary surface, increasing the barrier height potential and decreasing the conductivity, as demonstrated in Eq. 23 [57,58,67]:

$$
\mathrm{M}_{2} \mathrm{O}_{3} \stackrel{\mathrm{SnO}_{2}}{\rightarrow} 2 \mathrm{M}_{\mathrm{Sn}}^{\prime}+\mathrm{V}_{\mathrm{O}}^{\bullet \bullet}+3 \mathrm{O}_{\mathrm{O}}^{\mathrm{X}}
$$

There are many papers available in the literature [56-58,61-63,66-70], which studied the influence of doping agent into the tin oxide matrix ceramic. The possible microstructural, morphological, and varistor property changes that may occur with the addition of certain elements are searched.

\subsection{Effect of $\mathrm{Ca}, \mathrm{Ba}, \mathrm{Sr}$ addition on $\mathrm{Co}$, $\mathrm{Sb}$-doped $\mathrm{SnO}_{2}$ varistors}

Aguilar-Martínez et al. [69] investigated the effect of calcium (sample named SCa), barium (sample named $\mathrm{SBa}$ ), and strontium (sample named $\mathrm{Sr}$ ) additions on the microstructure and electrical properties of $\mathrm{SnO}_{2}-\mathrm{Co}_{3} \mathrm{O}_{4}-\mathrm{Sb}_{2} \mathrm{O}_{5}$ ceramic varistors.

By XRD analysis, it should be noted that the concentrations of dopants added $(\mathrm{SbO}, \mathrm{CaO}, \mathrm{Ba}$, and $\mathrm{SrO}$ ) were too small to be detected by the X-ray equipment. The microstructure of the samples was characterized by scanning electron microscopy. As shown Figure 16, it was found 
that the addition of strontium and calcium promotes densification and grain growth. The addition of $\mathrm{BaO}$ leads to a significant alteration of microstructure, changing the grain size and the morphology of grains from a nearly round shape to smaller and elongated grains. Barium addition causes increase of porosity, reduction of grain size, and changes in the grain morphology (from approximately equiaxed to elongated grains) [69].

(a)

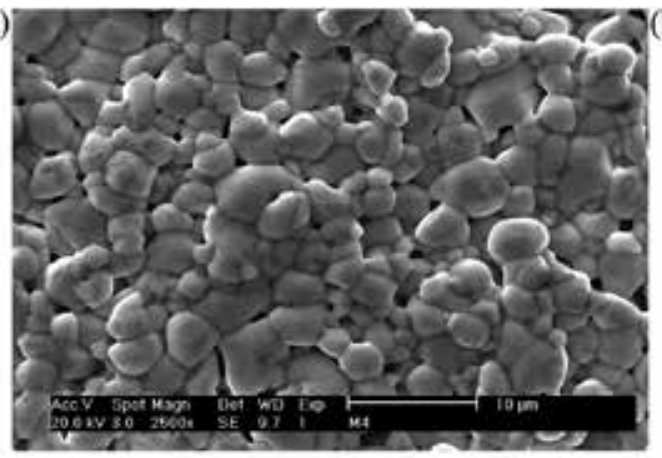

(c)

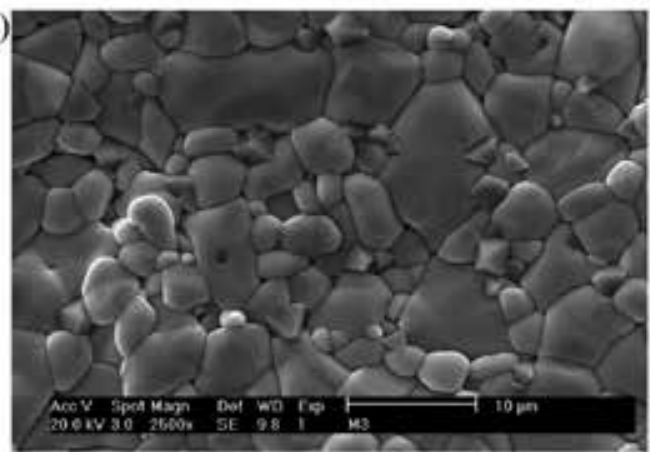

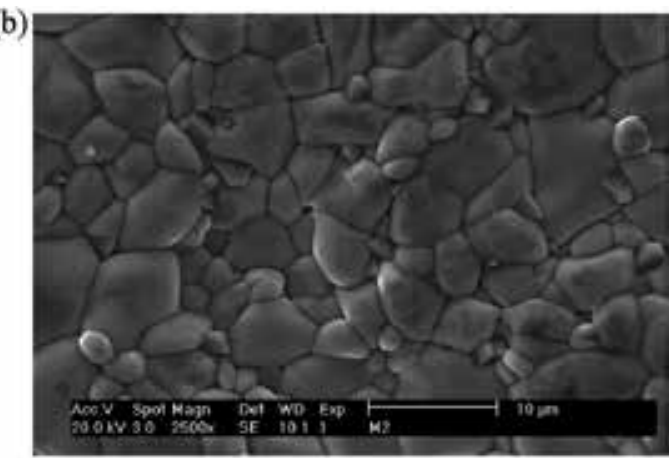

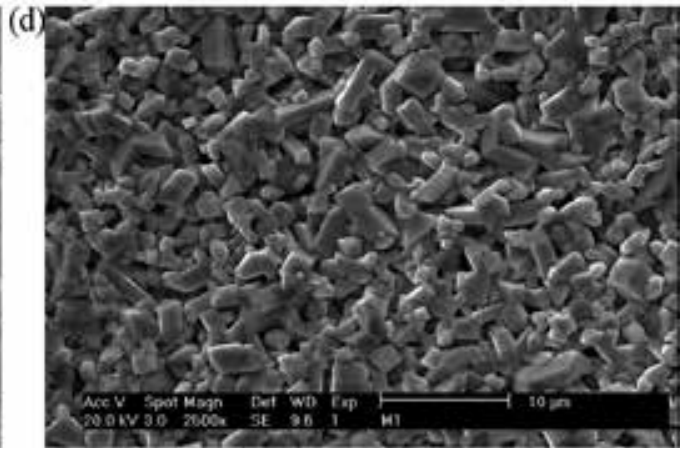

Figure 16. SEM images of the as-sintered surfaces of $\mathrm{SnO}_{2}$-based varistors: (a) $\mathrm{S}$, (b) SCa, (c) SSr, and (d) SBa [69].

Since electrical conduction in $\mathrm{SnO}_{2}$-based varistor ceramics is controlled by the grain-boundary barriers, the observed fact (the significant grain growth in a $\mathrm{SnO}_{2}$-system with $\mathrm{SrO}$ and $\mathrm{CaO}$ added) suggests that $\mathrm{Sr}$ and Ca materials are more suitable for low-voltage varistor preparation. The current-voltage curves of all prepared ceramic samples are nonlinear behavior. Figure 17 shows graphs of current density versus electric field for ceramics with and without additions sintered at $1350{ }^{\circ} \mathrm{C}$ [69].

Ceramics with calcium addition exhibit the lowest electric field at a fixed current density (10${ }^{3} \mathrm{~A} \mathrm{~cm}^{-2}$ ). The addition of strontium shows a similar effect on microstructure and currentvoltage characteristics. However, the $\mathrm{BaO}$ addition showed that low-field conductivity is slightly lower with respect to the reference material, but the high-field part remains unchanged. This behavior may be attributed to the resulting microstructure. Despite the grain morphology and porosity, the samples S (only Co an Sb as dopants), SCa, and SBa showed 


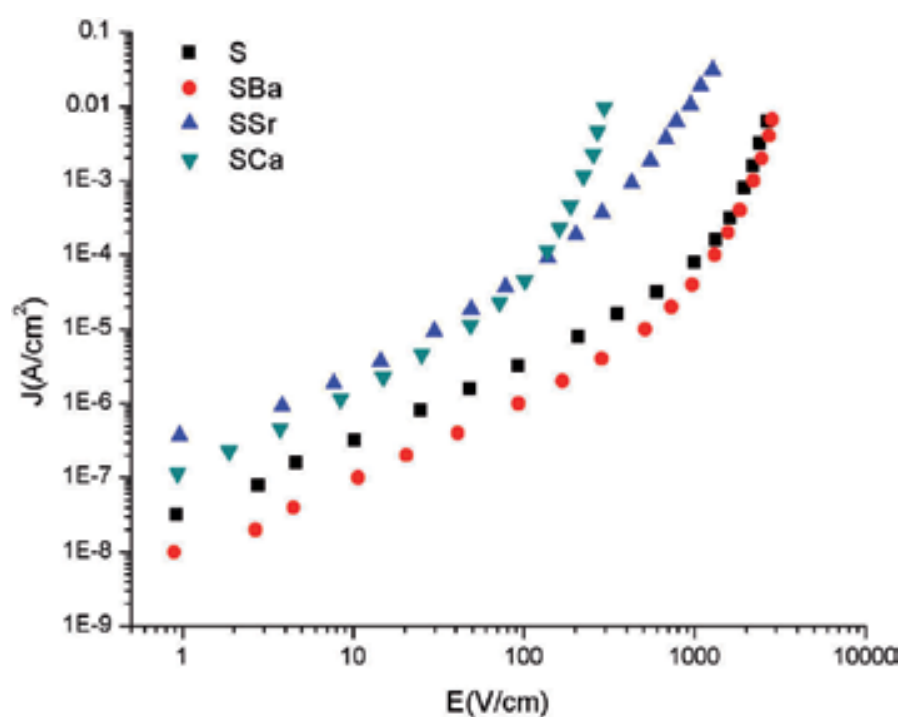

Figure 17. J versus E characteristic plots for all samples [69].

nonlinear coefficients of 5.7, 5.0, and 4.9, respectively, higher than the value for sample SSr (nonlinear coefficient of 2.7) [69].

\subsection{Effect of Er addition on $\mathrm{Co}, \mathrm{Nb}$-doped $\mathrm{SnO}_{2}$ varistors}

The addition of $\mathrm{Er}_{2} \mathrm{O}_{3}(\mathrm{Co}, \mathrm{Nb})$-doped $\mathrm{SnO}_{2}$ was studied by Qi et al. [70] at different concentrations $(0.1,0.5,1$, and $2 \mathrm{~mol} \%)$ and different temperatures of sintering $\left(1250{ }^{\circ} \mathrm{C}, 1300{ }^{\circ} \mathrm{C}\right.$, and $1350{ }^{\circ} \mathrm{C}$ for $1 \mathrm{~h}$ ). The XRD analysis carried out by the authors did not show evidence of the second phase formation into the $\mathrm{SnO}_{2}$-rutile crystalline phase. The SEM micrographs of the varistors prepared are in Figure 18, showing the decreases of grain size associated with the increase of $\mathrm{Er}_{2} \mathrm{O}_{3}$ concentration into ceramic matrix. Also, the decreases of grain size occur with lower temperature of sintering. With the addition of $2.0 \mathrm{~mol} \%$ of $\mathrm{Er}_{2} \mathrm{O}_{3}$ modifier agent, the $\mathrm{SnO}_{2}$ grain size was reduced from $12.9 \mu \mathrm{m}$ to $6.5 \mu \mathrm{m}$ when the sample sintered at $1350^{\circ} \mathrm{C}$ for 1 $\mathrm{h}$, from $9.7 \mu \mathrm{m}$ to $3.7 \mu \mathrm{m}$ when sample was sintered at $1300^{\circ} \mathrm{C}$ for $1 \mathrm{~h}$, and from $6.8 \mu \mathrm{m}$ to 2.4 $\mu \mathrm{m}$ when samples were sintered at $1250^{\circ} \mathrm{C}$ for $1 \mathrm{~h}$.

Figure 19 shows the plots of applied electric field versus current density for different concentrations of $\mathrm{Er}_{2} \mathrm{O}_{3}$ sintered at $1350{ }^{\circ} \mathrm{C}, 1300{ }^{\circ} \mathrm{C}$, and $1250{ }^{\circ} \mathrm{C}$ during $1 \mathrm{~h}$. It was observed from Figure 19 that the threshold voltage of the $\mathrm{SnO}_{2}$-based varistors increased significantly from $305 \mathrm{~V} \mathrm{~mm}^{-1}$ to $1083 \mathrm{~V} \mathrm{~mm}^{-1}$ with increasing $\mathrm{Er}_{2} \mathrm{O}_{3}$ concentrations over the range of 0-2.0 mol $\%$ sintered at $1350^{\circ} \mathrm{C}$ during $1 \mathrm{~h}$ and from $1083 \mathrm{~V} \mathrm{~mm}^{-1}$ to $2270 \mathrm{~V} \mathrm{~mm}^{-1}$ with decreasing sintered temperatures from $1350^{\circ} \mathrm{C}$ to $1250^{\circ} \mathrm{C}$ during $1 \mathrm{~h}$. Only the samples sintered at $1300{ }^{\circ} \mathrm{C}$ have decrease on nonlinear coefficient with $\mathrm{Er}_{2} \mathrm{O}_{3}$ addition. There is no observed significant change on height of the potential barrier for samples sintered ate $1250^{\circ} \mathrm{C}$ and $1300{ }^{\circ} \mathrm{C}$. 


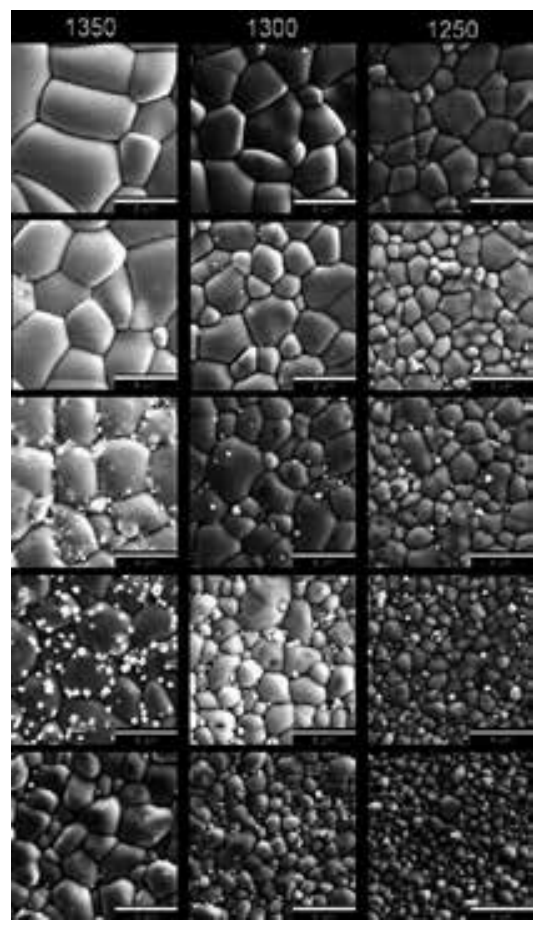

Figure 18. Microstructure variation of the $\mathrm{SnO}_{2}$-based varistor system sintered at $1350{ }^{\circ} \mathrm{C}, 1300{ }^{\circ} \mathrm{C}$, and $1250{ }^{\circ} \mathrm{C}$ during $1 \mathrm{~h}$ with the composition (all in mol\%): $100 \mathrm{SnO}_{2}+0.75 \mathrm{Co}_{2} \mathrm{O}_{3}+0.1 \mathrm{Nb}_{2} \mathrm{O}_{5}+x \mathrm{Er}_{2} \mathrm{O}_{3}$ : (from top to bottom) $x=0.0, x=0.1, x$ $=0.5, x=1.0, x=2.0[70]$.
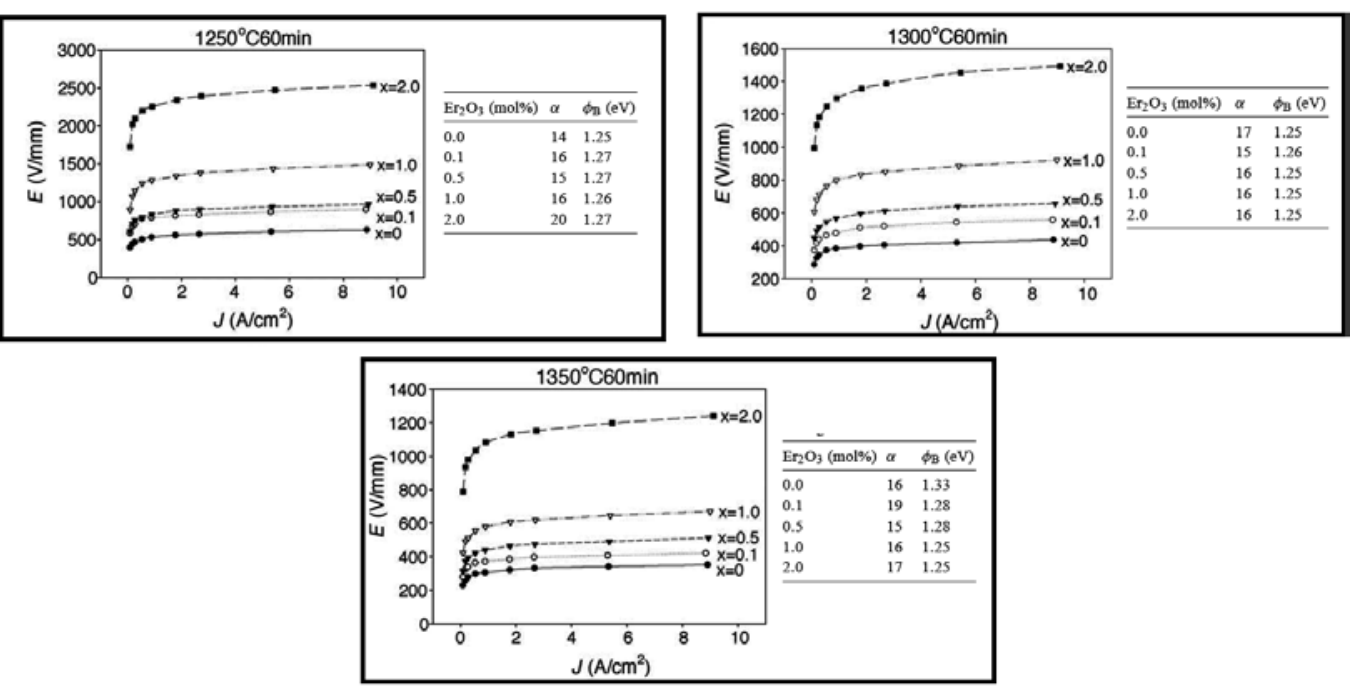

Figure 19. $\mathrm{E}$ versus $\mathrm{J}$ curves for the $\mathrm{SnO}_{2}$-based varistor system sintered at different temperatures during $1 \mathrm{~h}$ with the composition (all in $\mathrm{mol} \%$ ) $100 \mathrm{SnO}_{2}+0.75 \mathrm{Co}_{2} \mathrm{O}_{3}+0.1 \mathrm{Nb}_{2} \mathrm{O}_{5}+x \mathrm{Er}_{2} \mathrm{O}_{3}$ ( $x$ ranging from 0.0 to 2.0) [70]. 


\section{Conclusions}

The study of $\mathrm{SnO}_{2}$-based varistor systems is recent, so a huge amount of published papers do not exist. Research involving the material is mostly related to the understanding of the influence of dopants on densification materials prepared by mixing oxide and the change in the parameters of the potential barrier formed at grain boundary region, which is directly related to the nonlinear coefficient and determines the quality of varistor ceramics. The bivalent metals $\left(\mathrm{Ba}^{2+}, \mathrm{Ca}^{2+}, \mathrm{Co}^{2+}, \mathrm{Zn}^{2+}\right.$, and others) have proven action as a densifying agent since the defects generated by their addition to the ceramic matrix assist in mass diffusion. The addition of trivalent ions $\left(\mathrm{Cr}^{3+}, \mathrm{Er}^{3+}\right.$, and others) causes the increase of nonlinearity coefficient due to the higher adsorption electron acceptor species on the surface of the grain boundary and thus causing a reduction in conductivity of the material. The new methodologies for the chemical synthesis of ceramic powder promote the homogeneous distribution of dopants into the ceramic matrix and reduce segregation and the formation of secondary phases, confirmed by XRD analysis, which are harmful factors on the electrical properties of the varistor and facilitate the integration of the material in today's electronic devices electrical protection. The use of microwave oven is a new processing step aimed to reduce the time and temperature of sintering step and can be considered a promising procedure for the varistors production. The preparation of varistors as film emerges as a new possibility in order to facilitate integration of this material in electronic circuits.

\section{Acknowledgements}

The authors thank the LMA-IQ and the financial support by the Brazilian research funding agencies CNPq and FAPESP (CEPID/CDMF- 2013/07296-2and process $n^{\circ}$.

\section{Author details}

Glauco M.M.M. Lustosa, Natalia Jacomaci, João P.C. Costa, Gisane Gasparotto, Leinig A. Perazolli and Maria A. Zaghete*

*Address all correspondence to: zaghete@iq.unesp.br

Interdisciplinary Laboratory of Electrochemistry and Ceramics (LIEC), Chemistry InstituteUNESP, Araraquara/SP, Brazil

\section{References}

[1] Pianaro SA, Bueno PR, Olivi P, Longo E, Varela JA. Electrical properties of the $\mathrm{SnO}_{2}$ based varistor. J Mater Sci Mater El. 1998;9:159-165. DOI: 10.1023/A:1008821808693 
[2] Furtado JGM. Correlações entre fenômenos de grão e de contornos de grão e o desempenho de cerâmicas varistoras [thesis]. Rio de Janeiro: Universidade Federal do Rio de Janeiro; 2005.

[3] Matsuoka M. Nonohmic properties of zinc-oxide ceramics. Jpn J Appl Phys. 1971;10:736-746.DOI:10.1143/JJAP.10.736

[4] Bartkowiak M, Comber MG, Mahan GD. Energy handling capability of ZnO varistors. J Appl Phys. 1996;79:8629-8633.DOI: 10.1063/1.362484

[5] Castro MS, Benavente MA, Aldao CM. Degradation in ZnO varistor. J Phys Condens Mater. 1993;5:341-342.DOI: 10.1088/0953-8984/5/33A/125

[6] Xuetong Z, Jianyin L, Huan L, Shengtao L. The impulse current degradation of ZnO varistor ceramics. Proceedings of 2011 International Conference on Electrical Insulating Materials (ISEIM),2011;no:43-46. DOI: 10.1109/ISEIM.2011.6826272

[7] Pianaro SA, Bueno PR, Longo E, Varela JA. A new $\mathrm{SnO}_{2}$-based varistor system. J Mater Sci Lett. 1995;14:692-694. DOI: 10.1007/BF00253373

[8] Gupta TK. Application of zinc oxide varistors. J Am Ceram Soc. 1990;73:1817-1840. DOI: 10.1111/j.1151-2916.1990.tb05232.x

[9] Levinson LM, Philipp HR. ZnO varistors for transient protection. IEEE Trans Parts HybPac. 1977;13:338-343. DOI: 10.1109/TPHP.1977.1135218

[10] Pianaro SA, Bueno PR, Longo E, Varela JA. Microstructure and electric properties of a $\mathrm{SnO}_{2}$ based varistor. Ceram Int. 1999;25:1-6. DOI: 10.1016/S0272-8842(97)00076-X

[11] He J, Zeng R, Chen S, Tu Y. Thermal characteristics of high voltage whole-solid insulated polymeric ZnO surge arrester. IEEE Trans Power Deliver. 2003:18:1221-1227. DOI: 10.1109/TPWRD.2003.817492

[12] Santos P A. A importância do tempo de sinterização sobre as propriedades elétricas de varistores de $\mathrm{SnO}_{2}$ [thesis]. Ponta Grossa: Universidade Estadual de Ponta Grossa; 2004.

[13] Prisching D, Pecina AH. Temperature behavior of $\mathrm{ZnO}$ varistors before and after post sintering heat treatment. Mater Let. 2000;43:295-302. DOI: 10.1016/ S0167-577X(99)00277-3

[14] Bueno PR, Pianaro SA, Pereira EC, Varela JA. Investigation of the electrical properties of $\mathrm{SnO}_{2}$ varistor system using impedance spectroscopy. J Appl Phys. 1998;84:3700-3705. DOI: 10.1063/1.368587

[15] Oliveira MM, Rengel JHG, Sousa VC, Leite ER, Longo E, Bueno PR, Varela JA. Desenvolvimento devaristores à base de $\mathrm{SnO}_{2}$ para aplicação em redes de alta tensão. Cerâmica. 2006;54:149-154. DOI: 10.1590/S0366-69132006000300007 
[16] Clarke DR. Varistor ceramics. J Am Ceram Soc. 1999;82:485-502.DOI: 10.1111/j. 1151-2916.1999.tb01793.x

[17] Moulson A, Herbert JM. Electroceramics: Materials, Properties and Applications. 2nd ed. London: Chapman \& Hall; 2003. 576 p. DOI:10.1002/0470867965

[18] He J, Peng Z, Fu Z, Wang Z, Fu X. Effect of ZnO doping on microstructural and electrical properties of $\mathrm{SnO}_{2}-\mathrm{Ta}_{2} \mathrm{O}_{5}$ based varistor. J Alloys Compd. 2012;528:79-83. DOI: 10.1016/j.jallcom.2012.02.172

[19] Feng H, Peng Z, Fu X, Fu Z, Wang C, Qui L, Miao H. Effect of $\mathrm{SnO}_{2}$ doping on microstructural and electrical properties of $\mathrm{ZnO}-\mathrm{Pr}_{6} \mathrm{O}_{11}$ based varistor ceramics. J Alloys Compd. 2011;509:7175-7180. DOI: 10.1016/j.jallcom.2011.04.042

[20] Glot AB, Gaponov AV, Sandoval-García AP. Electrical conduction in $\mathrm{SnO}_{2}$ varistors. Physica B. 2010;405:705-711. DOI: 10.1016/j.physb.2009.09.091

[21] Bastami H, Taheri-Nassaj E. (Co, Nb, Sm)-doped tin dioxide varistor ceramics sintered using nanopowders prepared by coprecipitation method. J Am Ceram Soc. 2011;94:3249-3255. DOI: 10.1111/j.1551-2916.2011.04467.x

[22] Gupta TK, Carlson WG. A grain-boundary defect. Model for instability/stability of a ZnO varistor. J Mater Sci. 1985;20:3487-3900. DOI: 10.1007/BF01113755

[23] Leite ER, Varela JA, Longo E. A new interpretation for the degradation phenomenon of ZnO varistor. J Mater Sci. 1992;27:5325-5329. DOI: 10.1007/BF00553413

[24] Wang JF, Su WB, Chen HC, Wang WX, Zang GZ. (Pr, Co, Nb)-doped $\mathrm{SnO}_{2}$ varistors ceramics. J Am Ceram Soc. 2005;88:331-334. 10.1111/j.1551-2916.2005.00095.x

[25] Felix AA, Orlandi MO, Varela JA. Schottky-type grain boundaries in CCTO ceramics. Solid State Commun. 2011;151:1377-1381. DOI: 10.1016/j.ssc.2011.06.012

[26] Frenkel J. On pre-breakdown phenomena in insulator and electronic semi-conductor. Phys Rev. 1983;53:647-652. DOI: 10.1103/PhysRev.54.647

[27] Bwrnasconi J, Klein HP, Knecht B, Strassler S. Zinc oxide based varistor: a possible mechanism. Solid State Commun. 1976;20:1053-1056. DOI: 10.1016/0038-1098(77)90351-9

[28] Srague Electric Co. (USA). M. P. Pechini. Method of preparing lead and alkaline titanates and niobates and coating method using the same to form a capacitor. U.S. patent no. 3330697; 1967.

[29] Tang FQ, Uchikoshi T, Sakka Y. Electrophoretic deposition behavior of aqueous nanosized zinc oxide suspensions. J Am Ceram Soc. 2002;85:2161-2165. DOI: 10.1111/j.1151-2916.2002.tb00428.x 
[30] Stojanovic BD, Mitic V, Pejovic V, Vijatovic MM, Zaghete MA. Screen printed PLZT thick films prepared from nanopowders. J Eur Ceram Soc. 2007;27:4359-4362. DOI: 10.1016/j.jeurceramsoc.2007.02.170

[31] Lisboa Filho PN, Zenatti A, Casali GM, Paskocimas CA, Ortiz WA, LeiteER, Longo E. Magnetic behavior at low temperatures of Ti oxide polycrystalline samples. J Sol-Gel Sci Technol. 2002;24:241-245. DOI: 10.1023/A:1015336712094

[32] Magalhães EC. Propriedades Ópticas de Filmes Finos de Dióxido de Estanho Puro e Dopado com Flúor [thesis]. Salvador: Universidade Federal da Bahia; 2001.

[33] Sabila LF. Interação do complexo luminescente $\left[\mathrm{Eu}(\mathrm{tta})_{3}\right]$ com sílica mesoporosa [thesis]. Ilha Solteira: Universidade Estadual Paulista; 2009.

[34] Husing N, Schubert U. Aerogels-Airy Materials: Chemistry, Structure, and Properties. Angew Chem Inter Ed. 1998;37:22-45. DOI: 10.1002/(SICI)1521-3773(19980202)37:1/2<22::AID-ANIE22>3.0.CO;2-I

[35] Shubert H, Petzow G. Preparation and characterization of ceramic powders. In: Shigueyki Somiya editor. Advanced Ceramics III. 1st ed. Netherlands: Springer; 1990. p. 45-56. DOI: 10.1007/978-94-009-0763-8_3

[36] Mosquera A, Rodríguez-Páez JE, Varela JA, Bueno PR. Synthesis of $\mathrm{SnO}_{2}$ by chemical routes and its use in varistors production. J Eur Ceram Soc. 2007;27:3893-3896. DOI: 10.1016/j.jeurceramsoc.2007.02.056

[37] Shi JL. Solid state sintering of ceramics: pore microstructure models, densification equations and applications. J Mater Sci. 1999;34:3801-3812. DOI: 10.1023/A: 1004600816317

[38] Rahaman MN. Sintering of Ceramics. 1st ed. Boca Raton: CRC Press. 2007. 388 p. ISBN-10: 0849372860

[39] Rahaman MN. Ceramic Processing and Sintering. 2nd ed. New York: Handcover; 2003. 875 p. ISBN-10:0824709888

[40] Senos AMR, Vieira JM. Pore size distribution and particle rearrangement during sintering. In: P. Duran, J.F. Fernandez, editors.3rd EuroCeramics. San Lorenzo: Faenza Editrice Iberica; 1993. p. 821-826.ISBN-10: 848768307X

[41] Jamin CC. Constrained Sintering of Patterned Ceramic Films on Stiff Substrates [thesis]. Darmstadt: Technischen Universität Darmstadt; 2014.

[42] German RM. Sintering Theory and Practice. 1st ed. New York: Willey. 1996, 568p. ISBN: 978-0-471-05786-4

[43] Coble RL. Effects of particle-size distribution in initial-stage sintering. J Am Ceram Soc. 1973;56:461-466. DOI: 10.1111/j.1151-2916.1973.tb12524.x 
[44] Kim J, Kimura T, Yamaguchi ET. Sintering of zinc oxide doped with antimony oxide and bismuth oxide. J Am Ceram Soc. 1989;72:1390-1395. DOI: 10.1111/j. 1151-2916.1989.tb07659.x

[45] Wang CM, Thevuthasan S, Gao F, McCready DE, Chambers SA, Peden CHF. Interface characteristics of iso-structural thin film and substrate pairs. Nucl Instrum Meth B. 2003;207:1-9. DOI: 10.1016/S0168-583X(03)00512-3

[46] Thomas B, Skariah B. Spray deposited Mg-doped $\mathrm{SnO}_{2}$ thin film LPG sensor: XPS and EDX analysis in relation to deposition temperature and doing. J Alloy Compd. 2015;625:231-240. DOI: 10.1016/j.jallcom.2014.11.092

[47] Shishun Q, Ruzhong Z, Zhaosheng M. Densification behavior and microstructure evolution of evolution of LTCC film constrained by rigid substrate. Key Eng Mat. 2015;633:93-97. DOI: 10.4028/www.scientific.net/KEM.633.93

[48] Kim JS, Rudkin RA, Wang X, Atkinson A. Constrained sintering kinetics of 3YSZ films. J Eur Ceram Soc. 2011;31:2231-2239. DOI: 10.1016/j.jeurceramsoc.2011.05.044

[49] Bueno PR, Oliveira MR, Santos C, Longo E, Tebcherami SM, Varela JA. Varistores à base de $\mathrm{SnO}_{2}$ : estado da arte e perspectivas. Cerâmica. 2000;46:125-130. DOI: 10.1590/ S0366-69132000000300002

[50] Varela JA, Perazolli LA, Cerri ER, Leite E, Longo E. Sinterização de óxido de estanho e suas aplicações em eletrônica e no processamento de vidros ópticos de alta pureza. Cerâmica. 2001;47:117-123. DOI: 10.1590/S0366-69132001000200010.

[51] Cerri JA, Leite ER, Gouvêa D, Longo E, Varela JA. Effect of cobalt (II) oxide and manganese (IV) oxide on sintering of tin (IV) oxide. J Am Ceram Soc. 1996;79:799-804. DOI: 10.1111/j.1151-2916.1996.tb07949.x

[52] Perazolli LA, Giraldi TR, Biscaro RS, Varela JA, Longo E. Improved densification of $\mathrm{SnO}_{2}$ by doping with $\mathrm{ZnO}$. Sinter Sci Technol. 2000;13:117-122.

[53] Hao HS, Xu LH, Huang Y, Zhang XM, Xie ZP. Kinetics mechanism of microwave sintering in ceramic materials. Sci China Ser E: Tech Sci. 2009;52:2727-2731. DOI: 10.1007/s11431-008-0217-3

[54] Żymelka D, Saunier S, Goeuriot D, Molimard J. Densification and thermal gradient evolution of alumina during microwave sintering at $2.45 \mathrm{GHz}$. Ceram Int. 2013;39:3269-3277. DOI: 10.1016/j.ceramint.2012.10.015

[55] Lustosa GMMM, Costa JPC, Perazolli LA, Stojanovic BD, Zaghete MA. Electrophoretic deposition of $(\mathrm{Zn}, \mathrm{Nb}) \mathrm{SnO}_{2}$-films varistor superficially modified with $\mathrm{Cr}^{3+}$. J Eur Ceram Soc. 2015;35:2083-2089. DOI: 10.1016/j.jeurceramsoc.2015.01.022

[56] Leite DR, Cilense M, Orlandi MO, Bueno PR, Longo E, Varela JA. The effect of $\mathrm{TiO}_{2}$ on the microstructural and electrical properties of low voltage varistor based on 
(Sn,Ti)O $\mathrm{O}_{2}$ ceramics. Phys Status Solidi A. 2010;207:457-461. DOI: 10.1002/pssa. 200925304

[57] Bacelar WK, Bueno PR, Leite ER, Longo E, Varela JA. How $\mathrm{Cr}_{2} \mathrm{O}_{3}$ influences the microstructure and nonohmic features of the $\mathrm{SnO}_{2}\left(\mathrm{Co}_{x}, \mathrm{Mn}_{1-\mathrm{x}}\right) \mathrm{O}$-based varistor system. J Eur Ceram Soc. 2006;26:1221-1229. DOI: 10.1016/j.jeurceramsoc.2005.01.051

[58] Brankovic G, Brankovic Z, Bavolos MR, Cilense M, Varela JA. Influence of the common varistor dopants $\left(\mathrm{CoO}, \mathrm{Cr}_{2} \mathrm{O}_{3}\right.$ and $\left.\mathrm{Nb}_{2} \mathrm{O}_{5}\right)$ on the structural properties of $\mathrm{SnO}_{2}$ ceramics. Mater Charact. 2004;52:243-241. DOI: 10.1016/j.matchar.2002.11.001

[59] Perazolli LA, Gasparotto Gisane, Jacomaci N, Ruiz M, Zaghete MA, Foschini CR, Aguiar EC, Varela JA. $\mathrm{SnO}_{2}$ dense ceramic microwave sintered with low resistivity. Mater Sci Appl. 2012;3:272-280. DOI: 10.4236/msa.2012.35040

[60] Wang CM, Wang JF, Zhao Y, Su WB. Effects of copper oxide on the microstructural morphology and electrical properties of tin oxide-based varistor ceramics. J Phys D Appl Phys. 2006;39:1684-1689. DOI: 10.1088/0022-3727/39/8/031

[61] Gaponov AV, Glot AB. Electrical properties of $\mathrm{SnO}_{2}$ based varistor ceramics with $\mathrm{CuO}$ addition. Mater Sci-Mater El. 2010;21:331-337. DOI: 10.1007/s10854-009-9916-1

[62] Mazalli IO, Las WC, Cilense M. The effect of preparation method and Sb content on $\mathrm{SnO}_{2}-\mathrm{CuO}$ sintering. J Mater Sci. 2003;38:3325-3330. DOI: 10.1023/A:1025102524795

[63] Gaponov AV, Glot AB, Ivon AI, Chack AM, Jimenes-Santana G. Varistor and humidity-sensitive properties of $\mathrm{SnO}_{2}-\mathrm{Co}_{3} \mathrm{O}_{4}-\mathrm{Nb}_{2} \mathrm{O}_{5}-\mathrm{Cr}_{2} \mathrm{O}_{3}$ ceramics with $\mathrm{V}_{2} \mathrm{O}_{5}$ addition. Mater Sci Eng B. 2007;459:76-84. DOI: 10.1016/j.mseb.2007.10.003

[64] Wang, WX, WangJF, Chen HC, Su WB, Zang GZ. Effects of $\mathrm{Cr}_{2} \mathrm{O}_{3}$ on the properties of (Co, Nb)-doped $\mathrm{SnO}_{2}$ varistors. Mater Sci Eng B. 2003;9:470-474. DOI: 10.1016/ S0921-5107(02)00477-4

[65] Aguilar-Martínez JA, Pech-Canul MI, Hernández MB, Glot AB, Rodrígez E, GracíaOrtiz L. Effect of $\mathrm{Cr}_{2} \mathrm{O}_{3}$ on the microstructure and non-ohmic properties of $(\mathrm{Co}, \mathrm{Sb})$ doped $\mathrm{SnO}_{2}$ varistor. Rev Mex Fis. 2013;59:6-9.

[66] Qi P, Wang JF, Su WB, Cheng HC, Zang GZ, Wang CM, Ming BQ. (Yb,Co,Nb)-doped $\mathrm{SnO}_{2}$ varistors ceramics. Mater Sci Eng B. 2005;119:94-98. DOI: 10.1016/j.mseb. 2004.11.013

[67] Wang WX, Wang JF, Chen HC, Su WB, Jiang B, Zang GZ, Wang CM, Qi P. Varistor properties of $\mathrm{Sc}_{2} \mathrm{O}_{3}$-doped $\mathrm{Sn}$.Co.Nb ceramics. Ceram Int. 2005;31:287-291. DOI: 10.1016/j.ceramint.2004.05.018

[68] Leite DR, Las WC, Zaghete MA, Cilense M, Varela JA. The effect of Cr concentration and preparation method on the microstructure and electrical characterization of $\mathrm{SnO}_{2}$-based ceramics. Mater Res. 2003;6:457-461. DOI: 10.1590/ S1516-14392003000400005 
[69] Aguilar-Martínez JA, Rodríguez E, García-Villarreal S, Falcon-Franco L, Hernandez. Effect of $\mathrm{Ca}$, Sr and $\mathrm{Ba}$ on the structure, morphology and electrical properties of (Co,Sb)-doped $\mathrm{SnO}_{2}$ varistors. Mater Chem Phys. 2015;153:180-186. DOI: 10.1016/ j.matchemphys. 2015.01.001

[70] Qi P, Wang JF, Su WB, Chen HC, Zang GZ, Wang CM, Ming BQ. (Er, Co, Nb)-doped $\mathrm{SnO}_{2}$ varistor ceramics. Mater Chem Phys. 2005;92:578-584. DOI: 10.1016/j.matchemphys.2005.02.013 

Chapter 3

\title{
Porous Ceramics
}

\author{
Naboneeta Sarkar and Ik Jin Kim \\ Additional information is available at the end of the chapter \\ http://dx.doi.org/10.5772/61047
}

\begin{abstract}
The unique chemical composition and microstructure of porous ceramics enable the ceramic products used in a number of applications such as filtration of molten metals and hot corrosive gases, high-temperature thermal insulation, support for catalytic reactions, filtration of diesel engine exhaust gases, etc. These applications take advantage of special characteristics of porous ceramics such as low thermal mass, low thermal conductivity, controlled permeability, high surface area, low density, and high specific strength. In this chapter, we emphasize on direct foaming method, a simple and versatile approach that allows fabrication of porous ceramics with tailored microstructure along with distinctive properties. Foam stability is achieved upon controlled addition of amphiphiles to the colloidal suspension, which induce in situ hydrophobization, allowing the wet foam to resist coarsening upon drying and sintering.
\end{abstract}

Keywords: Porous ceramics, direct foaming, wet foam stability, Laplace pressure, adsorption free energy, microstructure

\section{Introduction}

Porous ceramics are widely used in various versatile applications, such as liquid gas filters, catalysis supports, gas distributors, insulators, preforms for metal-impregnated ceramic metal composites, and implantable bone scaffolds [1,2]. Unlike in metallic or polymeric products, pores have been traditionally avoided in ceramic components because of their inherently brittle nature [3, 4]. However, porous ceramics have become increasingly essential, especially for use in environments involving high temperatures, extensive wear and corrosive media [5, 
6]. Porous ceramics are advantageous in such application areas due to their high melting point, tailored electronic properties, and high corrosion and wear resistance, which combine favorably with the features gained by the introduction of voids into the solid material [7-10]. These features include low thermal conductivity, controlled permeability, high surface area, low density, high specific strength, and low dielectric constant. These properties can be tailored for each specific application by controlling the composition and microstructure of the porous ceramic. Changes in open and closed porosity, pores' size distribution, and pores' morphology can greatly affect a material's properties. These microstructural features are highly influenced by the processing route used to produce the porous material [11-15].

Foaming melts by gas injection creates gas bubbles in the liquid by the admixing of gasreleasing blowing agents into the molten metal, or by causing the precipitation of gas which had been previously dissolved in the liquid [16, 17]. The stabilization of such foams can be achieved by surfactants, which form dense monolayers on foam films. The surfactant films can reduce surface tension, increase surface viscosity, and create electrostatic forces to prevent foam from collapsing. The stabilization and destabilization mechanisms of coated bubbles exposed to surfactants to produce metallic foams are discussed elsewhere [18]. Colombo et al. [19] discussed different novel processing methods for cellular ceramics, including the burning out of fugitive pore formers. Established methods of producing porous ceramics employ the burning out of templates. The impregnating of a polymeric template increases struts throughout the material and thus increased the strength of the resulting ceramic foams [20]. The porosity of ceramics produced in this way depends on the template's type, content, and grain size. This limits the maximum useable content of such additives, as too high contents substantially weaken the material. Increased porosity can also be achieved by introducing highporosity granules - both natural (e.g., diatomite, tripolite, and swelled perlite) and synthesized (e.g., by the crushing of briquettes prepared by foaming) [21]. Chemical formations of gas bubbles within a ceramic mixture can also increase porosity. These include chemical reactions in the ceramic suspension or the decomposition of gas-forming additives. The kinetics of alumina slip swelling for the production of lightweight corundum materials have been investigated [22]. Another method is the impregnation of a polymer cellular matrix with a ceramic suspension and subsequent squeezing out, drying, and thermal treatment to remove the organic components [23]. The addition or embedding of ceramic fibers into the mixture, followed by molding with binders and the subsequent thermal treatment of the molded products, can also yield porous materials [24].

The introduction of air into a colloidal suspension is widely used during processing of highly porous foam ceramics $[25,26]$. Uniform, finely cellular foam can be produced by mixing into the ceramic suspension frothing agents that stabilize the resultant three-phase foam. Such cellular structures are preserved under subsequent drying and firing [27]. Much work has sought to develop processing parameters for such syntheses.

Less defective components, as compared with dry processing, have recently been shown to result from the wet processing of powders. It allows better control of the interactions between the powder and the particles and increases the homogeneity of particles' packing in the wet stage, leading to fewer and smaller defects in the final microstructure. This can be achieved 
either by consolidating the dispersion medium or by flocculating or coagulating the particles in the liquid medium. Such wet methods have recently been developed to incorporate gaseous phases into ceramic suspensions consisting of ceramic powder, solvent, dispersants, surfactants, and gelling agents. The process has been called direct foaming by the hydrophobization of particles' surfaces; the incorporation of the gaseous phase can result from mechanical frothing, injection of a gas stream, gas-releasing chemical reactions, or solvent evaporation [28]. Its simplicity, low cost, and versatility has made it popular for the manufacture of porous ceramics. Fig. 1 outlines common methods of preparing porous ceramics and their corresponding products' degrees of porosity. The fabrication methods of microporous ceramics currently available can be classified as replica techniques, methods that employ sacrificial templates and direct foaming [29]. Ceramics' microstructures and properties depend on their fabrication method. Therefore, consideration of the methods' cost, simplicity, and versatility is important. Stabilization of the introduced species' surfaces is required to overcome coalescence, Ostwald ripening, and phase separation and can be achieved using lower-energy molecules for droplet formation. These provide steric and electrostatic barriers against coalescence [30]. Early twentieth century works by Ramsden and Pickering showed that solid particles adsorbed at liquid-liquid interfaces can stabilize the resulting Pickering emulsions, through the introduced surface active molecules lowering the system's free energy by reducing the liquid-liquid interfacial area [31].

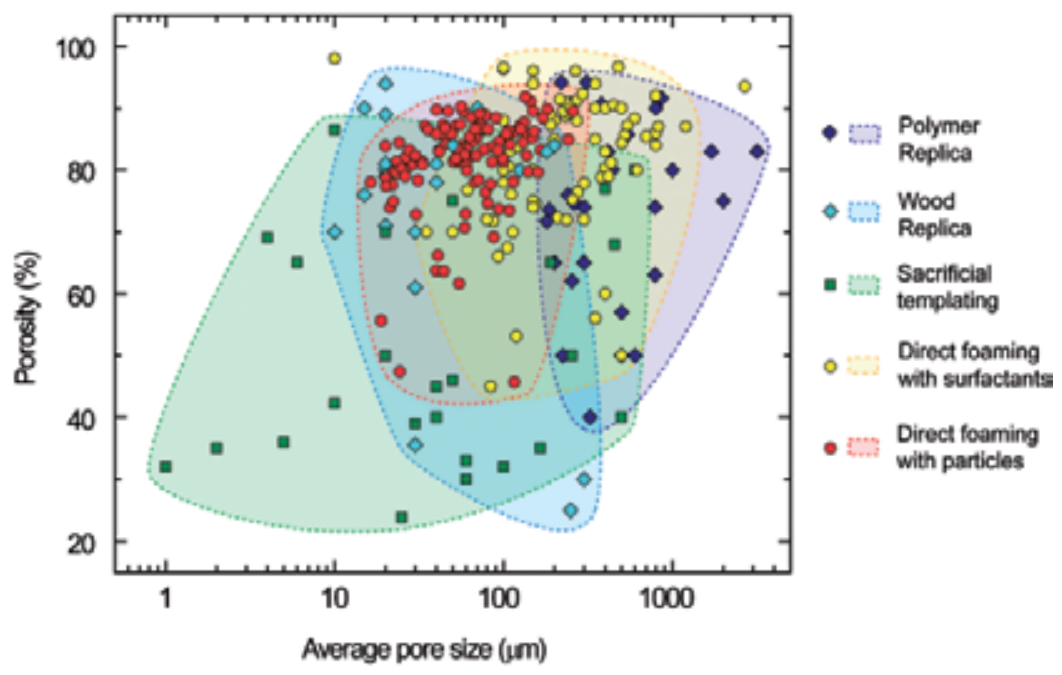

Figure 1. Typical porosity and average pores sizes achieved via replica, sacrificial templating, and direct foaming routes. $^{2}$

This chapter explores the stabilization of wet foams by colloidal amphiphilic particles and the development of fabrication techniques of solid macroporous ceramics with tailored microstructures. Each method is discussed and assessed with regard to the versatility and ease of fabrication and its influence on the microstructure and mechanical strength of the resulting macroporous ceramics. Given the importance of ceramics' foam microstructures, the effects of 
foam precursor suspensions - bubble size, distribution, contact angle, and surface tensionon the resultant porous ceramics' mechanical and physical properties are assessed here. Control of these parameters can allow the tailoring of the microstructures of porous ceramics produced by direct foaming.

\section{Processing routes to porous ceramics}

The processes for manufacturing porous ceramics can be classified into following four categories, which is schematically depicted in Fig. 2.

i. Replica techniques

ii. Sacrificial template

iii. Direct foaming

In this chapter, we reviewed the main processing techniques that can be used for the fabrication of porous ceramics with tailored microstructure. Replica techniques, sacrificial template, and direct foaming techniques is described here and compared in terms of microstructures and mechanical properties that could be achieved. These simple yet versatile approaches give rise to porous ceramics with unique microstructural features that control the properties and functions of the ceramic materials.

\subsection{Replica techniques}

Replica techniques involve the impregnation of a cellular structure with a ceramic suspension or precursor solution to produce a macroporous ceramic exhibiting a similar morphology to the original porous material (Fig. 2(a)). This is followed by the removal of excess slurry, pyrolysis of the polymeric substrate, and sintering to solidify the foam $[6,13]$. Therefore, the ceramic foam replicates the original organic polymer structure. Difficulties of slurry impregnation limit the realization of small cells. The struts contain central holes, which result from the burning out of the polyurethane template. Microcracks and pores also result. Replication generates large amounts of $\mathrm{CO}_{2}$ during firing due to the decomposition of the organic compounds [10,12]. Suitable biogenic porous structures have been used as templates to form cellular ceramics with particular microstructures that could also be produced by other methods. Those processes for the fabrication of bulk ceramics structures are discussed here.

This technique, reported in the 1960s, is the first method deliberately used for the production of macroporous ceramics [32]. First, polymeric sponges were used as templates to prepare ceramic cellular structures with various pore sizes, porosities and chemical compositions. In the polymer replica approach, a highly porous polymeric sponge is initially soaked in a ceramic suspension until its internal pores are filled. Binders and plasticizers are also added to the initial suspension to provide ceramic coatings sufficiently strong to prevent the struts from cracking during pyrolysis. This process is explored fully elsewhere [11, 13]. 
The resulting ceramic is formed after removal of the polymeric template. The ceramic coating is finally densified by sintering at $1000-1700^{\circ} \mathrm{C}$ depending on the material. Porous ceramics obtained via sponge replication can reach total open porosity levels of $40 \%-95 \%$ and are characterized by a reticulated structure of highly interconnected pores of between $200 \mu \mathrm{m}$ and $3 \mathrm{~mm}$. The disadvantages of this technique lie in the formation of the struts of the reticulated structure during pyrolysis of the polymeric template, which significantly weakens the mechanical strength of the resulting porous ceramic [21]. The technique also requires several steps, which lengthen its duration and increases its cost.

\subsection{Sacrificial templates}

A dispersed sacrificial phase can be homogeneously dispersed throughout a biphasic composite with a continuous matrix of ceramic particles or ceramic precursors. It is ultimately extracted to generate pores within the microstructure (Fig. 2(b)). This method is analogously opposite to replication and results in a negative replica of the original sacrificial template, as opposed to the positive morphology obtained from replication. The method of the sacrificial material's extraction from the consolidated composite depends primarily on the type of pore former employed [33]. A wide variety of sacrificial materials can be used as pore formers, including natural and synthetic organics, salts, liquids, metals, and ceramics. This technique is flexible and can employ various chemical compositions. Various oxides have been used to fabricate porous ceramics using starch particles as sacrificial templates [9, 10]. Nonoxide porous ceramics have also been produced using pre-ceramic polymers and various template materials [34,35]. Since this method produces a ceramic to the negative of the original template, the removal of the sacrificial phase does not lead to flaws in the struts as can occur using positive replicas. The microstructures obtained by this technique reflect directly the pattern of the sacrificial phase and higher mechanical strengths are generally achievable than by using positive replicas [36, 37].

\subsection{Direct foaming}

Direct foaming produces porous materials by the incorporation of air into a suspension or liquid medium. The foam structure is then set by high-temperature sintering to obtain crackfree, high-strength porous ceramics. The suspensions are stabilized in situ through the hydrophobization of the suspended particles by short chain amphiphilic molecules. The coated, hydrophobic particles irreversibly adsorb to the air-water interface, thus stabilizing it (Figs. 2(c) and 3) [38]. These wet foams can remain stable for several days and show no bubble coarsening, drainage, or creaming. The short-chain amphiphiles modify in situ the wetting behavior of the particles' surfaces, as in a Pickering emulsion. Ultrastable wet foams can be produced by direct foaming using particles instead of surfactants as foams stabilizers [16, 19, 25]. Porous ceramics' properties are also highly influenced by their chemical compositions and microstructures, with porosity, pore morphology, and size distribution being tailored by different compositions, different physical structures of the starting materials, and the use of different amphiphiles [30-36]. This review focuses on this process. 

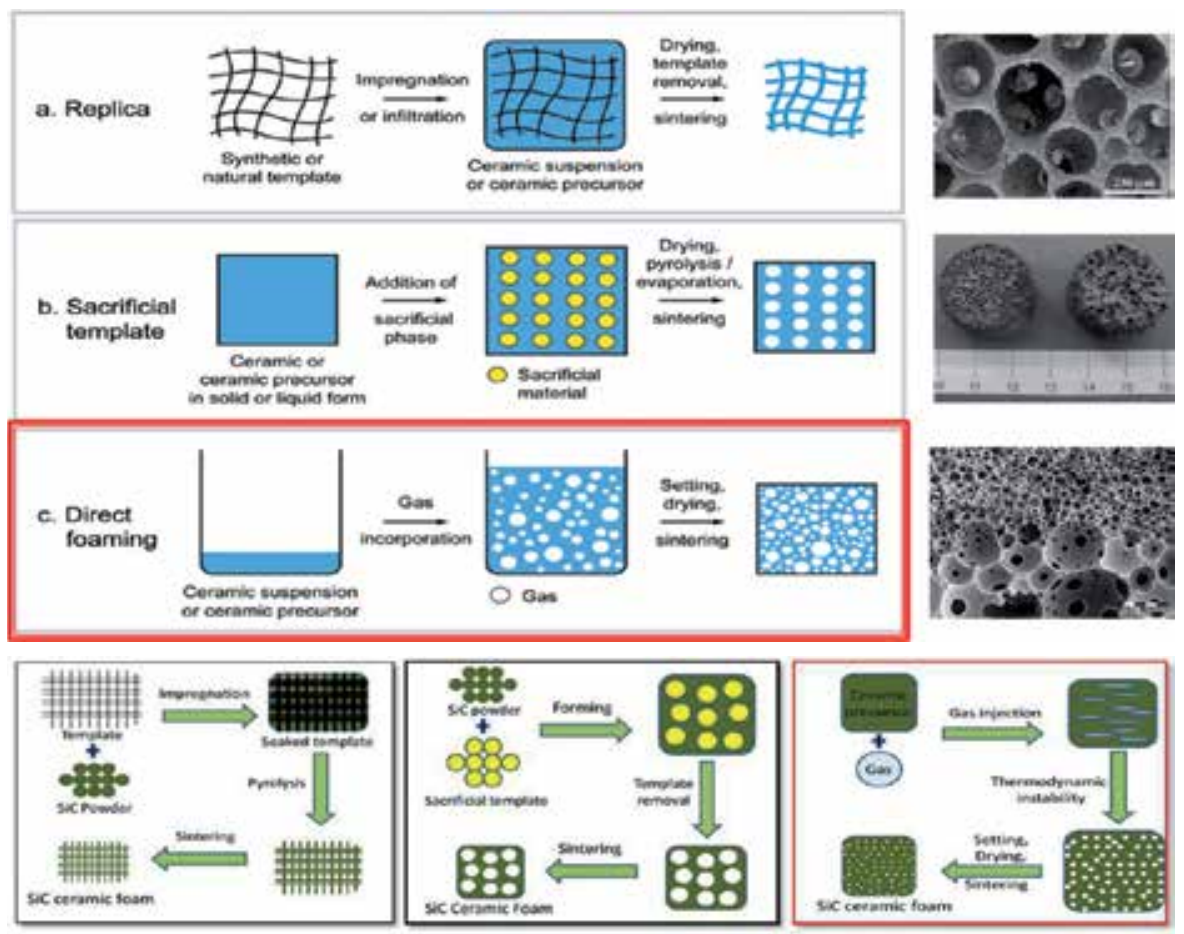

Preparation of SIC ceramie foam by (a) Replica technique, (b) sacrificial Template Method and (c) direct foaming

Figure 2. Currently available methods of forming porous ceramics. ${ }^{2}$

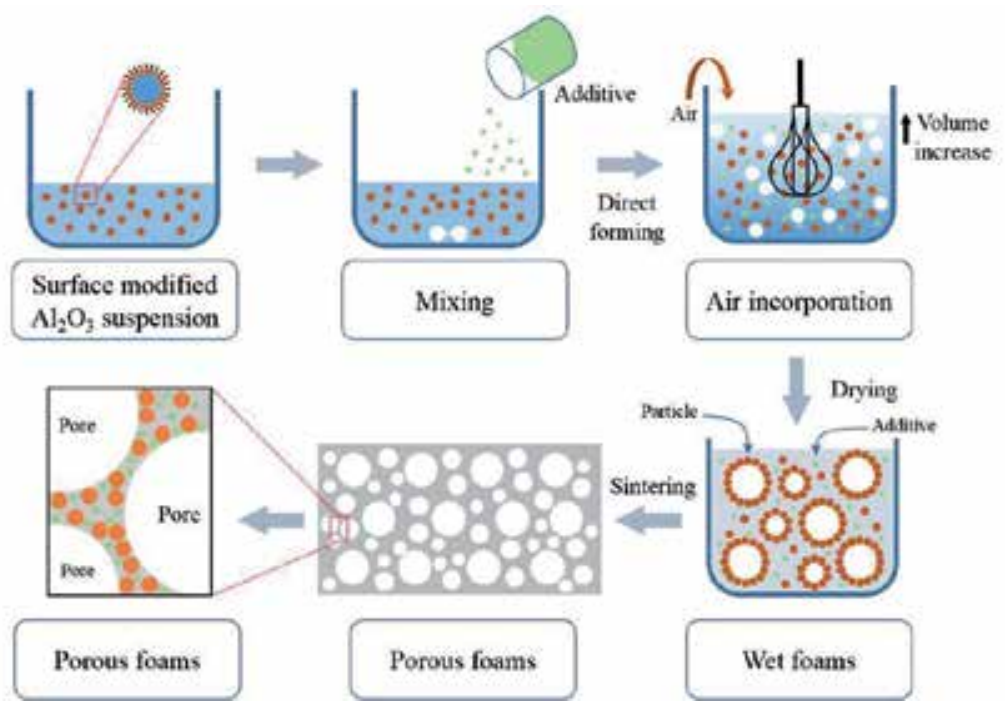

Figure 3. In situ hydrophobization of particles and solid foam formation by direct foaming. ${ }^{4}$ 


\section{Process to stabilization}

\subsection{Zeta potential and in situ hydrophobization}

Colloids are suspensions or liquid foams that are generally thermodynamically unstable. The instability arises due to their high gas-liquid interfacial areas, which raise the free energy of the system. To achieve a stable system, free energy must be minimized. The electrokinetic properties of a colloidal system can be described using the zeta potential (Figure 4(a)). Higher charges on the particles' surfaces stabilize a colloidal suspension by preventing the particles from coming into contact and coalescing. Colloids with high zeta potential (negative or positive) are electrically stabilized while colloids with low zeta potentials tend to coagulate or flocculate as shown in Table 1. A suspension's $\mathrm{pH}$ affects its charge distribution, and hence its zeta potential. The isoelectric point (IEP) is the $\mathrm{pH}$ at which a colloid's zeta potential is zero; it can be used to derive information about the $\mathrm{pH}$ ranges in which a colloid is stable. A suspension's $\mathrm{pH}$ can be modified to allow dissociated surfactant to adsorb electrostatically as counter ions onto oppositely charged alumina hydroxyl surface groups [39]. The suspension's inorganic particles can be stabilized in situ by the particles' hydrophobization with different colloidal particles containing predominantly $-\mathrm{OH}_{2}{ }^{+},-\mathrm{OH}$, and - $\mathrm{O}^{-}$surface groups. Surfaces with predominantly $-\mathrm{OH}_{2}{ }^{+}$and $-\mathrm{OH}$ groups can be achieved on inorganic alumina particles at $\mathrm{pH}$ 4.5 and $\mathrm{pH} 9.5$, respectively. This could be derived from the zeta potential data for bare alumina particles (Fig. 4(b)), which confirm that the surface exhibits mainly $-\mathrm{OH}_{2}^{+}$(positive net charge) and $-\mathrm{OH}$ (neutral net charge) groups under those conditions [26, 31, 20]. Amphiphiles of short chain carboxylic acids and gallates are expected to adsorb well onto alumina particles. Propyl gallate has been used to modify the surfaces of particles by ligand exchange reactions [15]. The surface hydroxyl groups $\left(-\mathrm{OH}\right.$ or $\left.-\mathrm{OH}_{2}^{+}\right)$were replaced by one or more of the molecule's hydroxyl groups $\left(-\mathrm{OH}\right.$ or $\left.-\mathrm{O}^{-}\right)$. Therefore, the adsorption of gallate molecules does not necessarily require oppositely charged surfaces and amphiphiles and can be used at $\mathrm{pH}$ values at which the surface groups and the molecules exhibit the same charge polarity. Hydrophobizing adsorption can change the wettability of particles at the interface of two immiscible phases, and the system is stabilized by the neutral forces between the particles and the amphiphilic coatings. Therefore, the choice of amphiphile depends upon the IEP and the zero net charge of the oxide. Surface hydrophobization can be accomplished by choosing amphiphiles with functional groups that react with the surface hydroxyl groups. Pyrogallol groups can efficiently adsorb on oxide surfaces via ligand exchange reactions $[14,16]$ and thus can be used with a short hydrocarbon tail to modify the surfaces of particles with intermediate IEPs. The selection of amphiphiles with suitable head groups and tail lengths allows the surface hydrophobization of particles of various compositions.

\subsection{Destabilizing suspension}

Colloidal dispersions can be thermodynamically unstable, with long-term kinetic stability determining their self-life. The main destabilization mechanisms are drainage (creaming and sedimentation), coalescence, and flocculation (Fig. 5). Creaming and sedimentation are caused by gravity: lighter particles float and heavier particles settle. They are reversible in that 

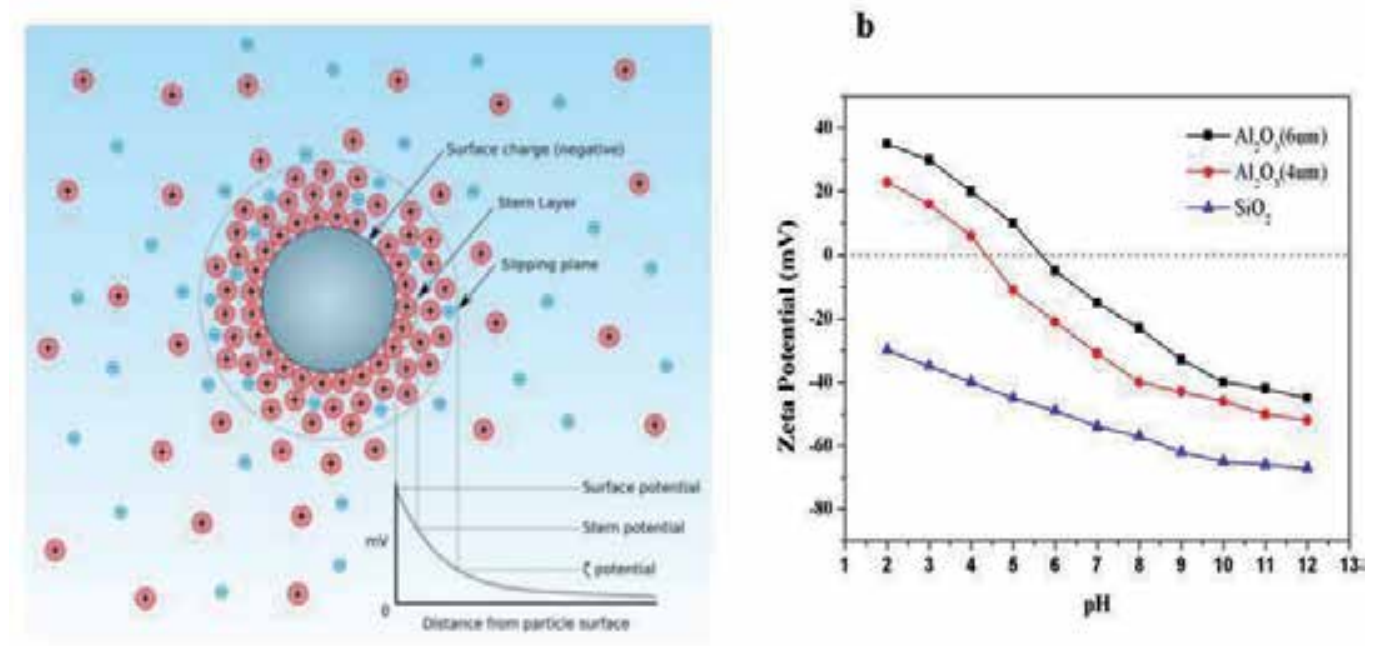

Figure 4. (a) The distribution of charges in a colloidal suspension; higher charges at the particles' surfaces can stabilize the system. (b) Zeta potential of raw $\mathrm{Al}_{2} \mathrm{O}_{3}$ and $\mathrm{SiO}_{2}$ colloidal particles.

\begin{tabular}{cc}
\hline Zeta potential $[\mathrm{mV}]$ & Stability behaviour of the colloid \\
\hline From 0 to \pm 5 & Rapid coagulation or flocculation \\
\hline From \pm 10 to \pm 30 & Incipient instability \\
\hline From \pm 30 to \pm 40 & Moderate stability \\
\hline From \pm 40 to \pm 60 & Good stability \\
\hline More than \pm 61 & Excellent stability \\
\hline
\end{tabular}

Table 1. Zeta potential as key indicator of the stability of colloidal dispersions

mechanical agitation (homogenization or simple shaking) will redisperse the suspension. Coalescence and flocculation are not reversible and so affect a suspension's stability. Flocculation is the clustering of colloidal particles via attractive van der Waals forces. It can be overcome or prevented by higher-energy ultrasonification or by generating particles with repulsive interactions [40]. Coalescence is the greatest destabilizing mechanism. It involves smaller particles collapsing into each other, forming larger particles with different properties. Many dispersion techniques have been developed to prevent coalescence [41].

\subsection{Suspension stability}

The foams require the adsorption of particles on the surfaces of air bubbles upon their formation. Alumina particles can be hydrophobized by modification with short-chain carboxylic acids: the carboxylate groups adsorb to the alumina's surface [42], leaving the hydrophobic tail in contact with the aqueous solution. This has been shown to stabilize the dispersion [43]. 


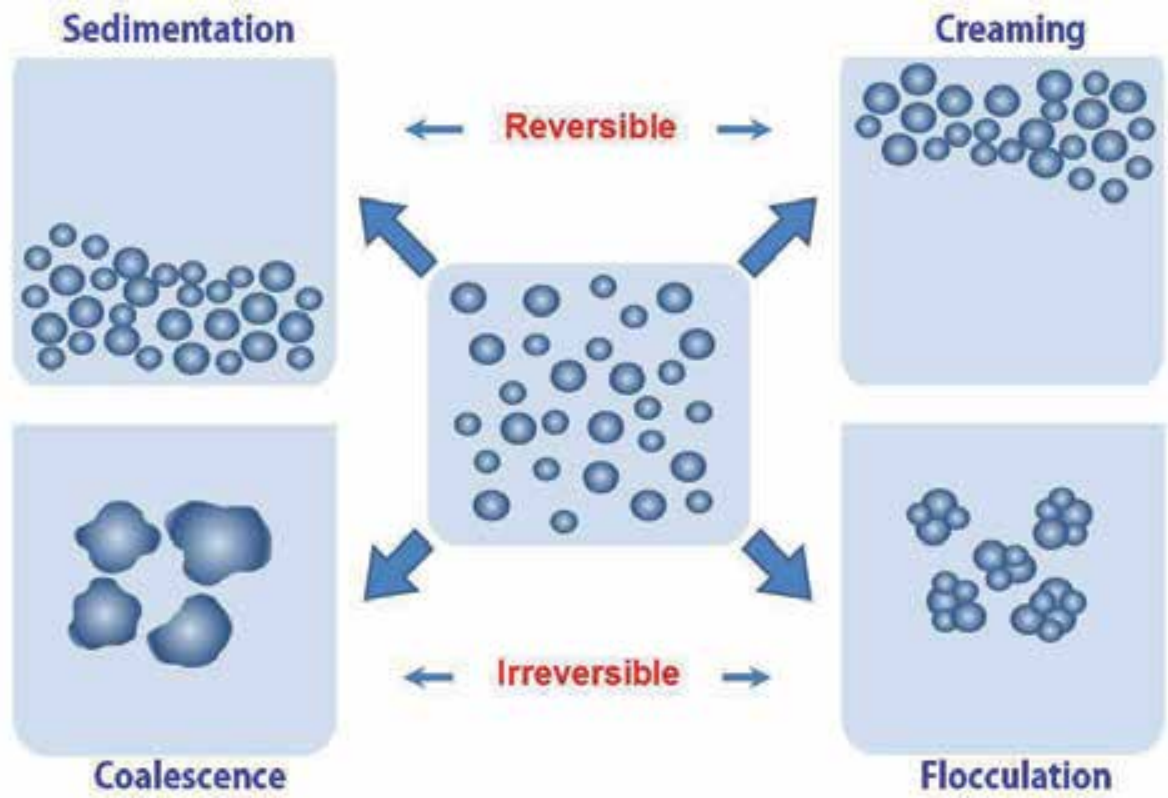

Figure 5. The destabilization of colloidal suspensions.

The hydrophobicity imparted by the first layer of depronated amphiphiles adsorbed onto the surface leads to an energetically unfavorable exposure of hydrophobic species to the aqueous phase. This favors the adsorption of additional molecules from the aqueous phase onto the particles' surfaces to decrease the system's free energy, which determines the stability of a suspension or wet foam. Particles attached to foam and mists' gas-liquid interfaces lower the overall free energy by replacing part of the interfacial area rather than reducing the interfacial tension, as in the case of surfactants [5]. The energy of the attachment, i.e., the Gibbs free energy (G), gained by the adsorption of a particle of radius $r$ at the interface can be calculated using simple geometrical arguments that lead to the following equation (Fig. 6).

$$
G=\pi r^{2} \Upsilon_{\mathrm{LG}}(1-\cos \theta) \text { for } \theta<90^{\circ}
$$

where $\theta$ is the contact angle and ${ }_{L G}$ is the gas-liquid interfacial tension. While the maximum energy gain can only be achieved at $\theta=90^{\circ}$, contact angles as low as $20^{\circ}$ can yield attachment energies in the order of $10^{3} \mathrm{kT}$ in systems of $100 \mathrm{~nm}$ particles [2]. The high energy associated with the adsorption of particles at interfaces contrasts to low adsorption energies of surfactants and leads to foams stabilized by particles being more stable than those stabilized with surfactants. It also leads to steric layers which strongly hinder bubbles' shrinkage and expansion, minimizing Ostwald ripening for very long periods of time [46].

The particle systems described in Fig. 6 had adsorption achieved by ligand exchange, whereby a surface hydroxyl group is exchanged for another group. This occurred because of the 
favorable change in the surface charge by the removal of $\left(\mathrm{OH}_{2}^{+}\right)$, a better leaving group, and replacement with $(-\mathrm{OH})[44,45]$.

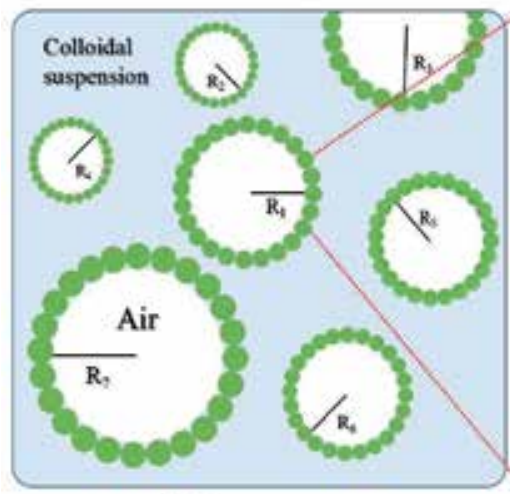

Avg $\Delta P=\frac{1}{n} \sum_{i=1}^{n} \frac{2 \gamma}{R_{n}}$ (when spherical bubble)
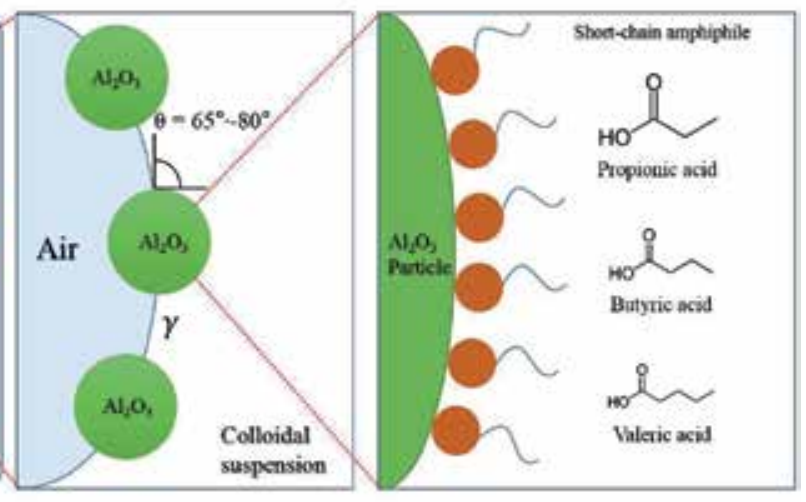

$\Delta G=\pi r r^{2}(1-\cos \theta)^{2}\left(\theta<90^{\circ}\right)$

$$
\text { (1) }
$$

Figure 6. Foams produced through the adsorption of colloidal particles at the gas-liquid interface.

\subsection{Contact angle and surface tension}

After the stabilizing effects of zeta potential and $\mathrm{pH}$, contact angle and surface tension are important determinants of colloidal systems' properties. Once a suspension is stabilized, the degree of hydrophobization is the main property which affects the production of foam. Given their thermodynamic instability, foams are often kinetically stabilized through the adsorption of surface active molecules or colloidal particles at the gas-liquid interfaces [46, 47]. The adsorbed molecules and particles stabilize the system by inhibiting the coalescence and Ostwald ripening of droplets and bubbles. Adsorption at the fluid interfaces occurs when particles are not completely wetted by any of the fluids, thus exhibiting a finite equilibrium contact angle at the triple phase boundary.

The equilibrium contact angle $(\theta)$ is determined by the balancing of the interfacial tensions (Equation 1). A decrease in surface tension upon increasing the initial amphiphile concentration can be observed. However, above a critical amphiphile concentration, surface tension decreased sharply. Above this critical amphiphile concentration, the particles are sufficiently hydrophobic at the air-water interface and decrease surface tension more greatly than that expected from free amphiphiles alone [48]. This significant reduction in surface tension upon particle adsorption was caused by a decrease of the total area of the highly energetic air-water interface. Similar surface tension effects have been observed in systems employing various amphiphiles [18]

Controlling particles' contact angles at the interface is important as it determines their wettability (Fig. 7). Tailoring particles' contact angles via modification of chemical composition 
enables the creation of foams with a variety of functionalities [19]. Contact angle depends on surface chemistry, roughness, impurities, particle size, and fluid phase composition. Theoretical and experimental work has shown that stabilization is achieved when contact angles are of an intermediate range of $20-86^{\circ}$ for oil-in-water foams and of $94-160^{\circ}$ for water in oil foams [49]. Contact angle can also be tailored by changing the particles' surface chemistry or adjusting the composition of the fluids. Metallic and ceramic particles can achieve any contact angle $(0<$ $\theta<180^{\circ}$ ) by reacting or adsorbing hydrophobic molecules on their surfaces [28, 29]. The use of short amphiphiles to tailor particles' wettability is a general and versatile approach for the surface modification of a wide range of ceramic and metallic materials [20].

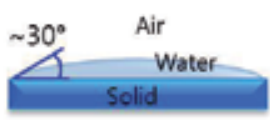

Hydrophilic

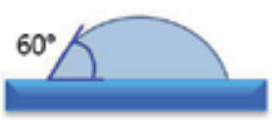

Partially

Hydrophilic

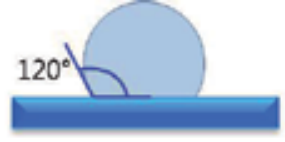

Partially hydrophobic

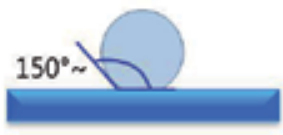

Hydrophobic

Figure 7. The wettability of particles in immiscible phases. $^{2}$

\subsection{Wet foam stability}

Liquid foams are thermodynamically unstable due to their high gas-liquid interfacial area. Several physical processes can occur to decrease the overall free energy and destabilize the foam [36]. Drainage occurs through gravity; light gas bubbles rise forming a denser foam layer, while the heavier liquid phase is concentrated below. Coalescence takes place when the thin films formed after drainage is not stable enough to keep adjacent cells apart. Their collapse results in the joining of neighboring bubbles. The stability of the thin films is therefore described in terms of attractive and repulsive interactions between the bubbles. van der Waals forces drive the bubbles closer. They can be overcome by electrostatic forces, steric repulsions force, or ligand exchange reactions. Surfactant or particles adsorbed at the air-water interface can also reduce van der Walls forces [22]. Ostwald ripening or disproportionation is another destabilizing effect that is more difficult to overcome. It occurs due to differences in the Laplace pressures between bubbles of different sizes. Laplace pressure inside a gas bubble arises from the curvature of the air-water interface. The Laplace pressure $\left(\mathrm{N} / \mathrm{m}^{2}\right)$ is the pressure difference between the inner and the outer side of a bubble or droplet. For spherical bubble of radius $R$ and gas-liquid interfacial energy $\gamma$, the Laplace pressure $\Delta \mathrm{P}$ is given by $2 \gamma / \mathrm{R}$. The pressure and force generated for the stabilization can be also calculated through the measurement of bubbles at the intersection. It can be calculated by the equation given below.

$$
\Delta \mathrm{P}=\gamma\left(\frac{1}{R_{1}}+\frac{1}{R_{2}}\right)=\frac{2 \gamma}{R}(\text { spherical bubble })
$$


The difference in the Laplace pressure between bubbles of distinct sizes (R) leads to bubble disproportionation and Ostwald ripening because of the steady diffusion of gas molecules from smaller to larger bubbles over time. This process can be slowed by using surfactants or particles adsorbed at the interface, which decrease the interfacial energy. Wet foam's stability is also related to the degree of hydrophobicity achieved from the surfactant, which replaces part of the highly energetic interface area and lowers the free energy of the system, leading to an apparent reduction in the surface tension of the suspension [49]. Stability also depends on surface charge screening, the electrical diffuse layer around a particle's surface not sufficiently thick to overcome the attractive van der Waals forces between particles. Overcoming the van der Waals attractions requires a stable hydrophobizing mechanism (examined above). Therefore, experiments were conducted as per reported theoretical explanations [18].

These actions' combined effects may collapse the foam within minutes after air incorporation. Foams' life times have been increased from several hours to days and months by the adsorption of the short chain amphiphilic molecules [50], while only a few minutes or hours' stabilization results from the use of long-chain surfactants or proteins at the air-water interface [35]. Unlike other particle-stabilized foams [2], these foams percolate throughout the whole liquid phase and exhibit no drainage over days and months [49] due to the high concentration of modified particles in the initial suspension, which allows for the stabilization of very large total air-water interfacial areas.

\section{Results and discussions}

\subsection{Contact angle and surface tension}

The attachment of particles at gas liquid interfaces occurs when particles are not completely wetted or, in other words, are partially hydrophobic. This enables the production of highvolume stable foam, which produces porous ceramics after drying and sintering. Partially hydrophobic particles remain predominantly in the liquid phase and exhibit a contact angle $<90^{\circ}$. Therefore, controlling contact angles of the particles at the interface is important since the angles modify the wettability of the particles by changing their hydrophobicity, as shown in (Figs. 8-10). Generally, lower contact angles improve the wettability. Different contact angles can be achieved by imparting different hydrophobic molecules commonly known as surfactants.

It is shown from Fig. 8 that the average contact angle of the $\mathrm{d}_{50} \sim 40 \mathrm{~nm} \mathrm{Al}_{2} \mathrm{O}_{3}$ suspension decreased from $84^{\circ}$ to $67^{\circ}$ with the increased $\mathrm{SiO}_{2}$ content $\left(1.0\right.$ mole ratios in the $\mathrm{Al}_{2} \mathrm{O}_{3}$ suspension). Also, the increasing $\mathrm{SiO}_{2}$ content produced lower adsorption free energy due to the higher interparticle attraction, increasing the viscosity. The suspensions with mol ratios of $\mathrm{SiO}_{2}$ between 0.25 and 0.5 in the suspension show higher levels of attachment energy, resulting in highly stable foam in the sintered porous ceramics. Also, contact angle of around $70^{\circ}-75^{\circ}$ for the nanoparticle suspension leads to better wet foam stability and can give surface tensions of 21-33 $\mathrm{mNm}^{-1}$. The required partial hydrophobization of the particles occurs at this point, which leads to porous ceramics with higher porosity. 
Fig. 9 shows the effect of suspension added for the mullite phase on the contact angle and surface tension of the aqueous suspensions. From this graph, we can see the suspension exhibits contact angles of $46^{\circ}-55^{\circ}$, which enables high wet foam stability, as that indicates partial hydrophobization of particles has taken place. We observed that for all the evaluated samples, the surface tension of suspensions decreases, upon increasing the vol\% of suspension added for the mullite phase. This can be explained by an increase in surface hydrophobicity of the particles with increasing particle concentration.

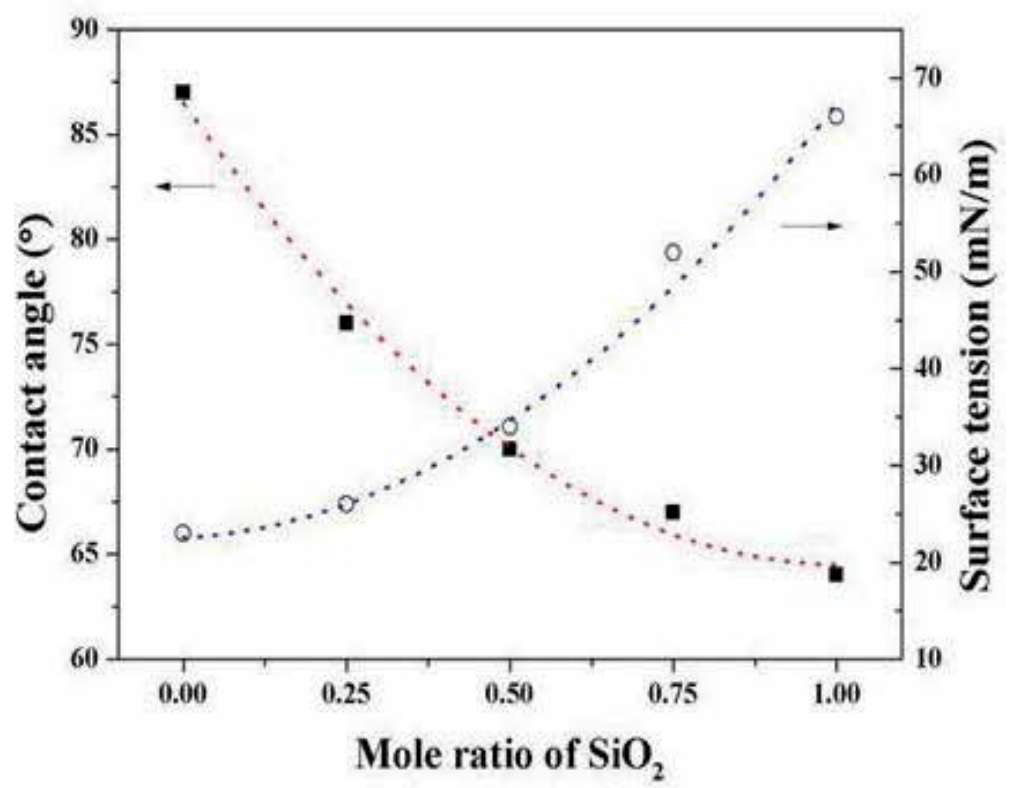

Figure 8. Contact angle and surface tension of colloidal suspension with respect to different mole ratio of $\mathrm{SiO}_{2}$.

In Fig. 10, the hydrophobization achieved via amphiphile adsorption was confirmed by contact angle measurements of the aqueous suspensions. As we can see, the $0.05-\mathrm{mol} / \mathrm{L}$ concentration of propionic acid was not sufficient enough to impart particle hydrophobicity, which results in unstable foams. From this graph, we can conclude that a contact angle of $65^{\circ}-72^{\circ}$ produces required particle hydrophobicity which enables high wet foam stability.

In Fig. 11, the degree of particle hydrophobization achieved by imparting different concentration of amphiphile was investigated with the help of surface tension measurements. The surface tension of suspensions containing $30 \mathrm{vol} \%$ particles and different concentration of amphiphiles is shown in Fig. 11. A decrease in surface tension upon increasing the amphiphile concentrations is observed for all the evaluated suspensions. The reduction in surface tension results from the adsorption of free amphiphile molecules to the air-water interface. The middle and short chain amphiphiles, i.e., butyric acid and valeric acid, respectively, impart relatively low surface energy, which enables sufficient hydrophobicity on the particle surface than the shortest chain amphiphile, i.e., propionic acid, does. 


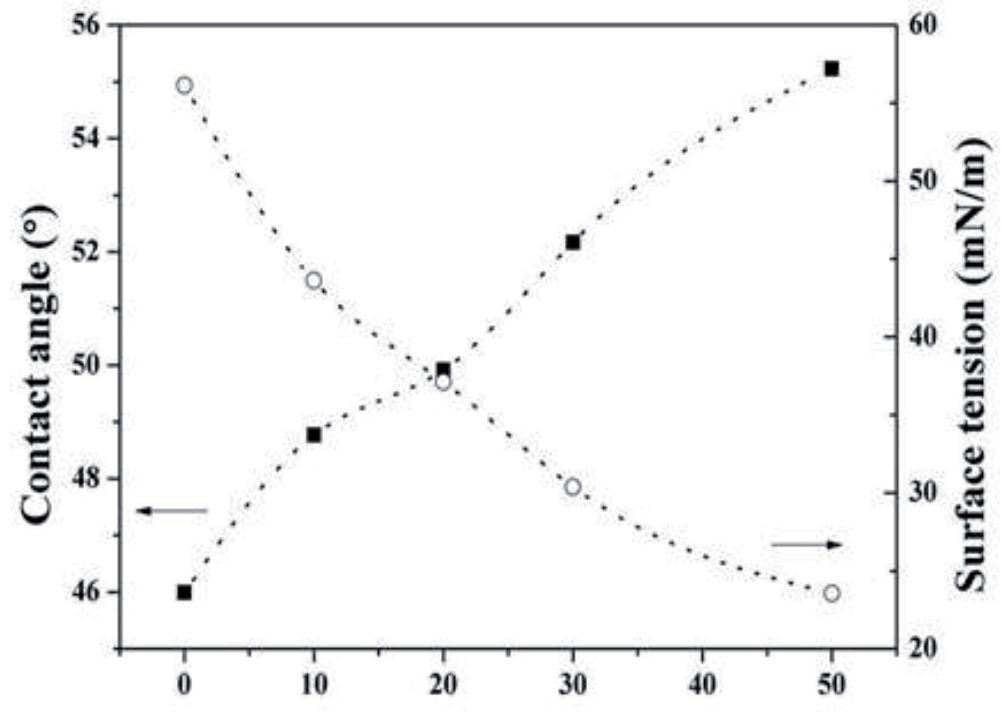

Suspension for mullite phase (vol\%)

Figure 9. Contact angle and surface tension of $\mathrm{Al}_{2} \mathrm{O}_{3}-\mathrm{TiO}_{2}$ equimolar suspension, with respect to different vol\% of $3: 2$ mole ratio of $\mathrm{Al}_{2} \mathrm{O}_{3}-\mathrm{SiO}_{2}$ suspension added for the mullite phase ${ }^{32}$

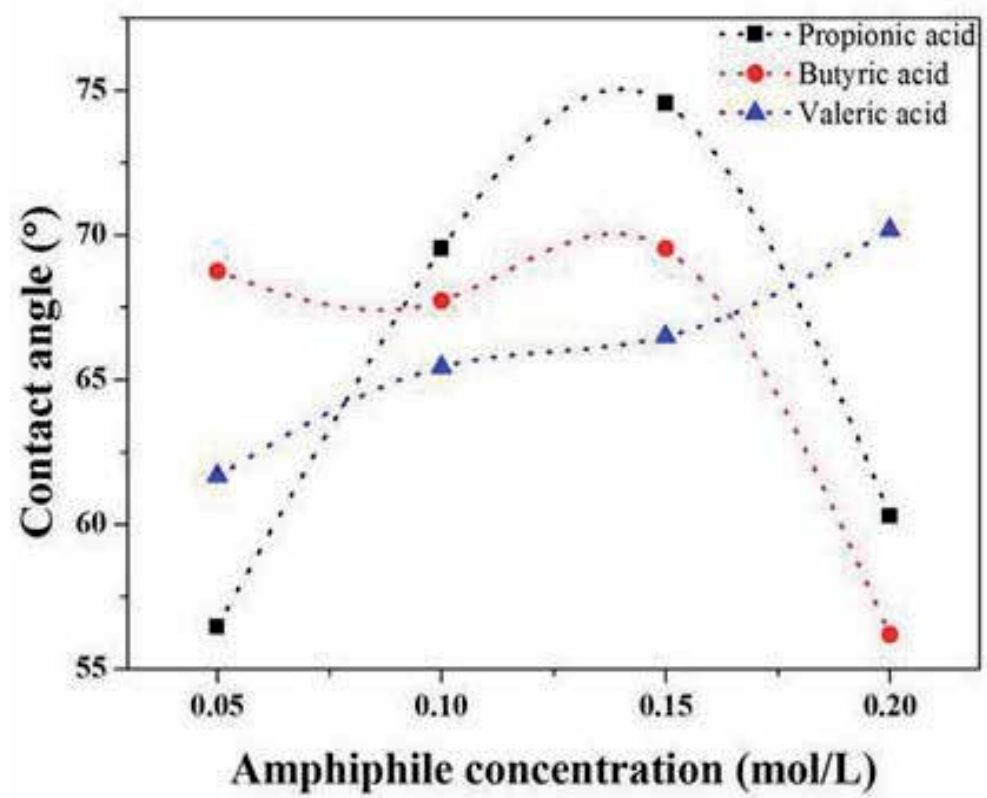

Figure 10. Contact angle of suspension with respect to different concentrations of amphiphiles. ${ }^{4}$ 


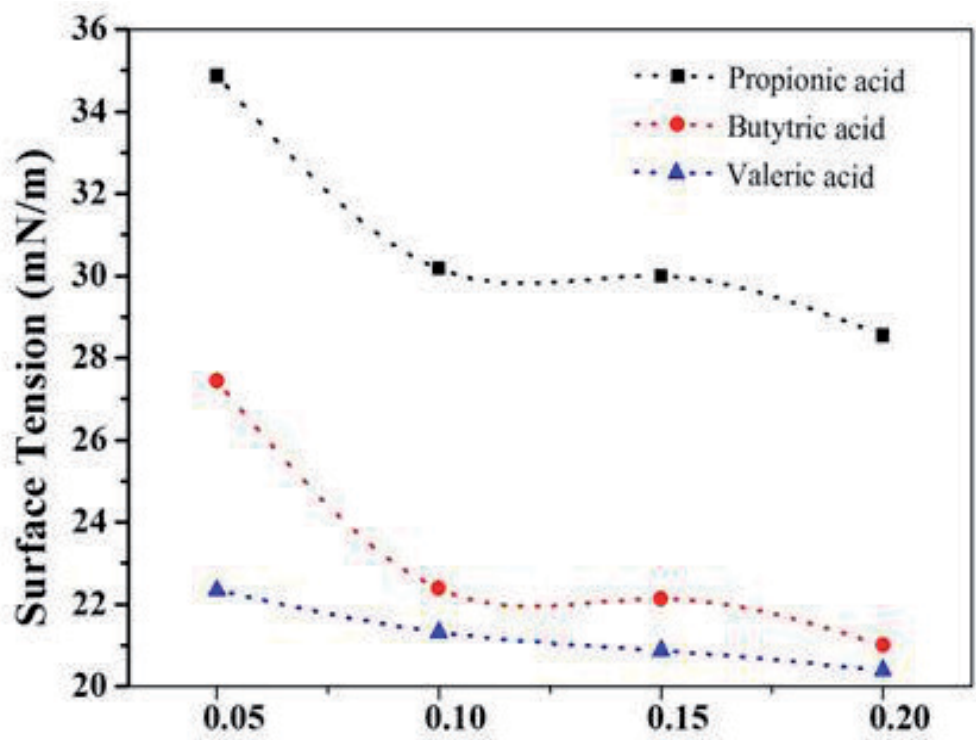

Amphiphile concentration ( $\mathrm{mol} / \mathrm{L})$

Figure 11. Surface tension of suspension with respect to different concentration of amphiphiles. ${ }^{4}$

\subsection{Air content and wet foam stability}

The total porosity of directly foamed ceramics is proportional to the amount of air incorporated into the suspension or liquid medium during the foaming process. The pore size, on the other hand, is determined by the stability of the wet foam. High-volume foams are formed upon mechanical frothing which strongly indicates the stabilization of air bubbles due to the attachment of particles to the air-water interface.

In Fig. 12, a relationship between the air content and the different concentration of amphiphiles has been plotted. It can be seen that for all three amphiphiles, the air content gradually increases until it achieves the highest value. This is because the particles were not sufficiently hydrophobized below this concentration (i.e., $0.15 \mathrm{~m} / \mathrm{mol}$ for propionic acid and $0.10 \mathrm{~m} / \mathrm{mol}$ for valeric acid). All the investigated suspension reports highest air content (i.e., $69 \%$ in case of propionic acid and 58-60\% in case of butyric acid and valeric acid) upon achieving sufficient hydrophobization. The decrease in air content at high amphiphile concentration is due to increase of suspension viscosity which resists the air incorporation to the suspension.

In Fig. 13, the influence of the amphiphile concentration on the wet foam stability is displayed. At very low amphiphile concentrations, no stable foams are obtained since the alumina particles are not sufficiently hydrophobized to stabilize the air-water interface of freshly formed air bubbles. Using $0.10 \mathrm{~mol} / \mathrm{L}$ of amphiphile results in rather unstable foam with wet foam stability of about $72-77 \%$. At a certain point between 0.15 and $0.2 \mathrm{~mol} / \mathrm{L}$ of amphiphile concentration, wet foams with highest stability are obtained. Propionic acid having the shortest 
hydrophobic chain requires more concentration $(0.20 \mathrm{~mol} / \mathrm{L})$ to result sufficient hydrophobization. However, the middle and long chain amphiphiles, i.e., butyric acid and valeric acid, respectively, produce effective hydrophobicity at around $0.15 \mathrm{~mol} / \mathrm{L}$. More concentrations of them increase the suspension viscosity results from increasing hydrophobicity of the particles, which prohibits the suspension to be foamed by mechanical stirring.

Fig. 14 establishes the air contents and foam stability of $\mathrm{Al}_{2} \mathrm{O}_{3}-\mathrm{TiO}_{2}$ equimolar suspension, with respect to different vol\% of 3:2 mole ratio of $\mathrm{Al}_{2} \mathrm{O}_{3}-\mathrm{SiO}_{2}$ suspension added for the mullite phase. High-volume foams with air content up to $83 \%$ form upon mechanical frothing, which strongly indicates the stabilization of air bubbles, due to the attachment of particles to the air-water interface. We measured the foam stability and observed that on the addition of $10 \mathrm{vol} \%$ suspension for the mullite phase, the foam stability suddenly decreased. This is probably due to the high viscosity of the suspension, due to higher particle concentration. However, 20, 30, and $50 \mathrm{vol} . \%$ of addition enhanced the foam stability, which might be explained by the optimum surface hydrophobicity being achieved, due to the increased particle concentration.

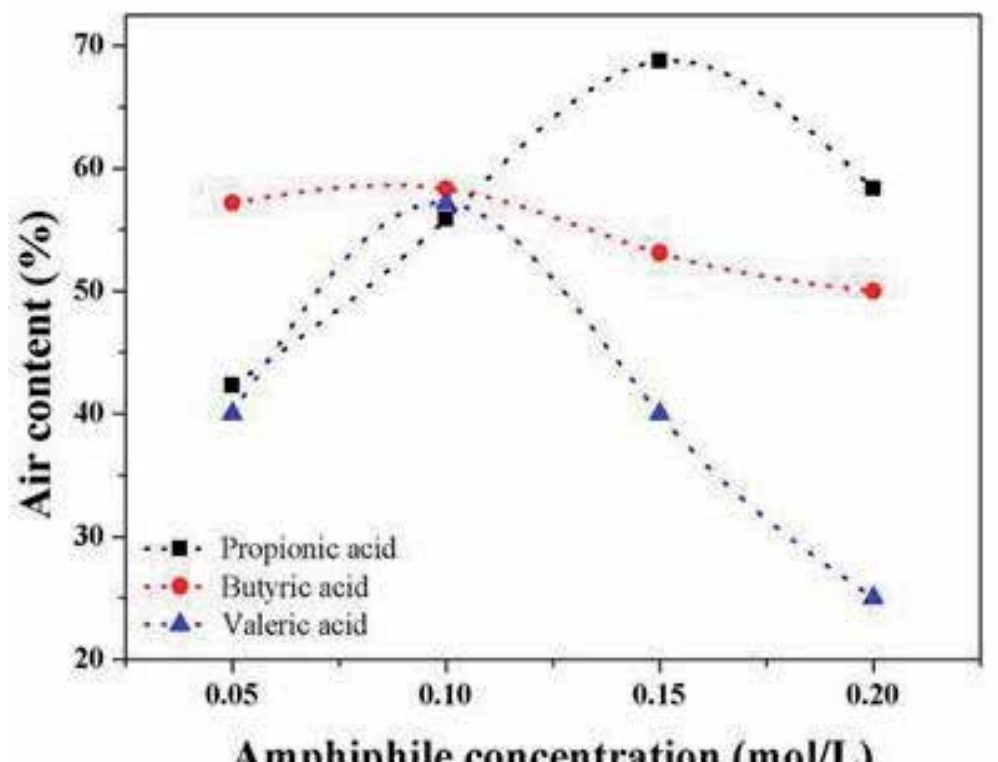

Amphiphile concentration ( $\mathrm{mol} / \mathrm{L})$

Figure 12. Air content of suspension with respect to different concentration of amphiphiles. ${ }^{4}$

In Fig. 15, the wet foam stability can be determined by observing the average bubble size with respect to the time after foaming. The foams stabilized with butyric acid and valeric acid show no significant bubble growth unlike the foam stabilized with propionic acid which shows a little coarsening. We can attribute the first two cases of remarkable resistance to the irreversible adsorption of the partially hydrophobized particles at the air-water interface. Therefore, the bubble size remains almost constant with the increase of time up to 6 hours of foaming. The foams stabilized with propionic acid are prone to bubble coarsening due to the pressure 


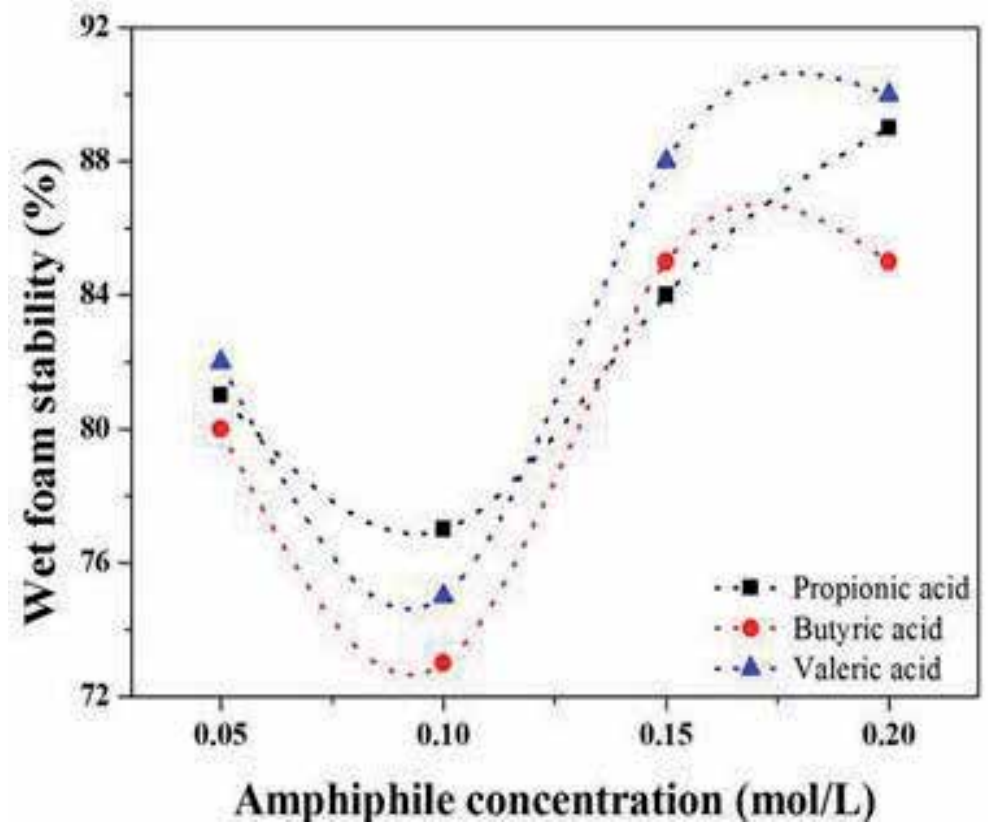

Figure 13. Wet foam stability of suspension with respect to different concentration of amphiphiles. ${ }^{4}$

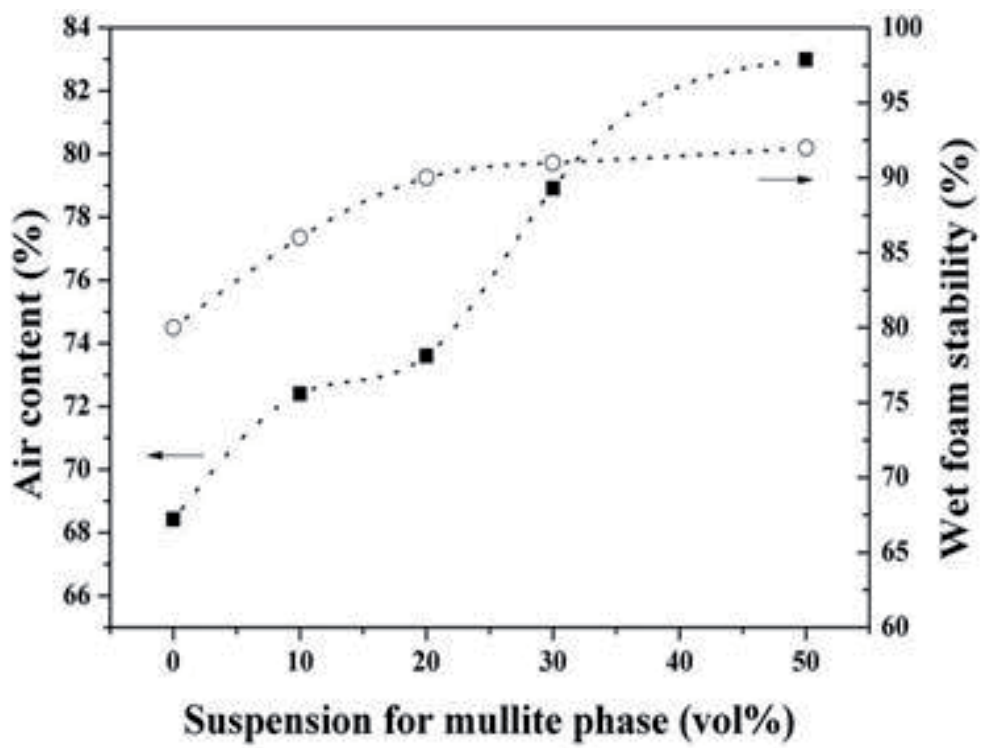

Figure 14. Air content and foam stability of $\mathrm{Al}_{2} \mathrm{O}_{3}-\mathrm{TiO}_{2}$ equimolar suspension, with respect to different vol\% of $3: 2 \mathrm{~mole}$ ratio of $\mathrm{Al}_{2} \mathrm{O}_{3}-\mathrm{SiO}_{2}$ suspension added for the mullite phase. ${ }^{32}$

difference between two bubbles of different radius which leads to Ostwald ripening. This thermodynamically driven spontaneous process occurs because the internal pressure of a 
particle is indirectly proportional to the radius of the particle. Large particles, with their lower surface to volume ratio, result in a lower energy state, whereas the smaller particles exhibit higher surface energy. As the system tries to lower its overall energy, molecules on the surface of a small particle tends to detach. It diffuses through colloidal solution and attaches to the surface of larger particle. Therefore, the number of smaller particles continues to shrink, while larger particles continue to grow [17].

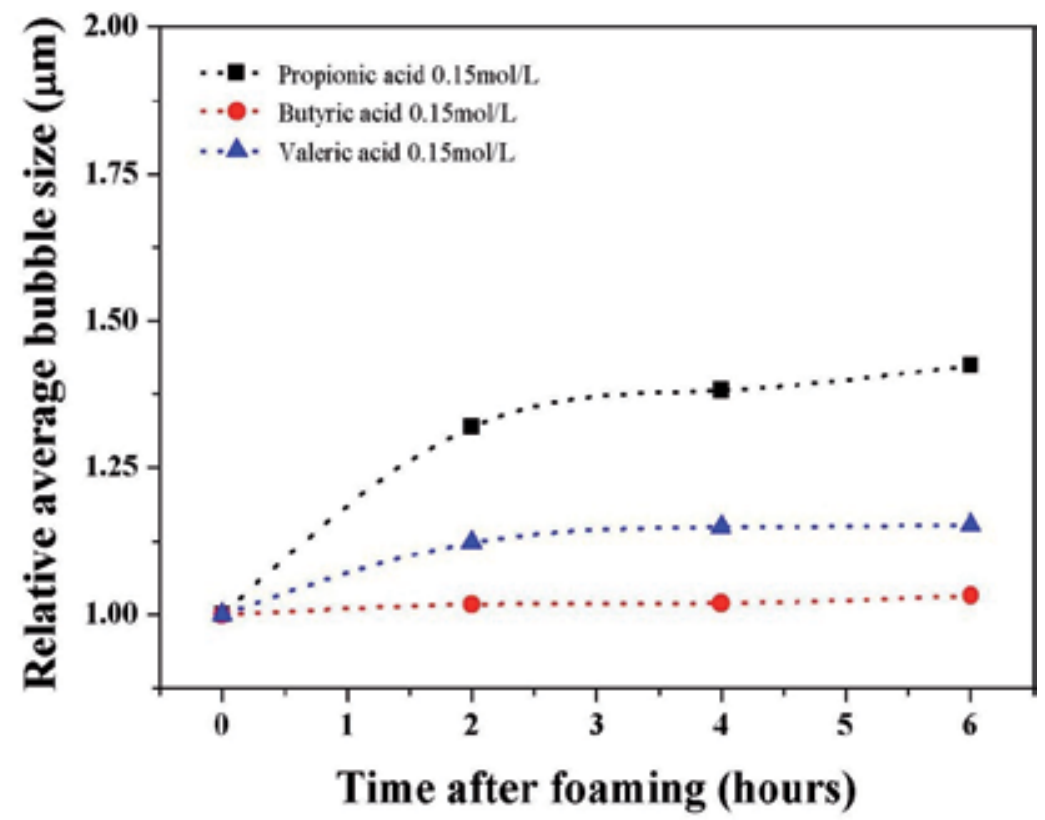

Figure 15. Relative average bubble size of suspension with respect to time after foaming. ${ }^{4}$

\subsection{Adsorption free energy}

The adsorption free energy plays an important role in stabilizing foams. Particles attached to the gas-liquid interfaces of foams lower the system free energy, by replacing part of the gasliquid interfacial area. According to Equation (1), G (the Gibbs free energy) is greatest when $\theta$ is $90^{\circ}$; however, the foam stabilization of particles readily occurs when $\theta$ is between $50^{\circ}$ and $90^{\circ}$.

Fig. 16 shows the change in the adsorption energy corresponding to the different mole ratio of $\mathrm{SiO}_{2}$ content used to stabilize the suspension. $\mathrm{An}_{2} \mathrm{Al}_{2} \mathrm{O}_{3}$ loading of $30 \mathrm{vol}$. \% in the suspension was taken as a standard, and experiments were performed with $0.01 \mathrm{~mol} \mathrm{~L}^{-1}$ amphiphiles for stabilization of the particles. The calculations show that the energy level decreases with the nanoparticle size and with increase in $\mathrm{SiO}_{2}$ content. However, after the middle value (0.75) of the $\mathrm{SiO}_{2}$ loading, the van der Waals attraction force between the particles gradually increases, forcing the suspension to destabilize and finally decrease the wet foam stability from $87 \%$ to 


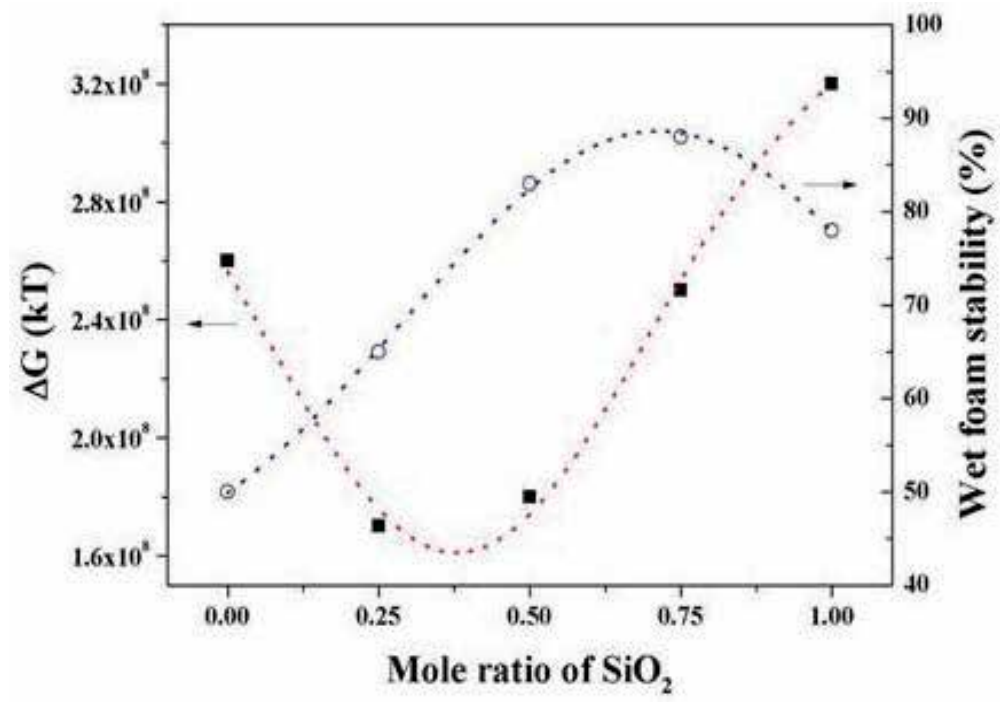

Figure 16. Free energy and wet foam stability with respect to the different mole ratio of $\mathrm{SiO}_{2}$.

$68 \%$. A higher energy of adsorption of $1.7 \times 10^{8} \mathrm{kTs}$ could be achieved in the initial suspension without $\mathrm{SiO}_{2}$ content. The adsorption free energy decreases with the increasing concentration. Higher contact angle of $62^{\circ}-75^{\circ}$ with a lower interfacial energy of $1.7 \times 10^{8} \mathrm{kTs}$ were seen at $\mathrm{SiO}_{2}$ mole ratio of 0.25 giving an interfacial tension of $42-45 \mathrm{mNm}^{-1}$.

Fig. 17 establishes the relationship between adsorption free energy corresponding to the foam stability, with respect to the different vol.\% of suspension added for the mullite phase. Low adsorption free energy resulting from the spontaneous bubble growth leads to foam instability. The investigated samples exhibit much higher adsorption free energy of about $2.2 \times 10^{-13} \mathrm{~J}$ to $2.7 \times 10^{-13} \mathrm{~J}$ at the interface, resulting in irreversible adsorption of particles at the air-water interface, which leads to outstanding stability.

In Fig. 18, a relationship between adsorption free energy corresponding to the concentrations of different chain length of amphiphile has been established. Stable and unstable zones have been described relating to the data obtained by the wet foam stability graph. Low adsorption free energy (e.g., $2.05 \times 10^{-13} \mathrm{~J}$ to $3.78 \times 10^{-13} \mathrm{~J}$ ) results from the spontaneous bubble growth leads to foam instability. However, higher adsorption free energy of about $4.52 \times 10^{-13} \mathrm{~J}$ to $8.22 \times 10^{-13} \mathrm{~J}$ at the interface results in irreversible adsorption of particles at the air-water interface which leads to outstanding stability.

\subsection{Laplace pressure and bubble size}

Fig. 19 shows the wet foam stability corresponding to the pressure exerted by the bubbles (Laplace pressure) with respect to the different mole ratio of $\mathrm{SiO}_{2}$ content. The Laplace pressure increases with the increase in $\mathrm{SiO}_{2}$ concentration. This behavior can be attributed to the fact that high silica content requires a large volume of water in the suspension, which subsequently 


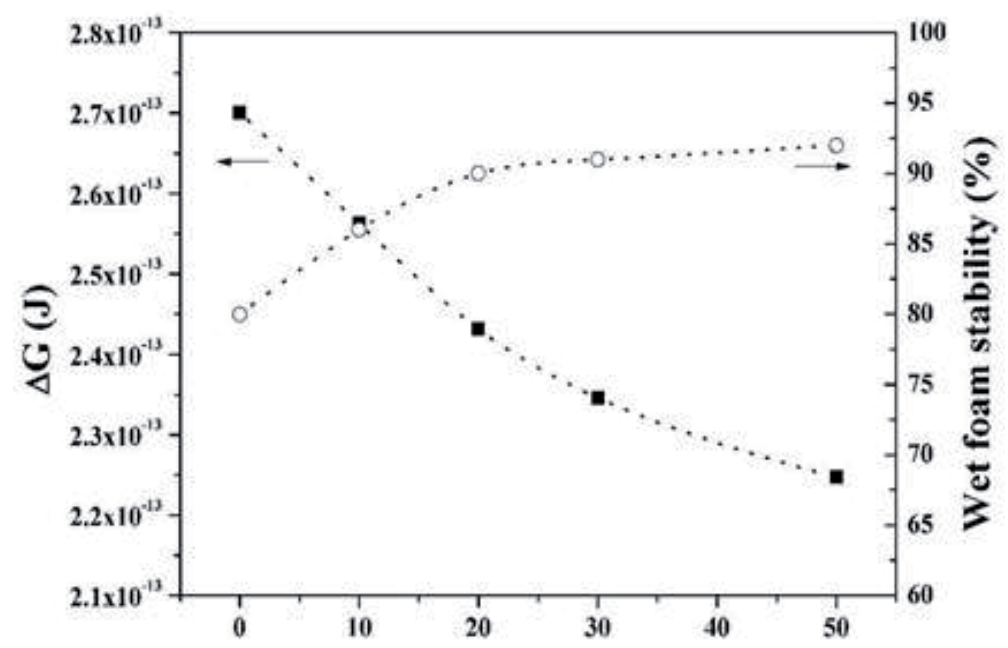

Suspension for mullite phase (vol\%)

Figure 17. Adsorption free energy and foam stability of $\mathrm{Al}_{2} \mathrm{O}_{3}-\mathrm{TiO}_{2}$ equimolar suspension, with respect to different vol $\%$ of 3:2 mole ratio of $\mathrm{Al}_{2} \mathrm{O}_{3}-\mathrm{SiO}_{2}$ suspension added for the mullite phase. ${ }^{32}$

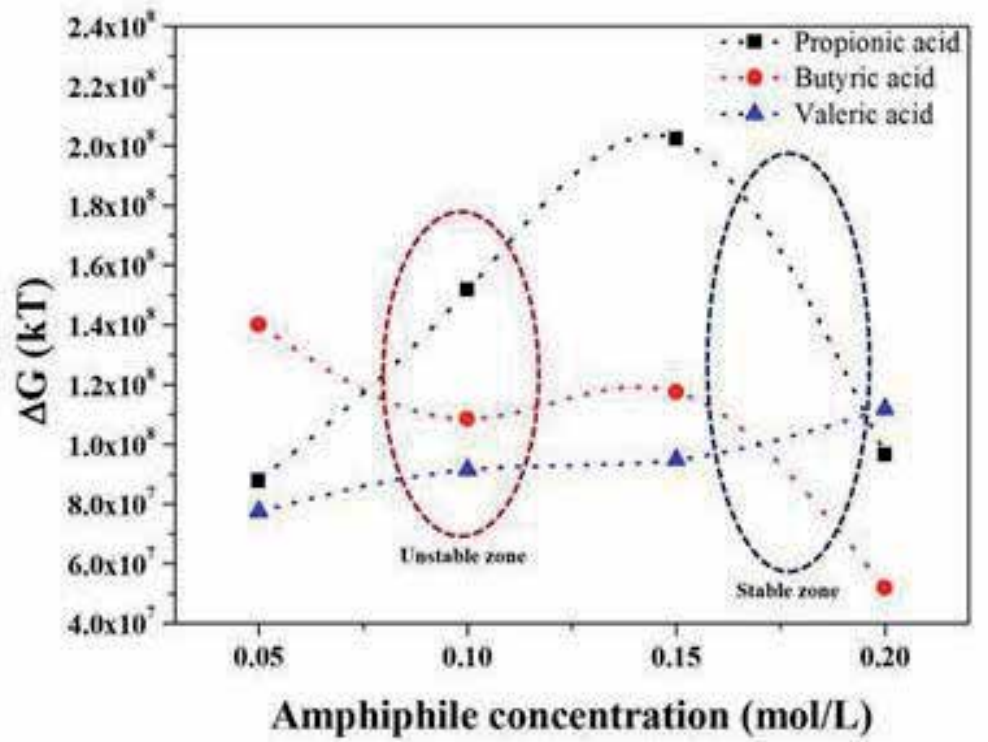

Figure 18. Adsorption free energy of suspension with respect to different concentration of amphiphiles. ${ }^{4}$

lowers the outer pressure of the bubble. The wet foam stability suddenly decreases due to high Laplace pressure when the mole ratio of $\mathrm{SiO}_{2}$ reached at 0.60 . The wet foams were stable at the pressure difference between 20 and $25 \mathrm{mPa}$, which corresponds to the $\mathrm{SiO}_{2}$ mole ratio content of $0.25-0.50$. The stability increased to more than $80 \%$ at a $\mathrm{SiO}_{2}$ mole ratio of 0.75 . 


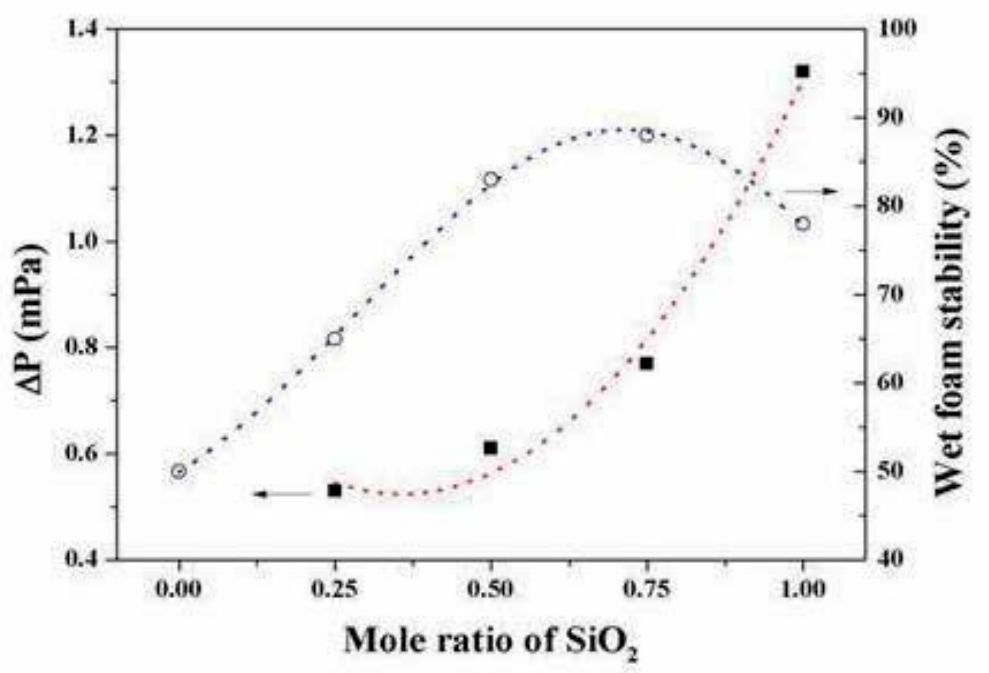

Figure 19. Laplace pressure and wet foam stability with respect to the different mole ratio of $\mathrm{SiO}_{2}$ content.

Fig. 20 plots the graph of the Laplace pressure and average bubble size of all evaluated suspensions, with respect to the various vol.\% of suspension for the mullite phase. As we can see, instability occurs when the Laplace pressure is too low. Wet foam stability occurs when the Laplace pressure is about 1.5-2.2 $\mathrm{mPa}$. The degree of particle hydrophobization influences the average bubble size of the resultant foams. Fig. 20 shows that the average bubble size decreases with increasing particle concentration and particle hydrophobicity. This is due to the decrease in surface tension and increase in foam viscosity that result from higher particle concentrations. This reduces the resistance of air bubbles against rupture and thus leads to the production of foams with average bubble sizes.

In Fig. 21, the Laplace pressure of all evaluated suspensions has been plotted in a graph with respect to the various concentration of different chain length of amphiphile. As we can see, the instability occurs when the Laplace pressure is too low as in case of $0.10 \mathrm{~mol} / \mathrm{L}$ of amphiphile concentration. Wet foam stability occurs when Laplace pressure is about $0.8-1.4 \mathrm{mPa}$. Valeric acid, having the longest chain length, exhibits high Laplace pressure resulting in outstanding stability of wet foam.

The degree of particle hydrophobization, which is directly related to the concentration of amphiphile, influences the average bubble size of the resultant foams. Fig. 22 shows the bubble size of the suspension and the pore size by thin film or struts formed after the foaming of the particle stabilized suspension and sintering. The average bubble size for these types of stabilized foams was $98-140 \mu \mathrm{m}$. The required partial hydrophobization of the particles occurs at this point, which leads to porous ceramics with porosity greater than $80 \%$ and pore size of about $108 \mu \mathrm{m}$ after sintering at $1300^{\circ} \mathrm{C}$ for 1 hour.

In Fig. 23, it can be seen that the average bubble size decreases with increasing amphiphile concentration and particle hydrophobicity. This is due to the decrease in surface tension and 


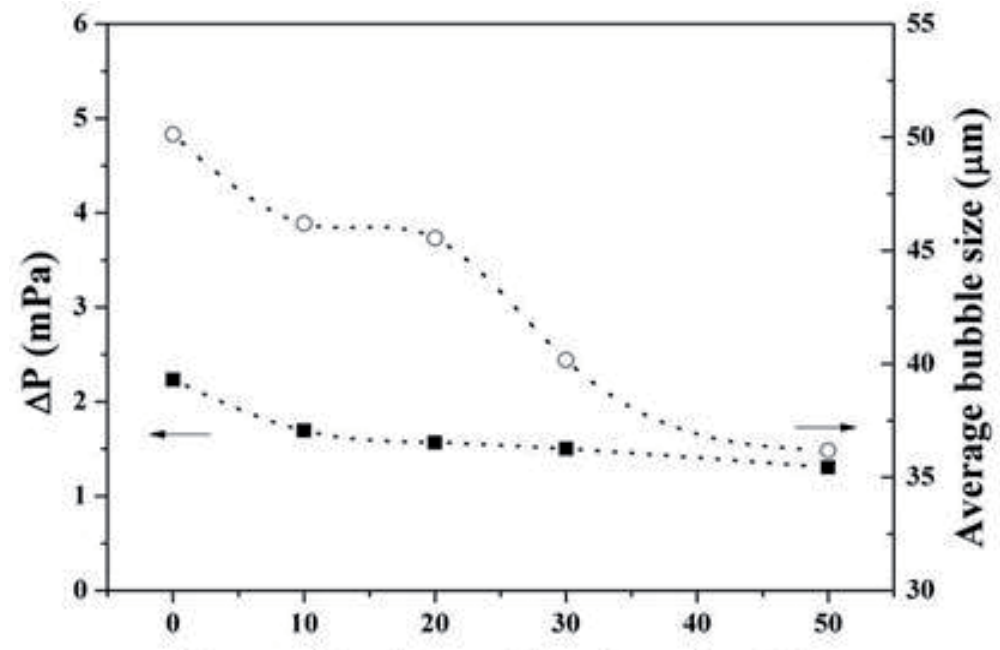

Suspension for mullite phase (vol\%)

Figure 20. Laplace pressure and bubble size of $\mathrm{Al}_{2} \mathrm{O}_{3}-\mathrm{TiO}_{2}$ equimolar suspension, with respect to different vol\% of $3: 2$ mole ratio of $\mathrm{Al}_{2} \mathrm{O}_{3}-\mathrm{SiO}_{2}$ suspension added for the mullite phase. ${ }^{32}$

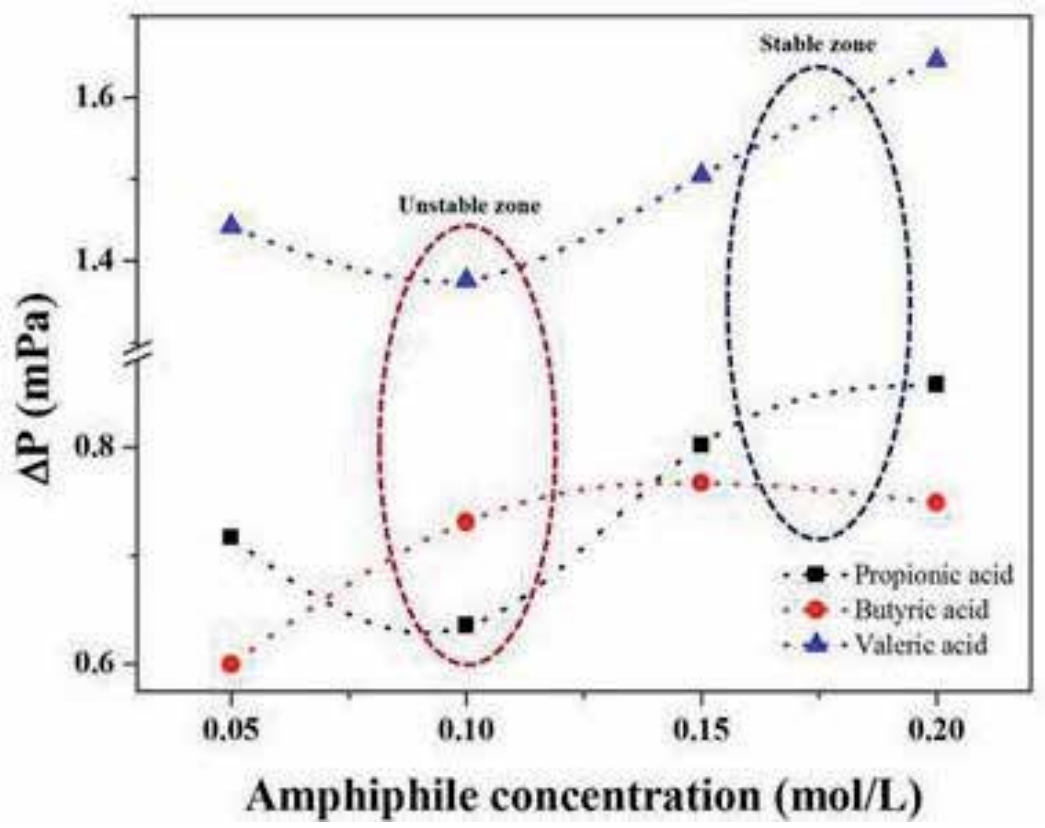

Figure 21. Laplace pressure of suspension with respect to different concentration of amphiphiles. ${ }^{4}$

increase in foam viscosity because of higher amphiphile concentrations. This decreases the resistance of air bubbles against rupture and thus leads to produce foams with average bubble sizes. It is interesting to note that valeric acid, having the longest amphiphilic chain, produces 


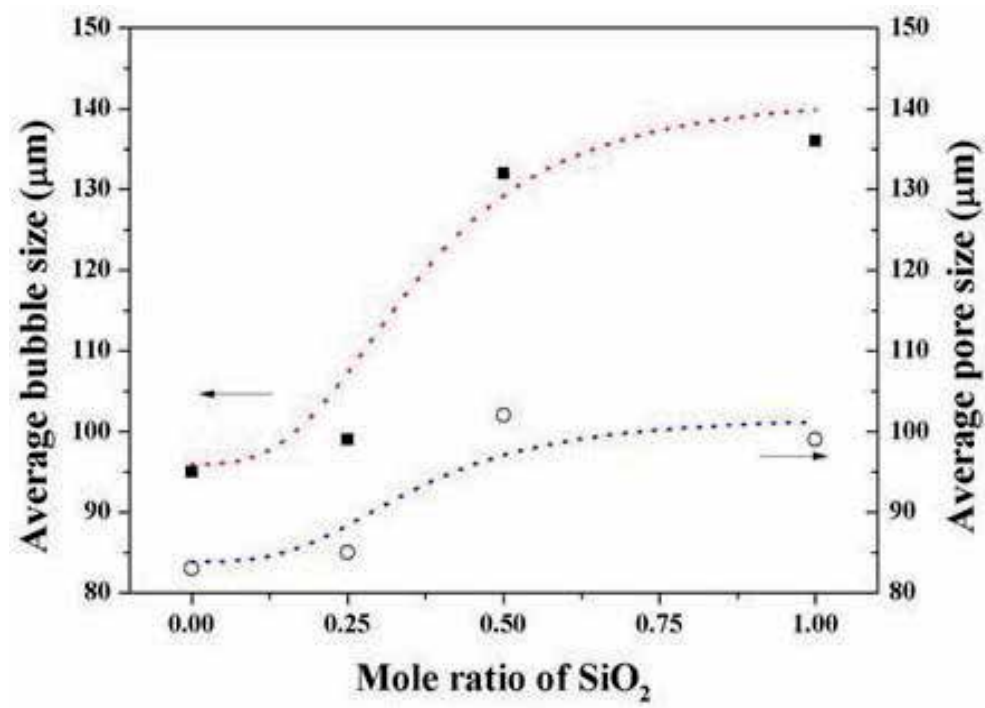

Figure 22. Bubble size and pore size with respect to the $\mathrm{SiO}_{2}$ content of the wet foam before and after sintering at $1300^{\circ} \mathrm{C}$ for 1 hour.

very small sized bubbles of about $35-25 \mu \mathrm{m}$. This can be attributed to the greater hydrophobicity, which results in enhanced stability of particle stabilized foams against bubble coalescence and Ostwald ripening [see Fig. 26(c)].

\subsection{Microstructure analysis}

The microstructures are described in Fig. 24, where tailored, open and closed, interconnected pores can be seen. Also, it can be seen that the larger and smaller pores are uniformly distributed. In Fig. 24a-d, different compositions of $\mathrm{Al}_{2} \mathrm{O}_{3} / \mathrm{SiO}_{2}$ with well-developed and narrow pore size distribution can be seen. It shows a hierarchical pore distribution with porosities up to $80 \%$ from larger to smaller pores and thick struts (films in wet foams). It leads to produce more stable foams sintered to form porous ceramics with high mechanical strength.

Fig. 25 shows the microstructures of porous (a) AT, (b) ATM1, (c) ATM3, and (d) ATM5, sintered at $1500^{\circ} \mathrm{C}$ for 1 hour. The microstructures obtained generally consist of open, interconnected pores with a narrow pore size distribution. The composition without addition of mullite (Fig. 25(a)) shows the characteristic microstructure of $\mathrm{Al}_{2} \mathrm{TiO}_{5}$ : an open porous and microcracked $\mathrm{Al}_{2} \mathrm{TiO}_{5}$ matrix phase, with the presence of abnormal grain growth. These grains can be attributed to unreacted $\mathrm{Al}_{2} \mathrm{O}_{3}$ and $\mathrm{TiO}_{2}$ due to the formation reaction kinetics, which is a process led by the nucleation and growth of $\mathrm{Al}_{2} \mathrm{TiO}_{5}$ grains, and finally the diffusion of the reactants through the matrix. It is evident from Fig. 25b-d that the addition of mullite has a beneficial effect on grain growth control.

The scanning electron microscope images of $30 \mathrm{Vol} \% \mathrm{Al}_{2} \mathrm{O}_{3}-\mathrm{SiO}_{2}$ porous ceramics sintered at $1300^{\circ} \mathrm{C}$ with different chain length amphiphile of concentration $0.15 \mathrm{~mol} / \mathrm{L}$ are shown in Fig. 26. The microstructures obtained are generally consists of closed pores. It is interesting to note 


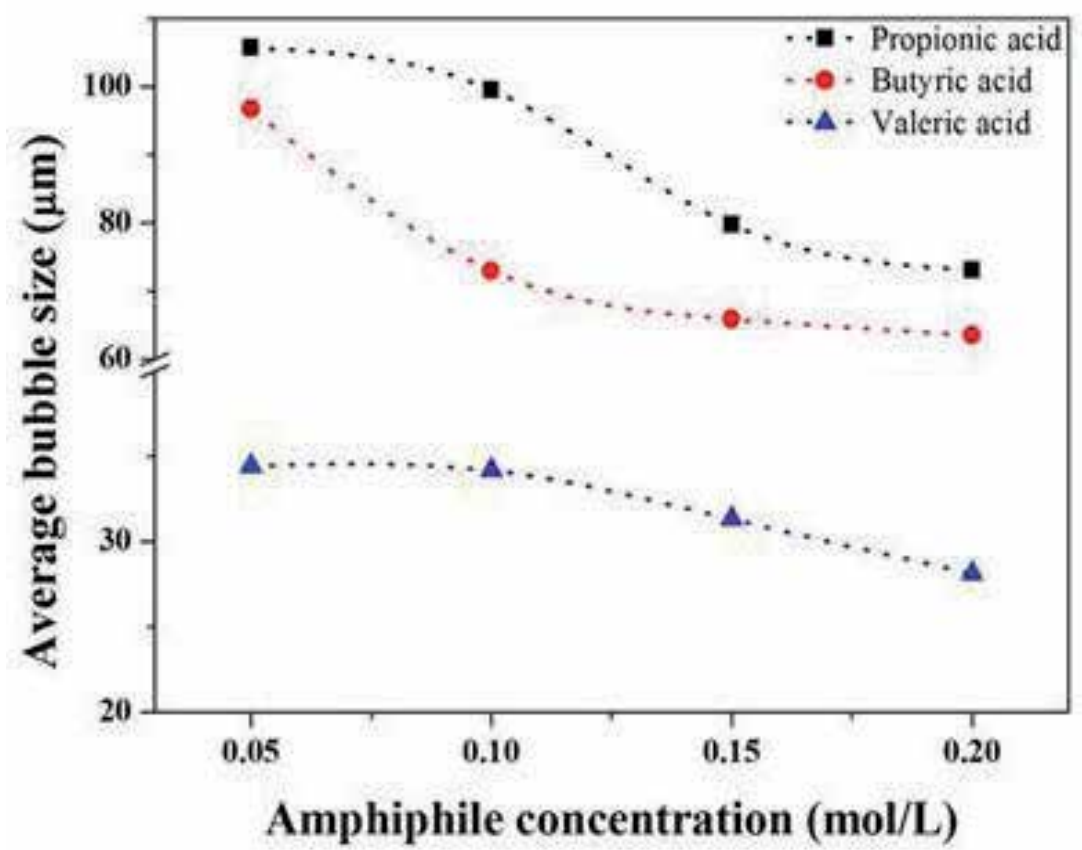

Figure 23. Average bubble size of suspension with respect to different concentration of amphiphiles. ${ }^{4}$

that at the same concentration of amphiphile, the shortest chain carboxylic acid, i.e., propionic acid, produces relatively large pore size than the longest chain carboxylic acid, i.e., valeric acid. This can be attributed to the fact that greater hydrophobicity is achieved with the aid of long carbon chain present in valeric acid which results in small and uniform pore size. The smaller cell sizes result from the high stability of the foams in the wet state, which impedes bubble coarsening. The dense struts as shown in the inset of Fig. 26a-c plays vital role for improving the mechanical strength of the porous ceramics.

\section{Conclusions}

Porous ceramics' microstructures and properties are affected by their method of synthesis. Direct foaming can simply, inexpensively and quickly prepare macroporous ceramics. Open or closed porosities of $45 \%-85 \%$ having been demonstrated. The pores produced by this method result from the direct incorporation of air bubbles into a ceramic suspension, eliminating the need for pyrolysis before sintering. Cellular structures prepared by direct foaming are generally stronger than those prepared by replica synthesis due mainly to the absence of flaws in the cell struts. Given the importance of the chosen synthetic method, this review examines currently available processes for forming porous ceramics. Direct foaming is a simple and versatile process for the low-cost manufacture of porous ceramics for various applications. Its continuous study will result in further improvements of its method and wider applicability 

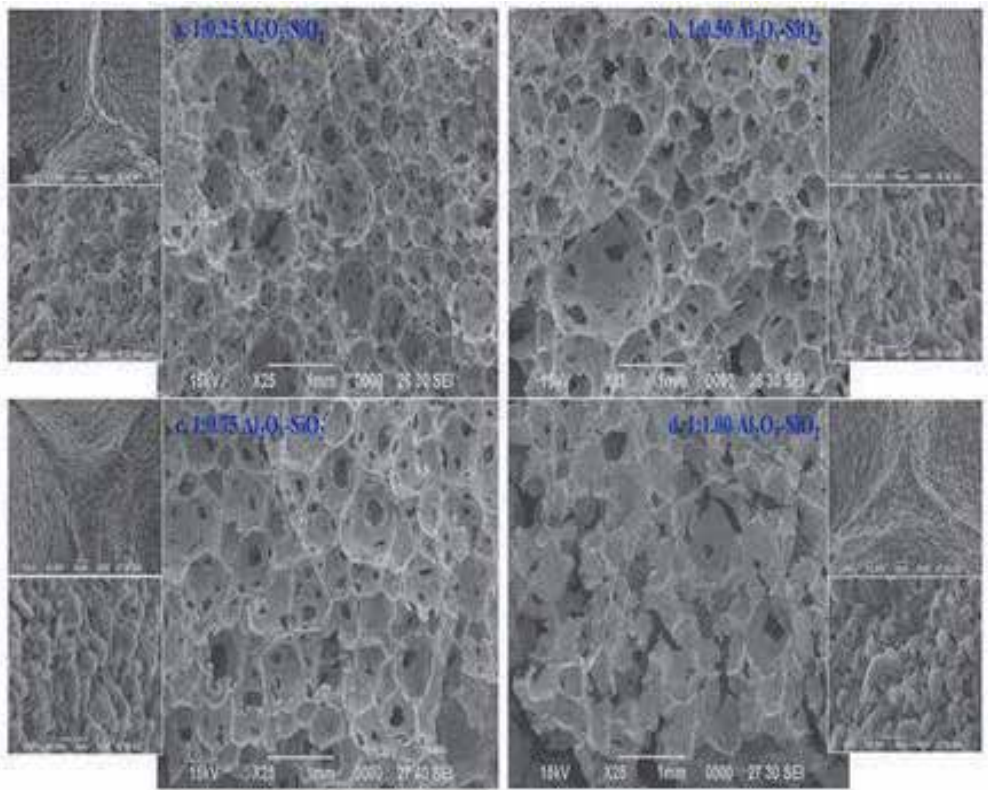

Figure 24. Microstructures and thin film (inner cell) of porous ceramics sintered at $30 \mathrm{vol} \% \mathrm{Al}_{2} \mathrm{O}_{3}$ with respect to the different mole ratio of $\mathrm{SiO}_{2}$ content.
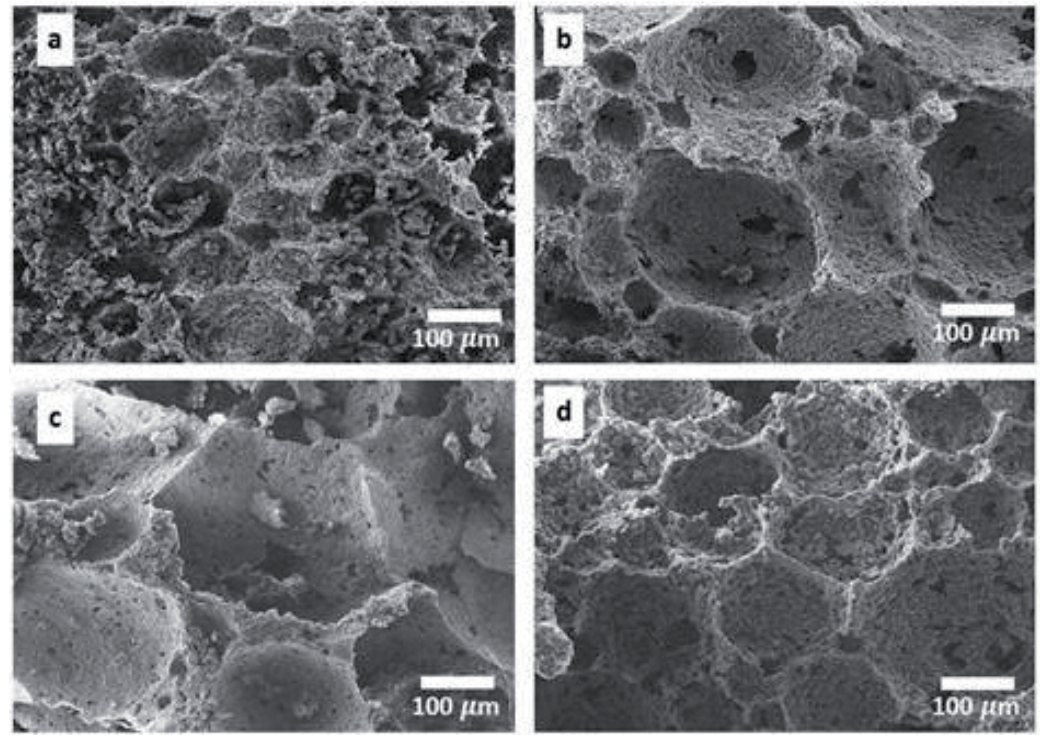

Figure 25. Microstructures of (a) AT, (b) ATM1, (c) ATM3, and (d) ATM5 porous ceramics, sintered at $1500^{\circ} \mathrm{C}$ for 1 hour. ${ }^{32}$

of its products. Examination of the literature led to the proposal of an equation describing the inverse proportionality of wet foam stability to the surface of the liquid-air interface. 

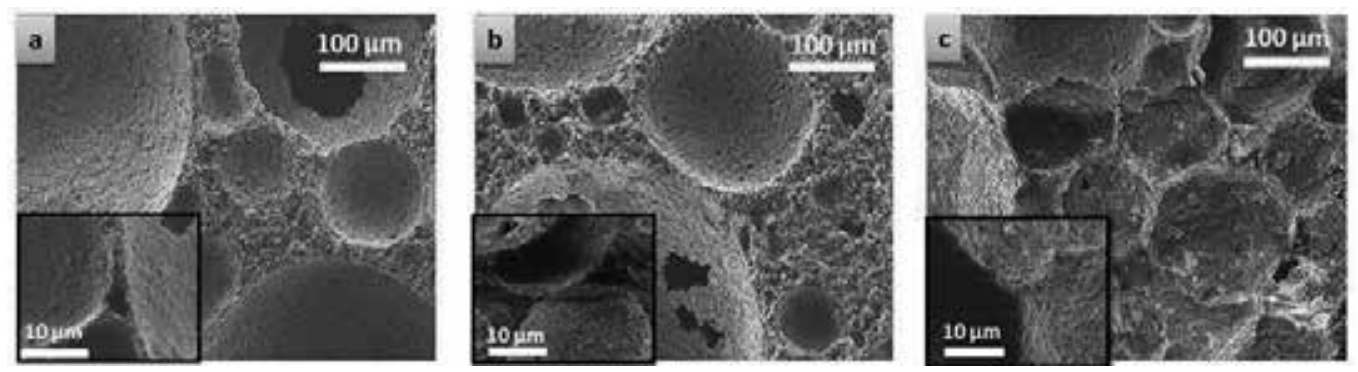

Figure 26. Microstructures of porous ceramics using $0.15 \mathrm{~mol} / \mathrm{L}$ of (a) propionic acid, (b) butyric acid, and (c) valeric acid; the inset in (a), (b), and (c) show single dense struts obtained with direct foaming method. ${ }^{4}$

$$
W_{f S} \infty\left(\frac{1}{\gamma}\right)
$$

$W_{f S}=$ Wet foam stability

$\gamma=$ surface tension

\section{Acknowledgements}

This research was financially supported by the Ministry of Education, Science Technology (MEST), and The National Research Foundation of Korea (NRF) through the Human Resource Training Project for Regional Innovation and Hanseo University.

\section{Author details}

Naboneeta Sarkar and Ik Jin Kim*

*Address all correspondence to: ijkim@hanseo.ac.kr

Department of Materials Science and Engineering, Institute of Processing and Application of Inorganic Materials (PAIM), Hanseo University, \# , Haemi-myun, Daegok-ri, Seosan-city, Chungnam, South Korea

\section{References}

[1] M. Scheffler and P. Colombo, Cellular Ceramics: Structure, Manufacturing, Properties and Applications. p 645. Weinheim, Wiley-VCH, 2005. 
[2] A. R. Studart, U. T. Gonzenbach, E. Tervoort, and L. J. Gauckler, “Processing routes to macroporous ceramics - a review," J. Am. Ceram. Society (2006).

[3] J. Banhart, "Manufacturing Routes for Metallic foams," JOM (2000).

[4] N. Sarkar, J. G. Park, S. Mazumder, A. Pokhrel, C. G. Aneziris, and I. J. Kim, Effect of amphiphile chain length on wet foam stability of porous ceramics, Ceram. Int., 41 [3] (2015) 4021-4027.

[5] J. Banhart, "Manufacture, classification and application of cellular metals and foams," Prog. Mater. Sci., 46 (2001) 559-632.

[6] W. Ramsden, "Separation of solids in the surface-layers of solutions and 'suspensions'," Proc. R. Soc. Lond., 72 (1903) 156.

[7] Ya. Guzman, "Certain principles of formation of porous ceramic structures, properties and applications - a review," Glass Ceram., 9 (2003) 28-31.

[8] P. Colombo and J.R. Hellmann, "Ceramic foams from preceramic polymers," Mat Res. Innovat., 6 (2002) 260-272.

[9] H. M. Princen and A. D. Kiss, "Rheology of foams and highly concentrated Emulsions," J. Colloid. Interface Sci., 128 [1] (1989) 176-187.

[10] W. D. Kingery, H. K. Bowen, and D. R. Uhlmann, Introduction to Ceramics, 2nd edition. Wiley Interscience Publication, 1975.

[11] P. Colombo, "Conventional and novel processing methods for cellular ceramics," Phil. Trans. R. Soc. A., 364 (2006), 109-124.

[12] B. Neirinck, J. Fransaer, O. V. der Biest, JefVleugels, "A novel route to produce porous ceramics," J. Euro. Cerm. Soc., 29 (2009) 833-836.

[13] B. P. Binks, "Particles as surfactants-similarities and differences," Curr. Opin. Colloid Interface Sci., 7 (2002) 21-41.

[14] Brent S. Murray, "Stabilization of bubbles and foams," Curr. Opin. Colloid Interface Sci., 12 (2007) 231-241.

[15] T. S. Horozov, "Foams and foam films stabilized by solid particles," Curr. Opin. Colloid Interface Sci., 13 (2008) 134-140.

[16] P. C. Hidber, T. J. Graule, and L. J. Gauckler, "Influence of the dispersant structure on properties of electrostatically stabilized aqueous alumina suspension," J. Eur. Ceram. Soc., 17 [2-3] (2002) 239-249.

[17] A. Pokhrel, J. G. Park, J. S. Nam, D. S. Cheong, and I. J. Kim, "Stabilization of wet foams for porous ceramics using amphiphilic particles," J. Kor. Ceram. Soc., 48 [5] (2011) 463-466. 
[18] N. D. Denkov, I. B. Ivanov, P. A. Kralchevsky, and D. T. Wasan, "A possible mechanism of stabilization of emulsions by solid particles," J. Colloid. Interface Sci., 150, [2] (1992) 589-593.

[19] L. J. Gauckler, Th. Graule, and F. Baader, "Ceramic forming using enzyme catalyzed reactions," Mater. Chem. Phys., 61 (1999) 78-102.

[20] A. Pokhrel, Zhao Wei, and I. J. Kim, "Wet foam stabilized by amphiphiles to tailor the microstructures of porous ceramics," Key Eng. Mater., 512-515 (2012) 288-292.

[21] A. B. Subramaniam, C. Mejean, M. Abkarian, and H. W. Stone, "Microstructure, morphology and lifetime of armored bubbles exposed to surfactants," Langmuir, 22 [14] (2006) 5986-5990.

[22] U. T. Gonzenbach, A. R. Studart, D. Steinlin, E. Tervoort, and L. J. Gauckler, "Processing of particle-stabilized wet foams into porous ceramics," J. Am. Ceram. Soc., 90 [11] (2007) 3407-3414.

[23] U. T. Gonzenabach, A. R Studart, E. Tervoort, and L. J. Gauckler, "Stabilization of foams with inorganic colloidal particles," Langmuir, (2006) 10983-10988.

[24] T. N. Hunter, R. J. Pugh, G. V. Fanks, and G. J. Jameson, "A role of particles in stabilizing foams and emulsions," Adv. Colloid. Inter. Sci., 137 (2008) 57-81.

[25] U. T. Gonzenbach, A. R. Studart, E. Tervoort, and L. J. Gauckler, "Macroporous ceramics from particle-stabilized wet foams," J. Am. Ceram. Soc., 90 [1] (2007) 19-22.

[26] P. J.Wilde, "Interface: their role in foam and emulsion behavior" Curr. Opin. Colloid Interface Sci., 5 (2000) 176-181.

[27] G. Morris, M. R. Pursell, S. J. Neethling, and J. J. Cilliers, "The effect of particle hydrophobicity, separation distance and packing patterns on the stability of a thin film," J. Colloid Interface Sci., 327 (2008) 138-144.

[28] U. T. Gonzenbach, A. R. Studart, E. Tervoort, and L. J. Gauckler, "Tailoring the microstructure of particle-stabilized wet foams," Langmuir, 23[3] (2007) 1025-1032.

[29] I. Akartuna, A. R. Studart, E. Tervoot, U. T. Gonzenbach, and L. J. Gauckler, “Stabilization of oil-in-water emulsions by colloidal particles modified with short amphiphiles," Langmuir, 24 (2008) 7161-7168.

[30] A. R. Studart, U. T. Gonzenbach, I. Akartuna, E. Tervoort, and L. J. Gauckler, "Materials from foams and emulsions stabilized by colloidal particles," J. Mater. Chem., (2007) 3283-3289.

[31] A. Pokhrel, J. G. Park, G. H. Jho, J. Y. Kim, and Ik Jin Kim, “Controlling the porosity of particle stabilized $\mathrm{Al}_{2} \mathrm{O}_{3}$ based ceramics," J. Kor. Ceram. Society., 48 [6] (2011) 600-603. 
[32] N. Sarkar, J. G. Park, S. Mazumder, A. Pokhrel, C. G. Aneziris, and I. J. Kim, " $\mathrm{Al}_{2} \mathrm{TiO}_{5}$-mullite porous ceramics from particle stabilized wet foam," Ceram. Int., 41 [5] (2015) 6306-6311.

[33] I. Aranberri, B. P. Binks, J. H. Clint, and P. D. I. Fletcher, "Synthesis of macroporous silica from solid-stabilised emulsion templates," J. Porous. Mater.,16 (2009) 429-437.

[34] U. T. Gonzenabach, A. R Studart, E. Tervoort, and L. J. Gauckler, “Ultrastable particle-stabilized foams," Angew. Chem. Int. Ed., 45 (2006) 3526-3530.

[35] E. Dickinson, R. Ettelaie, T. Kostakis, and B. S. Murray, "Factors controlling the formation and stability of air bubbles stabilized by partially hydrophobic silica nanoparticles," Langmuir, 20 (2004) 8517-8525.

[36] T. Fukasawa and M. Ando, "Synthesis of porous ceramics with complex pore structure by freeze-dry processing," J. Am. Ceram. Soc., 84 [1] (2001) 230-232.

[37] T. Fukasawa, Z. Y. Deng, M. Ando, T. Ohji, and Y. Goto, "Pore structure of porous ceramics synthesized from water-based slurry by freeze-dry process," J. Mater. Sci., 36 (2001) 2523-2527.

[38] I. Akartuna, A. R. Studart, E. Tervoot, and L. J. Gauckler, "Macro porous ceramics from particle-stabilized emulsions," Adv. Mater., 20 (2008) 4714-4718.

[39] I. Akartuna, E. Tervoot, A. R. Studart, and L. J. Gauckler, "General route for the assembly of functional inorganic capsules," Langmuir 25[21], (2009) 12419-12424.

[40] A. Pokhrel, J. G. Park, W. Zhao, and I. J. Kim, "Functional porous ceramics using amphiphilic molecule," J. Ceram. Process. Res., 13 [4] (2012) 420-424.

[41] Brent. S. Murray and Ettelaie, "Foam stability: proteins and nanoparticles," Curr. Opin. Colloid Interface Sci., 9 (2004) 314-320.

[42] D. M. Alguacil, E. Tervoort, C. Cattin, and L. J.Gauckler, "Contact angle and adsorption behavior of carboxylic acids on $\alpha-\mathrm{Al}_{2} \mathrm{O}_{3}$ surfaces," J. Colloid Interface Sci., 353 (2011) 512-518.

[43] G. Kaptay, "On the equation of the maximum capillary pressure induced by solid particles to stabilize emulsions and foams and on the emulsion stability diagrams," Colloids Surf. A: Physicochem. Eng. Aspects., 282-283 (2006) 387-401.

[44] S. Barg, C. Soltmann, M. Andrade, D. Koch, and G. Grathwohl, "Cellular ceramics by direct foaming of emulsified ceramic powder suspensions," J. Am. Ceram. Soc., 91 [9] (2008) 2823-2829.

[45] C. Tuck and J. R. G. Evans, "Porous ceramics prepared from aqueous foams," J. Mater. Sci. Lett., 18 (1999) 1003-1005.

[46] F. Schuth and W. Schmidt, "Microporous and mesoporous materials" Adv. Eng. Mater., 4 [5] 92005) 269-279 
[47] A. R. Studart, R. Libanori, A, Moreno, U. T. Gonzenbach, E. Tervoort, and L.J. Gauckler, "Unifying model for the electrokinetic and phase behavior of aqueous suspensions containing short and long amphiphiles," Langmuir, 27 (2011) 11835-11844.

[48] J. C. H. Wong, E. Tervoort, S. Busato, Urs. T. Gonzanbech, A. R. Studart, P. Ermanni, and L. J. Gauckler, “Designing macro porous polymers from particle-stabilized foams," J. Mater. Chem., 20 (2010) 5628-5640.

[49] A. R. Studart, Julia Studer, Lei Xu, K. Yoon, H. C. Shum, and D. A. Weitz, "Hierarchical porous materials made by drying complex suspensions," Langmuir, 27 [3] (2011) 955-964.

[50] P. C. Hiemenz and R. Ayagopalan, "Principles of colloid and surface chemistry," p. 650. 3rd edition. Marcel Dekker Inc, New York, 1997. 


\title{
Chapter 4
}

\section{Electrochemical Synthesis of Rare Earth Ceramic Oxide Coatings}

\author{
Teresa D. Golden, Yajuan Shang, Qi Wang and \\ Ting Zhou
}

Additional information is available at the end of the chapter

http://dx.doi.org/10.5772/61056

\begin{abstract}
Rare earth ceramic oxides are used in several applications including, phosphors, gas sensors, fuel cells, catalytic converters, and corrosion protection. These materials exhibit attractive properties such as fracture toughness, stiffness, and high strengthto-weight ratios. Synthesis of rare earth oxides includes a long list of techniques, but electrodeposition is one that has not been used as extensively as other techniques. This chapter discusses in detail the electrochemical synthesis of lanthanum, cerium, and praseodymium oxides. The physical and chemical properties of the electrodeposited oxides are characterized by $\mathrm{x}$-ray diffraction, scanning electron microscopy, $\mathrm{x}$-ray photoelectron spectroscopy, and other techniques. The electrochemical synthesis and post-treatment of other rare earth oxides, such as gadolinium, terbium, samarium, neodymium, europium, and dysprosium oxides are also covered in this chapter. Two main mechanisms of electrodeposition for rare earth oxides are discussed in detail.
\end{abstract}

Keywords: Electrodeposition, rare earth oxides, cathodic, anodic

\section{Introduction}

Ceramic oxides $\left(\mathrm{M}_{\mathrm{x}} \mathrm{O}_{\mathrm{y}}\right)$ typically have a combination of properties that make them attractive for many applications. These oxides exhibit fracture toughness and hardness, and can be used to make low weight composites of high strength. Ceramic oxides can also be used as protection coatings because of their interesting corrosion inhibiting properties [1-3]. These 
structural ceramics can be used to coat specific components exposed to extreme conditions, such as high temperature, high stress, or high friction. Of the ceramic oxides, rare earth oxides (REOs) are interesting materials and are a type of ceramic oxide that has many promising properties. Rare earth oxides can be used to color glass, for example, $\mathrm{Er}_{2} \mathrm{O}_{3}$ adds a light pink color while $\mathrm{Sm}_{2} \mathrm{O}_{3}$ produces a yellow color $[4,5]$. REOs are used in the making of phosphors or fluorescent lighting [6,7]. Rare earth oxides such as cerium oxide have also been important in automotive catalytic converters [8]. The most common stoichiometry for rare earth oxides is $\mathrm{R}_{2} \mathrm{O}_{3}$; however other compounds containing $\mathrm{Ce}$, $\mathrm{Pr}$, or $\mathrm{Tb}$ can exhibit several oxide phases, $\mathrm{RO}_{\mathrm{x}}(1.5<\mathrm{x}<2)$ and compounds like $\mathrm{CeO}_{2}, \mathrm{Pr}_{6} \mathrm{O}_{11}$, and $\mathrm{Tb}_{4} \mathrm{O}_{7}$ are common. Applications for rare earth oxide coatings include gas sensors [9, 10], fuel cells $[11,12]$, catalysis [13, 14], and corrosion protection [1, 15-18].

There is a long list of processing techniques for producing rare earth oxides including spray hydrolysis, pulsed laser deposition, chemical vapor deposition, solid state reactions, sol-gel method, and melt infiltration [19-24]. However, electrochemical synthesis has not been used extensively to deposit rare earth oxide coatings. The electrodeposition mechanism can be complex for many of the reactions and present a formidable challenge. In fact the majority of the electrodeposition work has focused on cerium oxide coatings and powders [25-28]. Typically, the redox potential for the rare earth oxides is not readily accessible in aqueous solutions, making synthesis difficult. But electrochemical deposition offers several advantages including low processing temperature, control of the driving force, and deposition onto various shapes [29-31]. This chapter covers the electrochemical deposition (not electrophoretic or soaking methods) of rare earth oxides as films for various applications.

\section{Electrochemical synthesis techniques for ceramic oxides}

For the deposition of ceramic oxides, there are three main methods. These include electrophoretic, electrolytic (base generation), and direct electrodeposition. Electrophoretic deposition occurs when a high electric field is applied in a solution that contains suspended particles. The charged particles in solution migrate to and then are deposited on the electrode surface. Typically, much higher voltages or currents are used to drive the ions in solution during this deposition compared to electrodeposition. Electrophoretic deposition tends to give thicker coatings than other techniques.

Electrolytic deposition occurs when cathodic reactions produce colloidal particles in solution next to the electrode surface. This method has an electrogeneration of base or local change of $\mathrm{pH}$ at the electrode surface. The solution contains metal salts or metal complexes. This may result in powdery or loosely adherent coatings. The cathodic electrodeposition or base generation method for synthesizing oxides was first described by Switzer [32]. The local increase in $\mathrm{pH}$ happens either by consumption of hydronium ions or production of hydroxide ions. Depending on the species in solution, both of these mechanisms may be occurring. The most likely reactions include [33]: 


$$
\begin{gathered}
\mathrm{H}^{+}+\mathrm{e}^{-} \rightarrow \mathrm{H}_{\mathrm{ads}} \\
2 \mathrm{H}^{+}+2 \mathrm{e}^{-} \rightarrow \mathrm{H}_{2} \\
2 \mathrm{H}_{2} \mathrm{O}+2 \mathrm{e}^{-} \rightarrow \mathrm{H}_{2}+2 \mathrm{OH}^{-} \\
\mathrm{O}_{2}+2 \mathrm{H}_{2} \mathrm{O}+4 \mathrm{e}^{-} \rightarrow 4 \mathrm{OH}^{-}
\end{gathered}
$$

If a nitrate salt is present in the solution then hydronium ions can be consumed or hydroxide ions produced by:

$$
\begin{gathered}
\mathrm{NO}_{3}{ }^{-}+2 \mathrm{H}^{+}+2 \mathrm{e}^{-} \rightarrow \mathrm{NO}_{2}{ }^{-}+\mathrm{H}_{2} \mathrm{O} \\
\mathrm{NO}_{3}{ }^{-}+10 \mathrm{H}^{+}+8 \mathrm{e}-\rightarrow \mathrm{NH}_{4}^{+}+3 \mathrm{H}_{2} \mathrm{O} \\
\mathrm{NO}_{3}^{-}+\mathrm{H}_{2} \mathrm{O}+2 \mathrm{e}^{-} \rightarrow \mathrm{NO}_{2}^{-}+2 \mathrm{OH}^{-} \\
\mathrm{NO}_{3}^{-}+7 \mathrm{H}_{2} \mathrm{O}+8 \mathrm{e}^{-} \rightarrow \mathrm{NH}_{4}^{+}+10 \mathrm{OH}^{-}
\end{gathered}
$$

With any of these reactions, the local $\mathrm{pH}$ at the electrode surface is increased and can be as high as 11-12 compared to the lower $\mathrm{pH}$ in the bulk of the solution.

Direct electrodeposition occurs when there is a direct oxidation or reduction (exchange of electrons) between the metal ion or metal ion complex and electrode to produce the metal oxide on the surface. This method is typical for electrochemical reactions, such as reduction of metal ions in solution to produce pure metal on an electrode surface (plating).

In this chapter, we cover only electrolytic and direct electrodeposition for the production of rare earth oxide coatings. The oxides or hydroxides of lanthanum, cerium, praseodymium, neodymium, samarium, europium, gadolinium, terbium, and dysprosium have been electrochemically produced. To date, the bulk of the electrochemical literature covers cerium oxide $\left(\mathrm{CeO}_{2}\right)$, about 40:1 compared to the other rare earth oxides. It must be noted that in aqueous solutions, the lanthanide hydroxides are stable in alkaline solutions but return to their corresponding cations in acid solutions [34]. This is true for all the lanthanide series; however, a few do have a stable oxide that may be accessible during deposition under the correct conditions. These include $\mathrm{CeO}_{2}, \mathrm{PrO}_{2}, \mathrm{NdO}_{2}$, and $\mathrm{TbO}_{2}$. In practice, this means that most of the rare earths are deposited as hydroxides or hydrated oxide species and post-treatment is needed 
to produce the desired stoichiometry. We will make note of this in our discussions when applicable for each section.

\section{Electrochemical synthesis of lanthanum oxide $\left(\mathrm{La}_{2} \mathrm{O}_{3}\right)$}

Lanthanum oxide $\left(\mathrm{La}_{2} \mathrm{O}_{3}\right)$ has been utilized in several technological applications, such as lightemitting phosphors, solid oxide fuel cells, catalysis, automobile exhaust-gas converters, and sorbent materials [35-39]. There are only a few papers reporting the attempt to electrodeposit lanthanum oxides from aqueous solutions [39-42]. In practice, $\mathrm{La}_{2} \mathrm{O}_{3}$ has not been deposited directly using electrodeposition. However, lanthanum hydroxide, $\mathrm{La}(\mathrm{OH})_{3}$, has been electrochemically deposited. Bocchetta et al. first showed that it was possible to obtain $\mathrm{La}(\mathrm{OH})_{3}$ from a solution of lanthanum nitrate using galvanostatic deposition at a cathodic current of 1 $\mathrm{mA} / \mathrm{cm}^{2}$ [40]. They obtained nanowires on an Al substrate, and the authors proposed that deposition occurred through a base generation mechanism. Yao et al. did a similar type of deposition using lanthanum nitrate and ammonia nitrate to obtain $\mathrm{La}(\mathrm{OH})_{3}$ nanorods on a copper substrate [41]. Like previous authors, they also proposed a base generation mechanism in which hydroxide ions are formed from the nitrate and water reduction:

$$
\begin{gathered}
\mathrm{NO}_{3}^{-}+\mathrm{H}_{2} \mathrm{O}+2 \mathrm{e}^{-} \rightarrow \mathrm{NO}_{2}^{-}+2 \mathrm{OH}^{-} \\
2 \mathrm{H}_{2} \mathrm{O}+2 \mathrm{e}^{-} \rightarrow \mathrm{H}_{2}+2 \mathrm{OH}^{-}
\end{gathered}
$$

However, by studying the SEM images along the potential-time curve, they also proposed that the evolution of hydrogen (reaction 10) was important in obtaining the nanorod formation. The $\mathrm{H}_{2}$ bubbles acted as a dynamic template forcing the nanorods in a vertical growth direction through the pressure of the bubbles.

The formation of $\mathrm{La}_{2} \mathrm{O}_{3}$ from $\mathrm{La}(\mathrm{OH})_{3}$ was first done by Liu et al. [42]. They fabricated $\mathrm{La}(\mathrm{OH})_{3}$ nanospindles and nanorods on F-doped $\mathrm{SnO}_{2}$ substrates using galvanostatic deposition from a bath containing $0.01 \mathrm{M} \mathrm{La}\left(\mathrm{NO}_{3}\right)_{3}$ and 30-50\% DMSO. After obtaining $\mathrm{La}(\mathrm{OH})_{3}$ nanorods, the coating was sintered at $690^{\circ} \mathrm{C}$. A pure hexagonal structure of $\mathrm{La}_{2} \mathrm{O}_{3}$ was obtained as revealed by the XRD pattern. The percentage of DMSO in the deposition solution affected the nanostructure of the deposits. Lower concentration produced nanorods, higher concentration produced nanospindles.

Other researchers also obtained nanorods, nanospindles, and nanocapsules of $\mathrm{La}_{2} \mathrm{O}_{3}$ by electrodeposition of $\mathrm{La}(\mathrm{OH})_{3}$ using the base generation method and then sintering [43-45]. However, it was shown by $\mathrm{CHN}$ analysis and FTIR that nitrates were codeposited into the $\mathrm{La}(\mathrm{OH})_{3}$ hexagonal lattice. A sharp peak at $1383 \mathrm{~cm}^{-1}$ in the FTIR spectra for the hydroxide sample is due to the vibration modes of $\mathrm{NO}_{3}{ }^{-}$ions intercalated in the deposit structure during electrodeposition. After sintering, no nitrates were present in the coating. Very nice vertically 
aligned uniform nanorods were prepared of $\mathrm{La}(\mathrm{OH})_{3}$ and $\mathrm{La}_{2} \mathrm{O}_{3}$ using a pulsed electrodeposition method followed by heat treatment [43]. In conclusion, while $\mathrm{La}_{2} \mathrm{O}_{3}$ has not been directly electrodeposited onto various substrates, $\mathrm{La}(\mathrm{OH})_{3}$ can be deposited from a nitrate solution using the base generation method and then heat treated (typically $\sim 600{ }^{\circ} \mathrm{C}$ ) to obtain $\mathrm{La}_{2} \mathrm{O}_{3}$.

\section{Electrochemical synthesis of cerium oxides}

Cerium oxide $\left(\mathrm{CeO}_{2}\right)$ is of interest in the area of catalysis [46]. Much effort has been dedicated to studying the role of ceria in several well-established industrial processes such as three-waycatalysis (TWC) systems and fluid catalytic cracking (FCC) systems, where $\mathrm{CeO}_{2}$ is a key component in catalyst formulation. Cerium oxide is used to remove automotive exhaust gases such as $\mathrm{NO}, \mathrm{CO}$, and $\mathrm{CH}_{\mathrm{x}}$, and to eliminate $\mathrm{SO}_{\mathrm{x}}$ and $\mathrm{NO}_{\mathrm{x}}$ from fuel gases [47]. Ceria also demonstrates catalytic function in the removal of soot from diesel engine exhaust, elimination of organics from wastewaters (catalytic wet oxidation), and cracking of heavy oil in zeolite. In addition, $\mathrm{CeO}_{2}$ is a semiconducting and ionic-conducting oxide. It can substitute for $\mathrm{ZrO}_{2}$ as the electrolyte material in solid oxide fuel cell (SOFC) systems and has been regarded as a model system for mixed ionic/electronic conductor investigations [48].

Particle size plays a significant role in the unique properties and applications of cerium oxide. Generally speaking, the smaller the particle size, the lower the packing porosity and the higher the surface area. Catalytic activity and electrical conductivity of crystalline cerium oxide are dependent on particle size, where electronic conductivity predominates in the nanocrystalline phase and ionic conductivity mainly controls the microcrystalline structure [49]. The nanocrystalline phase of cerium oxide is favorable for formation of a nonstoichiometric structure due to reduced enthalpy of defect formation and propensity for oxygen vacancies. The fluorite structure of $\mathrm{CeO}_{2}$ favors oxygen vacancy formation in the lattice, enhancing the catalytic reactivity of $\mathrm{CeO}_{2}$ in TWC, FCC, and other gas phase oxidation and reduction reactions [50]. Nanocrystalline cerium oxide improves catalytic properties significantly, leading to higher conversion of carbon monoxide to dioxide and sulfur dioxide to elemental sulfur at lower temperatures. The improved catalytic reactivity was also demonstrated in the oxidation of methane [51-53]. The sinterability of crystalline cerium oxide increases with decreasing particle size. The reduction of sintering temperature for nanocrystalline cerium oxide overcomes processing temperature difficulty and makes it a promising candidate as an electrolyte in solid oxide fuel cells $[52,53]$. Ceria can also be used for corrosion protection on a number of different substrates [54-56].

Cerium typically forms two types of oxides, cerium dioxide $\left(\mathrm{CeO}_{2}\right)$ and cerium sesquioxide $\left(\mathrm{Ce}_{2} \mathrm{O}_{3}\right)$. Cerium sesquioxide $\left(\mathrm{Ce}_{2} \mathrm{O}_{3}\right)$ has two structural forms, hexagonal (A-type) and cubic (C-type). Cerium oxide $\left(\mathrm{CeO}_{2}\right)$ has a fluorite $\left(\mathrm{CaF}_{2}\right)$ structure (fcc) with space group Fm3m. Figure 1 shows the structure of the stoichiometric $\mathrm{CeO}_{2}$ with the oxygen (represented by circles) four coordinated and the cerium (represented by solid balls) eight coordinated. The cerium atom is at the center of the tetrahedron and the tetrahedral corners are occupied by oxygen atoms. Cerium oxide can exist as a non-stoichiometric oxide, that is a mixture of $\mathrm{Ce}(\mathrm{III})$ oxide 
and $\mathrm{Ce}(\mathrm{IV})$ oxide, while still retaining the fluorite cubic structure. The coatings can be easily identified by $x$-ray diffraction (XRD) analysis.

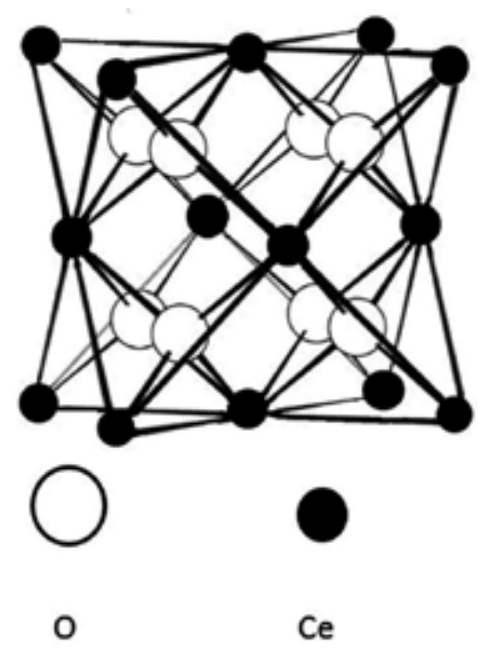

Figure 1. Fluorite structure of cerium oxide.

For the electrodeposition of rare earth oxides, cerium oxide is by far the most studied. It is also one of the few that has been deposited by both electrolytic (base generation) and direct electrodeposition. Cathodic electrodeposition (i.e., base generation electrochemical method) was first introduced for the plating of cerium oxide films [32]. Switzer et al. used this method to produce cerium oxide films and powders [57, 58]. Crystalline, randomly oriented cerium oxide coatings were deposited galvanostatically from a cerium nitrate solution. During the synthesis, the $\mathrm{pH}$ changed from $\sim 4.5$ to 7.5 , showing that base was generated during deposition.

An in-depth study was done by Aldykiewicz et al. to understand the base generation mechanism for $\mathrm{CeO}_{2}$ deposition [59]. They proposed a mechanism involving oxygen to produce an oxidizing agent (i.e., $\mathrm{H}_{2} \mathrm{O}_{2}$ ) for $\mathrm{Ce}(\mathrm{III})$ to $\mathrm{Ce}(\mathrm{IV})$ formation. With an oxidant available in the system, cerium oxide film formation was accomplished through a four- or two-electron process to a hydroxide intermediate. A critical $\mathrm{pH}$ value above 8.7 was needed to keep the cerium hydroxide ions stable in solution. The final step was the precipitation of $\mathrm{CeO}_{2}$ onto the electrode surface. This mechanism was supported by rotation disk electrode experiments and XANES studies. Li et al. studied the mechanism proposed by Aldykiewicz with in situ atomic force microscopy technique (AFM) and concluded that a cerium hydroxide species is produced at the electrode surface with $\mathrm{CeO}_{2}$ forming nuclei out of this hydroxide "gel". The rate-determining step for this mechanism is then the nucleation and growth of the $\mathrm{CeO}_{2}$ crystals [60-62].

Zhitomirsky also proposed that hydrogen peroxide plays a dominant role in the two-electron reduction process for the earlier mentioned mechanism [63-65]. He used $\mathrm{H}_{2} \mathrm{O}_{2}$ as an additive 
for the cathodic electrodeposition of $\mathrm{CeO}_{2}$ and $\mathrm{Gd}$-doped ceria films from aqueous and mixed alcohol-water solutions of cerium chloride or nitrate. He then proposed that a $\mathrm{CeO}_{2} \cdot \mathrm{nH}_{2} \mathrm{O}$ or $\mathrm{Ce}(\mathrm{OH})_{3} \mathrm{OOH}$ deposit formed via two- or four-electron reduction, owing to the participation of hydrogen peroxide in the oxidation step. Zhitomirsky noticed that there was always a lot of cracking of the films, probably due to dehydration of the film and/or mismatch of the linear thermal expansion coefficients for the coatings and substrate. For example, stainless steel, a common substrate used for ceria deposition, has a linear thermal expansion coefficient of $\sim 12.5$ $x 10^{-6} \mathrm{~K}^{-1}$. For ceria, the linear thermal expansion coefficient has been reported to range from 9 to $18 \times 10^{-6} \mathrm{~K}^{-1}$ at $298 \mathrm{~K}$ [66-69]. In addition, $\alpha$ increased as the oxygen vacancies increased for ceria, indicating that the $+3 /+4$ ratio of cerium in the coatings is important. It is reasonable to assume that the thermal expansion coefficient values for thin coatings or nanocrystalline films will be different than that measured for bulk cerium oxide. This cracking or "stain-glass" effect that occurs for deposition of $\mathrm{CeO}_{2}$ can be seen in Figure 2. Zhitomirsky added polymers (PVB or PVP) into the deposition solution, which were electrochemically intercalated into the deposit, so that the resultant films exhibited better adherence and crack-proof properties [63, 70]. Switzer took a different approach, in which he used anodic deposition at different applied voltages to directly oxidize $\mathrm{Ce}(\mathrm{III})$ to $\mathrm{Ce}(\mathrm{IV})$ and obtained crack free films [25]. A XANE study on electrodeposited cerium oxide thin films revealed that anodic deposition led to higher percentage of $\mathrm{Ce}(\mathrm{IV})$ species while cathodic base generation method led to the formation of high percentage of $\mathrm{Ce}(\mathrm{III})$ species in the composition [71]. In fact, no matter what electrodeposition method is used, the coatings obtained typically have a mixed stoichiometry of $\mathrm{CeO}_{2}$ ${ }_{x}$. Much of the work for deposition of cerium oxide has been done using the base generation method; however several researchers have studied the deposition using direct oxidation of $\mathrm{Ce}(\mathrm{III})$ to $\mathrm{Ce}(\mathrm{IV})$ to produce the films [25, 27, 28, 72].

Direct anodic deposition of $\mathrm{CeO}_{2}$ as a film is difficult in aqueous solutions. A simplified Pourbaix diagram, as shown in Figure 3, can help elucidate the different species that are stable at various pHs and voltages [34]. The dotted lines frame the boundaries of oxidation and reduction for water. At $\mathrm{pHs}$ below $7, \mathrm{Ce}^{3+}$ ions are stable between the reduction and oxidation limits of the electrolyte; however, as the $\mathrm{pH}$ increases above $7, \mathrm{Ce}(\mathrm{OH})_{3}$ precipitates.

Golden et al. proposed a deposition route in which the $\mathrm{Ce}^{3+}$ ion in solution was first stabilized using a ligand $[27,28]$. Several weakly to strongly bound cerium complexes were studied for the direct anodic deposition of $\mathrm{CeO}_{2}$. The deposition proceeded best when a ligand such as acetate or lactate was complexed with cerium in solution. The deposition was found to be $\mathrm{pH}$ and temperature dependent. Figure 4 shows the $x$-ray diffraction patterns for films deposited at different pHs. As seen from the XRD pattern, for a solution $\mathrm{pH}$ between 7 and 9, the deposited $\mathrm{CeO}_{2}$ film exhibits a preferred (111) orientation, but at a $\mathrm{pH}$ of 9 to 11 , the $\mathrm{CeO}_{2}$ films exhibit a random orientation. At solution $\mathrm{pHs}$ higher than 11, no $\mathrm{CeO}_{2}$ deposits on the electrode surface, although $\mathrm{CeO}_{2}$ powder (confirmed by XRD) is generated and settles at the bottom of the reaction cell. Golden et al. found that the preferred oriented $\mathrm{CeO}_{2}$ films could be obtained by tailoring the deposition conditions. The optimized deposition parameters included anodic deposition at current densities lower than $-0.06 \mathrm{~mA} / \mathrm{cm}^{2}$ and temperatures higher than $50^{\circ} \mathrm{C}[1]$. 


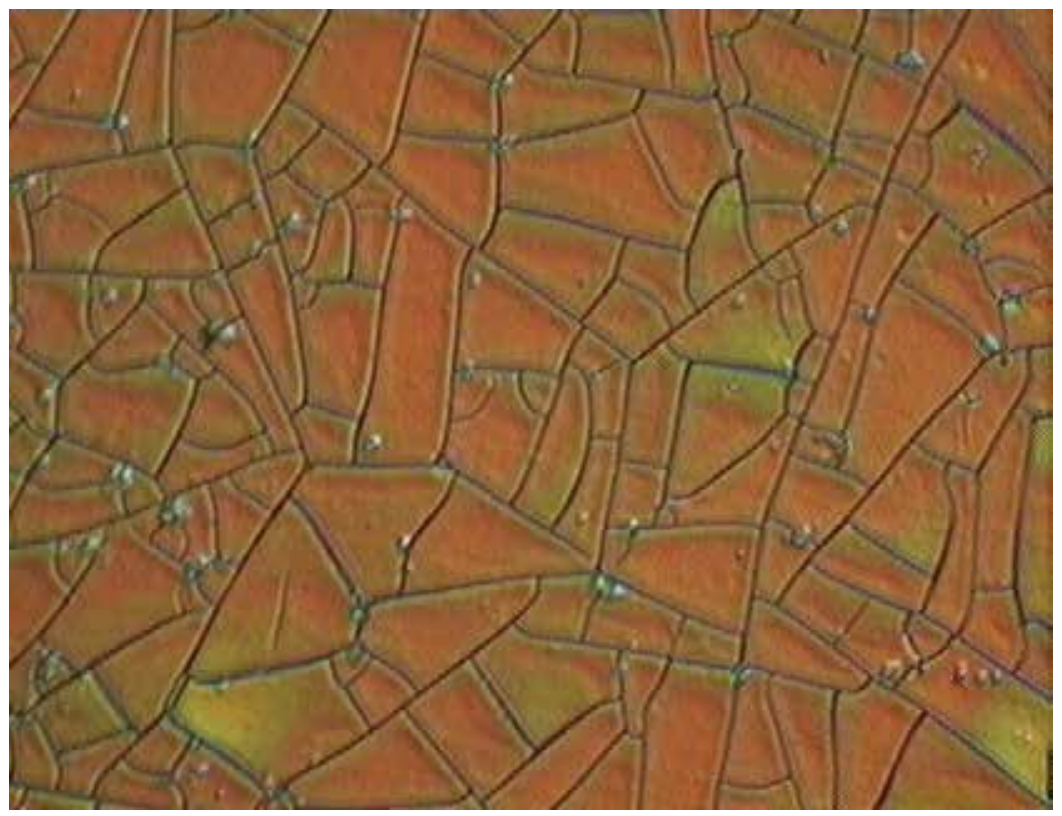

Figure 2. Optical Micrograph of an electrodeposited cerium oxide film on stainless steel. 800x magnification. (from T. Golden).

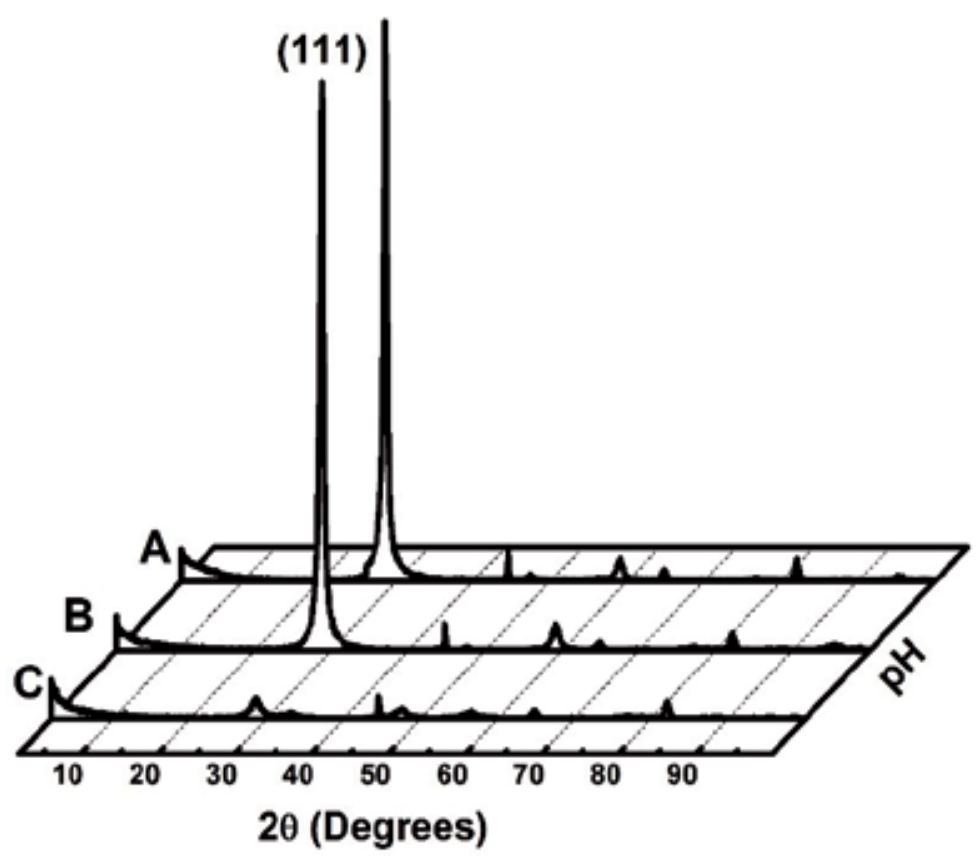

Figure 4. X-ray diffraction patterns of cerium oxide films deposited at a pH of (A) 7.5, (B) 8.5 and (C) 10.5. Deposition temperature, $70^{\circ} \mathrm{C} ; \mathrm{j}_{\text {anodic }}=-0.06 \mathrm{~mA} / \mathrm{cm}^{2}$. Y-axis represents $\mathrm{x}$-ray intensity in cps. 


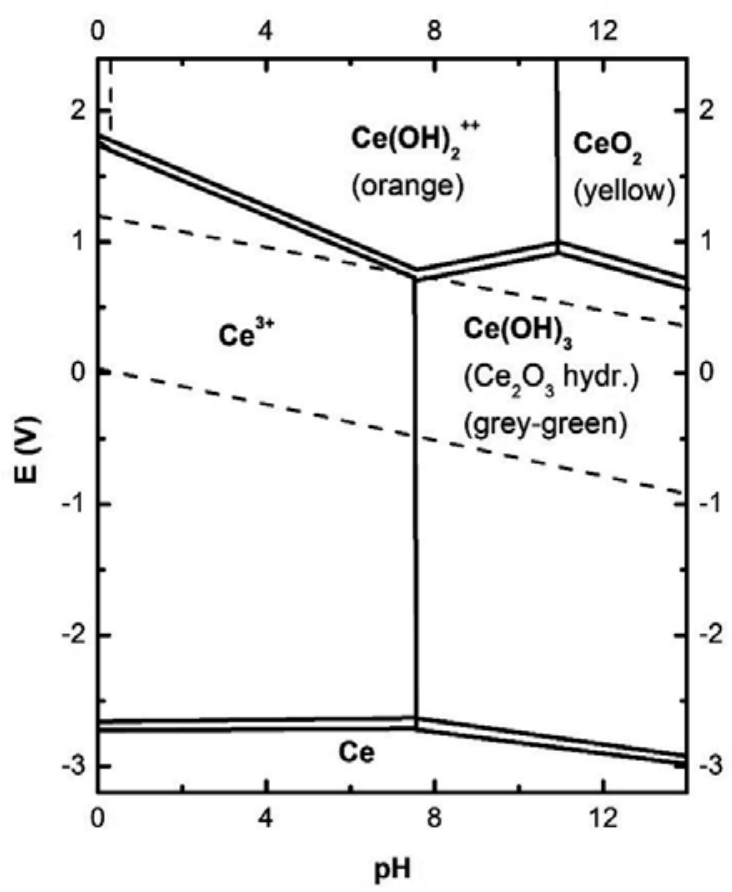

Figure 3. Simplified Pourbaix diagram for the Ce system in aqueous solution.

The electrodeposition of cerium oxide has an approximate linear relationship with fixed current density and deposition time up to a point. Typically, the faradaic yield drops off $35 \%$ after a certain film thickness due to the insulating quality of the cerium oxide coating [73]. After long periods of deposition time ( $24 \mathrm{hrs})$, the current becomes negligible. [27, 28].

Cerium oxide has been deposited from electrolytic solution containing either cerium nitrate or cerium chloride salts. Using chloride salts poses a problem, in that the deposits tend to be amorphous and incorporate chloride ions into the films except under certain conditions. Creus et al. found that to deposit using cerium chloride salts required either an addition of $\mathrm{H}_{2} \mathrm{O}_{2}$ to the aqueous electrolyte solution or use of a mixed water-ethyl alcohol solution [74]. Others also found that the base generation method could be used for the deposition from chloride salts when the plating solution contained a mixture of water and ethanol $[70,75,76]$.

A major thrust in recent years has been to electrodeposit cerium oxide onto various substrates for corrosion protection. Successful deposition of cerium oxide has been accomplished on surfaces such steels [77-79], zinc [15, 80], aluminum [81], and nickel superalloys [82, 83]. Linear polarization and tafel analysis were applied to test the corrosion protection effect of the asdeposited cerium oxide-oriented films [1]. The corrosion current decreased from $7.94 \times 10^{-9}$ for the substrate to $7.59 \times 10^{-10} \mathrm{~A} \bullet \mathrm{cm}^{-2}$ for the $\mathrm{CeO}_{2}$ film coated substrate in a $0.1 \mathrm{M} \mathrm{NaCl}$ solution. Film coated substrate in a $0.1 \mathrm{M} \mathrm{NaCl}$ increased from $2.63 \times 10^{6}$ for the substrate to $6.69 \times 10^{7}$ $\Omega \bullet \mathrm{cm}^{2}$ for the $\mathrm{CeO}_{2}$ film showing increased corrosion protection for the coating. 


\section{Electrochemical synthesis of praseodymium oxides}

Praseodymium oxide is a versatile and useful material, which is made up of a series of oxide compounds with the general formula $\operatorname{Pr}_{n} \mathrm{O}_{2 n-2}(n=4,5,6,7,8,9,10,12)$ [84-86]. $\operatorname{Pr}_{2} \mathrm{O}_{3}$ has a hexagonal structure and belongs to the A-type rare earth structure, while, $\operatorname{PrO}_{2}$ and $\operatorname{Pr}_{6} \mathrm{O}_{11}$ have a fluorite structure (similar to $\mathrm{CeO}_{2}$ ) where the metals are eight-coordinate. The mixed valence states in praseodymium oxide compounds make them useful materials with several important applications. Two areas of interest for praseodymium oxide films include the use of this material as an ethanol sensor and as a catalyst. [87-90]. Tsang et al. found that $\operatorname{Pr}_{6} \mathrm{O}_{11}$ could detect ethanol in air and the optimal sensitivity $(100 \%)$ was obtained at about $250{ }^{\circ} \mathrm{C}-300{ }^{\circ} \mathrm{C}$ [87]. The $\operatorname{Pr}_{6} \mathrm{O}_{11}$ sensors gave a linear response to ethanol concentrations in the range of 200 $8000 \mathrm{ppm}$. Praseodymium oxide is a promising candidate to substitute silicon dioxide as a high-K dielectric, with a dielectric constant up to 10 times higher than $\mathrm{SiO}_{2}$ (dielectric constant is around 30) and very low leakage currents. Among the different compositions of praseodymium oxide, $\operatorname{Pr}_{6} \mathrm{O}_{11}$ has the highest $\mathrm{K}$ value and $\mathrm{Pr}_{2} \mathrm{O}_{3}$ is a good dielectric [91-93]. Praseodymium oxide films can be formed by several different methods including molecular beam epitaxy, pulsed-laser deposition (PLD), sputtering, electrocrystallization of molten salts, chemical vapor deposition (CVD), and spin coating [92, 94-99].

However, the literature for the electrochemical deposition of praseodymium oxide is quite sparse. There are only a couple of references using electrodeposition and even in these the initial deposition component is praseodymium hydroxide, which is converted to $\operatorname{Pr}_{6} \mathrm{O}_{11}$ or $\mathrm{PrO}_{2}$ by sintering $[100,101]$. In both instances, $\operatorname{Pr}\left(\mathrm{NO}_{3}\right)_{3}$ and $\mathrm{H}_{2} \mathrm{O}_{2}$ were used as electrolyte and the deposition occurred by the base generation method. The reactions are [101]:

$$
\begin{gathered}
\mathrm{H}_{2} \mathrm{O}_{2}(\mathrm{aq})+2 \mathrm{e}^{-} \rightarrow 2 \mathrm{OH}^{-}(\mathrm{aq}) \\
\mathrm{NO}_{3}^{-}(\mathrm{aq})+\mathrm{H}_{2} \mathrm{O}(\mathrm{l})+2 \mathrm{e}^{-} \rightarrow \mathrm{NO}_{2}^{-}(\mathrm{aq})+2 \mathrm{OH}^{-}(\mathrm{aq}) \\
2 \mathrm{H}_{2} \mathrm{O}(\mathrm{l})+2 \mathrm{e}^{-} \rightarrow 2 \mathrm{OH}^{-}(\mathrm{aq})+\mathrm{H}_{2}(\mathrm{~g}) \\
2 \mathrm{Pr}(\mathrm{OH})_{3}(\mathrm{~s}) \rightarrow 2 \mathrm{PrO}_{2}(\mathrm{~s}) \text { or } \operatorname{Pr}_{6} \mathrm{O}_{11}(\mathrm{~s})+2 \mathrm{H}_{2} \mathrm{O}(\mathrm{l})+\mathrm{H}_{2}(\mathrm{~g})
\end{gathered}
$$

where the electrochemical generation of hydroxide ions increases the $\mathrm{pH}$ at the electrode surface and causes formation of Pr hydroxide on the surface. After deposition, the film is dried and sintered to produce Pr oxide.

Shrestha et al. electrodeposited an ultrathin layer of praseodymium hydroxide on ITO by

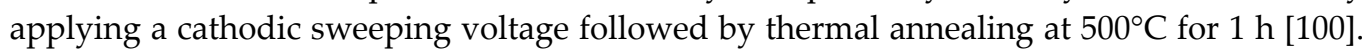
The predominant phase of the annealed film was $\operatorname{Pr}_{6} \mathrm{O}_{11}$. The XRD pattern of the deposit was 
indexed as $\operatorname{Pr}_{6} \mathrm{O}_{11}$ (JCPDS 06-0329). The SEM showed the surface covered with small and uniform globular shaped $\operatorname{Pr}_{6} \mathrm{O}_{11}$ particles. The deposited particles did not seem to undergo aggregation into larger islands on the ITO surface, suggesting that the colloidal particles once formed near the cathode quickly accumulated on the ITO surface in the short electrodeposition time. The surface coverage increased with the number of electrodeposition cycles.

Golden et al. studied using both potentiostatic and galvanostatic control for the cathodic deposition method to produce Pr oxide films. For the potentiostatic method, a potential from $-1.0 \mathrm{~V}$ to $-1.3 \mathrm{~V}$ was maintained while for the galvanostatic method, the deposition current density was set at $0.8 \mathrm{~mA} / \mathrm{cm}^{2}$. The electrolyte solution contained praseodymium nitrate, ammonium nitrate, and potassium chloride. A simplified Pourbaix diagram is shown in Figure 5. Within the aqueous region, at acidic $\mathrm{pHs}$ the $\mathrm{Pr}^{3+}$ ion is stable and at basic $\mathrm{pHs}$ the $\mathrm{Pr}$ hydroxide is stable. $\mathrm{PrO}_{2}$ is stable at $\mathrm{pH}$ above 8 , but is at an overpotential above $\mathrm{O}_{2}$ evolution in the aqueous solution. Therefore, increasing the local $\mathrm{pH}$ at the electrode surface by generating base is likely to produce Pr hydroxide nuclei for deposition.

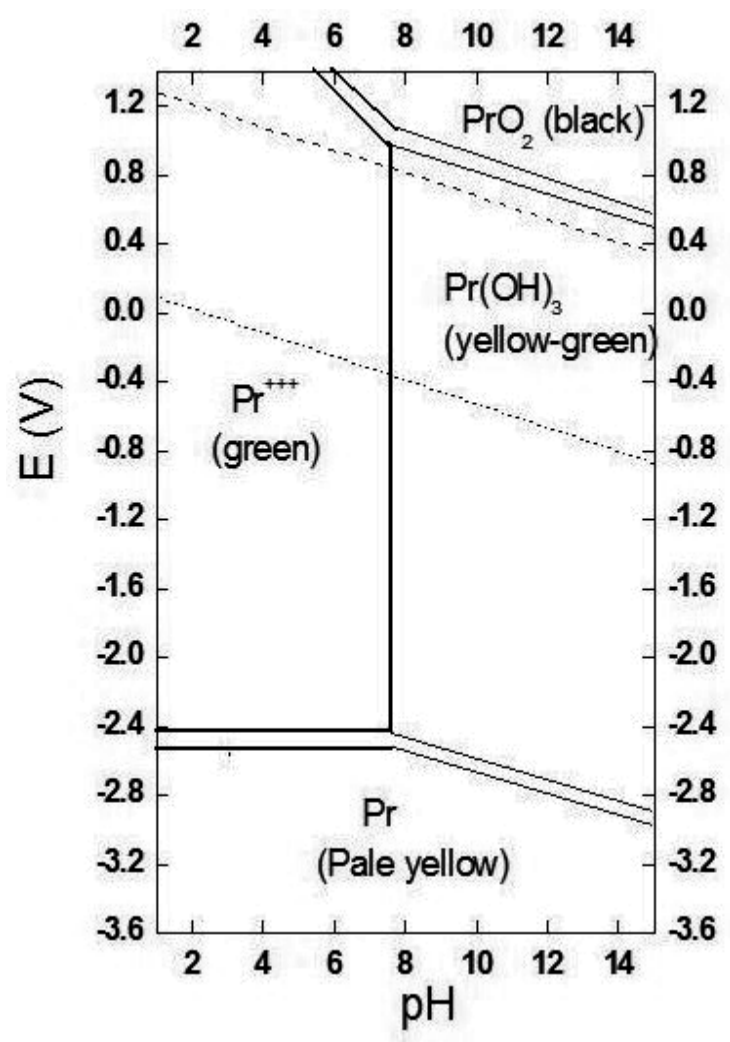

Figure 5. Simplified Pourbaix diagram for the Pr system in aqueous solution.

The XRD pattern for the as deposited film on a stainless steel substrate is shown in Figure 6. Both potentiostatic and galvanostatic methods gave similar results. The XRD pattern matches 
the reflections for $\operatorname{Pr}(\mathrm{OH})_{3}$ with some $\operatorname{Pr}\left(\mathrm{NO}_{3}\right)_{3}$ contamination. Pr compounds have a light green color when the valence of $\operatorname{Pr}$ is +3 , or dark brown/black color when the valence is +4 . Since the film on the stainless steel substrate is a light green color, the valence state of $\mathrm{Pr}$ in the film is probably closer to +3 . The newly deposited films were sintered at $600{ }^{\circ} \mathrm{C}$, and the film color turned black. Figure 7 is the XRD pattern of a sintered electrodeposited film. The XRD pattern matches a random orientation of $\operatorname{Pr}_{6} \mathrm{O}_{11}$ face-centered cubic (fcc) structure (PDF \#42-1121). Table 1 shows a comparison of the experimental data to the ICDD database for $\operatorname{Pr}_{6} \mathrm{O}_{11}$.

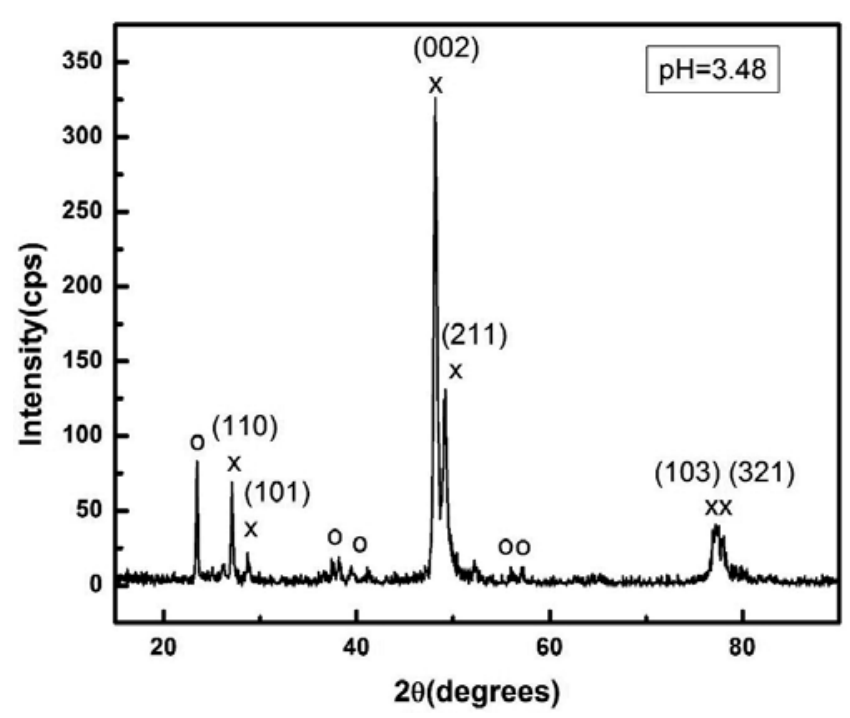

Figure 6. XRD pattern of the electrodeposited film on a stainless steel substrate using galvanostatic method with applied current density of $0.8 \mathrm{~mA} / \mathrm{cm}^{2}$, electrolyte solution composed of $0.1 \mathrm{M} \mathrm{NH}_{4} \mathrm{NO}_{3}$ and $\left.0.1 \mathrm{M} \operatorname{Pr}\left(\mathrm{NO}_{3}\right)_{3}, \mathrm{pH}=3.48\right)$.

The crystallite size and strain of the praseodymium oxide films were also calculated from the XRD data by examining the peak position and peak broadening of the reflections. The broadening of the peaks arises from three areas: instrumental broadening, crystallite size, and lattice strain. Contributions from these three factors can be determined by the WilliamsonHall method when at least 3 or 4 peaks exist in a XRD pattern [102]. Separation of the peak broadening due to crystallite size and lattice strain can be obtained by plotting $\mathrm{B}_{\mathrm{r}} \cos \theta$ versus $\sin \theta$, where the crystallite size is calculated from the y-intercept and strain from the slope. The calculated crystallite size ranged from 20 to $40 \mathrm{~nm}$ for the electrodeposited Proxide films.

The oxidation state of Pr in sintered praseodymium oxide films can be studied using XPS. The core-level binding energies for praseodymium oxide and the exact position of each peak from XPS are listed into Table 2. Figure 8 is the high resolution XPS spectra of the Pr $3 \mathrm{~d}$ core level showing the $3 \mathrm{~d} 5 / 2$ and $3 \mathrm{~d} 3 / 2$ signals separated by $20.2 \mathrm{eV}$, with the peak positions at $933.3 \mathrm{eV}$ and $953.5 \mathrm{eV}$, respectively. A strong shoulder can be seen on the lower BE sides of the $\operatorname{Pr} 3 \mathrm{~d} 5 / 2$ and $\operatorname{Pr} 3 \mathrm{~d} 3 / 2$ peaks, with comparable intensity and a distance between around 4.5 and $4.3 \mathrm{eV}$, 


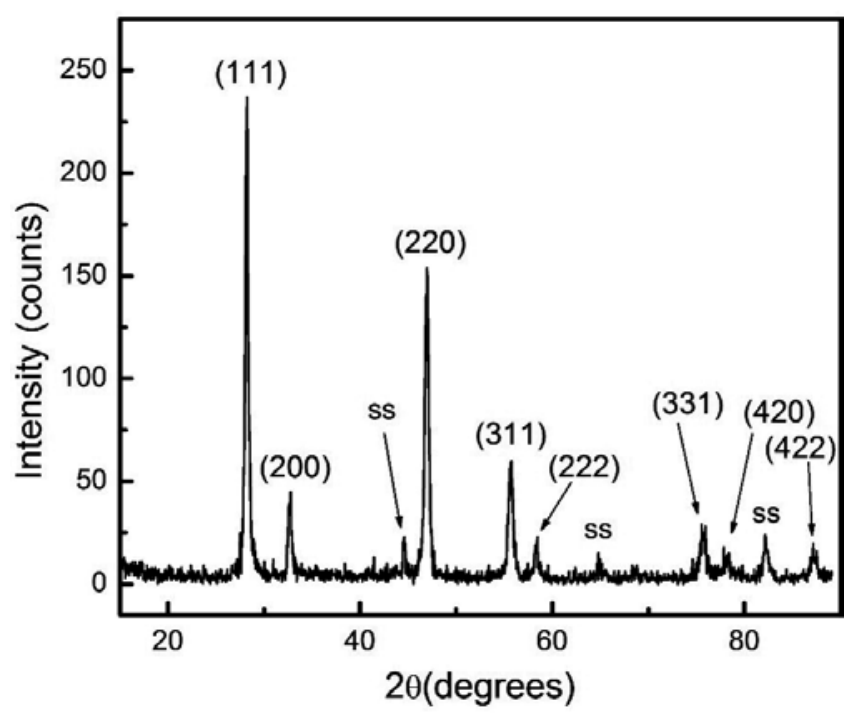

Figure 7. XRD pattern of praseodymium oxide film obtained by sintering the deposited film at $600{ }^{\circ} \mathrm{C}$ for $1 \mathrm{~h}$.

\begin{tabular}{|c|c|c|c|c|}
\hline hkl & Experimental $2 \theta\left({ }^{\circ}\right)$ & $\mathbf{I} / \mathrm{I}_{0}$ & PDF \#42-1121 $\theta\left(^{\circ}\right)$ & $\mathbf{I} / \mathbf{I}_{0}$ \\
\hline 111 & 28.238 & 100 & 28.249 & 100 \\
\hline 200 & 32.741 & 18 & 32.739 & 28 \\
\hline 220 & 46.951 & 65 & 46.993 & 30 \\
\hline 311 & 55.743 & 24 & 55.706 & 24 \\
\hline 222 & 58.436 & 8 & 58.424 & 4 \\
\hline 400 & - & - & 68.588 & 3 \\
\hline 331 & 75.557 & 10 & 75.753 & 5 \\
\hline 420 & 78.065 & 6 & 78.083 & 4 \\
\hline 422 & 87.255 & 7 & 87.265 & 4 \\
\hline
\end{tabular}

Table 1. Comparison of XRD data of the sintered electrodeposited film and PDF card. (Golden et al.).

this is consistent with results in literature for praseodymium [103, 104]. The XPS spectra of polycrystalline powders of $\operatorname{Pr}_{2} \mathrm{O}_{3}, \operatorname{PrO}_{2}$, and $\operatorname{Pr}_{6} \mathrm{O}_{11}$ all have an energy separation of the $\operatorname{Pr} 3 \mathrm{~d} 3 / 2$ and $\operatorname{Pr} 3 \mathrm{~d} 5 / 2$ core levels in the range of $17.5-23.0 \mathrm{eV}$. In addition, the Pr $3 \mathrm{~d} 5 / 2$ core level spectra of these praseodymium oxides exhibit a shoulder at $4-4.5 \mathrm{eV}$ on the lower binding energy side of the metal main peak. The relative intensities of the Pr $3 \mathrm{~d}$ main peak and satellite peak vary with the $\operatorname{Pr}(\mathrm{III}) / \operatorname{Pr}(\mathrm{IV})$ ratio [105]. Specifically, the main peak intensity increases as the relative content of $\operatorname{Pr}(\mathrm{III})$ increases whereas the satellite peak intensity decreases. Therefore, the variation of relative intensities of the main and satellite peaks can be used to examine the change in Pr valence. The Pr 3d XPS spectra of $\mathrm{Pr}_{2} \mathrm{O}_{3}$ and $\mathrm{PrO}_{2}$ are almost identical in most 
respects, such as the shape of the peak and the overall fine structure. The main and satellite peaks for $\operatorname{Pr}_{6} \mathrm{O}_{11}$ are situated between $\mathrm{PrO}_{2}$ and $\operatorname{Pr}_{2} \mathrm{O}_{3}$. The $\operatorname{Pr} 3 \mathrm{~d} 5 / 2$ binding energy is $935.0 \mathrm{eV}$ for $\operatorname{Pr}(\mathrm{IV})$ and $932.9 \mathrm{eV}$ for $\operatorname{Pr}(\mathrm{III})$. Our experimental results are $933.3 \mathrm{eV}$ for $\operatorname{Pr} 3 \mathrm{~d} 5 / 2$, which is an indication of a $\operatorname{Pr}+3 /+4$ mixture such as in $\operatorname{Pr}_{6} \mathrm{O}_{11}$. By curve fitting the $\operatorname{Pr} 3 \mathrm{~d}$ XPS spectrum and determining the areas of the fitted peaks, a non-stoichiometric ratio is determined as $\mathrm{PrO}_{1.80}$, an indication of the mixed valence state of $\operatorname{Pr}(\mathrm{III})$ and $\operatorname{Pr}(\mathrm{IV})$ (Table 3).

\begin{tabular}{lllllllll}
\hline Oxide & $\operatorname{Pr} 5 \mathrm{p}$ & $\operatorname{Pr} 5 \mathrm{~s}$ & $\operatorname{Pr} 4 \mathrm{~d}$ & $\operatorname{Pr} 4 \mathrm{p}$ & $\operatorname{Pr} 4 \mathrm{~s}$ & $\operatorname{Pr} 3 \mathrm{~d}_{5 / 2}$ & $\operatorname{Pr} 3 \mathrm{~d}_{3 / 2}$ & $\mathrm{O} 1 \mathrm{~s}$ \\
\hline Peak position (eV) & 20.08 & 36.8 & 116.2 & 217.2 & 304.7 & 933.3 & 954.7 & 530.3 \\
\hline
\end{tabular}

Table 2. Core-level binding energies for sintered electrodeposited praseodymium oxide measured by XPS.

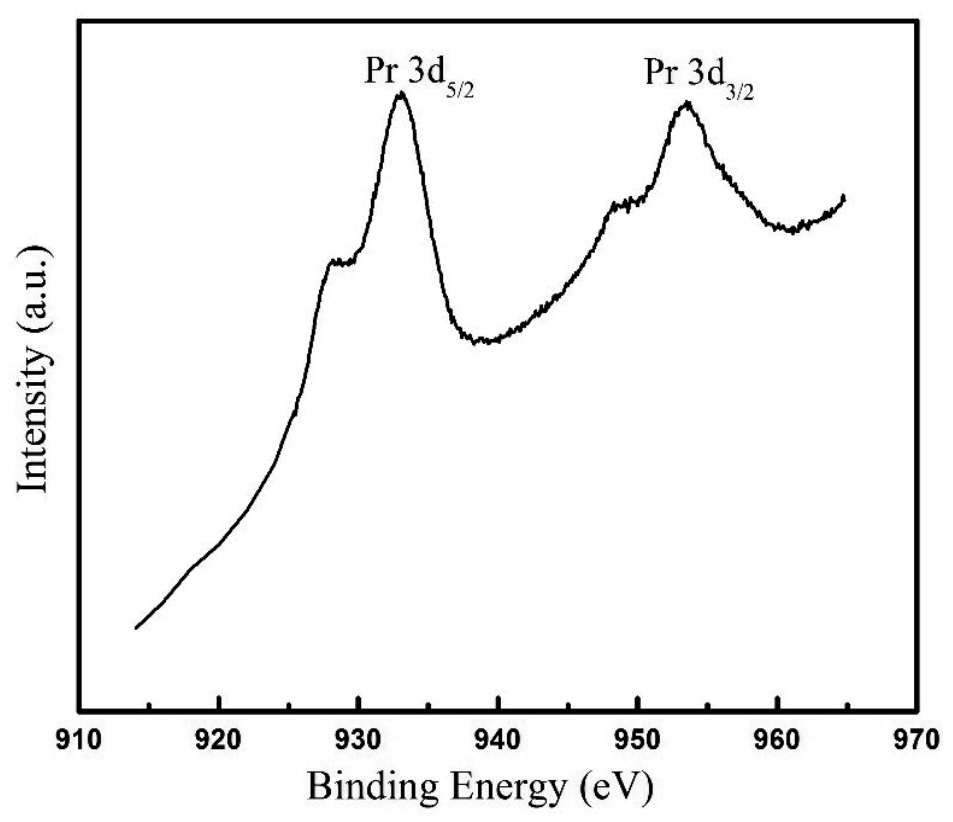

Figure 8. High-resolution XPS spectra of Pr 3d core level showing the spin-orbit splitting of the $3 \mathrm{~d}$ level.

The $\mathrm{pH}$ effect was also studied as one of the parameters for the electrodeposition of the $\mathrm{Pr}$ oxide films. When the $\mathrm{pH}$ value of the electrolyte solution was below 7, films could be electrodeposited onto the substrate; however, powders only formed in the solution when the $\mathrm{pH}$ was above 7, due to bulk formation of $\operatorname{Pr}(\mathrm{OH})_{3}$. XRD of the electrodeposited films showed that intensities of the reflections belonging to $\operatorname{Pr}(\mathrm{OH})_{3}$, such as (110), (101), (103), (321), and (220), increased with increasing $\mathrm{pH}$ (up to $\mathrm{pH} 7$ ) of the electrolyte, and the intensities of the peaks due to $\operatorname{Pr}\left(\mathrm{NO}_{3}\right)_{3}$ decreased with increasing $\mathrm{pH}$.

The morphology of the praseodymium oxide film is interesting and is shown in Figure 9. Before sintering, the films appeared smooth and continuous, but after sintering, cracks appeared in 
the films (similar to $\mathrm{CeO}_{2}$ films) due to shrinkage and mismatch between the film and substrate. However, at higher magnification in the SEM images, the Pr oxide is distributed as platelets across the surface and the film has a high surface area. This may be beneficial in catalysis.

\begin{tabular}{ccccc}
\hline Peak \# & $\begin{array}{c}\text { Praseodymium } \\
\text { contribution }\end{array}$ & Peak position (eV) & Area & \% Area \\
\hline $\mathrm{m}_{1}$ & $\operatorname{Pr}(\mathrm{III})$ & 927.408 & 171980 & 9.7440 \\
\hline $\mathrm{m}_{2}$ & $\operatorname{Pr}(\mathrm{IV})$ & 928.837 & 207250 & 11.74221 \\
\hline $\mathrm{s}_{2}$ & $\operatorname{Pr}(\mathrm{IV})$ & 932.384 & 423730 & 24.0079 \\
\hline $\mathrm{s}_{1}$ & $\operatorname{Pr}(\mathrm{III})$ & 934.128 & 261960 & 14.8424 \\
\hline $\mathrm{m}_{1}{ }^{\prime}$ & $\operatorname{Pr}(\mathrm{III})$ & 947.820 & 132190 & 7.48986 \\
\hline $\mathrm{m}_{2}{ }^{\prime}$ & $\operatorname{Pr}(\mathrm{IV})$ & 948.956 & 82829.93 & 20.69302 \\
\hline $\mathrm{s}^{\prime}{ }^{\prime}$ & $\operatorname{Pr}(\mathrm{IV})$ & 953.220 & 363640 & 6.8773 \\
\hline $\mathrm{s}^{\prime}{ }^{\prime}$ & $\operatorname{Pr}(\mathrm{III})$ & 956.640 & 121380 & 100 \\
\hline $\mathrm{Total}$ & & & 687510 & 38.9537 \\
\hline $\operatorname{Pr}(\mathrm{III})$ & & & 1.567 \\
\hline $\operatorname{Pr}(\mathrm{IV}) / \operatorname{Pr}(\mathrm{III})$ & & &
\end{tabular}

Table 3. Peak list of $\operatorname{Pr} 3 \mathrm{~d}$ and calculation of Pr valence.
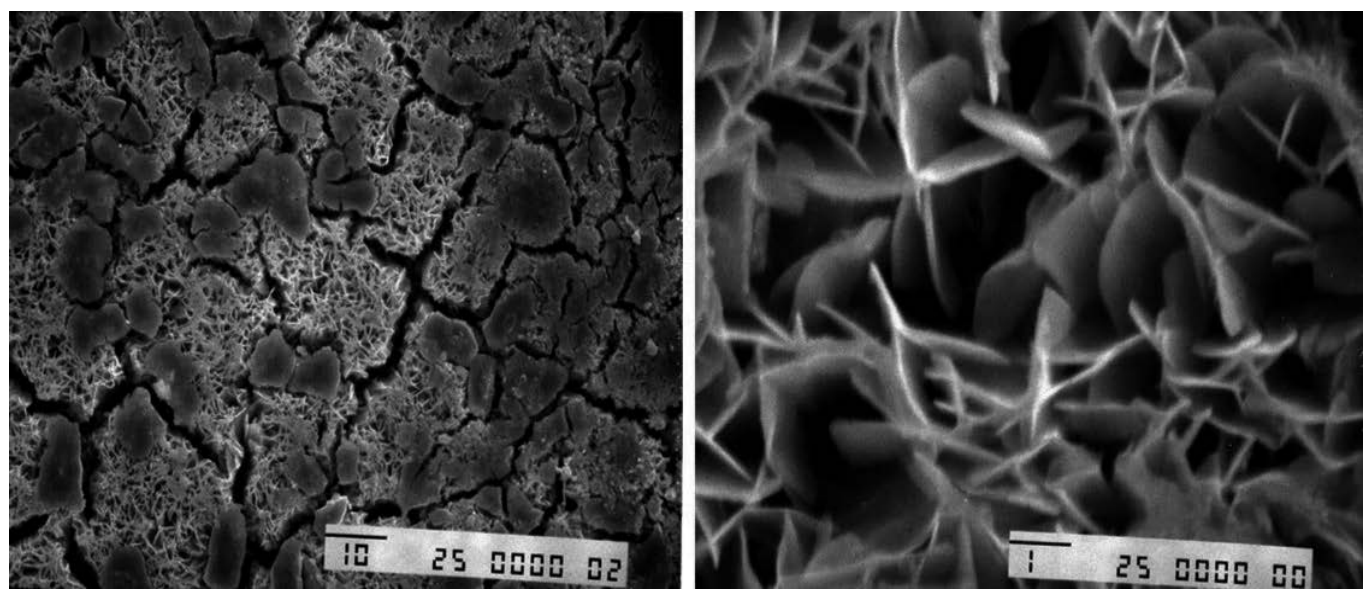

Figure 9. SEM images of $\operatorname{Pr}_{6} \mathrm{O}_{11}$ film obtained by cathodic electrodeposition on stainless steel in an electrolyte system composed of $0.1 \mathrm{M} \operatorname{Pr}\left(\mathrm{NO}_{3}\right)_{3}$ and $0.1 \mathrm{M} \mathrm{NH}_{4} \mathrm{NO}_{3}$ solution, $\mathrm{j}=0.8 \mathrm{~mA} / \mathrm{cm}^{2}, \mathrm{~T}=25^{\circ} \mathrm{C}$, and after sintering at $600{ }^{\circ} \mathrm{C}$ for $1 \mathrm{~h}$; (left) magnification 1000. (T. Golden); (right) magnification 10000.

In conclusion, $\operatorname{Pr}_{6} \mathrm{O}_{11}$ films were successfully obtained on stainless steel substrates (Golden et al.) using the base generation method and then sintered at $600{ }^{\circ} \mathrm{C}$. X-ray diffraction 
showed the films matched the $\operatorname{Pr}_{6} \mathrm{O}_{11}$ fluorite structure and the crystallite size was calculated as 20 to $40 \mathrm{~nm}$. Scanning electron microscopy was utilized to study the surface texture and microstructure of deposits. As-deposited films had uniform morphology but sintering caused cracking of the films. SEM showed interesting surface texture and platelet structure for the deposits. The oxidation state of Pr oxide was determined by XPS and revealed that the praseodymium oxide was non-stoichiometric with the oxidation state of Pr between +3 and +4 .

\section{Electrochemical synthesis of other rare earth oxides}

The remaining literature for electrodeposition of pure rare earth oxides is sparse. Most of the research is on doping of $\mathrm{CeO}_{2}$ with another rare earth oxide (i.e., $\mathrm{PrO}_{2}, \mathrm{Sm}_{2} \mathrm{O}_{3}, \mathrm{Gd}_{2} \mathrm{O}_{3}$, and $\mathrm{Tb}_{2} \mathrm{O}_{3}$ ) to increase the oxygen vacancies, ionic conductivity, or catalytic activity [106-109]. However, there are a few reports of individual REO coatings prepared by electrodeposition using the base generation method. Lair et al. prepared $\mathrm{Sm}_{2} \mathrm{O}_{3}$ by electrodepositing $\mathrm{Sm}(\mathrm{OH})_{3}$ from a nitrate solution and then sintering at $600{ }^{\circ} \mathrm{C}$ for $1 \mathrm{~h}$ [110]. The as-deposited Sm-based films were thick and adherent to the substrate even though cracking was observed in the film. Raman spectra of the as-deposited films had peaks at 1054 and $741 \mathrm{~cm}^{-1}$ attributed to the internal vibration modes of nitrate ions. Both nitrate-related peaks greatly diminished after annealing and major peaks for $\mathrm{Sm}_{2} \mathrm{O}_{3}$ increased in the spectrum.

Other researchers prepared $\mathrm{Gd}_{2} \mathrm{O}_{3}$ by electrodepositing $\mathrm{Gd}(\mathrm{OH})_{3}$ from a nitrate solution and then sintering at $700{ }^{\circ} \mathrm{C}$ for $3 \mathrm{~h}[111,112]$. The authors used a cathodic pulse current method where $t_{\text {on }}=10 \mathrm{~ms}$ and $t_{\text {off }}=10 \mathrm{~ms}$. The deposition mechanism was still a base generation method:

Electrochemical step:

$$
\begin{gathered}
\mathrm{NO}_{3}^{-}+\mathrm{H}_{2} \mathrm{O}+2 \mathrm{e}^{-} \rightarrow \mathrm{NO}_{2}^{-}+2 \mathrm{OH}^{-} \\
\mathrm{O}_{2}+2 \mathrm{H}_{2} \mathrm{O}+4 \mathrm{e}^{-} \rightarrow 4 \mathrm{OH}^{-} \\
2 \mathrm{H}_{2} \mathrm{O}+2 \mathrm{e}^{-} \rightarrow \mathrm{H}_{2}+2 \mathrm{OH}^{-}
\end{gathered}
$$

Chemical step:

$$
\begin{gathered}
\mathrm{Gd}^{3+}+3 \mathrm{OH}^{-}+\mathrm{yH}_{2} \mathrm{O} \rightarrow\left[\mathrm{Gd}(\mathrm{OH})_{3} \mathrm{yH}_{2} \mathrm{O}\right] \\
\mathrm{Gd}^{3+}+3 \mathrm{OH}^{-}+\mathrm{xNO}_{3}^{-}+\mathrm{yH}_{2} \mathrm{O} \rightarrow\left[\mathrm{Gd}(\mathrm{OH})_{(3-\mathrm{x})}\left(\mathrm{NO}_{3}\right)_{\mathrm{x}} \mathrm{yH}_{2} \mathrm{O}\right]
\end{gathered}
$$


The reduction of nitrate ions and water in the electrochemical step causes the electrogeneration of base at the cathode surface due to the increase of local $\mathrm{pH}$, which leads to the formation of gadolinium hydroxide deposit on the electrode. Analysis of the films showed a high nitrogen content indicating nitrate ions had been intercalated into the deposit during electrodeposition. SEM images of the sintered coatings did show formed nanorods $\sim 20-30 \mathrm{~nm}$ in diameter and up to $1 \mu \mathrm{m}$ in length.

$\mathrm{Lu}$ et al. electrodeposited $\mathrm{TbO}_{2-x}$ coatings onto copper substrates from a nitrate solution using the base generation method [113]. SEM images of the electrodeposited $\mathrm{TbO}_{2-x}$ samples showed flower-like structures made up of numerous leaf-like nanosheets, in which the leaf-shaped nanosheets were approximately $100 \mathrm{~nm}$ in thickness and $1 \mu \mathrm{m}$ in width. The crystal structure was analyzed by powder XRD. The values of the lattice constant were close to those of $\mathrm{TbO}_{1.75}$.

\section{Conclusion}

The electrodeposition of rare earth oxides onto various substrates can be accomplished by two different electrochemical mechanisms: cathodic electrogeneration of base method or direct anodic deposition. The majority of the literature for REO electrodeposition covers $\mathrm{CeO}_{2}$ or REO-doped $\mathrm{CeO}_{2}$. A variety of morphologies has been obtained for the REOs films, such as nanocrystalline films, nanorods, nanotubes, nanosheets, as well as flower-like and coral-like nanostructures. Some sections covered in detail include the direct electrodeposition of $\mathrm{CeO}_{2}$ using a complexing ligand to stabilize the ceria ions in solution and the cathodic deposition of $\operatorname{Pr}_{6} \mathrm{O}_{11}$.

\section{Author details}

Teresa D. Golden ${ }^{1 *}$, Yajuan Shang ${ }^{2}$, Qi Wang ${ }^{3}$ and Ting Zhou ${ }^{1}$

*Address all correspondence to: tgolden@unt.edu

1 University of North Texas, Department of Chemistry, Denton, TX, USA

2 Eli Lilly \& Company, Indianapolis, USA

3 Yeshiva University, Department of Physics, New York, USA

\section{References}

[1] Wang AQ, Golden TD. Electrodeposition of oriented cerium oxide films. Int. J. Electrochem. 2013;482187:1-10. DOI: 10.1155/2013/482187. 
[2] Wang AQ, D'Souza NA, Golden TD. Electrosynthesis of nanocrystalline cerium oxide/layered silicate powders. J. Mater. Chem. 2006;16:481-488. DOI: 10.1039/ B506976A.

[3] Wang Q, D'Souza NA, Golden TD. Ceramic montmorillonite nanocomposites by electrochemical synthesis. Appl. Clay Sci. 2008;42:310-317. DOI: 10.1016/j.clay. 2008.02.004.

[4] Duran P, Recio P, Jurado JR, Pascual C, Moure C. Preparation, sintering, and properties of translucent erbium oxide $\left(\mathrm{Er}_{2} \mathrm{O}_{3}\right)$-doped tetragonal zirconia. J. Am. Ceram. Soc. 1989;72:2088-2093. DOI: 10.1111/j.1151-2916.1989.tb06036.x.

[5] Erbe EM, Day DE. Properties of $\mathrm{Sm}_{2} \mathrm{O}_{3}-\mathrm{Al}_{2} \mathrm{O}_{3}-\mathrm{SiO}_{2}$ glasses for in vivo applications. J. Am. Ceram. Soc. 1990;73:2708-2713. DOI: 10.1111/j.1151-2916.1990.tb06750.x.

[6] Zhang P, Lu Z, Yuan Q, Hou Q, Golden TD, Ren X, Weng L, Wang H. A novel composite phosphor via one-pot synthesis: Single matrix with controllable luminescence. Mater. Chem. Phys. 2012;134:1190-1196. DOI: 10.1016/j.matchemphys.2012.04.020.

[7] Schubert EF, Kim JK. Solid-state light sources getting smart. Science. 2005;308:1274-1278. DOI: 10.1126/science.1108712.

[8] Shelef M, McCabe RW. Twenty-five years after introduction of automotive catalysts: what next? Catal. Today. 2000;62:35-50. DOI: 10.1016/S0920-5861(00)00407-7.

[9] Niu X, Du W, Du W. Preparation, characterization and gas-sensing properties of rare earth mixed oxides. Sensor Actuat. B-Chem. 2004;99:399-404. DOI: 10.1016/j.snb. 2003.12.006.

[10] Niu X, Zhong H, Wang X, Jiang K. Sensing properties of rare earth oxide doped $\operatorname{In}_{2} \mathrm{O}_{3}$ by a sol-gel method. Sensor Actuat. B-Chem. 2006;115:434-438. DOI: 10.1016/j.snb. 2005.10.004.

[11] Murray EP, Tsai T, Barnett SA. A direct-methane fuel cell with a ceria-based anode. Nature. 1999;400:649-651. DOI: 10.1038/23220.

[12] Singhal, SC. Advances in solid oxide fuel cell technology. Solid State Ionics. 2000;135:305-313. DOI: 10.1016/S0167-2738(00)00452-5.

[13] Monte RD, Kaspar J. Nanostructures $\mathrm{CeO}_{2}-\mathrm{ZnO}_{2}$ mixed oxides. J. Mater. Chem. 2005;15:633-648. DOI: 10.1039/b414244f.

[14] Colussi S, De Leitenburg C, Dolcetti G, Trovarelli A. The role of rare earth oxides as promoters and stabilizers in combustion catalysts. J. Alloys Compd. 2004;374:387-392. DOI: 10.1016/j.jallcom.2003.11.028.

[15] Hamlaouri Y, Remazeilles C, Bordes M, Tifouti L, Pedraza F. Electrodeposition of ceria-based layers on zinc electroplated steel. Corr. Sci. 2010;52:1020-1025. DOI: 10.1016/j.corsci.2009.11.027. 
[16] Huang X, Li N, Wang H, Sun H, Sun S, Zhang J. Electrodeposited cerium film as chromate replacement for tinplate. Thin Solid Films. 2008;516:1037-1043. DOI: 10.1016/j.tsf.2007.08.044.

[17] Stoyanova E, Stoychev D. in: Hong S. Corrosion behavior of stainless steels modified by cerium oxides layers. Handbook of Corrosion Resistance. Croatia: InTech; 2012. 239 p. DOI: $10.5772 / 33382$.

[18] Rudd AL, Breslin CB, Mansfeld F. The corrosion protection afforded by rare earth conversion coatings applied to magnesium. Corros. Sci. 2000;42:275-288. DOI: 10.1016/S0010-938X(99)00076-1.

[19] Liu T, Zhang Y, Shao H, Li X. Synthesis and characteristics of $\mathrm{Sm}_{2} \mathrm{O}_{3}$ and $\mathrm{Nd}_{2} \mathrm{O}_{3}$ nanoparticles. Langmuir. 2003;19:7569-7572. DOI: 10.1021/la0343501.

[20] Yu X, Li F, Ye X, Xin X, Xue Z. Synthesis of cerium(IV) oxide ultrafine particles by solid-state reactions. J. Am. Ceram. Soc. 2000;83:964-966. DOI: 10.1111/j. 1151-2916.2000.tb01306.x.

[21] Ozer N. Optical properties and electrochromic characterization of sol-gel deposited ceria films. Sol. Energy Mater. Sol. Cells. 2001;68:391-400. DOI: 10.1016/ S0927-0248(00)00371-8.

[22] Mikhelashvili V, Eisenstein G, Edelmann F. Characteristics of electron-beam-gunevaporated $\mathrm{Er}_{2} \mathrm{O}_{3}$ thin films as gate dielectrics for silicon. J. Appl. Phys. 2001;90:5447-5449. DOI: 10.1063/1.1413239.

[23] Jones L, Kumar D, Singh RK, Holloway PH. Luminescence of pulsed laser deposited Eu doped yttrium oxide films. Appl. Phys. Lett. 1997;71:404-406. DOI: S0003-6951(97)03027-1.

[24] Kale SS, Jadhav KR, Patil PS. Characterizations of spray-deposited lanthanum oxide $\left(\mathrm{La}_{2} \mathrm{O}_{3}\right)$ thin films. Mater. Lett. 2005;59:3007-3009. DOI: 10.1016/j.matlet.2005.02.091.

[25] Kulp EA, Limmer SJ, Bohannan EW, Switzer JA. Electrodeposition of nanometerthick ceria films by oxidation of cerium (III)-acetate. Solid State Ionics. 2007;178:749-757. DOI: 10.1016/j.ssi.2007.03.012.

[26] Zhou Y, Phillips RJ, Switzer JA. Electrochemical synthesis and sintering of nanocrystalline cerium (IV) oxide powders. J. Am. Ceram. Soc. 1995;78:981-985. DOI: 10.1111/j. 1151-2916.1995.tb08425.x.

[27] Wang Q, Golden TD. Anodic deposition of cerium oxide: I. Formation of crystalline thin films. J. Electrochem. Soc. 2003;150:C616-C620. DOI: 10.1149/1.1596164.

[28] Golden TD, Wang Q. Anodic deposition of cerium oxide thin films: II. Mechanism studies. J. Electrochem. Soc. 2003;150:C621-C624. DOI: 10.1149/1.1596165. 
[29] Conrad HA, Corbett JR, Golden TD. Electrochemical deposition of $\gamma$-phase zinc-nickel alloys from alkaline solution. J. Electrochem. Soc. 2012;159:C29-C32. DOI: 10.1149/2.027201jes.

[30] Ahmad YH, Mohamed AMA. Electrodeposition of nanostructured nickel-ceramic composite coatings: a review. Int. J. Electrochem. Sci. 2014;9:1942-1963. ISSN: 1452-3981.

[31] Ahmad YH, Tientong J, D'Souza N, Mohamed AMA, Golden TD. Characterization and corrosion resistance of electrodeposited Ni-Mo-silicate platelet nanocomposite coatings. Surf. Coat. Technol. 2014;259:517-525. DOI: 10.1016/j.surfcoat.2014.10.036.

[32] Switzer JA. Electrochemical synthesis of ceramic films and powders. Am. Ceramic Soc. Bull. 1987;66:1521-1524. ISSN: 0002-7812.

[33] Therese GHA, Kamath, PV. Electrochemical synthesis of metal oxides and hydroxides. Chem. Mater. 2000;12:1195-1204. DOI: 10.1021/cm990447a.

[34] Pourbaix M. Handbook of Atlas of Electrochemical Equilibria in Aqueous Solutions. Houston: NACE; 1974. 644 p. DOI: 10.1016/0022-0728(67)80059-7.

[35] Mao G, Zhang H, Lia H. Selective Synthesis of morphology and species controlled $\mathrm{La}_{2} \mathrm{O}_{3}: \mathrm{Eu}^{3+}$ and $\mathrm{La}_{2} \mathrm{O}_{2} \mathrm{CO}_{3}: \mathrm{Eu}^{3+}$ phosphors by hydrothermal method. J. Electrochem. Soc. 2012;159:J48-J53. DOI: 10.1149/2.031203jes.

[36] Muttay EP, Tsai T, Barnett SA. A direct-methane fuel cell with a ceria-based anode. Nature. 1999;400:649-651. DOI: 10.1038/23220.

[37] Andriamasinoro D, Kieffer R, Kiennemann A, Poix P. Preparation of stabilized copper-rare earth oxide catalysts for the synthesis of methanol from syngas. Appl. Catal. 1993;106:201-212. DOI: 10.1016/0926-860X(93)80178-S.

[38] Sun J, Qiu XP, Zhu WT. $\mathrm{H}_{2}$ from steam reforming of ethanol at low temperature over $\mathrm{Ni} / \mathrm{Y}_{2} \mathrm{O}_{3}, \mathrm{Ni} / \mathrm{La}_{2} \mathrm{O}_{3}$ and $\mathrm{Ni} / \mathrm{Al}_{2} \mathrm{O}_{3}$ catalysts for fuel-cell application. Int. J. Hydrogen Energy. 2005;30:437-445. DOI: 10.1016/j.ijhydene.2004.11.005.

[39] Gonzalez-Rovira L, Sanchez-Amaya JM, Lopez-Haro M, Hungria AB, Boukha Z, Bernal S, Botana FJ. Formation and characterization of nanotubes of $\mathrm{La}(\mathrm{OH})_{3}$ obtained using porous alumina membranes. Nanotechnology. 2008;19:495305/1-495305/9. DOI: 10.1088/0957-4484/19/49/495305.

[40] Bocchetta P, Santamaria M, Di Quarto F. Template electrosynthesis of $\mathrm{La}(\mathrm{OH})_{3}$ and $\mathrm{Nd}(\mathrm{OH})_{3}$ nanowires using porous anodic alumina membranes. Electrochem. Commun. 2007;9:683-688. DOI: 10.1016/j.elecom.2006.10.053.

[41] Yao CZ, Wei BH, Ma HX, Gong QJ, Jing KW, Sun H, Meng LX. Facile fabrication of $\mathrm{La}(\mathrm{OH})_{3}$ nanorod arrays and their application in wastewater treatment. Mater. Lett. 2011;65: 490-492. DOI: 10.1016/j.matlet.2010.10.065. 
[42] Liu Z, Zheng D, Su Y. Facile and efficient electrochemical synthesis of lanthanum hydroxide nanospindles and nanorods. Electrochem. Solid-State Lett. 2010;13:E15-E18. DOI: $10.1149 / 1.3486446$.

[43] Khosrow F, Aghazadeh M, Arhamib B. Facile synthesis of vertically aligned one-dimensional (1D) $\mathrm{La}(\mathrm{OH})_{3}$ and $\mathrm{La}_{2} \mathrm{O}_{3}$ nanorods by pulse current deposition. J. Electrochem. Soc. 2013;160:D150-D155. DOI: 10.1149/2.050304jes.

[44] Aghazadeh M, Golikand AN, Ghaemi M, Yousefi T. A novel lanthanum hydroxide nanostructure prepared by cathodic electrodeposition. Mater. Lett. 2011;65:1466-1468. DOI: 10.1016/j.matlet.2011.02.039.

[45] Aghazadeh M, Golikand AN, Ghaemi M, Yousefi $\mathrm{T}$. $\mathrm{La}_{2} \mathrm{O}_{3}$ nanoplates prepared by heat-treatment of electrochemically grown $\mathrm{La}(\mathrm{OH})_{3}$ nanocapsules from nitrate medium. J. Electrochem. Soc. 2011;158:E136-E141. DOI: 10.1149/2.057112jes.

[46] Trovareli A. Catalytic properties of ceria and $\mathrm{CeO}_{2}$-containing materials. Cat. Rev. Sci. Eng. 1996;38:439-520. DOI: 10.1080/01614949608006464.

[47] Trovarelli A, Boaro M, Rocchini E, De Leitenburg C, Dolcetti G. Some recent developments in the characterization of ceria-based catalysts. J. Alloys Compd. 2001;323-324:584-591. DOI: 10.1016/S0925-8388(01)01181-1.

[48] Chiang YM, Lavik EB, Blom DA. Defect thermodynamics and electrical properties of nanocrystalline oxides: Pure and doped $\mathrm{CeO}_{2}$. Nanostruct. Mater. 1997;9:633-642. DOI: 10.1016/S0965-9773(97)00142-6.

[49] Tschope A, Sommer E, Birringer R. Grain size-dependent electrical conductivity of polycrystalline cerium oxide I. Experiments. Solid State Ionics. 2001;139:255-265. DOI: 10.1016/S0167-2738(01)00678-6.

[50] Zhang Y, Anderson S, Muhammed M. Nanophase catalytic oxides: I. Synthesis of doped cerium oxides as oxygen storage promoters. Appl. Catal., B: Environ. 1995;6:325-337. DOI: 10.1016/0926-3373(95)00041-0.

[51] Tschope A, Liu W, Flytzani-Stephanopoulos M, Ying JY. Redox activity of nonstoichiometric cerium oxide- based nanocrystalline catalysts. J. Catal. 1995;157:42-50. DOI: $10.1006 /$ jcat.1995.1266.

[52] Zhou Y, Rahaman MN. Effect of redox reaction on the sintering behavior of cerium oxide. Acta Mater. 1997;45:3635-3639. DOI: 10.1016/S1359-6454(97)00052-9.

[53] Kleinlogel C, Gaukler LJ. Sintering and properties of nanosized ceria solid solutions. Solid State Ionics. 2000;135:567-573. DOI: 10.1016/S0167-2738(00)00437-9.

[54] Arnott DR, Hinton BRW, Ryan NE, Cationic film-forming inhibitors for the protection of the AA 7075 aluminum alloy against corrosion in aqueous chloride solution. Corrosion (NACE). 1989;45:12-18. DOI: 10.5006/1.3577880. 
[55] Crossland AC, Thompson GE, Skeldon P, Wood GC, Smith CJE, Habazaki H, Shimi$\mathrm{zu} \mathrm{K}$. Anodic oxidation of Al-Ce alloys and inhibitive behavior of cerium species. Corros. Sci. 1998;40:871-885. DOI: 10.1016/S0010-938X(98)00007-9.

[56] Arenas MA, Conde A, De Damborenea J. Cerium: a suitable green corrosion inhibitor for tinplate. Corros. Sci. 2002;44:511-520. DOI: 10.1016/S0010-938X(01)00053-1.

[57] Zhou Y, Phillips RJ, Switzer JA. Electrochemical synthesis and sintering of nanocrystalline cerium(IV) oxide powders. J. Am. Ceram. Soc. 1995;78:981-985. DOI: 10.1111/j. 1151-2916.1995.tb08425.x.

[58] Zhou Y, Switzer JA. Growth of cerium(IV) oxide films by the electrochemical generation of base method. J. Alloys Compd. 1996;237:1-5. DOI: 10.1016/0925-8388(95)02048-9.

[59] Aldykiewicz AJ, Davenport AJ, Isaacs HS. Studies of the formation of cerium-rich protective films using $\mathrm{x}$-ray absorption near-edge spectroscopy and rotating disk electrode methods. J. Electrochem. Soc. 1996;143:147-153. DOI: 10.1149/1.1836400.

[60] Li F, Newman RC, Thompson GE. In situ atomic force microscopy studies of electrodeposition mechanism of cerium oxide films: nucleation and growth out of a gel mass precursor. Electrochim. Acta. 1997;42:2455-2464. DOI: 10.1016/ S0013-4686(96)00433-1.

[61] Li F, Thompson GE, Newman RC. Force modulation atomic force microscopy: background, development and application to electrodeposited cerium oxide films. Appl. Surf. Sci. 1998;126:21-33. DOI: 10.1016/S0169-4332(97)00590-4.

[62] Li F, Thompson GE. In situ atomic force microscopy studies of the deposition of cerium oxide films on regularly corrugated surfaces. J. Electrochem. Soc. 1999;146:1809-1815. DOI: 10.1149/1.1391848.

[63] Zhitomirsky I, Petric A. Electrolytic and electrophoretic deposition of $\mathrm{CeO}_{2}$ films. Mater. Lett. 1999;40:263-268. DOI: 10.1016/S0167-577X(99)00087-7.

[64] Zhitomirsky I. Cathodic electrosynthesis of titanium and ruthenium oxides. Mater. Lett. 1998;33:305-310. DOI: 10.1016/S0167-577X(97)00120-1.

[65] Zhitomirsky I, Petric A. Electrochemical deposition of ceria and doped ceria films. Ceram. Int. 2001;27:149-155. DOI: 10.1016/S0272-8842(00)00054-7.

[66] Hayashi H, Kanoh Ma, Quan CJ, Inaba H, Wang S, Dokiya M, Tagawa H. Thermal expansion of Gd-doped ceria and reduced ceria. Solid State Ionics. 2000;132:227-233. DOI: 10.1016/S0167-2738(00)00646-9.

[67] Touloukian YS, Kirby RK, Taylor RE, Lee TYR. in: Touloukian YS, Ho CY. Thermal expansion nonmetallic solids. Handbook of Thermophysical Properties of Matter. New York: Springer; 1977. 1810 p. DOI: 10.1007/978-1-4757-1631-3. 
[68] Korner R, Ricken M, Noelting J, Riess I. Phase transformations in reduced ceria: determination by thermal expansion measurements. J. Solid State Chem. 1989;78:136-147. DOI: 10.1016/0022-4596(89)90137-0.

[69] Stecura S, Campbell WJ. Thermal expansion and phase inversion of rare-earth oxides. Bur. Mines Rept. Invest. 1961;5847:1-47. ISSN: 1066-5552.

[70] Yang L, Pang X, Fox-Rabinovich G, Veldhuis S, Zhitomirsky I. Electrodeposition of cerium oxide films and composites. Surf. Coat. Technol. 2011;206:1-7. DOI: 10.1016/ j.surfcoat.2011.06.029.

[71] Balasubramanian M, Melendres CA, Mansour AN. An X-ray absorption study of the local structure of cerium in electrochemically deposited thin films. Thin Solid Films. 1999;347:178-183. DOI: 10.1016/S0040-6090(98)01754-4.

[72] Wang AQ, Punchaipetch P, Wallace RM, Golden TD. X-ray photoelectron spectroscopy study of electrodeposited nanostructured $\mathrm{CeO}_{2}$ films. J. Vac. Sci. Technol. B. 2003;21:1169-1175. DOI: 10.1116/1.1577569.

[73] Arurault L, Monsang P, Salley J, Bes RS. Electrochemical preparation of adherent ceria coatings on ferritic stainless steel. Thin Solid Films. 2004;466:75-80. DOI: 10.1016/ j.tsf.2004.02.039.

[74] Creus J, Brezault F, Rebere C, Gadouleau M. Synthesis and characterization of thin cerium oxide coatings elaborated by cathodic electrolytic deposition on steel substrate. Surf. Coat. Technol. 2006;200:4636-4645. DOI: 10.1016/j.surfcoat.2005.04.027.

[75] Stoyanova E, Guergova D, Stoychev D, Avramova I, Stefanov P. Passivity of OC404 steel modified electrochemically with $\mathrm{CeO}_{2}-\mathrm{Ce}_{2} \mathrm{O}_{3}$ layers in sulfuric acid media. Electrochim. Acta. 2010;55:1725-1732. DOI: 10.1016/j.electacta.2009.10.057.

[76] Lu Y, Cai S, Liang Y, Bai C, Liu Z, Guo Y, Cai C. The mechanism of the nano-CeO films deposition by electrochemistry method as coated conductor buffer layers. Physica C: Superconductivity and its Applications. 2015;512:1-5. DOI: 10.1016/j.physc. 2015.02.038.

[77] Hamlaoui Y, Pedraza F, Remazeilles C, Cohendoz S, Rebere C, Tifouti L, Creus J. Cathodic electrodeposition of cerium-based oxides on carbon steel from concentrated cerium nitrate solutions: part I. Electrochemical and analytical characterization. Mater. Chem. Phys. 2009;113:650-657. DOI: 10.1016/j.matchemphys.2008.08.027.

[78] Hamlaoui Y, Tifouti L, Remazeilles C, Pedraza F. Cathodic electrodeposition of cerium based oxides on carbon steel from concentrated cerium nitrate. Part II: Influence of electrodeposition parameters and of the addition of PEG. Mater. Chem. Phys. 2010;120:172-180. DOI: 10.1016/j.matchemphys.2009.10.042.

[79] Hamlaoui Y, Pedraza F, Tifouti L. Investigation of electrodeposited cerium oxide based films on carbon steel and of the induced formation of carbonated green rusts. Corros. Sci. 2008;50:2182-2188. DOI: 10.1016/j.corsci.2008.05.017. 
[80] Martinez L, Roman E, De Segovia JL, Poupard S, Creus J, Pedraza F. Surface study of cerium oxide based coatings obtained by cathodic electrodeposition on zinc. Appl. Surf. Sci. 2011;257:6202-6207. DOI: 10.1016/j.apsusc.2011.02.033.

[81] Zivkovic LjS, Popic JP, Jegdic BV, Dohcevic-Mitrovic Z, Bajat JB, Miskovic-Stankovic VB. Corrosion study of ceria coatings on AA6060 aluminum alloy obtained by cathodic electrodeposition: Effect of deposition potential. Surf. Coat. Technol. 2014;240:327-335. DOI: 10.1016/j.surfcoat.2013.12.048.

[82] Bouchaud B, Balmain J, Bonnet G, Pedraza F. Optimizing structural and compositional properties of electrodeposited ceria coatings for enhanced oxidation resistance of a nickel-based superalloy. Appl. Surf. Sci. 2013;268:218-224. DOI: 10.1016/j.apsusc. 2012.12.065.

[83] Bouchaud B, Balmain J, Bonnet G, Pedraza F. Correlations between electrochemical mechanisms and growth of ceria based coatings onto nickel substrates. Electrochim. Acta. 2013;88:798-806. DOI: 10.1016/j.electacta.2012.10.112.

[84] Ferguson RE, Guth ED, Eyring L. Praseodymium oxides. I. Phase study by dissociation pressure measurements. J. Am. Chem. Soc. 1954;76:3890-3894. DOI: 10.1021/ ja01644a006.

[85] Burnham DA, Eyring L. Phase transformations in the praseodymium oxide-oxygen system: high-temperature x-ray diffraction studies. J. Phys. Chem. 1968;72:4415-4424. DOI: $10.1021 / \mathrm{j} 100859 \mathrm{a} 010$.

[86] Zhang J, Von-Dreele RB, Eyring L. Structures in the oxygen-deficient fluorite-related $\mathrm{R}_{\mathrm{n}} \mathrm{O}_{2 \mathrm{n}-2}$ homologous series: $\operatorname{Pr}_{12} \mathrm{O}_{22}$. J. Solid State Chem. 1996;122:53-58. DOI: 10.1006/ jssc.1996.0081.

[87] Tsang SC, Bulpitt C. Rare earth oxide sensors for ethanol analysis. Sens. Actuators, B: Chemical. 1998;52:226-235. DOI: 10.1016/S0925-4005(98)00233-0.

[88] Hussein GAM. Rare earth metal oxides: formation, characterization and catalytic activity. Thermoanalytical and applied pyrolysis review. J. Anal. Appl. Pyrolysis. 1996;37:111-149. DOI: 10.1016/0165-2370(96)00941-2.

[89] Poirier MG, Breault R, Kaliaguine S, Adnot A. Oxidative coupling of methane over praseodymium oxide catalysts. Appl. Catal. 1991;71:103-122. DOI: 10.1016/0166-9834(91)85009-K.

[90] Du W, Xie Xi, Xu D, Huang C. Preparation and electrochemical characterization of $\mathrm{PtRuO}_{2}-\mathrm{Ce}_{0.5} \mathrm{Pr}_{0.5} \mathrm{O}_{2-\delta} / \mathrm{C}$ catalysts for methanol electrooxidation. Energy Fuels. 2008;22:3346-3350. DOI: 10.1021/ef800200u.

[91] Osten HJ, Liu JP, Müssig HJ, Zaumseil P. Epitaxial, high- $k$ dielectrics on silicon: the example of praseodymium oxide. Microelectron. Reliab. 2001;41:991-994. DOI: 10.1016/S0026-2714(01)00054-3. 
[92] Wolfframm D, Ratzke M, Kappa M, Montenegro MJ, Dobeli M, Lippert Th, Reif J. Pulsed laser deposition of thin $\operatorname{Pr}_{x} \mathrm{O}_{y}$ films on $\mathrm{Si}(100)$. Mater. Sci. Eng., B. 2004;109:24-29. DOI: 10.1016/j.mseb.2003.10.022.

[93] Wu M, Alivov YI, Morkoc H. High- $\kappa$ dielectrics and advanced channel concepts for Si MOSFET. J. Mater. Sci. - Mater. Electron. 2008;19:915-951. DOI: 10.1007/ s10854-008-9713-2.

[94] Osten HJ, Liu JP, Mussig HJ. Band gap and band discontinuities at crystalline $\operatorname{Pr}_{2} \mathrm{O}_{3} /$ $\mathrm{Si}(001)$ heterojunctions. Appl. Phys. Lett. 2002;80:297-299. DOI: 10.1063/1.1433909.

[95] Horio N, Hiramatsu M, Nawata M, Imaeda K, Torii T. Preparation of zinc oxide/ metal oxide multilayered thin films for low-voltage varistors. Vacuum. 1998;51:719-722. DOI: 10.1016/S0042-207X(98)00293-0.

[96] Kaneko Y, Mori S, Yamanaka J. Synthesis of electrochromic praseodymium-doped vanadium oxide films by molten salt electrolysis. Solid State Ionics. 2002;151:35-39. DOI: 10.1016/S0167-2738(02)00601-X.

[97] Malchus M, Jansen M. Electrocrystallization of $\mathrm{PrO}_{2}$ and $\mathrm{TbO}_{2-x}$ from alkali hydroxide melts and characterization of the fluorite-related $\mathrm{TbO}_{2-\mathrm{x}}$. Solid State Sci. 1998;2:65-70. DOI: 10.1016/S1293-2558(00)00111-4.

[98] Lo-Nigro R, Toro RG, Malandrino G, Fragala IL, Rossi P, Dapporto, P. Study of the thermal properties of $\operatorname{Pr}(\mathrm{III})$ precursors and their implementation in the MOCVD growth of praseodymium oxide films. J. Electrochem. Soc. 2004;151:F206-F213. DOI: 10.1149/1.1779336.

[99] Leach C, Freer R, Azough F, Ling Z. Direct observation of the barrier structure of a praseodymium-doped grain boundary in a zinc oxide bicrystal by charge collection microscopy. Interface Sci. 2000;8:141-146. DOI: 10.1023/A:1008772421392.

[100] Shrestha S, Marken F, Elliott J, Yeung CMY, Mills CE, Tsang SC. Electrochemical deposition of praseodymium oxide on tin-doped indium oxide as a thin sensing film. J. Electrochem. Soc. 2006;153:C517-C520. DOI: 10.1149/1.2198094.

[101] Sawangphruk M, Foord JS. Localized electrodeposition of praseodymium oxide on boron-doped diamond. Diamond Relat. Mater. 2010;19:885-888. DOI: 10.1016/ j.diamond.2010.02.023.

[102] Cullity BD, Stock SR. Elements of X-ray Diffraction. 3rd ed. Prentice Hall; 2001, 664 p. ISBN-13: 978-0201610918.

[103] Sarma DD, Rao CNR. J. Electron. XPES studies of oxides of second- and third-row transition metals including rare earths. Spectrosc. Relat. Phenom. 1980;20:25-45. DOI: 10.1016/0368-2048(80)85003-1. 
[104] Uwamino Y, Ishizuka T. X-ray photoelectron spectroscopy of rare-earth compounds. J. Electron. Spectrosc. Relat. Phenom. 1984;34:67-78. DOI: 10.1016/0368-2048(84)80060-2.

[105] Lei S, Yunsong H, Yunbo J, Xianming L, Guien Z, Yuheng Z. Study on the crystal and electronic structure of $\mathrm{Y}_{1-\mathrm{x}} \mathrm{Pr}_{\mathrm{x}} \mathrm{Ba}_{2} \mathrm{Cu}_{3} \mathrm{O}_{7-\mathrm{y}}$ ceramics. J. Phys.: Condens. Matter. 1998;10:7015-7024. DOI: 10.1088/0953-8984/10/31/017.

[106] Rovira LG, Delgado JJ, ElAmrani K, Rio E, Chen X, Calvino JJ, Botana FJ. Synthesis of ceria-praseodimia nanotubes with high catalytic activity for $\mathrm{CO}$ oxidation. Catal. Today. 2012;180:167-173. DOI: 10.1016/j.cattod.2011.05.006.

[107] Zivkovic L, Lair V, Lupan O, Ringuede A. Effect of samarium addition and annealing on the properties of electrodeposited ceria thin films. Thin Solid Films. 2011;519:3538-3543. DOI: 10.1016/j.tsf.2011.01.245.

[108] Khalipova OS, Lair V, Ringuede A. Electrochemical synthesis and characterization of gadolinia-doped ceria thin films. Electrochim. Acta. 2014;116:183-187. DOI: 10.1016/ j.electacta.2013.11.022.

[109] Qu D, Xie F, Meng H, Gong L, Zhang W, Chen J, Li G, Liu P, Tong Y. Preparation and characterization of nanocrystalline $\mathrm{CeO}_{2}-\mathrm{Tb}_{2} \mathrm{O}_{3}$ films obtained by electrochemical deposition method. J. Phys. Chem. C. 2010;114:1424-1429. DOI: 10.1021/jp907628g.

[110] Lair V, Zivkovic LS, Lupan O, Ringuede A. Synthesis and characterization of electrodeposited samaria and samaria-doped ceria thin films. Electrochim. Acta. 2011;56:4638-4644. DOI: 10.1016/j.electacta.2011.02.101.

[111] Aghazadeh M, Yousefi T. Preparation of $\mathrm{Gd}_{2} \mathrm{O}_{3}$ nanorods by electrodeposition-heattreatment method. Mater. Lett. 2012;73:176-178. DOI: 10.1016/j.matlet.2012.01.009.

[112] Abed F, Aghazadeh M, Arhami B. Preparation of $\mathrm{Gd}_{2} \mathrm{O}_{3}$ coral-like nanostructures by pulse electrodeposition-heat-treatment method. Mater. Lett. 2013;99:11-13. DOI: 10.1016/j.matlet.2013.02.025.

[113] $\mathrm{Lu} \mathrm{X,} \mathrm{Li} \mathrm{G,} \mathrm{Yu} \mathrm{X,} \mathrm{Tong} \mathrm{Y.} \mathrm{Electrochemical} \mathrm{synthesis} \mathrm{and} \mathrm{characterization} \mathrm{of} \mathrm{TbO}_{2-\mathrm{x}}$ flowerlike nanostructures. Electrochem. Solid-State Lett. 2008;11:K85-K88. DOI: 10.1149/1.2945878. 


\title{
Chapter 5
}

\section{Thermal Barrier Ceramic Coatings - A Review}

\author{
Sumana Ghosh \\ Additional information is available at the end of the chapter \\ http://dx.doi.org/10.5772/61346
}

\begin{abstract}
Thermal barrier coatings (TBCs) provide effective thermal barrier to the components of gas turbine engines by allowing higher operating temperatures and reduced cooling requirements. Plasma spraying, electron-beam physical vapor deposition, and solution precursor plasma spray techniques are generally used to apply the TBCs on the metallic substrates. The present article addresses the TBCs formed by different processing techniques, as well as the possibility of new ceramic, glass-ceramic, and composite materials as TBCs. Promising bond coat materials for a TBC system have been also stated.
\end{abstract}

Keywords: Processing techniques, new TBC materials, engine applications

\section{Introduction}

Thermal barrier coatings (TBCs) enable the engines to operate at higher temperatures without raising the base metal temperatures using cooling systems inside the hot section components and thus, enhance the operating efficiency of the engines [1]. Therefore, continued development of TBCs is essential to increase the inlet gas temperature further for improving the performance of gas turbines. Hence, TBCs with low thermal conductivity, phase stability, and high resistance to sintering have ever increasing demands [2]. Generally, TBCs consist of a ceramic (e.g., yttria partially stabilized zirconia) top coat and a NiCoCrAlY/PtAl-based metallic bond coat. A bond coat is deposited between the metallic substrate and the top coat to protect the metal substrate from oxidation and high temperature corrosion and assist the coupling of the ceramic top coat and the metallic substrate [3]. Two methods are generally used to deposit the ceramic top coat. These are the electron beam physical vapor deposition (EB-PVD) and the atmospheric plasma sprayed (APS) methods. TBCs with EB-PVD top coats generally provide longer thermal cycle lifetimes because of its more strain-tolerant columnar structure than those observed with APS TBCs. However, APS TBCs are widely applied due to lower thermal 
conductivity and lower processing costs [3]. Recently, various processing techniques have been developed to deposit the ceramic coatings.

The objective of this article is to present an overview of the TBC requirement, application of TBCs, degradation mechanisms for TBCs, different processing techniques used for preparation of TBCs, and their thermal properties. Recent developments in TBC material have been also described. The prospect of innovative materials as bond coat in a TBC system has been elucidated.

\section{Main requirements for TBCs}

TBCs must have low weight and low thermal conductivity and they should withstand large stress variations due to heating and cooling, as well as thermal shock. They must be chemically compatible with the underlying metal and the thermally grown oxide (TGO) and should operate in an oxidizing environment. TBCs must provide thermal insulation to the underlying superalloy engine parts. They must have strain compliance in order to minimize the thermal expansion mismatch stresses with the superalloy parts. Additionally, they must reflect much of the radiant heat from the hot gas and thereby, preventing it from reaching the superalloy substrate. Further, TBCs must provide thermal protection to the substrate for prolonged service times and thermal cycles without failure [4].

\section{Applications of TBCs}

TBCs provide thermal insulation to superalloy engine parts such as the combustor, rotating blades, stationary guide vanes, blade outer air-seals, shrouds in the high-pressure section behind the combustor, and afterburners in the tail section of jet engines. Significant gastemperature increase can be achieved by using TBCs in association with innovative air-cooling approaches than that obtained by earlier materials including single-crystal Ni-based superalloys [4].

\section{Degradation mechanisms}

During service, several kinetic processes occur in parallel. Interdiffusion occurs between the bond coat and the superalloy. Consequently, Al diffuses from the bond coat to form the TGO. Microstructural, chemical, and phase changes occur in all the materials including the ceramic top coat. The rates of these thermally activated processes are expected to increase exponentially with temperature. These processes generally lead to degradation and failure of the coating [5]. During service, failure of the TBC system occurs depending upon the following three factors: 


\subsection{Bond coat degradation}

Bond coat plays an important role in promoting the durability of the TBC system. But the role of the bond coat is very complex and poorly understood. In most practical cases, oxidation of the bond coat becomes the predominant coating failure mechanism. During high temperature exposure, NiCrAlY bond coat is oxidized resulting in a TGO layer on the bond coat. After reaching a critical thickness, the TGO becomes prone to spallation, which in turn results to the failure of the TBC system. It is very difficult to establish the exact mechanisms of bond coatinduced TBC failure for various coating types. However, all researchers agree on the significance of spallation or cracking of the TGO for the failure of air plasma-sprayed TBC system. Detailed research is being conducted to find out a solution to the problem regarding bond coat degradation in the TBC system [5]. Nanostructured NiCrAlY bond coat may improve the life expectancy of thermal barrier coatings. Daroonparvar et al. [6] investigated the microstructural evolution of TGO layer on the conventional and nanostructured atmospheric plasma sprayed (APS) NiCrAlY coatings in TBC systems during oxidation. It was observed that the growth of $\mathrm{Ni}(\mathrm{Cr}, \mathrm{Al})_{2} \mathrm{O}_{4}$ (as spinel) and $\mathrm{NiO}$ on the surface of the $\mathrm{Al}_{2} \mathrm{O}_{3}$ layer (as pure TGO) in nano TBC systems was much lower compared to that of normal TBC systems during thermal exposure at $1,150^{\circ} \mathrm{C}$. These two oxides play a detrimental role in causing crack nucleation and growth, reducing the life of the TBC in air. This microstructure optimization of the TGO layer is primarily associated with the formation of a continuous, dense, uniform $\mathrm{Al}_{2} \mathrm{O}_{3}$ layer over the nanostructured NiCrAlY coating [6]. The interfacial failure mechanism of the TBC system was numerically investigated by $\mathrm{Xu}$ et al. [7], considering the role of mixed oxides (MO), which was induced by the discontinuous $\alpha-\mathrm{Al}_{2} \mathrm{O}_{3}$ at the top coat-bond coat interface. High growth rate of $\mathrm{MO}$ will stimulate the initiation and propagation of interface cracks resulting in debonding of the top coat. The high coverage ratio of $\mathrm{MO}$ at the interface will accelerate the propagation of an interface crack. Therefore, the durability and performance of TBCs can be improved by suppressing the formation of $\mathrm{MO}$ [7]. The prediction for spallation of thermal barrier coatings has proven to be an intricate problem [8]. The spallation usually occurs through buckling that is driven by strain energy release within the ceramic top coat. If the delamination interface is at the bond-coat/TGO interface, then spallation occurs within the underlying TGO layer. Prior to spallation, substantial sub-critical damage must develop at one or both of the TGO interfaces. Evans [8] stated that the strain energy within the TGO produced during cooling contributes significantly to this damage development and not that within the top coat. Critical strain energy within the TGO layer is assumed to be a possible pragmatic method of predicting the spallation. Several factors such as phase changes in the bond coat, mechanical constraint imposed by the top coat on the mechanical stability of the bond coat interface, TGO growth on a non-planar interface on stress development, and localized Al depletion in nucleating fast-growing non-protective TGO influence the TBC failure [8].

\subsection{Generation of high residual stress}

Residual stress has a vital effect on the performance of a TBC system. The role of residual stress is very complex and varies with the difference in system configurations. Thermal expansion mismatch between the three layers generates residual stress resulting in degradation of a TBC 
system. Although extensive research has been initiated to study the effect of residual stress on TBC life, there is still ample scope to carry out this study on novel TBC systems involving novel compositions [9]. High residual stresses are induced in the TBC due to thermal expansion mismatch and bond coat (BC) oxidation leading to failure by spalling and delamination. An analysis of the stress distributions in TBC systems, which is a prerequisite for the understanding of failure mechanisms, was performed by Sfar et al. [10] using the finite element method (FEM). Cracks in the interface region were considered in the FE models in order to determine the loading conditions for their propagation and thus, the failure criteria of the TBCs as cracking usually occurs at or near the interfaces between BC/TGO and TBC/TGO depending on the processing mode of the TBC. The modified crack closure integral (MCCI) method combined with an FE analysis led to highly accurate energy release rate values. Moreover, this method enables the determination of mode-dependent energy release rates. TBC failure models could be developed and verified using this tool and appropriate crack propagation criteria [10]. Yang et al. [11] investigated the residual stress evolution in air plasma-sprayed yttria-stabilized zirconia (YSZ) TBCs after thermal treatments at $1,150^{\circ} \mathrm{C}$. The residual stress in the YSZ layer was measured using Raman spectroscopy and the curvature method. Generally, as-deposited YSZ layer was under compressive stress and subsequently after thermal treatment for $30 \mathrm{~h}$ it was under tensile stress partly due to the monoclinic to tetragonal phase transformation in the YSZ layer. Sintering of the YSZ layer occurred with prolonged thermal treatment resulting in the gradual transformation of the residual stress, from tensile to compressive stress. Further, $\beta-\mathrm{NiAl}$ to $\gamma / \gamma^{\prime}-\mathrm{Ni}_{3} \mathrm{Al}$ phase transformation in the bond coat also plays an important role on the stress development in the top coat [11].

\subsection{Top coat degradation}

Top coat degradation is another parameter that governs TBC failure. The ceramic top coat has a tendency to crack due to stress generated from thermal expansion mismatch between the three layers of the TBC system. When the top coat cracks, oxygen easily diffuses to the bond coat leading to the catastrophic failure of the TBC system. Significant research is being carried out to improve the microstructure, mechanical properties, and stability of the ceramic top coat [12]. TBCs are subject to many kinds of degradation, e.g., erosion, foreign object damage (FOD), oxidation, etc., which deteriorate the integrity and mechanical properties of the whole system. Moreover, a new type of damage has been highlighted, i.e., corrosion by molten CalciumMagnesium-Alumino Silicates, known as CMAS with the aim to increase the turbine inlet temperature. Basu et al. studied interactions between YSZ materials synthesized via the solgel process and synthetic CMAS powder via a step-by-step methodology. However, CMAS can cause faster sintering of the ceramic and thereby, leading to loss of strain tolerance in the protective coating. Further, a dissolution/re-precipitation mechanism between YSZ and CMAS resulted in the transformation of the initial tetragonal YSZ into globular particles of monoclinic zirconia. In addition, CMAS infiltrated both EB-PVD and sol-gel YSZ coatings at $1,250^{\circ} \mathrm{C}$ for $1 \mathrm{~h} \mathrm{[12].} \mathrm{Thompson} \mathrm{and} \mathrm{Clyne} \mathrm{[13]} \mathrm{deposited} \mathrm{a} \mathrm{vacuum} \mathrm{plasma} \mathrm{spray} \mathrm{(VPS)} \mathrm{MCrAlY} \mathrm{bond}$ coat and atmospheric plasma spray (APS) zirconia top coat onto a nickel superalloy substrate. They measured the stiffness of detached top coats by cantilever bending and also by nanoindentation technique. Measurements were made on as-sprayed specimens and after various 
heat treatments. Significant changes were detected in the Young's modulus of the heat treated top coat. The rate of sintering was found to be a function of temperature and weather. The coating was detached with the substrate during heat treatment. During high temperature exposure the effects of stiffening of the top coat on the stress development within the TBC system was included by using a well-known, modified numerical model. Sintering of the top coat enhanced debonding at the top coat-bond coat interface resulting in top coat spallation under service conditions [13]. It has been found by Abubakar et al. [14] that the use of low grade fuels in land-based turbines in Saudi Arabia results in hot corrosion due to the diffusion of a molten salt $\left(\mathrm{V}_{2} \mathrm{O}_{5}\right)$ into the top coat of the TBCs. Consequently, volumetric expansion of the coating occurs due to the tetragonal-to-monoclinic transformation of zirconia in the planar reaction zone near the surface of the coating. They used a phase field model for estimating the kinetics of microstructure evolution during the corrosion process at $900^{\circ} \mathrm{C}$ and close agreement between numerical and experimental results was achieved. The transformation-induced stresses were predicted by coupling the phase transformation with elasticity. The result showed that the coating spallation occurred due to very high compressive stress development within the coating cross section [14].

\section{Processing techniques for TBCs}

\subsection{EB-PVD process}

In the EB-PVD process, the source material is heated with an electron beam, vapors are produced, and the evaporated atoms condense on the substrate. Crystal nuclei form on favored sites and grow laterally and in thickness to form individual columns that provide in-plane compliance [15]. A TGO layer often forms on the bond coat in these TBC systems and increases the residual stress. Further, brittleness of the top coat increases with the sintering of the coating. Consequently, the adhesion of the bond coat to the top coat becomes weak at high temperatures. Therefore, the TGO layer is very detrimental for TBC performance [16]. Movchan and Yakovchuk [17] described the design of a new generation of electron beam units for the deposition of the TBCs and cost-effectiveness of the one-step deposition process. They produced variants of graded TBC, which consist of bond coats of $\mathrm{NiAl}$ or $\mathrm{MCrAlY}+\mathrm{NiAl}$ and YSZ-based outer ceramic layer in a one-step cycle by evaporation of a composite ingot. The composition and structure of the bond coats, outer ceramic layer, and the transition barrier zones of the substrate/bond coat and bond coat/outer ceramic layers was controlled in a broad range. They have shown distributions of chemical elements in the coating/substrate system and microstructure after deposition and after heat treatment. Various types of graded TBCs were subjected to thermal cycling tests at $1,150^{\circ} \mathrm{C}$ and their thermal cyclic resistance was monitored [17]. Current numerical approaches in modeling the intrinsic failure of TBC relies largely on the fact that spallation occurs when the accumulating strain energy stored in the coating exceeds a fixed critical value resembling interfacial adhesion. If this is to be entirely correct, one would expect that this critical value of interfacial adhesion varies with different materials, but stays independent of their thermal exposure history. Wu et al. [18] characterized the adhesion of oxide-bond coat interface among five systematically prepared material systems 
using a unique cross-sectional indentation technique. The results re-confirmed that interfacial adhesion is a material-specific property and the adhesion is dynamic, particularly with time and temperature. Certain parameters such as the oxide growth rate, rumpling of the oxidebond coat interface, and phase transformation of bond coat were studied as a function of thermal exposure to understand the dynamics. They clearly indicated that the oxide-bond coat interfacial adhesion depends strongly on the phase distribution of the bond coats and TGO growth rate while having little effect from TGO rumpling and residual stress [18].

\subsection{APS process}

In the APS process, ceramic powders are introduced into a high temperature plasma plume, melted inside the plume, and accelerated towards the substrate wherein molten droplets spread and form splats that are rapidly quenched. In one pass, several successive splats are deposited on the substrate and the coating thickness is increased by means of several passes [19]. A typical fractured cross-section of the plasma sprayed ceramic coating show layers of splats along with interlamellar pores, cracks, and globular pores [15]. Coating compliance is increased by the presence of the cracks and thereby, extending their lifetimes [19]. The resulting coating microstructure is strongly dependent on processing conditions such as spray parameters (e.g., torch current, plasma gas flow rate, carrier gas flow rate, torch traverse velocity, and stand off distance) and feedstock materials (e.g., size, temperature, and velocity). Splat morphologies are changed with the angle of impact of impinging particle [15]. Higher substrate temperatures lead to lower porosity and improved inter-splat contact resulting in enhanced coating properties [20]. During service operations at high temperatures, a TGO layer, mainly an $\mathrm{Al}_{2} \mathrm{O}_{3}$ layer, is developed between the bond coat and the top coat due to the oxidation of the bond coat. This is the most important factor that determines the lifetime of the TBC system. The thickness of this layer increases with increasing operation time. High stresses are present at the bond coat and TGO interface because of oxide layer growth, thermal expansion misfit, and applied loads. As a result, crack initiates and propagates resulting in spallation of the ceramic layer, and finally, system degradation [3]. During thermal exposure at $\geq 1,000^{\circ} \mathrm{C}, \mathrm{Ni}(\mathrm{Cr}$, $\mathrm{Al})_{2} \mathrm{O}_{4}$ (spinels) and $\mathrm{NiO}$ clusters are also formed at the interface of the $\mathrm{Al}_{2} \mathrm{O}_{3}$ layer and the ceramic coating in the TBC system with $\mathrm{MCrAlY}(\mathrm{M}=\mathrm{Ni}, \mathrm{Co})$ bond coat. Cracks were nucleated on these oxide clusters and grew into the ceramic coating leading to premature TBC separation. A heat treatment in a low pressure oxygen environment was found to promote the formation of a uniform, thin protective layer of $\mathrm{Al}_{2} \mathrm{O}_{3}$ at the ceramic-bond coat interface and can reduce these detrimental oxides [21].

Thermo-mechanical properties of TBCs have been studied to improve TBC performance. The Young's modulus of the ceramic top coat is an important factor that affects the thermal stress distribution in TBCs and thus, thermal fatigue behavior. Apparent Young's modulus $\left(\mathrm{E}_{\mathrm{ap}}\right)$ indicates the macro-elastic properties of the coatings. $E_{\text {ap }}$ of the top coat is usually much lower than the value for dense YSZ due to the porous microstructure. The extremely low $\mathrm{E}_{\text {ap }}$ values are also attributed to the weak bonding between the particles because of the extremely high cooling rate. Tang and Schoenung [22] conducted bending tests of the TBC specimens exposed to thermal cycling to determine their $\mathrm{E}_{\mathrm{ap}}$. The $\mathrm{E}_{\mathrm{ap}}$ decreased with increasing thermal cycles, up 
to certain thermal cycles, and then remained unchanged for increased thermal cycles. The breaking of the bonds at the splat boundaries or the formation of new cracks caused by thermal strain is the reason for the decrease in $E_{a p}$ with increasing thermal cycles. Effect of heat treatment on the elastic properties of the separated porous plasma sprayed zirconia TBCs was investigated by D. Basu et al. [23]. The depth-sensitive indentation technique was employed to determine the elastic moduli of the coatings. The characteristic moduli were dependent on the indentation load. The increase of moduli with decreased indentation load was attributed to the presence of small pores and micro-cracks at the subsurface. Heat treatment of the coatings at $1,100^{\circ} \mathrm{C}$ increased the elastic moduli appreciably due to the formation of sintering necks and the elimination of the micro-pores within the lamellae.

Functionally graded $\mathrm{Al}_{2} \mathrm{O}_{3}-\mathrm{ZrO}_{2} \mathrm{TBC}$ was prepared by plasma spraying technique and reported elsewhere [24]. Functionally-graded TBC was found to reduce the oxidation rate of the TBC system. Thus, large residual stress associated with the formation of TGO was minimized. The $\mathrm{Al}_{2} \mathrm{O}_{3}$ interlayer should be very thin to increase the adhesion of the layers. However, low fracture toughness of $\mathrm{Al}_{2} \mathrm{O}_{3}$ might lead to TBC failure. In addition, phase transformation of $\gamma-\mathrm{Al}_{2} \mathrm{O}_{3}$ to $\alpha-\mathrm{Al}_{2} \mathrm{O}_{3}$ could induce additional residual stress, which should be minimized to get reliable TBC systems. Thick thermal barrier coatings (thickness $>1 \mathrm{~mm}$ ) have been developed for increased thermal protection by using the APS method [25]. However, low thermal shock resistance is the problem with the thick coating. Certain degrees of porosity and micro-cracks, preferably segmentation cracks, in TBCs favor to achieve high thermal shock resistance. Chen et al. [26] prepared a new functionally-graded thermal barrier coating based on $\mathrm{LaMgAl}_{11} \mathrm{O}_{19}$ (LaMA)/YSZ by using air plasma spraying technique. The coefficient of thermal expansion (CTE) of the functionally-graded coating varied gradually from the YSZ bottom layer to the LaMA top layer, resulting in the decrease in residual stress level than that of the LaMA/YSZ double ceramic layered TBC system. Excellent thermal cycling lifetime $\left(\sim 11,749\right.$ cycles at $\left.\sim 1,372^{\circ} \mathrm{C}\right)$ of the functionally graded TBC proved the potential of these TBCs for advanced applications [26].

\subsection{Plasma-Enhanced Chemical Vapor Deposition (PECVD) method}

Thick, partially yttria-stabilized zirconia coatings have been deposited by plasma-enhanced chemical vapor deposition (PECVD) method. The morphology and phase composition of the coatings was studied after annealing treatments at the temperature range of 1,100 to $1,400^{\circ} \mathrm{C}$ up to 1,000 h. The as-deposited columnar morphology of the coating was similar to that observed in the coating prepared by the EBPVD technique. The PECVD method is suitable for developing TBCs as it provides thermally stable coating at elevated temperatures [27].

\subsection{Electrostatic Spray-Assisted Vapor Deposition method (ESAVD)}

TBCs, such as 8 wt. $\% \mathrm{Y}_{2} \mathrm{O}_{3}-\mathrm{ZrO}_{2}$ (YSZ), provide effective thermal barrier to the gas turbine blades and are able to protect them, leading to further increase in the operating temperature. A novel and cost-effective electrostatic spray-assisted vapor deposition (ESAVD) technique was utilized to prepare YSZ coatings, which involves spraying atomized zirconium and yttrium alkoxide precursor droplets within an electric field wherein they are subjected to 
decomposition and/or chemical reactions in the vapor phase near the heated substrate. The coatings were characterized by scanning electron microscopy, X-ray diffraction, and Raman spectroscopy. Vyas and Choy [28] produced thick and uniform YSZ films using the ESAVD method. Raman spectroscopy identified carbon to be present in the as-deposited coatings. When heat treatment of the YSZ coating was conducted at $1,000^{\circ} \mathrm{C}$ for $2 \mathrm{~h}$, carbon was removed and the adhesion of the TBC coating to the bond coat improved [28].

\subsection{Solution-Precursor Plasma Spray (SPPS) process}

In this process, an aqueous chemical precursor feedstock is injected into the plasma jet where the droplets undergo a series of physical and chemical reactions and then deposited on the substrate as coating. Microstructural observations of this type of TBC show fine splats and vertical cracks in a porous matrix. TBCs deposited by the optimized solution-precursor plasma spray (SPPS) process exhibit superior durability relative to TBCs formed by the APS and EBPVD processes. Thick and durable TBCs can be deposited by this process. Failure of these TBCs occurs by large scale buckling of the ceramic top coat [29]. The efficiency of TBCs used to protect and insulate metal components in engines increases with the thickness of the TBCs. However, the durability of thick TBCs deposited using conventional deposition methods has not been adequate. Jadhav et al. [30] deposited highly durable, 4 mm-thick $\mathrm{ZrO}_{2}-7 \mathrm{wt} \% \mathrm{Y}_{2} \mathrm{O}_{3}$ (7YSZ) TBCs on bond-coated superalloy substrates using the SPPS method. The average thermal cycling life of the SPPS TBCs was 820 cycles, while most of the conventional air plasma-sprayed coatings of the same composition and thickness deposited on similar bond-coated superalloy substrates were observed to be detached partially from the substrates in the as-sprayed condition. Only the APS TBC failed after 40 thermal cycles. Significantly higher in-plane indentation fracture toughness and high degree of strain tolerance due to the presence of the vertical cracks in the SPPS TBCs led to the dramatic improvement in the thermal cycling life of the SPPS TBCs over APS TBCs [30].

\subsection{Sol-gel process}

Recently, a new, attractive sol-gel route has been successfully developed to synthesize and deposit the TBCs [31-34]. Non-directional deposition and formation of thin or thick coating by dip or spray technique or the combined method of both techniques can be performed by this technique. Sol-gel TBCs show an isotropic microstructure having randomly distributed porosities leading to a good compromise between thermal conductivity and mechanical strength. The degradation of sol-gel TBCs is initiated by the formation of a regular crack network either during the post-deposition thermal treatment required to sinter the deposit or during the first cycles of oxidation. In both cases, this regular surface crack network forms on account of the in-plane stress release due to the sinter-induced shrinkage of the zirconia scale. Subsequently, enlargement and coalescence of the cracks occur under cumulative oxidation cycles promoting the detachment of individual TBC layers and finally, the complete spallation of the TBC. To improve the cyclic oxidation resistance of the TBCs, the sintering efficiency after the TBC deposition needs to be improved or the crack network needs to be stabilized by filling crack grooves by supplementary dip or spray coating passes [33]. In addition, the feasibility 
of consolidating sol-gel TBCs by additional fillings of zirconia into the sinter-induced cracks was investigated by adjusting different process parameters such as the choice of either dipcoating or spray-coating and the modification of the slurry viscosity [34]. Basically, the optimization of both the sintering heat treatment and the procedure for filling the initial crack network promotes a significant improvement of the sol-gel TBC durability during cyclic oxidation at $1,100^{\circ} \mathrm{C}$. Typically, a sol-gel TBC that is properly sintered and adequately reinforced can be cycled for $1 \mathrm{~h}$ at $1,100^{\circ} \mathrm{C}$ one thousand and five hundred times without spalling, which is nearly equivalent to the performance of EB-PVD TBCs [33, 34].

\subsection{Composite sol-gel method}

Composite sol-gel method and pressure filtration microwave sintering (PFMS) technologies were utilized to form novel YSZ $\left(\mathrm{ZrO}_{2}-6 \mathrm{wt} \% \mathrm{Y}_{2} \mathrm{O}_{3}\right)-\left(\mathrm{Al}_{2} \mathrm{O}_{3} / \mathrm{YAG}\right)$ (alumina-yttrium aluminum garnet, $\mathrm{Y}_{3} \mathrm{Al}_{5} \mathrm{O}_{12}$ ) double-layer ceramic coatings. The thin $\mathrm{Al}_{2} \mathrm{O}_{3} / \mathrm{YAG}$ layer showed good adhesion with the substrate. Cyclic oxidation tests were carried out at $1,000^{\circ} \mathrm{C}$, which indicated that double-layer ceramic coatings can prevent the oxidation of alloy and improve the spallation resistance. The $250 \mu \mathrm{m}$ coating had better thermal barrier effect than that of the 150 $\mu \mathrm{m}$ coating during thermal stability tests at $1,000^{\circ} \mathrm{C}$ and $1,100^{\circ} \mathrm{C}$ at different cooling gas rates. These beneficial effects are mainly attributed to the decrease of the rate of TGO scale development and the reduced thermal stresses by means of nano/micro-composite structure. This double-layer coating can be considered as a promising TBC [35].

\subsection{Spark Plasma Sintering (SPS) method}

Pt-modified Ni aluminides and MCrAlY coatings (where $\mathrm{M}=\mathrm{Ni}$ and/or $\mathrm{Co}$ ) are widely used on turbine blades and vanes for protection against oxidation and corrosion and as bond coat in TBC systems. The SPS method can be used by Monceau et al. [36] to develop rapidly new coating compositions and microstructures. This technique allows the formation of multilayered coatings on a superalloy substrate. They have shown the possibility of fabricating MCrAlY overlays with local $\mathrm{Pt}$ and/or Al enrichment and coatings made of $\zeta-\mathrm{PtAl}_{2}, \varepsilon-\mathrm{PtAl}, \alpha$ $\mathrm{AlNiPt}_{2}$, martensitic $\beta$-(Ni,Pt)Al, or Pt-rich $\gamma / \gamma^{\prime}$ phases. Further, they have demonstrated the prospect of achievement of a complete TBC system with a porous and adherent YSZ layer on a $\gamma / \gamma^{\prime}$ low mass bond coating. Additionally, they have discussed the difficulties of fabrication such as $\mathrm{Y}$ segregation, risks of carburization, local overheating, or difficulty to coat complex shape parts [36]. Recently, Boidot et al. [37] prepared complete TBC systems on single crystal $\mathrm{Ni}$-based superalloy substrate in a one-step SPS process. A proto-TGO layer in situ was formed during the fabrication of the TBC systems. Formation of a dense, continuous, slow-growing alumina layer (TGO) between a ceramic top coat and an underlying bond coat during service influences the lifetime of the TBC systems. During thermal treatment at $1,100^{\circ} \mathrm{C}$ in air, the amorphous oxide layer transforms to $\alpha-\mathrm{Al}_{2} \mathrm{O}_{3}$ in the as-deposited samples. Oxidation kinetics during annealing was in good agreement with the protective $\alpha-\mathrm{Al}_{2} \mathrm{O}_{3}$ layer formation [37]. In the last decade, an increasing interest was given to Pt-rich $\gamma-\gamma^{\prime}$ alloys and coatings as they have shown good oxidation and corrosion properties. SPS has been proved to be a fast and efficient tool to fabricate coatings on superalloys including entire TBC systems. Selezneff et al. [38] used the SPS technique to fabricate doped Pt-rich $\gamma-\gamma^{\prime}$ bond coatings on the superalloy 
substrate, whereas the doping elements were reactive elements (e.g., Hf, Y or $\mathrm{Zr}, \mathrm{Si}$ ) and metallic additions of Ag. These samples were then coated with Y-PSZ TBC through the EBPVD method. The performance of such TBC system was compared to a conventional TBC system consisting of a $\beta-(\mathrm{Ni}, \mathrm{Pt}) \mathrm{Al}$-based bond coat. Thermal cycling tests were performed in air and spallation was observed during this test. It was noted that most of the Pt-rich $\gamma-\gamma^{\prime}$ samples showed better adherence of the ceramic coating than that of the $\beta$-samples. Cross-sectional scanning electron microscopy was used to characterize the thickness and the composition of the oxide scales after cyclic oxidation test. It was proved that the doping elements have significant influence on the oxide scale formation, metal/oxide roughness, $\mathrm{Al}$ and Pt content under the oxide scale, and TBC adhesion. It was established that RE-doping can not improve the oxidation kinetics of Pt-rich $\gamma-\gamma^{\prime}$ bond coat. Moreover, $\gamma-\gamma^{\prime}$-based systems were superior to $\beta-(\mathrm{Ni}, \mathrm{Pt}) \mathrm{Al}$ bond coat with respect to ceramic top coat adherence and better oxide scale adherence [38].

\subsection{Low-pressure plasma spraying process}

The TBC must exhibit high thickness $(100-300 \mu \mathrm{m})$, vertical cracks should be present in the TBC in order to be a strain tolerant layer, and it must have high porosity to decrease the thermal conductivity. Rousseau et al. [39] prepared a Y-PSZ layer using low-pressure plasma spraying technique by introducing a solution of nitrate salt into a low-pressure plasma discharge. The characteristics and stability of the Y-PSZ layers were analyzed by several techniques. Optical emission spectroscopy indicated that the oxidant chemistry of the plasma caused oxide formation and the nitrate elimination at low temperature $\left(\mathrm{T}<300^{\circ} \mathrm{C}\right)$. Effects of the several parameters such as power of the plasma discharge, post-treatment and heat treatment on structure, morphology, and stability of the Y-PSZ coatings was studied by X-ray diffraction (XRD), scanning electron microscopy (SEM), water porosimetry, and thermal diffusivity measurement. It was observed that Y-PSZ coating (porosity-50\%) had good thermal barrier property at high temperatures [39].

\subsection{Thermal plasma process}

Superior properties such as high-melting point, high phase stability, low sintering ability, low thermal conductivity, and low oxygen permeability of lanthanum zirconate (LZ) have made it one of the most promising TBC materials for high-temperature applications. However, the production methods used to synthesize lanthanum zirconate are highly time-consuming and the powder is not commercially available. Hence, the thermal plasma process was utilized to synthesize, spheroidize, and spray deposits of lanthanum zirconate material by Ramachandran et al. [40]. They demonstrated the effectiveness of thermal plasma as a major materials processing technique. Suitable characterization techniques were used to study the material modifications after respective plasma processing exposures [40].

\subsection{Cathodic Plasma Electrolytic Deposition (CPED) method}

Inconel alloys (IN738) have a wide range of applications in industries as high temperature structural materials. Further, different surface treatments and coatings have been developed 
for the improvement of the properties of Inconel alloys. Bahadori et al. [41] deposited $\mathrm{Al}_{2} \mathrm{O}_{3}$ ceramic coating on MCrAlY bond-coated Ni-based superalloy using the CPED method in an ethanol solution of $\mathrm{Al}\left(\mathrm{NO}_{3}\right)_{3} \cdot 9 \mathrm{H}_{2} \mathrm{O}(18 \mathrm{~g} / \mathrm{l})$. Several samples were prepared under different deposition conditions and characterized by XRD, SEM, and energy dispersive $\mathrm{X}$-ray spectrometer (EDS). The XRD analysis confirmed the presence of $\mathrm{Al}_{2} \mathrm{O}_{3}$ and $\mathrm{Ni}_{3} \mathrm{Al}$ phases. The results were in good agreement with the composition of the MCrAlY bond coat based on the thermal expansion data. SEM micrograph showed changes in the microstructure of the specimen by varying the $\mathrm{pH}$ of the solution [41].

\subsection{Detonation gun spray technique}

Kim et al. [42] had taken a new approach and fabricated an excellent functionally-graded thermal barrier coating (FGM TBC) by using the detonation gun spray process in association with a newly-proposed shot-control method. FGM TBCs were sprayed in the form of multilayered coatings having a compositional gradient across the thickness. FGM TBCs consisted of a finely mixed microstructure of metals and ceramics with no interfaces between the layers. The gradient ranged from $100 \%$ NiCrAlY metal on the substrate to a $100 \% \mathrm{ZrO}_{2}-8$ wt $\% \mathrm{Y}_{2} \mathrm{O}_{3}$ ceramic for the topcoat. In the FGM layer of the FGM TBCs, the ceramics and metals maintained their individual properties without any phase transformation during the spraying process. They investigated the thermal shock properties of FGM TBCs and compared the data obtained with those for traditional duplex TBCs [42].

\subsection{Plasma laser hybrid spraying technique}

Post-treatments of sprayed coatings and simultaneous spraying processes by a plasma laser hybrid technique have been tried by Chwa and Akira [43] to improve the lifetime of TBC coatings. An analytic technique using a low-viscosity resin with a fluorescent dye under a high vacuum has been investigated for the accurate observation of the microstructure of TBCs prepared by a post-laser treatment and a laser hybrid spraying process. Coatings formed by post-laser treatments and laser hybrid spraying processes showed significantly improved thermal shock resistance compared to as-sprayed coatings as a consequence of water quenching tests. The relationship of the microstructure of TBCs modified by laser treatment and thermal shock resistance has been evaluated by the careful observation of samples. They suggested the optimum process conditions for improving the thermal shock resistance of TBCs [43].

\subsection{Electrophoretic deposition method}

Wang et al. [43] synthesized $\mathrm{Gd}_{2} \mathrm{O}_{3}$ doped 4-YSZ (G-YSZ) ceramic coatings by electrophoretic deposition method followed by vacuum sintering and isothermally annealing at $1,000^{\circ} \mathrm{C}$ for different times. XRD was used to investigate their phase composition. SEM was employed to examine their microstructure, while EDS was used to assess the composition of the composite coatings. The results showed that YSZ coating was composed of tetragonal and monoclinic phases after vacuum sintering at $1,000^{\circ} \mathrm{C}$ for $2 \mathrm{~h}$ under vacuum $\left(<10^{-3} \mathrm{~Pa}\right)$. G-YSZ composite coatings were composed of tetragonal and monoclinic phases and a small amount of 
$\mathrm{Gd}_{2} \mathrm{Zr}_{2} \mathrm{O}_{7}$ phase after vacuum sintering at $1,000^{\circ} \mathrm{C}$ for $2 \mathrm{~h}$ while the content of the monoclinic phase in G-YSZ composite coatings increased with the increase of $\mathrm{Gd}_{2} \mathrm{O}_{3}$ concentration. It was found that after isothermal annealing at $1,000^{\circ} \mathrm{C}$ in air for $100 \mathrm{~h}, \mathrm{G}-\mathrm{YSZ}$ composite coatings were composed of tetragonal $\mathrm{ZrO}_{2}$ phase, monoclinic $\mathrm{ZrO}_{2}$ phase, and cubic phase whereas the $\mathrm{Gd}_{2} \mathrm{Zr}_{2} \mathrm{O}_{7}$ phase disappeared [44].

\section{Relatively new developments of TBC materials}

\subsection{Ceramic top coat}

Vassen et al. [45] investigated three zirconate materials as potential TBC materials. They deposited $150 \mu \mathrm{m}$ Ni-Co-Cr-Al-Y bond coat on IN738 substrate before deposition of zirconate (thickness-240 $\mu \mathrm{m}$ ) as top coat. They indicated that $\mathrm{SrZrO}_{3}$ can not be used as a top coat in TBC systems as the coating showed a phase transition with a volume expansion at $\sim 730^{\circ} \mathrm{C}$ that led to the failure of the samples. $\mathrm{BaZrO}_{3}$ showed relatively poor thermal and chemical stability resulting in early failure in thermal cycling tests. On the other hand, Young's modulus of the pyrochlore $\mathrm{La}_{2} \mathrm{Zr}_{2} \mathrm{O}_{7}$ was found to be lower than that of YSZ. Fracture toughness of this material was comparable to the toughness of plasma-sprayed YSZ coatings. Furthermore, $\mathrm{La}_{2} \mathrm{Zr}_{2} \mathrm{O}_{7}$ has favorable thermal conductivity at elevated temperatures, which is $\sim 20 \%$ lower than that of YSZ. Failure of $\mathrm{La}_{2} \mathrm{Zr}_{2} \mathrm{O}_{7}$ coating was not observed after the first thermal cycling tests at temperatures $>1,200^{\circ} \mathrm{C}$ and the coating showed thermal stability. Thus, $\mathrm{La}_{2} \mathrm{Zr}_{2} \mathrm{O}_{7}$ is a very promising material for advanced TBCs. Moskal et al. [46] studied a double-ceramic-layered (DCL) coating consisting of monolayer coatings $\mathrm{Nd}_{2} \mathrm{Zr}_{2} \mathrm{O}_{7}$ and 8YSZ. The coatings had $~ 300$ $\mu \mathrm{m}$ thickness and porosities of $\sim 5 \%$. The chemical and phase composition analysis of the DCL layers revealed an external $\mathrm{Nd}_{2} \mathrm{Zr}_{2} \mathrm{O}_{7}$ ceramic layer ( 80 $\mu$ m thick), a transitional zone $(\sim 120$ $\mu \mathrm{m}$ thick), and an internal 8YSZ layer (100 $\mu \mathrm{m}$ thick). The $\mathrm{Nd}_{2} \mathrm{Zr}_{2} \mathrm{O}_{7}$ pyrochlore phase was the only one-phase component. The surface topography of both TBC systems was typical for plasma sprayed coatings, and compressive stress state had a value in the range of $\sim 5-10 \mathrm{MPa}$. Measurements of the thermal parameters, i.e., thermal diffusivity indicated better thermal insulation for both new types of layers as compared to the standard 8YSZ layers [46].

$\mathrm{Yb}_{2} \mathrm{O}_{3}(10 \mathrm{~mol} \%)$ and $\mathrm{Gd}_{2} \mathrm{O}_{3}(20 \mathrm{~mol} \%)$ doped $\mathrm{SrZrO}_{3}$ was investigated by Ma et al. [47] as a material for TBC applications. Measurement of thermal expansion coefficients (TECs) of sintered bulk $\mathrm{Sr}\left(\mathrm{Zr}_{0.9} \mathrm{Yb}_{0.1}\right) \mathrm{O}_{2.95}$ and $\mathrm{Sr}\left(\mathrm{Zr}_{0.8} \mathrm{Gd}_{0.2}\right) \mathrm{O}_{2.9}$ displayed a positive influence on phase transformations of $\mathrm{SrZrO}_{3}$ by doping $\mathrm{Yb}_{2} \mathrm{O}_{3}$ or $\mathrm{Gd}_{2} \mathrm{O}_{3}$. It was observed that both dopants can reduce the thermal conductivity of $\mathrm{SrZrO}_{3}$. Dense $\mathrm{Sr}\left(\mathrm{Zr}_{0.9} \mathrm{Yb}_{0.1}\right) \mathrm{O}_{2.95}$ and $\operatorname{Sr}\left(\mathrm{Zr}_{0.8} \mathrm{Gd}_{0.2}\right) \mathrm{O}_{2.9}$ had lower hardness, Young's modulus, and comparable fracture toughness as compared to YSZ. At operating temperatures $<1,300^{\circ} \mathrm{C}$, the cycling lifetimes of plasma sprayed $\operatorname{Sr}\left(\mathrm{Zr}_{0.9} \mathrm{Yb}_{0.1}\right) \mathrm{O}_{2.95} /$ $\mathrm{YSZ}$ and $\mathrm{Sr}\left(\mathrm{Zr}_{0.8} \mathrm{Gd}_{0.2}\right) \mathrm{O}_{2.9} / \mathrm{YSZ}$ double DLC were comparable to that of $\mathrm{YSZ}$ coating. However, at operating temperatures $>1,300^{\circ} \mathrm{C}$, the cycling lifetime of $\operatorname{Sr}\left(\mathrm{Zr}_{0.9} \mathrm{Yb}_{0.1}\right) \mathrm{O}_{2.95} / \mathrm{YSZ}$ DLC was about $25 \%$ longer than YSZ coating, while that was shorter for $\operatorname{Sr}\left(\mathrm{Zr}_{0.8} \mathrm{Gd}_{0.2}\right) \mathrm{O}_{2.9} / \mathrm{YSZ} \mathrm{DLC}$ compared to YSZ coating [47]. The rare earth zirconates $\left(\mathrm{M}_{2} \mathrm{Zr}_{2} \mathrm{O}_{7}, \mathrm{M}=\mathrm{La} \rightarrow \mathrm{Gd}\right)$ have a low intrinsic thermal conductivity and high temperature phase stability, which make them 
attractive candidates for TBC applications. Electron-beam evaporation, directed-vapor deposition (EB-DVD) technique was used by Zhao et al. [48] to investigate the synthesis of $\mathrm{Sm}_{2} \mathrm{Zr}_{2} \mathrm{O}_{7}(\mathrm{SZO})$ coatings and to explore the relationships between the deposition conditions and the coating composition, pore morphology, structure, texture, and thermal conductivity. The coatings exhibited significant fluctuations in composition because of the vapor pressure differences of the constituent oxides. It was noticed that the coatings had a metastable fluorite structure due to kinetic limitations that hindered the formation of the equilibrium pyrochlore structure. The morphology of growth of EB-DVD SZO was identical to those of EB-DVD 7YSZ and EB-PVD Gd $\mathrm{Zr}_{2} \mathrm{O}_{7}$. The conductivity values of the as-deposited SZO coatings were nearly one-half of their DVD 7YSZ counterparts. This may be ascribed to their lower intrinsic conductivity [48].

Alumina-based ceramic coating with a composition of $\mathrm{La}_{2} \mathrm{O}_{3}, \mathrm{Al}_{2} \mathrm{O}_{3}$ and $\mathrm{MgO}\left(\mathrm{MMeAl}_{11} \mathrm{O}_{19}\right.$, $\mathrm{M}-\mathrm{La}, \mathrm{Nd}$; Me-alkaline earth elements, magnetoplumbite structure) has been developed as TBC by the researchers [49, 50]. Lanthanum hexaaluminate (LHA) coating has long-term structural and thermo-chemical stability of up to $1673 \mathrm{~K}$ and significantly lower sintering rate than zirconia-based TBCs. The low thermal conductivity of LHA is ascribed to the random arrangement of LHA platelets leading to micro-porous coating. The insulating properties of the material are related to its crystallographic feature. To meet the demand of advanced turbine engines, $\mathrm{LaTi}_{2} \mathrm{Al}_{9} \mathrm{O}_{19}$ (LTA) was proposed and investigated as a novel TBC material for application at $1,300^{\circ} \mathrm{C}$ by Xie et al. [51]. LTA showed excellent phase stability up to $1,600^{\circ} \mathrm{C}$. The thermal conductivities for LTA coating were in a range of $1.0-1.3 \mathrm{~W} \mathrm{~m}^{-1} \mathrm{~K}^{-1}\left(300-1,500^{\circ} \mathrm{C}\right)$. The values of thermal expansion coefficients increased from 8.0 to $11.2 \times 10^{-6} \mathrm{~K}^{-1}\left(200-1,400^{\circ} \mathrm{C}\right)$, which were comparable to those of YSZ. Both the LTA and YSZ coatings had a microhardness value of about $7 \mathrm{GPa}$, whereas the fracture toughness value was relatively lower than that of YSZ. However, the double-ceramic LTA/YSZ layer design balanced the lower fracture toughness. The LTA/YSZ TBC showed thermal cycling life of $\sim 700 \mathrm{~h}$ at $1,300^{\circ} \mathrm{C}$ [51]. Lathanum phosphate $\left(\mathrm{LaPO}_{4}\right)$ is considered as a potential TBC material on Ni-based superalloys because of its high temperature stability, high thermal expansion, and low thermal conductivity [52]. Further, lanthanum phosphate is expected to have good corrosion resistance in environments containing sulfur and vanadium salts. However, plasma spraying can not be easily used to make this type of coating. Detailed research is needed to establish the suitability of $\mathrm{LaPO}_{4}$ as TBC. Rare earth oxide coatings $\left(\mathrm{La}_{2} \mathrm{O}_{3}, \mathrm{CeO}_{2}, \mathrm{Pr}_{2} \mathrm{O}_{3}\right.$, and $\mathrm{Nb}_{2} \mathrm{O}_{5}$ as main phases) can be used as TBCs as they have lower thermal diffusivity and higher thermal expansion coefficient than $\mathrm{ZrO}_{2}$ [53]. Most of the rare earth oxides are polymorphic at elevated temperatures [54] and their phase instability affects the thermal shock resistance of these coatings to a certain extent. When zircon is used as a TBC material, it dissociates during plasma spraying and consequently coatings are composed of a mixture of crystalline $\mathrm{ZrO}_{2}$ and amorphous $\mathrm{SiO}_{2}$. For diesel engines, the decomposed $\mathrm{SiO}_{2}$ in the coating may cause problems due to the evaporation of $\mathrm{SiO}$ and $\mathrm{Si}(\mathrm{OH})_{2}$ [55]. The thermal barrier effect is supposed to be due to the $\mathrm{ZrO}_{2}$ phase in the coating [56]. However, few other silicates such as garnet almandine $\left[\mathrm{Fe}_{3} \mathrm{Al}_{2}\left(\mathrm{SiO}_{4}\right)_{3}\right]$, garnet pyrope $\left[\mathrm{Mg}_{3} \mathrm{Al}_{2}\left(\mathrm{SiO}_{4}\right)_{3}\right]$, garnet andradite-grossular $\left[\mathrm{Ca}_{3} \mathrm{Al}_{2}\left(\mathrm{SiO}_{4}\right)_{3}\right]$, and basalt (glass) have potential

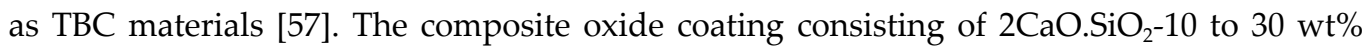
$\mathrm{CaO} . \mathrm{ZrO}_{2}$ shows excellent resistance to thermal shock and hot corrosion [58]. 
Researchers have conceived garnets $\left[\mathrm{Y}_{3} \mathrm{Al}_{\mathrm{x}} \mathrm{Fe}_{5-\mathrm{x}} \mathrm{O}_{12}(\mathrm{x}=0,0.7,1.4\right.$, and 5)] as TBC materials [59]. YAG $\left(\mathrm{Y}_{3} \mathrm{Al}_{5} \mathrm{O}_{12}\right)$ has superior high-temperature mechanical properties, low thermal conductivity, excellent phase/thermal stability up to the melting point and significantly lower oxygen diffusivity than those of zirconia. However, the major drawback of this material is its low melting point and relatively low thermal expansion coefficient [59]. Guo et al. [60] produced $\mathrm{BaLa}_{2} \mathrm{Ti}_{3} \mathrm{O}_{10}$ (BLT) by solid-state reaction of $\mathrm{BaCO}_{3}, \mathrm{TiO}_{2}$, and $\mathrm{La}_{2} \mathrm{O}_{3}$ for $48 \mathrm{~h}$ at $1,500^{\circ} \mathrm{C}$. BLT showed phase stability between room temperature and $1,400^{\circ} \mathrm{C}$. BLT showed a linearly increasing thermal expansion coefficient with increasing temperature up to $1,200^{\circ} \mathrm{C}$ and the coefficients of thermal expansion (CTEs) were in the range of $1 \times 10^{-5}-12.5 \times 10^{-6} \mathrm{~K}^{-1}$, comparable to those of 7YSZ. BLT coatings with stoichiometric composition were developed by APS technique. The coating contained segmentation cracks and had a porosity of $\sim 13 \%$. The microhardness for the BLT coating was in the range of 3.9-4.5 GPa. The thermal conductivity at $1,200^{\circ} \mathrm{C}$ was about $0.7 \mathrm{~W} / \mathrm{mK}$ and thereby, revealing it as a promising material in improving the thermal insulation property of TBC. Thermal cycling results showed that the BLT TBC had a lifetime of more than 1,100 cycles of about $200 \mathrm{~h}$ at $1,100^{\circ} \mathrm{C}$. The failure of the coating occurred by cracking at the TGO layer due to severe bond coat oxidation. Based on the experimental results BLT can be considered as a promising material for TBC applications [60]. Xu et al. [61] deposited DCL TBCs consisting of $\mathrm{La}_{2}\left(\mathrm{Zr}_{0.7} \mathrm{Ce}_{0.3}\right)_{2} \mathrm{O}_{7}$ (LZ7C3) and YSZ by EB-PVD method. They showed that the DCL coating had a much longer lifetime than the single layer LZ7C3 coating and much longer than that of the single layer YSZ coating. Similar thermal expansion behaviors of YSZ interlayer with LZ7C3 coating and TGO layer, high sintering-resistance of LZ7C3 coating and unique columnar growth within DCL coating led to the extension of thermal cycling life of DCL coating. The failure of DCL coating occurred due to the reductionoxidation of cerium oxide, the crack initiation, propagation and extension, the abnormal oxidation of bond coat, the degradation of $t^{\prime}$-phase in YSZ coating, and the outward diffusion of $\mathrm{Cr}$ alloying element into LZ7C3 coating [61]. $\mathrm{Dy}_{2} \mathrm{O}_{3}-\mathrm{Y}_{2} \mathrm{O}_{3}$ co-doped $\mathrm{ZrO}_{2}$ exhibits lower thermal conductivity and higher coefficient of thermal expansion. Thus, it is a promising ceramic thermal barrier coating material for aero-gas turbines and high temperature applications in metallurgical and chemical industry. $Q u$ et al. [62] prepared $\mathrm{Dy}_{2} \mathrm{O}_{3}-\mathrm{Y}_{2} \mathrm{O}_{3}$ co-doped $\mathrm{ZrO}_{2}$ ceramics using solid state reaction methods. $\mathrm{Dy}_{0.06} \mathrm{Y}_{0.072} \mathrm{Zr}_{0.868} \mathrm{O}_{1.934}$ exhibited a lower thermal conductivity and higher coefficient of thermal expansion as compared with standard $8 \mathrm{wt} \% \mathrm{Y}_{2} \mathrm{O}_{3}$-stabilized $\mathrm{ZrO}_{2}$ used in conventional TBCs. The compatibility between the TGO $\left(\mathrm{Al}_{2} \mathrm{O}_{3}\right)$ and the new compositions is complicated to ensure the durability of TBCs. $\mathrm{Dy}_{0.06} \mathrm{Y}_{0.072} \mathrm{Zr}_{0.868} \mathrm{O}_{1.934}$ was found to be compatible with $\mathrm{Al}_{2} \mathrm{O}_{3}$ whereas $\mathrm{YAlO}_{3}$ and $\mathrm{Dy}_{3} \mathrm{Al}_{2}\left(\mathrm{AlO}_{4}\right)_{3}$ were formed when $\mathrm{Dy}_{0.25} \mathrm{Y}_{0.25} \mathrm{Zr}_{0.5} \mathrm{O}_{1.75}$ and $\mathrm{Al}_{2} \mathrm{O}_{3}$ were mixed and sintered [62].

New alternative TBC materials to YSZ for applications above 1,473 K are being explored by researchers. Zhou et al. [63] prepared $\mathrm{Y}_{4} \mathrm{Al}_{2} \mathrm{O}_{9}(\mathrm{YAM})$ ceramics by solid state reaction at 1,873 $\mathrm{K}$ for $12 \mathrm{~h}$. They investigated the phase stability, thermophysical properties, and sinteringresistance behavior of the material. XRD results revealed single monoclinic phase YAM. Even no new phase appeared after long-term annealing. The thermal conductivities of YAM ceramic decreased gradually with the increase of temperature ranges from room temperature to 1,273 $\mathrm{K}$. The minimum value obtained was $\sim 1.81 \mathrm{~W} \mathrm{~m}^{-1} \mathrm{~K}^{-1}$, which is lower than that of YSZ. YAM showed moderate thermal expansion coefficient, i.e., $8.91 \times 10^{-6} \mathrm{~K}^{-1}$ in the temperature range 
of 300-1,473 K. In comparison to YSZ, YAM has lower density and higher sintering-resistance ability, which is very favorable for TBC applications. The results indicated that YAM is a promising ceramic material candidate for application in the TBC system [63]. YSZ is usually used as ceramic top coat for gas turbine blades and vanes. The accelerated phase transformation and the intensified sintering of the YSZ top coat at temperatures between $1,200^{\circ} \mathrm{C}$ and $1,300^{\circ} \mathrm{C}$ lead to microstructural changes resulting in higher thermal stress generation and lifetime reduction. Additionally, thermal conductivity $(\lambda)$ of the top coat increases. Therefore, lanthanum zirconate $\left(\mathrm{La}_{2} \mathrm{Zr}_{2} \mathrm{O}_{7}\right)$ and gadolinium zirconate $\left(\mathrm{Gd}_{2} \mathrm{Zr}_{2} \mathrm{O}_{7}\right)$ is being suggested by researchers as a top coat because of their high phase stability up to their melting points and the lower thermal conductivity compared to YSZ. Bobzin et al. [64] deposited single-(SCL) and DCL top coats consisting of $7 \mathrm{wt} \%$ yttria-stabilized zirconia (7YSZ), $\mathrm{La}_{2} \mathrm{Zr}_{2} \mathrm{O}_{7}$, or $\mathrm{Gd}_{2} \mathrm{Zr}_{2} \mathrm{O}_{7}$ using the EB-PVD method. They wanted to investigate the temperature-dependent phase behavior and change of thermal conductivity of SCL and DCL top coats, as well as the influence of different top coat materials and architectures on the growth of the TGO. Morphology and coating thickness were determined using SEM. The SCL and DCL systems showed a columnar microstructure with a coating thickness of about $150 \mu \mathrm{m}$. The thermal conductivity of SCL and DCL systems was measured between $400^{\circ} \mathrm{C}$ and $1,300^{\circ} \mathrm{C}$ by laser flash technique. The XRD of SCL and DCL systems were carried out after isothermal oxidation at $1,300^{\circ} \mathrm{C}$. Finally, the TGO phase was identified by XRD and EDS analysis. Correlation between morphology, architecture, coating material, and TGO behavior can give details of oxygen diffusion processes [64].

Investigation of the $\mathrm{ZrO}_{2}-\mathrm{YO}_{1.5}-\mathrm{TaO}_{2.5}$ system reveals several promising aspects for TBC applications. Unique presence of a stable, non-transformable, tetragonal region in this ternary oxide system allows for phase stability to elevated temperatures, e.g.,1,500 ${ }^{\circ} \mathrm{C}$. Yttria- and tantala-containing compositions exhibited significantly high resistance to vanadate corrosion compared to 7YSZ. Further, yttria- and tantala-stabilized zirconia compositions within the non-transformable tetragonal phase field exhibited toughness values comparable or higher than those of 7YSZ and thereby, increasing their stability as TBCs. Pitek and Levi discussed about these promising attributes based on recent experimental works [65]. Liu et al. [66] prepared pyrochlore-type $\left(\mathrm{La}_{0.8} \mathrm{Eu}_{0.2}\right)_{2} \mathrm{Zr}_{2} \mathrm{O}_{7}$ feedstocks by spray drying and used that to produce ceramic thermal barrier coatings. DCL TBCs with a first layer of $8 \mathrm{wt} \% \mathrm{YSZ}$ and a top layer of $\left(\mathrm{La}_{0.8} \mathrm{Eu}_{0.2}\right)_{2} \mathrm{Zr}_{2} \mathrm{O}_{7}$ were deposited by plasma spraying. Plasma-sprayed $\left(\mathrm{La}_{0.8} \mathrm{Eu}_{0.2}\right)_{2} \mathrm{Zr}_{2} \mathrm{O}_{7}$ coatings were composed of a defect fluorite-type phase and a $t-\mathrm{ZrO}_{2}$ phase. However, after thermal shock tests at $1,250^{\circ} \mathrm{C}$ for 32 cycles, $\left(\mathrm{La}_{0.8} \mathrm{Eu}_{0.2}\right)_{2} \mathrm{Zr}_{2} \mathrm{O}_{7}$ coatings exhibited a pyrochlore-type structure. The thermal shock failure of DCL $\left(\mathrm{La}_{0.8} \mathrm{Eu}_{0.2}\right)_{2} \mathrm{Zr}_{2} \mathrm{O}_{7} / \mathrm{YSZ}$ coatings mainly occurred at the interface between the YSZ and $\left(\mathrm{La}_{0.8} \mathrm{Eu}_{0.2}\right)_{2} \mathrm{Zr}_{2} \mathrm{O}_{7}$ layers. However, the TGO layer from the bond coat had no effect on the thermal shock failure [66]. Two kinds of rare earth zirconate $\left(\mathrm{Sm}_{0.5} \mathrm{La}_{0.5}\right)_{2} \mathrm{Zr}_{2} \mathrm{O}_{7}$ and $\left(\mathrm{Sm}_{0.5} \mathrm{La}_{0.5}\right)_{2}\left(\mathrm{Zr}_{0.8} \mathrm{Ce}_{0.2}\right)_{2} \mathrm{O}_{7}$ ceramics were prepared by Hong-song et al. [67] through solid state reaction at $1,600^{\circ} \mathrm{C}$ for $10 \mathrm{~h}$. They investigated the phase compositions, microstructures, and thermophysical properties of these materials. XRD results confirmed the formation of single phase $\left(\mathrm{Sm}_{0.5} \mathrm{La}_{0.5}\right)_{2} \mathrm{Zr}_{2} \mathrm{O}_{7}$ and $\left(\mathrm{Sm}_{0.5} \mathrm{La}_{0.5}\right)_{2}\left(\mathrm{Zr}_{0.8} \mathrm{Ce}_{0.2}\right)_{2} \mathrm{O}_{7}$ with pyrochlore structure. Dense microstructures of these materials and absence of other phases among the particles were revealed by SEM studies. The TEC of the ceramic increased with the increasing temperature, while the thermal conductivity 
decreased. TECs of $\left(\mathrm{Sm}_{0.5} \mathrm{La}_{0.5}\right)_{2} \mathrm{Zr}_{2} \mathrm{O}_{7}$ and $\left(\mathrm{Sm}_{0.5} \mathrm{La}_{0.5}\right)_{2}\left(\mathrm{Zr}_{0.8} \mathrm{Ce}_{0.2}\right)_{2} \mathrm{O}_{7}$ were lower than that of $\mathrm{Sm}_{2} \mathrm{Zr}_{2} \mathrm{O}_{7}$. The $\mathrm{CeO}_{2}$ addition resulted in the higher TEC of $\left(\mathrm{Sm}_{0.5} \mathrm{La}_{0.5}\right)_{2}\left(\mathrm{Zr}_{0.8} \mathrm{Ce}_{0.2}\right)_{2} \mathrm{O}_{7}$ than those of $8 \mathrm{YSZ}$ and $\left(\mathrm{Sm}_{0.5} \mathrm{La}_{0.5}\right)_{2} \mathrm{Zr}_{2} \mathrm{O}_{7}$. Although the TEC of $\left(\mathrm{Sm}_{0.5} \mathrm{La}_{0.5}\right)_{2} \mathrm{Zr}_{2} \mathrm{O}_{7}$ was lower than that of $8 \mathrm{YSZ}$, still it can serve as a TBC. Doping with $\mathrm{La}_{2} \mathrm{O}_{3}$ or $\mathrm{CeO}_{2}$ led to phonon scattering resulting in much lower thermal conductivities of $\left(\mathrm{Sm}_{0.5} \mathrm{La}_{0.5}\right)_{2} \mathrm{Zr}_{2} \mathrm{O}_{7}$ and $\left(\mathrm{Sm}_{0.5} \mathrm{La}_{0.5}\right)_{2}\left(\mathrm{Zr}_{0.8} \mathrm{Ce}_{0.2}\right)_{2} \mathrm{O}_{7}$ than that of $\mathrm{Sm}_{2} \mathrm{Zr}_{2} \mathrm{O}_{7}$. In comparison to the thermal conductivity of $\left(\mathrm{Sm}_{0.5} \mathrm{La}_{0.5}\right)_{2} \mathrm{Zr}_{2} \mathrm{O}_{7}$ the thermal conductivity of $\left(\mathrm{Sm}_{0.5} \mathrm{La}_{0.5}\right)_{2}\left(\mathrm{Zr}_{0.8} \mathrm{Ce}_{0.2}\right)_{2} \mathrm{O}_{7}$ was relatively lower. The experimental results showed that $\left(\mathrm{Sm}_{0.5} \mathrm{La}_{0.5}\right)_{2} \mathrm{Zr}_{2} \mathrm{O}_{7}$ and $\left(\mathrm{Sm}_{0.5} \mathrm{La}_{0.5}\right)_{2}\left(\mathrm{Zr}_{0.8} \mathrm{Ce}_{0.2}\right)_{2} \mathrm{O}_{7}$ are novel candidate materials for TBCs in near future [67].

\subsection{Composite top coat}

A new TBC was developed by Dietrich et al. [68] from a powder mixture of metal and normal glass by using vacuum plasma spraying technique. This type of TBC material had a similar thermal expansion coefficient of a metal substrate. The thermal conductivity of this composite top coat was about two times greater than that of YSZ. Long thermal cycling life of the metalglass TBC was attributed to high thermal expansion coefficient, good adherence to the bond coat, and absence of open porosity and thereby, preventing the bond coat oxidation from corrosive gases [68]. Majumdar and Jana [69] studied the properties of a TBC prepared from $3 \mathrm{wt} \%$ YSZ dispersed in a high temperature resistant alumino-borosilicate glassy matrix. The YSZ-glass composite coating was applied on stainless steel substrate by a simple and costeffective enameling technique. The thermal gradient of $800 \mu \mathrm{m}$ thick TBC was found to be 175$180^{\circ} \mathrm{C}$ after $30 \mathrm{~min}$ exposure at $1,000^{\circ} \mathrm{C}$. Significant improvement of the gradient to $650-675^{\circ} \mathrm{C}$ was observed after long exposure of the coated surface at $1,000^{\circ} \mathrm{C}$ when compressed air cooling was utilized [69]. The spallation of ceramic coating from the bond coat is an important problem for TBC systems. Basically, the spallation is caused by the oxidation and hot corrosion at the interface of the ceramic layer and bond coat. Keyvani et al. [70] investigated the oxidation and hot corrosion behavior of plasma sprayed nanostructured $\mathrm{Al}_{2} \mathrm{O}_{3} / \mathrm{YSZ}$ composite TBC coatings on Ni-based (IN-738LC) superalloy substrate and compared it with the conventional YSZ. The coatings were deposited by plasma spray method. High temperature oxidation test at $1,100^{\circ} \mathrm{C}$ and hot corrosion test at $1,050^{\circ} \mathrm{C}$ using $\mathrm{Na}_{2} \mathrm{SO}_{4}$ and $\mathrm{V}_{2} \mathrm{O}_{5}$ molten salts were conducted on the coatings. The experimental data demonstrated that the nanostructured $\mathrm{Al}_{2} \mathrm{O}_{3} / \mathrm{YSZ}$ composite coating had higher oxidation and hot corrosion resistance than those of the conventional YSZ coating. The microstructural analysis indicated that the growth of TGO was much less for this nanostructured $\mathrm{Al}_{2} \mathrm{O}_{3} / \mathrm{YSZ}$ composite coating. Further, the composite top coating prevented infiltration of both oxygen and aggressive molten salt [70]. Novel YSZ (6 wt \% yttria partially stabilized zirconia)- $\left(\mathrm{Al}_{2} \mathrm{O}_{3} / \mathrm{YAG}\right.$ ) (alumina-yttrium aluminum garnet, $\left.\mathrm{Y}_{3} \mathrm{Al}_{5} \mathrm{O}_{12}\right)$ DLC coatings were formed by using the composite sol-gel and pressure filtration microwave sintering (PFMS) technologies by Ren et al. [71]. The microstructural observations showed that microsized YAG particles were embedded in nano-sized $\alpha-\mathrm{Al}_{2} \mathrm{O}_{3}$ film. A thin $\mathrm{Al}_{2} \mathrm{O}_{3} / Y A G$ layer had good adherence with the substrate and the thick YSZ top layer. Cyclic oxidation tests at $1,000^{\circ} \mathrm{C}$ indicated that they can resist oxidation of alloy and improve the spallation resistance. The thermal insulation capability tests at $1,000^{\circ} \mathrm{C}$ and $1,100^{\circ} \mathrm{C}$ indicated that $250 \mu \mathrm{m}$ coating had better thermal barrier effect than that of the $150 \mu \mathrm{m}$ coating at different cooling gas rates. The 
decrease in oxidation rate for forming a TGO scale using the sealing effect of $\alpha-\mathrm{Al}_{2} \mathrm{O}_{3}$ and the reduced thermal stresses by means of nano/micro composite structure led to these beneficial effects. This double-layer coating can be considered as a promising TBC [71].

\subsection{Glass-ceramics as TBC materials}

$\mathrm{MgO}-\mathrm{Al}_{2} \mathrm{O}_{3}-\mathrm{TiO}_{2}$ and $\mathrm{ZnO}-\mathrm{Al}_{2} \mathrm{O}_{3}-\mathrm{SiO}_{2}$ based glass-ceramic coatings have been developed as TBCs for gas turbine engine components by Datta and Das [72,73]. These coatings were formed on nimonic alloy substrates using the vitreous enameling technique. $\mathrm{MgO}-\mathrm{Al}_{2} \mathrm{O}_{3}-\mathrm{TiO}_{2}$-based glass coating was applied on nimonic alloy substrate by spraying the glass slurry, drying, and then firing at about $1,160^{\circ} \mathrm{C}$ for $5-6 \mathrm{~min}$. Further, the glass coating was heat treated for $1 \mathrm{~h}$ at $880^{\circ} \mathrm{C}$ followed by $1 \mathrm{~h}$ at $1,020^{\circ} \mathrm{C}$ to develop crystals such as magnesium aluminum titanate as a major phase along with magnesium silicate and aluminum titanate as minor phases in the glass matrix. The thermal shock resistance of the glass-ceramic coating was found to be more than 10 cycles when repeatedly heated to $750^{\circ} \mathrm{C}$ and immediately quenched in cold water. No chipping or spalling defect was observed. Slight weight gain was noted during the thermal endurance test at $1,000^{\circ} \mathrm{C}$ for $100 \mathrm{~h}$. However, the operating temperature of this coating is limited to $750^{\circ} \mathrm{C}$. Glass-ceramic coating based on $\mathrm{ZnO}-\mathrm{Al}_{2} \mathrm{O}_{3}-\mathrm{SiO}_{2}$ systems can operate at high working temperatures of up to $1,000^{\circ} \mathrm{C}$. This type of glass coating was applied on a nimonic alloy through the spraying of a suitable glass slip, drying, and firing at $1,200^{\circ} \mathrm{C}$ for $5-6 \mathrm{~min}$. The glass coating was subsequently heat treated at $1,000^{\circ} \mathrm{C}$ for $1 \mathrm{~h}$ to develop gahnite, willemite, and cristobalite crystalline phases. Thermal shock at $1,000^{\circ} \mathrm{C}$ for 10 cycles showed no chipping. During the thermal endurance test at $1,000^{\circ} \mathrm{C}$ for $100 \mathrm{~h}$, negligible weight gain was observed. Figure 1(a) shows the oxidative weight gain of the bare substrate and $\mathrm{MgO}-$ $\mathrm{Al}_{2} \mathrm{O}_{3}-\mathrm{TiO}_{2}$-based glass-ceramic coated substrate during the oxidation test at $1,000^{\circ} \mathrm{C}$ for 100 h. Typical SEM image of $\mathrm{MgO}-\mathrm{Al}_{2} \mathrm{O}_{3}-\mathrm{TiO}_{2}$-based glass-ceramic coating is shown in Figure 2(b).
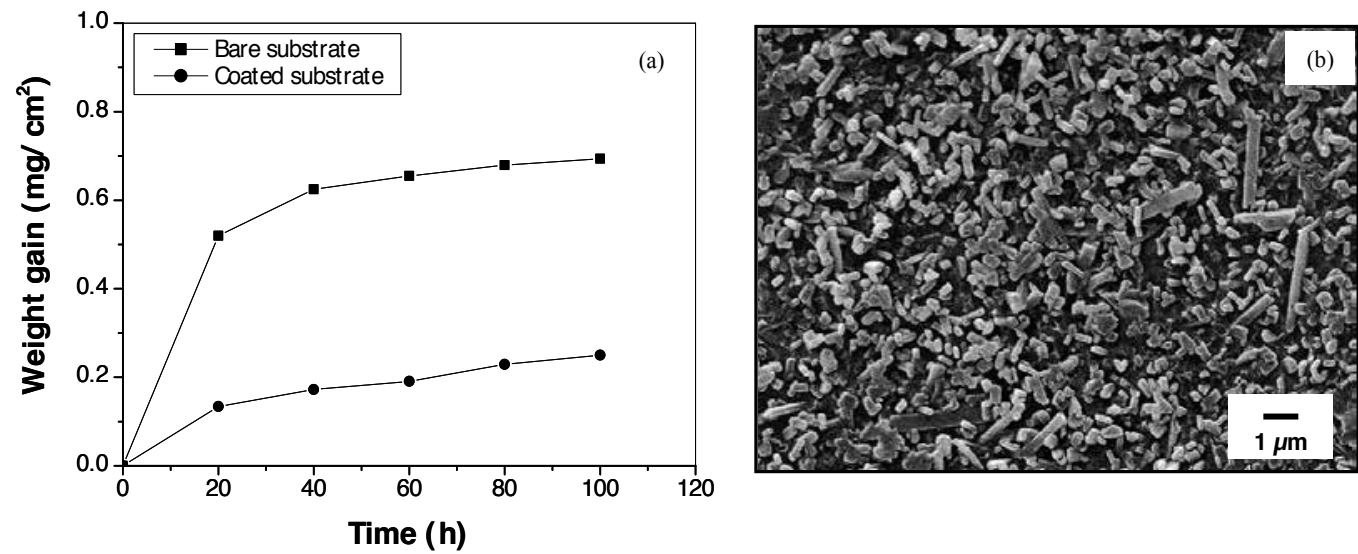

Figure 1. (a) Oxidative weight gain of $\mathrm{MgO}-\mathrm{Al}_{2} \mathrm{O}_{3}-\mathrm{TiO}_{2}$-based glass-ceramic coated substrate at $1,000^{\circ} \mathrm{C}$ for $100 \mathrm{~h}$ and (b) typical SEM microstructure of the corresponding coating. 


\section{Promising bond coat materials for TBC systems}

TBCs with ceramic top coat and MCrAlY (M=Ni, Co) bond coat are generally applied on gas turbine engine components to protect them from high temperature exposure [3]. The bond coat provides thermo-elastic relaxation to accommodate the high stresses generated in the TBC system. The chemistry and microstructure of bond coat affects the structure and morphology of the TGO [3]. The oxidation of bond coat needs to be restricted to improve the performance of the TBC system. Glass-ceramics may be used as bond coats because of several reasons. As this bond coat is basically oxide-based, failure of the TBC system from bond coat oxidation may be avoided. Further, high stress may be accommodated by the viscous flow of the glassceramics, which may increase the stability of the TBC system during thermal cycling at high operating temperatures. In addition, this TBC system may protect the metallic component from oxidation and creep failure more effectively because of the lower thermal conductivity of glassceramics compared to metals. Detailed studies on the TBC system consisting of $8 \mathrm{wt} \% \mathrm{YSZ}$ $(\sim 400 \mu \mathrm{m})$ top coat, $\mathrm{BaO}-\mathrm{MgO}-\mathrm{SiO}_{2}$-based glass-ceramic bond coat $(\sim 100 \mu \mathrm{m})$ and nimonic alloy (AE 435) substrate have been carried out by Das [74]. The glass-ceramic bond coat and YSZ top coat were applied on the nimonic alloy substrate by conventional enameling and air plasma spraying techniques, respectively. Figure 2 depicts the typical SEM cross-sectional micrograph of this kind of TBC system, which is composed of $\mathrm{BaO}-\mathrm{MgO}-\mathrm{SiO}_{2}$-based glassceramic bond coat, 8-YSZ top coat, and nimonic superalloy substrate.

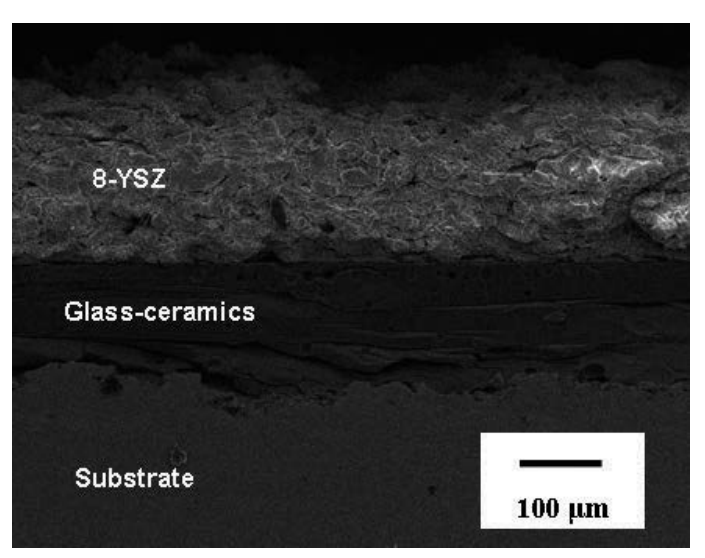

Figure 2. Typical TBC system consisting of glass-ceramic bond coat, 8-YSZ top coat, and nimonic superalloy substrate.

The $90^{\circ}$ bend tests on these TBC systems showed that only a small amount of YSZ coating chipped off from the edges, indicating strong adherence of the TBC with the nimonic alloy substrate. The microhardness and Young's modulus values of YSZ coating, glass-ceramic coating, and nimonic alloy substrate of the TBC system were lower on the cross-section than those obtained on the plan-section at a load of $100 \mathrm{mN}$. The four-point bend test on the TBC system displayed low stiffness (bending elastic modulus-45-52 GPa at room temperature) that leads to low residual stresses in the TBC resulting in high thermo-mechanical stability of the 
TBC system [74]. Das et al. [75] studied the oxidation behavior of a TBC system consisting of $8 \mathrm{wt} \%$ YSZ top coat, $\mathrm{BaO}-\mathrm{MgO}-\mathrm{SiO}_{2}$-based glass-ceramic bond coat, and nimonic alloy (AE 435) substrate wherein static oxidation test was carried out at $1,200^{\circ} \mathrm{C}$ for $500 \mathrm{~h}$ in air. Oxidation resistance of this TBC system was compared with the conventional TBC system under identical heat treatment conditions. Both TBC systems were characterized by SEM, as well as EDS analysis. The TGO layer was not found between the bond coat and the top coat in the case of glass-ceramic bonded TBC system, while the conventional TBC system showed a TGO layer of $\sim 16 \mu \mathrm{m}$ thickness at the bond coat-top coat interface [75].

Thermal cyclic behavior of glass-ceramic bonded TBC on nimonic alloy substrate was investigated by Das et al. [76]. In that study, a TBC system comprised of $8 \mathrm{wt} \%$ YSZ top coat, BaO$\mathrm{MgO}-\mathrm{SiO}_{2}$-based glass-ceramic bond coat, and nimonic alloy (AE 435) substrate was subjected to thermal shock test from $1,000^{\circ} \mathrm{C}$ to room temperature for 100 cycles. Specimens held at $1,000^{\circ} \mathrm{C}$ for $5 \mathrm{~min}$ were forced air quenched, as well as water quenched from the same conditions. Microstructural changes were investigated using SEM. The phase analysis was conducted by XRD analysis and EDS analysis. Deterioration was not observed in the top coats after 100 cycles in the case of forced air quenched specimens, whereas the top coats were damaged in the water quenched specimens. After thermal cycling experiments interfacial cracks did not appear at the top coat-bond coat and bond coat-substrate interfaces both in forced air quenched and water quenched specimens. Further, the top coat retained its phase stability [76]. The mechanical properties of a glass-ceramic bonded TBC system have been reported by Ghosh [77].Glass-ceramic bonded TBC showed good thermal gradient property as both the glass-ceramic bond coat and YSZ top coat can act as a thermal barrier to the nimonic alloy substrate and reduce the substrate temperature. The thermal gradient of a TBC-coated substrate was $856^{\circ} \mathrm{C}$ after 45 min holding of the $\mathrm{YSZ}$ coating at $1,200^{\circ} \mathrm{C}$. The present TBC prevents the thermal conduction to the nimonic alloy substrate as both the glass-ceramic bond coat and the YSZ top coat have low thermal conductivity. Thermal conductivity measurement showed that the $\sim 100 \mu \mathrm{m}$ glass-ceramic coated substrate had lower thermal conductivity ( 23$27 \mathrm{~W} / \mathrm{m} . \mathrm{K}$ at $\left.1,000^{\circ} \mathrm{C}\right)$ than that of the bare nimonic alloy substrate $\left(\sim 28 \mathrm{~W} / \mathrm{m} . \mathrm{K}\right.$ at $\left.1,000^{\circ} \mathrm{C}\right)$. Moreover, the thermal conductivity of the glass-ceramic- $(\sim 100 \mu \mathrm{m})$ and YSZ $(\sim 400 \mu \mathrm{m})$-coated nimonic alloy substrate was much lower $\left(17.19 \mathrm{~W} / \mathrm{m} . \mathrm{K}\right.$ at $\left.1,000^{\circ} \mathrm{C}\right)$ than that of the bare nimonic alloy substrate $\left(\sim 28 \mathrm{~W} / \mathrm{m} . \mathrm{K}\right.$ at $\left.1,000^{\circ} \mathrm{C}\right)[74,78,79]$.

Efficient gas turbines can be achieved through the use of engineered components having the capability of operating at higher metal temperatures with longer lifetimes. Gas turbine Inlet temperatures can exceed the melting temperatures of nickel-based superalloys. Advanced air cooling system in association with TBCs can decrease the underlying substrate temperature. NiCoCrAlY overlay coatings are generally used as bond coatings for industrial gas turbines. Extensive research is being carried out to find the suitable bond coat composition. Seraffon et al. [80] reported a new type of bond coat with a wide range of compositions. They focused on the oxidation behavior of the bond coatings at $950^{\circ} \mathrm{C}$. A range of $\mathrm{Ni}-\mathrm{Co}-\mathrm{Cr}-\mathrm{Al}$ coatings were deposited on sapphire substrates using the physical vapor deposition technique and magnetron sputtering method. Co-sputtering of two targets, such as $\mathrm{Ni}-10 \% \mathrm{Cr}, \mathrm{Ni}-20 \% \mathrm{Cr}, \mathrm{Ni}-50 \% \mathrm{Cr}$, $\mathrm{Ni}-20 \% \mathrm{Co}-40 \% \mathrm{Cr}$, or $\mathrm{Ni}-40 \% \mathrm{Co}-20 \% \mathrm{Cr}$ target, and a pure $\mathrm{Al}$ target was used for the 
deposition of coatings. The coatings were then oxidized in air for $500 \mathrm{~h}$ at $950^{\circ} \mathrm{C}$. All samples were characterized by measuring the change in coating thickness using pre- and post-exposure metrology only and also the change in specimen weight. Thick coatings $(20-30 \mu \mathrm{m})$ were deposited by magnetron sputtering successfully. EDS analysis was used to determine the elemental compositions of the samples. Furthermore, XRD was used to identify the major oxides formed during thermal exposure. The selective growth of protective $\mathrm{Cr}_{2} \mathrm{O}_{3}, \mathrm{Al}_{2} \mathrm{O}_{3}$ or other less protective mixed oxides was observed. The oxide scale growth rate indicated the suitable coatings that produce more protective oxides and allow future optimization of the bond coating composition for service within the turbine section of industrial gas turbines [80].

In the last decade, it has been observed that Pt-rich $\gamma-\gamma^{\prime}$ alloys and coatings have good oxidation and corrosion properties. Selezneff et al. [38] used this technique to fabricate doped Pt-rich $\gamma-\gamma^{\prime}$ bond coatings on AM1® superalloy substrate. These TBC systems were compared with the conventional TBC system composed of a $\beta-(\mathrm{Ni}, \mathrm{Pt}) \mathrm{Al}$ bond coating. Most of the compositions were superior to the $\beta$-(Ni,Pt)Al bond coatings with respect to ceramic top coat adherence and better oxide scale adherence of the $\gamma-\gamma^{\prime}$-based systems [38]. Iridium modified nickel alluminides are promising bond coats because of their ability to promote $\alpha-\mathrm{Al}_{2} \mathrm{O}_{3}$ scale growth and to form an oxygen diffusion barrier Ir layer. An innovative Al-Ni-Ir alloy was formulated by Lamastra et al. [81]. A detailed microstructural investigations of both powder and bulk samples were conducted to compare the phase composition, oxidation behavior, and thermal stability of the proposed system with those of the Ir free ones. The AlNiIr system was composed of $\mathrm{Al}_{3} \mathrm{Ni}_{2}, \mathrm{AlNi}_{3}$ and $\beta-\mathrm{NiAl}$. It was assumed that the presence of Ir promoted the alumina scale growth, which started at $\sim 1000^{\circ} \mathrm{C}$. Ni-poor and Al-rich islands were observed in both as cast and oxidized AlNiIr bulk samples. However, Ir had high concentration in Alrich islands and thereby, suggesting higher affinity of iridium towards $\mathrm{Al}$ than $\mathrm{Ni}$. After oxidation at $1,150^{\circ} \mathrm{C}$, the $\alpha-\mathrm{Al}_{2} \mathrm{O}_{3}$ scale growth was observed increasing the TGO thickness with dwelling time. Both Ir ODB and Ir-rich islands at the interface between the alloy and the $\mathrm{Al}_{2} \mathrm{O}_{3}$ scale were not identified due to the low Ir amount. However, metallic Ir and the compound $\mathrm{Al}_{2.75} \mathrm{Ir}$ were detected in the powder after thermal treatment at $1,000^{\circ} \mathrm{C}$ [81].

Developing new bond coat is an effective way to extend the service life of TBCs during high temperature exposure. Yao et al. [82] prepared a novel TBC system composed of an $\left(\mathrm{Al}_{2} \mathrm{O}_{3}-\right.$ $\mathrm{Y}_{2} \mathrm{O}_{3}$ )/ (Pt or Pt-Au) composite bond coat and a YSZ top coat and Ni-based superalloy by magnetron sputtering and EB-PVD, respectively. Cyclic oxidation tests in air at $1,100^{\circ} \mathrm{C}$ for 200 $h$ showed that the YSZ top coat and alloy substrate can be bonded together effectively by the $\left(\mathrm{Al}_{2} \mathrm{O}_{3}-\mathrm{Y}_{2} \mathrm{O}_{3}\right) /(\mathrm{Pt}$ or $\mathrm{Pt}-\mathrm{Au})$ composite coating. So, this kind of TBC had excellent oxidation resistance and cracking/buckling resistance, which can be attributed to the sealing effect of such coating. Therefore, the interdiffusion between the bond coat and alloy substrate as well as substrate oxidation can be avoided. The toughening effect of noble metals and composite structure of bond coat resulted in inhibition of the micro-cracks propagation and relaxation of the stress in the bond coat. This ceramic/noble metal composite coating has great prospect for the TBC applications [82]. Wang et al. [83] produced NiAl and NiAlHf/Ru coatings on nickelbased single crystal superalloy in order to investigate the interdiffusion behavior and cyclic oxidation resistance at $1,100^{\circ} \mathrm{C}$. Needle-like topologically close-packed phases and secondary 
reaction zone ( $\sim 30 \mu \mathrm{m}$ thick layer) were formed in the NiAl-coated superalloy after annealing at $1,100^{\circ} \mathrm{C}$ for $100 \mathrm{~h}$ while the precipitates of TCP and SRZ were effectively constrained in the $\mathrm{NiAlHf} / \mathrm{Ru}$-coated alloy. The NiAlHf/Ru coating exhibited superior cyclic oxidation resistance as compared to the NiAl coating. They have shown that Ru and Hf have important roles in terms of affecting interdiffusion and cyclic oxidation [83]. Zhang et al [84] developed gradient TBCs consisting of $\left(\mathrm{Gd}_{0.9} \mathrm{Yb}_{0.1}\right)_{2} \mathrm{Zr}_{2} \mathrm{O}_{7}$-yttria-stabilized zirconia (8YSZ) and Hf-doped NiAl bond coat by EB-PVD technique. The effect of the interfacial structure between $\left(\mathrm{Gd}_{0.9} \mathrm{Yb}_{0.1}\right)_{2} \mathrm{Zr}_{2} \mathrm{O}_{7}(\mathrm{GYbZ})$ and $8 \mathrm{YSZ}$ layers on the thermal cycling behavior was investigated by comparing the DCL coatings with gradient thermal barrier coatings (GTBCs). The thermal cycling tests showed that the GTBCs had a more extended lifetime than that of the DCL coatings. The failure of GYbZ-8YSZ DCL coating with clear interface between different ceramic layers occurred through delaminating cracking as a result of crack initiation and propagation caused by stress concentration within the ceramic layers. Further, the failure of GTBC occurred due to the thermal expansion mismatch between the Hf-doped NiAl bond coat and the TGO layer [84].

\section{Conclusions}

In the future, $\mathrm{TBC}$ s are required to be more suitably designed for the thermal protection of gas turbine engine components to significantly increase engine operating temperatures, fuel efficiency, and engine reliability. However, coating durability is a vital factor to increase the engine operating temperature. Therefore, the coating behavior and failure modes under high temperature, high thermal gradient cyclic conditions should be properly understood to develop next-generation advanced TBCs.

\section{Acknowledgements}

The authors are very grateful to Mr. K. Dasgupta, Director, CSIR-Central Glass and Ceramic Research Institute (CSIR-CGCRI), Kolkata-700 032, India, for his kind permission to publish this book chapter.

\section{Author details}

\section{Sumana Ghosh*}

Address all correspondence to: sumana@cgcri.res.in

Bio-ceramics and Coating Division, CSIR-Central Glass and Ceramic Research Institute, Kolkata, India 


\section{References}

[1] Tang F, Ajdelsztajn L, Kim GE, Provenzano V, Schoenung JM. Effects of variations in coating materials and process conditions on the thermal cycle properties of NiCrAlY/YSZ thermal barrier coatings. Materials Science and Engineering A. 2006; 425: 94-106.

[2] Matsumoto M, Takayama H, Yokoe D, Mukai K, Matsubara H, Kagiya Y, Sugita Y. Thermal cycle behavior of plasma sprayed $\mathrm{La}_{2} \mathrm{O}_{3}, \mathrm{Y}_{2} \mathrm{O}_{3}$ stabilized $\mathrm{ZrO}_{2}$ coatings. Scripta Materialia. 2006; 54: 2035-2039.

[3] Martena M, Botto D, Fino P, Sabbadini S, Gola MM, Badini C. Modelling of TBC system failure: Stress distribution as a function of TGO thickness and thermal expansion mismatch. Engineering Failure Analysis. 2006; 13: 409-426.

[4] Clarke DR, Oechsner M, Padture NP. Thermal-barrier coatings for more efficient gasturbine engines. MRS bulletin. 2012; 37: 891-898.

[5] Busso EP, Lin J, Sakurai S, Nakayama M. Mechanistic study of oxidation-induced degradation in a plasma-sprayed thermal barrier coating system. Part I: Model formulation. Acta Materialia. 2001; 49: 1515-1528.

[6] Daroonparvar M, Hussain MS, Yajid MAM. The role of formation of continues thermally grown oxide layer on the nanostructured NiCrAlY bond coat during thermal exposure in air. Applied Surface Science. 2012; 261: 287-297.

[7] Xu R, Fan XL, Zhang WX, Wang TJ. Interfacial fracture mechanism associated with mixed oxides growth in thermal barrier coating system. Surface and Coatings Technology. 2014; 253: 139-147.

[8] Evans HE. Oxidation failure of TBC systems: An assessment of mechanisms. Surface and Coatings Technology. 2011; 206: 1512-1521.

[9] Haynes JA, Ferber MK, Porter WD. Thermal cycling behavior of plasma-sprayed thermal barrier coatings with various MCrAIX bond coats. Journal of Thermal Spray Technology. 2000; 9: 38-48.

[10] Sfar K, Aktaa J, Munz D. Numerical investigation of residual stress fields and crack behavior in TBC systems. Materials Science and Engineering: A. 2002; 333: 351-360.

[11] Yang L, Yang F, Long Y, Zhao Y, Xiong X, Zhao X, Xiao P. Evolution of residual stress in air plasma sprayed yttria stabilised zirconia thermal barrier coatings after isothermal treatment. Surface and Coatings Technology. 2014; 251: 98-105.

[12] Pujol G, Ansart F, Bonino J-P, Malié A, Hamadi S. Step-by-step investigation of degradation mechanisms induced by CMAS attack on YSZ materials for TBC applications. Surface and Coatings Technology. 2013; 237: 71-78. 
[13] Thompson JA, Clyne TW. The effect of heat treatment on the stiffness of zirconia top coats in plasma-sprayed TBCs. Acta Materialia. 2001; 49: 1565-1575.

[14] Abubakar AA, Akhtar SS, Arif AFM. Phase field modeling of $\mathrm{V}_{2} \mathrm{O}_{5}$ hot corrosion kinetics in thermal barrier coatings. Computational Materials Science. 2015; 99: 105-116.

[15] Kulkarni A, Vaidya A, Goland A, Sampath S, Herman H. Processing effects on porosity-property correlations in plasma sprayed yttria-stabilized zirconia coatings. Materials and Engineering A. 2003; 359: 100-111.

[16] Zhang D, Gong S, Xu H, Wu Z. Effect of bond coat surface roughness on the thermal cyclic behavior of thermal barrier coatings. Surface \& Coatings Technology. 2006; 201: 649-653.

[17] Movchan BA, Yakovchuk YK. Graded thermal barrier coatings, deposited by EBPVD. Surface \& Coatings Technology 2004;188-189: 85-92.

[18] Wu LT, Wu RT, Zhao X, Xiao P. Microstructure parameters affecting interfacial adhesion of thermal barrier coatings by the EB-PVD method. Materials Science \& Engineering: A. 2014; 594: 193-202.

[19] Basu SN, Ye G, Gevelber M, Wroblewski D. Microcrack formation in plasma sprayed thermal barrier coatings. International Journal of Refractory Metals \& Hard Materials. 2005; 23: 335-343.

[20] Bengtsson P, Johanneson TJ. Characterization of microstructural defects in plasma sprayed thermal barrier coatings. Journal of Thermal Spray Technology. 1995; 4: 245-251.

[21] Chen WR, Wu X, Dudzinski D, Patnaik PC. Modification of oxide layer in plasma sprayed thermal barrier coatings. Surface \& Coatings Technology. 2006; 200: 5863-5868.

[22] Tang F, Schoenung JM. Evolution of Young's modulus of air plasma sprayed yttriastabilized zirconia in thermally cycled thermal barrier coatings. Scripta Materialia. 2006; 54: 1587-1592.

[23] Basu D, Funke C, Steinbrech RW. Effect of heat treatment on elastic properties of separated thermal barrier coatings. Journal of Materials Research. 1999; 14: 4643-4650.

[24] Limargaa AM, Widjajab TS, Yip TH. Mechanical properties and oxidation resistance of plasma-sprayed multilayered $\mathrm{Al}_{2} \mathrm{O}_{3} / \mathrm{ZrO}_{2}$ thermal barrier coatings. Surface \& Coatings Technology. 2005; 197: 93-102.

[25] Guo HB, Kuroda S, Murakami H. Segmented thermal barrier coatings produced by atmospheric plasma spraying hollow powders. Thin Solid Films. 2006; 506-507: 136-139. 
[26] Chen X, Gu L, Zou B, Wang Y, Cao X. New functionally graded thermal barrier coating system based on $\mathrm{LaMgAl}{ }_{11} \mathrm{O}_{19} / \mathrm{YSZ}$ prepared by air plasma spraying. Surface \& Coatings Technology. 2012; 206: 2265-2274.

[27] Préauchat B, Drawin S. Properties of PECVD-deposited thermal barrier coatings. Surface \& Coatings Technology. 2001; 142-44: 835-842.

[28] Vyas JD, Choy K-L. Structural characterisation of thermal barrier coatings deposited using electrostatic spray assisted vapour deposition method. Materials Science and Engineering: A. 2000; 277: 206-212.

[29] Gell M, Xie L, Ma X, Jordan EH, Padture NP. Highly durable thermal barrier coatings made by the solution precursor plasma spray process. Surface and Coating Technology. 2004; 177-178: 97-102.

[30] Jadhav A, Padture NP, Wu F, Jordan EH, Gell M. Thick ceramic thermal barrier coatings with high durability deposited using solution-precursor plasma spray. Materials Science and Engineering: A. 2005; 405: 313-320.

[31] Viazzi C, Bonino JP, Ansart F. Synthesis by sol-gel route and characteri-zation of yttria stabilized zirconia coatings for thermal barrier applications. Surface \& Coatings Technology. 2006; 201: 3889-3893.

[32] Sniezewski J, Le MY, Lours P, Pin L, Minvie BV, Monceau D, Oquab D, Fenech J, Ansart F, Bonino J-P. Sol-gel thermal barrier coatings: Optimization of the manufacturing route and durability under cyclic oxidation. Surface \& Coatings Technology. 2010; 205:1256-1261.

[33] Pin L, Ansart F, Bonino J-P, Maoult YL, Vidal V, Lours P. Processing,repairing and cyclic oxidation behaviour of sol-gel thermal barrier coatings. Surface \& Coatings Technology. 2011; 206:1609-1614.

[34] Pin L, Ansart F, Bonino J-P, Le Maoult Y, Vidal V, Lours P. Reinforcedsol-gel thermal barrier coatings and their cyclic oxidation life. Journal of the European Ceramic Society. 2013; 33: 269-276.

[35] Ren C, He YD, Wang DR. Cyclic oxidation behavior and thermal barrier effect of YSZ- $\left(\mathrm{Al}_{2} \mathrm{O}_{3} / \mathrm{YAG}\right)$ double-layer TBCs prepared by the composite sol-gel method. Surface \& Coatings Technology. 2011; 206: 1461-1468.

[36] Monceau D, Oquab D, Estournes C, Boidot M, Selezneff S, Thebault Y, Cadoret Y. Ptmodified Ni aluminides, MCrAlY-base multilayer coatings and TBC systems fabricated by Spark Plasma Sintering for the protection of Ni-base superalloys. Surface \& Coatings Technology. 2009; 204: 771-778.

[37] Boidot M, Selezneff S, Monceau D, Oquab D, Estournès C. Proto-TGO formation in TBC systems fabricated by spark plasma sintering. Surface \& Coatings Technology. 2010; 205: 1245-1249. 
[38] Selezneff S, Boidot M, Hugot J, Oquab D, Estournès C, Monceau D. Thermal cycling behavior of EBPVD TBC systems deposited on doped Pt-rich $\gamma-\gamma^{\prime}$ bond coatings made by Spark Plasma Sintering (SPS). Surface \& Coatings Technology. 2011; 206: 1558-1565.

[39] Rousseau F, Fourmond C, Prima F, Serif MHV, Lavigne O, Morvan D, Chereau P. Deposition of thick and $50 \%$ porous YpSZ layer by spraying nitrate solution in a low pressure plasma reactor. Surface \& Coatings Technology. 2011; 206: 1621-1627.

[40] Ramachandran CS, Balasubramanian V, Ananthapadmanabhan PV. Synthesis, spheroidization and spray deposition of lanthanum zirconate using thermal plasma process. Surface \& Coatings Technology. 2012; 206: 3017-3035.

[41] Bahadori E, Javadpour S, Shariat MH, Mahzoon Fatemeh. Preparation and properties of ceramic $\mathrm{Al}_{2} \mathrm{O}_{3}$ coating as TBCs on MCrAly layer applied on Inconel alloy by cathodic plasma electrolytic deposition. Surface \& Coatings Technology. 2013; 228: S611S614.

[42] Kim JH, Kim MC, Park CG. Evaluation of functionally graded thermal barrier coatings fabricated by detonation gun spray technique. Surface \& Coatings Technology. 2003; 168: 275-280.

[43] Chwa SO, Akira O. Microstructures of $\mathrm{ZrO}_{2}-8 w \mathrm{wt} . \% \mathrm{Y}_{2} \mathrm{O}_{3}$ coatings prepared by a plasma laser hybrid spraying technique. Surface \& Coatings Technology. 2002; 153: 304-312.

[44] Wang W, Li C, Li J, Fan J, Zhou X. Effect of gadolinium doping on phase transformation and microstructure of $\mathrm{Gd}_{2} \mathrm{O}_{3}-\mathrm{Y}_{2} \mathrm{O}_{3}-\mathrm{ZrO}_{2}$ composite coatings prepared by electrophoretic deposition. Journal of Rare Earths. 2013; 31: 289-295.

[45] Vassen R, Cao X, Tietz F, Basu D, Sto ${ }^{\circ}$ ver D. Zirconates as new materials for thermal barrier coatings. Journal of the American Ceramic Society. 2000; 83: 2023-2028.

[46] Moskal G, Swad'zba L, Hetma'nczyk M, Witala B, Mendala B, Mendala J, Sosnowy P. Characterization of microstructure and thermal properties of $\mathrm{Gd}_{2} \mathrm{Zr}_{2} \mathrm{O}_{7}$-type thermal barrier coating. Journal of the European Ceramic Society 2012; 32: 2025-2034.

[47] Ma W, Mack D, Malzbender J, Vaßen R, St ${ }^{\circ}$ over D. $\mathrm{Yb}_{2} \mathrm{O}_{3}$ and $\mathrm{Gd}_{2} \mathrm{O}_{3}$ doped strontium zirconate for thermal barrier coatings. Journal of the European Ceramic Society. 2008; 28: 3071-3081.

[48] Zhao H, Levi CG, Wadley HNG. Vapor deposited samarium zirconate thermal barrier coatings. Surface \& Coatings Technology. 2009; 203: 3157-3167.

[49] Vassen R, Cao X, Dietrich M, Stoever D. Improvement of new thermal barrier coating systems using layered or graded structure. In: Singh M, Jessen T (Eds.) The 25th Annual International Conference on Advanced Ceramics and Composites: An Advanced Ceramics Odyssey, Cocoa Beach of Florida: American Ceramic Society; 2001. p 435 . 
[50] Friedrich CJ, Gadow R, Lischka MH. Lanthanum hexaaluminate thermal barrier coatings. In: Singh M, Jessen T (Eds.) The 25th Annual International Conference on Composites, Advanced Ceramics, Materials, and Structures: B, Cocoa Beach of Florida: American Ceramic Society; 2001. p 372-375.

[51] Xie X, Guoa H, Gonga S, Xu H. Lanthanum-titanium-aluminum oxide: A novel thermal barrier coating material for applications at $1300^{\circ} \mathrm{C}$. Journal of the European Ceramic Society. 2011; 31: 1677-1683.

[52] Sudre O, Cheung J, Marshall D, Morgan P, Levi CG. Thermal insulation coatings of $\mathrm{LaPO}_{4}$. In: Singh M, Jessen T (Eds.) The 25th Annual International Conference on Composites, Advanced Ceramics, Materials, and Structures: B, Cocoa Beach of Florida: American Ceramic Society; 2001. p 367.

[53] Ding C, Xi Y, Zhang Y, Qu J, Qiao, H. Thermophysical properties of plasma sprayed rare earth oxide coatings. In: Sandmeier S, Eschnauer H, Huber P, Nicoll AR. (Eds.) The 2nd Plasma-technik-symposium (Lucerne Switzerland, June 1991), Switzerland: Plasma-Technik AG, Wohlen; 1991. p 27-32.

[54] Warshaw I, Roy R. Polymorphism of the rare earth sesquioxides. The Journal of Physical Chemistry. 1965; 65: 2048-2051.

[55] Kvernes I, Lugscheider E, Ladru F. Lifetime and degradation processes of TBCs for diesel engines. In: Lecomte-Beckers J, Schuber F, Ennis PJ. (Eds.) Proceedings of the 6th Lie'ge Conference on Materials for Advanced Power Engineering (Universite de Lie'ge, Belgium), Forschungszentrum Ju lich GmbH, Ju lich; 1998. p 997-1001.

[56] Ramaswamy P, Seetharamu S, Varma KB, Rao KJ. Thermal barrier coating application of zircon sand. Journal of Thermal Spray Technology. 1999; 8: 447-453.

[57] Chra' ska P, Neufuss K, Kolman B, Dubsky J. Plasma spraying of silicates. In: Berndt CC. (Ed.) Proceedings of the 1st United Thermal Spray Conference: Thermal SprayA United Forum for Scientific and Technological Advances, Indiana USA: ASM International, Materials Park; 1997. p 477-481.

[58] Morgan PED, Marshall DB. Ceramic composites of monayite and alumina. Journal of the American Ceramic Society 1995; 78: 1553-1563.

[59] Nitin PP, Klemens PG. Low thermal conductivity in garnets. Journal of the American Ceramic Society. 1977; 80: 1018-1020.

[60] Guo H, Zhang H, Ma G, Gong S. Thermo-physical and thermal cycling properties of plasma-sprayed $\mathrm{BaLa}_{2} \mathrm{Ti}_{3} \mathrm{O}_{10}$ coating as potential thermal barrier materials. Surface \& Coatings Technology. 2009; 204: 691-696.

[61] Xu Z, He, S, He L, Mu R, Huang G, Cao X. Novel thermal barrier coatings based on $\mathrm{La}_{2}\left(\mathrm{Zr}_{0.7} \mathrm{Ce}_{0.3}\right)_{2} \mathrm{O}_{7} / 8 \mathrm{YSZ}$ double-ceramic-layer systems deposited by electron beam physical vapor deposition. Journal of Alloys and Compounds. 2011; 509: 4273-4283. 
[62] Qu L, Choy K-L, Thermophysical and thermochemical properties of new thermal barrier materials based on $\mathrm{Dy}_{2} \mathrm{O}_{3}-\mathrm{Y}_{2} \mathrm{O}_{3}$ co-doped zirconia. Ceramics International. 2014; 40: 11593-11599.

[63] Zhou X, Xu Z, Fan X, Zhao S, Cao X, He L. $\mathrm{Y}_{4} \mathrm{Al}_{2} \mathrm{O}_{9}$ ceramics as a novel thermal barrier coating material for high-temperature applications. Materials Letters. 2014; 134:146-148.

[64] Bobzin K, Bagcivan N, Brögelmann T, Yildirim B. Influence of temperature on phase stability and thermal conductivity of single- and double-ceramic-layer EB-PVD TBC top coats consisting of $7 \mathrm{YSZ}, \mathrm{Gd}_{2} \mathrm{Zr}_{2} \mathrm{O}_{7}$ and $\mathrm{La}_{2} \mathrm{Zr}_{2} \mathrm{O}_{7}$. Surface and Coatings Technology. 2013; 237: 56-64.

[65] Pitek FM, Levi CG. Opportunities for TBCs in the $\mathrm{ZrO}_{2}-\mathrm{YO}_{1.5}-\mathrm{TaO}_{2.5}$ system. Surface and Coatings Technology. 2007; 201: 6044-6050.

[66] Liu Z-G, Zhang W-H, Ouyang J-H, Zhou Y. Novel double-ceramic-layer

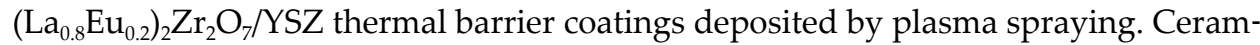
ics International. 2014; 40: 11277-11282.

[67] Hong-song Z, Qiang X, Fu-chi W, Ling L, Yuan W, Xiaoge C. Preparation and thermophysical properties of $\left(\mathrm{Sm}_{0.5} \mathrm{La}_{0.5}\right)_{2} \mathrm{Zr}_{2} \mathrm{O}_{7}$ and $\left(\mathrm{Sm}_{0.5} \mathrm{La}_{0.5}\right)_{2}\left(\mathrm{Zr}_{0.8} \mathrm{Ce}_{0.2}\right)_{2} \mathrm{O}_{7}$ ceramics for thermal barrier coatings. Journal of Alloys and Compounds. 2009; 475: 624-628.

[68] Dietrich M, Verlotski V, Vassen R, Stoever D. Metal-glass based composites for novel TBC-systems. Materials Science and Engineering Technology. 2001; 32: 669-672.

[69] Majumdar A, Jana S. Yttria doped zirconia in glassy matrix useful for thermal barrier Coating. Materials Letters. 2000; 44:197-202.

[70] Keyvani A. Microstructural stability oxidation and hot corrosion resistance of nanostructured $\mathrm{Al}_{2} \mathrm{O}_{3} / \mathrm{YSZ}$ composite compared to conventional YSZ TBC coatings. Journal of Alloys and Compounds. 2015; 623: 229-237.

[71] Ren C, He YD, Wang DR. Cyclic oxidation behavior and thermal barrier effect of YSZ- $\left(\mathrm{Al}_{2} \mathrm{O}_{3} / \mathrm{YAG}\right)$ double-layer TBCs prepared by the composite sol-gel method. Surface and Coatings Technology. 2011; 206: 1461-1468.

[72] Datta S, Das S. A new high temperature resistant glass-ceramic coating for gas turbine engine components. Bulletin of Materials Science 2005; 28: 689-696.

[73] Datta S, Das S. A new high temperature resistant glass-ceramic coating developed in CGCRI, Kolkata. Transactions of the Indian Ceramic Society. 2005; 64: 25-32.

[74] Das S. Study of structure and property relationship in thermal barrier coating system. Ph.D. thesis, Jadavpur University, Kolkata, 2010.

[75] Das S, Datta S, Basu D, Das GC. Glass-ceramics as oxidation resistant bond coat in thermal barrier coating system. Ceramics International. 2009; 35: 1403-1406. 
[76] Das S, Datta S, Basu D, Das GC. Thermal cyclic behavior of glass-ceramic bonded thermal barrier coating on nimonic alloy substrate. Ceramics International. 2009; 35: 2123-2129.

[77] Ghosh S. Microstructure and mechanical properties of a glass-ceramic bond coated TBC system. Procedia Materials Science. 2014; 6: 425-429.

[78] Ghosh S. Thermal behavior of glass-ceramic bond coat in a TBC system. Vacuum. 2014; 101: 367-370.

[79] Ghosh S. Thermal properties of glass-ceramic bonded thermal barrier coating system. Transactions of Nonferrous Metals Society of China. 2015; 25: 457-464.

[80] Seraffon M, Simms NJ, Sumner J, Nicholls JR. The development of new bond coat compositions for thermal barrier coating systems operating under industrial gas turbine conditions. Surface and Coatings Technology. 2011; 206: 1529-1537.

[81] Lamastra FR, Cacciotti I, Bellucci A, Nanni F. Innovative Al-Ni-Ir alloy for bond coats: Microstructure, phase analysis and oxidation behaviour. Intermetallics. 2012; 22: $241-250$.

[82] Yao J, He Y, Wang D, Peng H, Guo H, Gong S. Thermal barrier coatings with $\left(\mathrm{Al}_{2} \mathrm{O}_{3}-\right.$ $\left.\mathrm{Y}_{2} \mathrm{O}_{3}\right) /(\mathrm{Pt}$ or Pt-Au) composite bond coat and 8YSZ top coat on Ni-based superalloy. Applied Surface Science. 2013; 286: 298-305.

[83] Wang D, Peng H, Gong S, Guo H. NiAlHf/Ru: Promising bond coat materials in thermal barrier coatings for advanced single crystal superalloys. Corrosion Science. 2014; 78: 304-312.

[84] Zhang H, Guo L, Ma Y, Peng H, Guo H, Gong S. Thermal cycling behavior of $\left(\mathrm{Gd}_{0.9} \mathrm{Yb}_{0.1}\right)_{2} \mathrm{Zr}_{2} \mathrm{O}_{7} / 8 \mathrm{YSZ}$ gradient thermal barrier coatings deposited on Hf-doped NiAl bond coat by EB-PVD. Surface and Coatings Technology. 2014; 258: 950-955. 
Chapter 6

\title{
Electrocaloric Properties of $(\mathrm{Pb}, \mathrm{La})(\mathrm{Zr}, \mathrm{Ti}) \mathrm{O}_{3}$ and $\mathrm{BaTiO}_{3}$ Ceramics
}

\author{
Hiroshi Maiwa \\ Additional information is available at the end of the chapter \\ http://dx.doi.org/10.5772/61926
}

\begin{abstract}
The electrocaloric properties of $(\mathrm{Pb}, \mathrm{La})(\mathrm{Zr}, \mathrm{Ti}) \mathrm{O}_{3}(\mathrm{PLZT})$ and $\mathrm{BaTiO}_{3}$ ceramics were investigated by the indirect estimation and direct measurement of temperature-electric field (T-E) hysteresis loops. The measured T-E loops showed a similar shape to strain-electric field (s-E) loops. The adiabatic temperature change $\Delta \mathrm{T}$ due to electrocaloric effects was estimated from the polarization change of these samples. $\Delta \mathrm{Ts}$ of 0.58 and $0.36 \mathrm{~K}$ were estimated for the $(\mathrm{Pb}, \mathrm{La})(\mathrm{Zr}, \mathrm{Ti}) \mathrm{O}_{3}$ (PLZT)(9.1/65/35) ceramics and $\mathrm{BaTiO}_{3}$ ceramics sintered at $1400^{\circ} \mathrm{C}$, respectively. The measured temperature changes $\Delta \mathrm{Ts}$ in these samples upon the release of the electric field from $30 \mathrm{kV} / \mathrm{cm}$ to zero were 0.26 and $0.29 \mathrm{~K}$, respectively.
\end{abstract}

Keywords: Electrocaloric effect, $\mathrm{PLZT}, \mathrm{BaTiO}_{3}$, refrigerator

\section{Introduction}

The electrocaloric effect(ECE) is a phenomenon in which a material shows a reversible temperature change under an applied electric field [1,2]. There has been some problem in the conventional refrigerator. Since the conventional refrigerator operates by using a compressor, vibration generation is inevitable. The conventional refrigerator uses Freon as refrigerants; however, Freon acts implicated in ozone depletion. The other disadvantage includes the difficulty in down-scaling. Thermoelectric cooling using the Peltier device has been considered as a solid state cooling device; however, low efficiency has been a hindrance to the wide applications. In addition, common thermoelectric materials used as semi-conductors include bismuth telluride, lead telluride, silicon germanium, and bismuth-antimony alloys. Some of them are toxic. Although new high-performance materials for thermoelectric cooling are being actively researched, the good results have not been obtained. From the viewpoint of the refrigerator innovation, new refrigerators based on the new mechanism are expected. ECE is 
considered to be one of the new cooling mechanisms [1, 3, 4]. By using ECE, the application to compact a high energy-effective, inexpensive, and safe refrigerator would be considered, as shown in Fig. 1. ECE was discovered in 1930 by Kobeko and Kurchakov [5]. The research activities on ECE have been not active until the year 2006. In that year, "giant" temperature change in $\mathrm{Pb}\left(\mathrm{Zr}, \mathrm{TiO}_{3}\right.$ (PZT) thin films were activated at one sweep [6]. Figure 2 shows the relation between the numbers of the published papers and the published year. After 2006, the number of papers on ECE increased rapidly [7-17]. The operation principle of the refrigerator using ECE is shown in Fig. 3. By applying the electric field, the ferroelectrics are heated by ECE. This process corresponds to the compression process in the compressor type refrigerator. By removing the electric field, the directions of the polarization become random. This process is endothermic, corresponds to the expansion process in the compressor type refrigerator, and the object is cooled. The electrocaloric effect (ECE) is a phenomenon in which a material shows a reversible temperature change under an applied electric field. In order to create ECE cooling devices, materials with large ECEs are required. The electrocaloric temperature change $\Delta \mathrm{T}$ due to applied $\Delta \mathrm{E}$ is calculated from the following equation [6]:

$$
\Delta \mathrm{T}=-\frac{T}{\rho C} \int_{E_{1}}^{E_{2}}\left(\frac{\partial P}{\partial T}\right)_{E} d E
$$

Here, $\mathrm{C}$ and $\rho$ are the specific heat and density, respectively. Based on equation (1), a large ( $\mathrm{\partial P} /$ $\partial \mathrm{T})_{\mathrm{E}}$ (i.e., a large polarization change with temperature under high electric field) is desirable. With respect to achieving large $(\partial \mathrm{P} / \mathrm{\partial T})_{\mathrm{E}}$, relaxor materials have recently attracted attention [1, $3,4]$. For direct measurement of the $\Delta \mathrm{T}$, there are some difficulties. Most temperature changes are less than $1 \mathrm{~K}$. And heat dissipation from ferroelectric materials through electrode, wire, and/or the supporting jig for field application occurs. Most probably due to these difficulties, the reports on the direct measurement of $\Delta \mathrm{T}$ are limited thus far $[13,17,18]$. In this study, the electrocaloric temperature change, $\Delta \mathrm{T}$, due to applied $\Delta \mathrm{E}$, of the PLZT ceramics and $\mathrm{BaTiO}_{3}$ ceramics is estimated and directly measured. Concerning direct measurement of temperatureelectric field (T-E) hysteresis loops, the reports have been limited. Detailed measurements of various measurements are required to clarify the insights of the ECE $[4,18,19,20]$.

\section{Experimental procedure}

PLZT(7/65/35) and PLZT(9.1/65/35) ceramics and $\mathrm{BaTiO}_{3}$ ceramics were used for ECE measurement. PLZT(7/65/35) and PLZT(9.1/65/35) ceramics were sintered from the commercial powders (Hayashi Chemical) as starting materials. $\mathrm{BaTiO}_{3}$ ceramics were sintered from the commercial powders (Toda Kogyo). The powders were fired at $1225-1275^{\circ} \mathrm{C}$ for PLZT ceramics at $1300-1400^{\circ} \mathrm{C}$ for $\mathrm{BaTiO}_{3}$ ceramics, respectively [20-22].

The ceramics were polished and then produced electrodes using a silver paste. And the ceramics were polarized for $20 \mathrm{~min}$ in a silicone bath under a DC field of $20 \mathrm{kV} / \mathrm{cm}$ at room temperature. The dielectric constant and tan $\delta$ were measured at $1 \mathrm{kHz}$ with an oscillating 


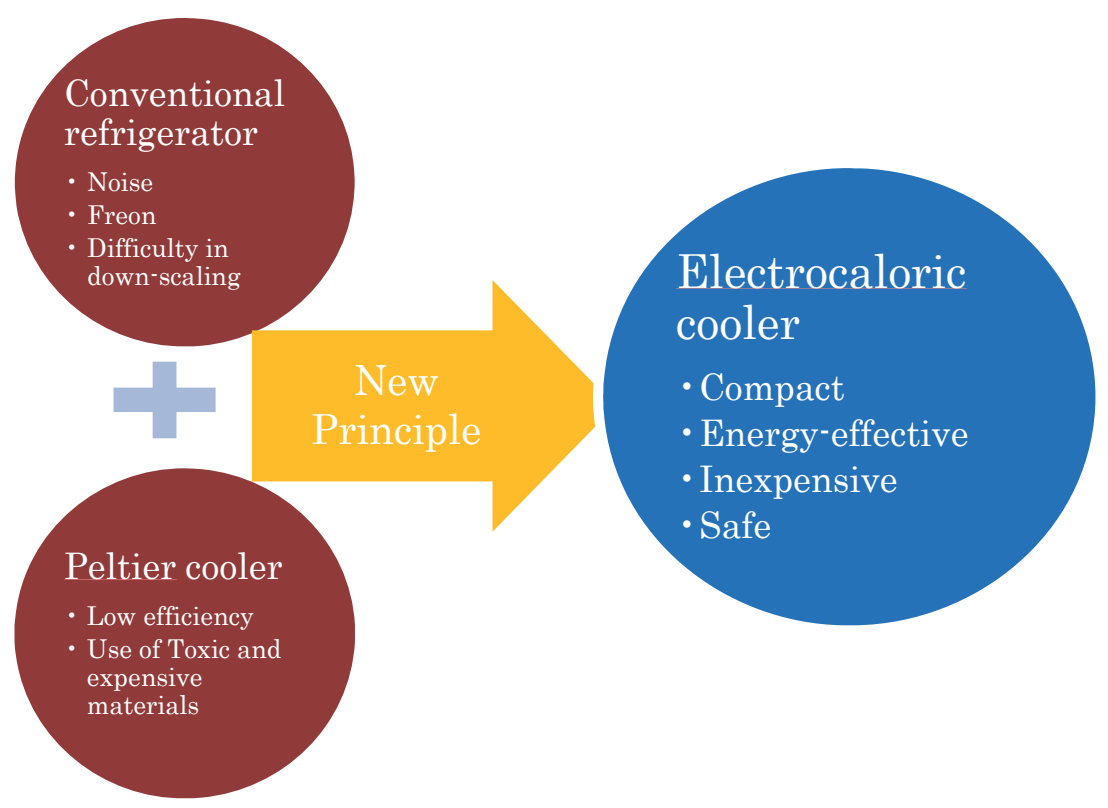

Figure 1. The merits of ECE cooler.

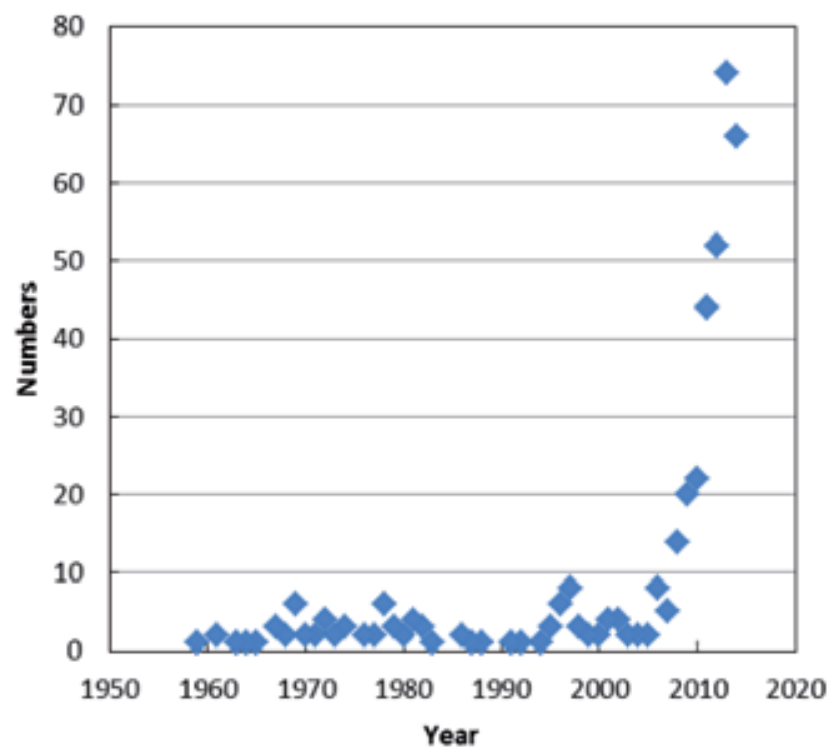

Figure 2. Year to year comparison of the numbers of papers on ECE, 1958-2014.

voltage of $1 \mathrm{~V}$. An alternating electric field of $0.1 \mathrm{~Hz}$ was used in these measurements. The dielectric constant was measured using an Agilent Technology impedance analyzer, 4192A. Piezoelectric $\mathrm{d}_{33}$ meter (IACAS ZJ-3B) was used for piezoelectric measurements. Polarization- 

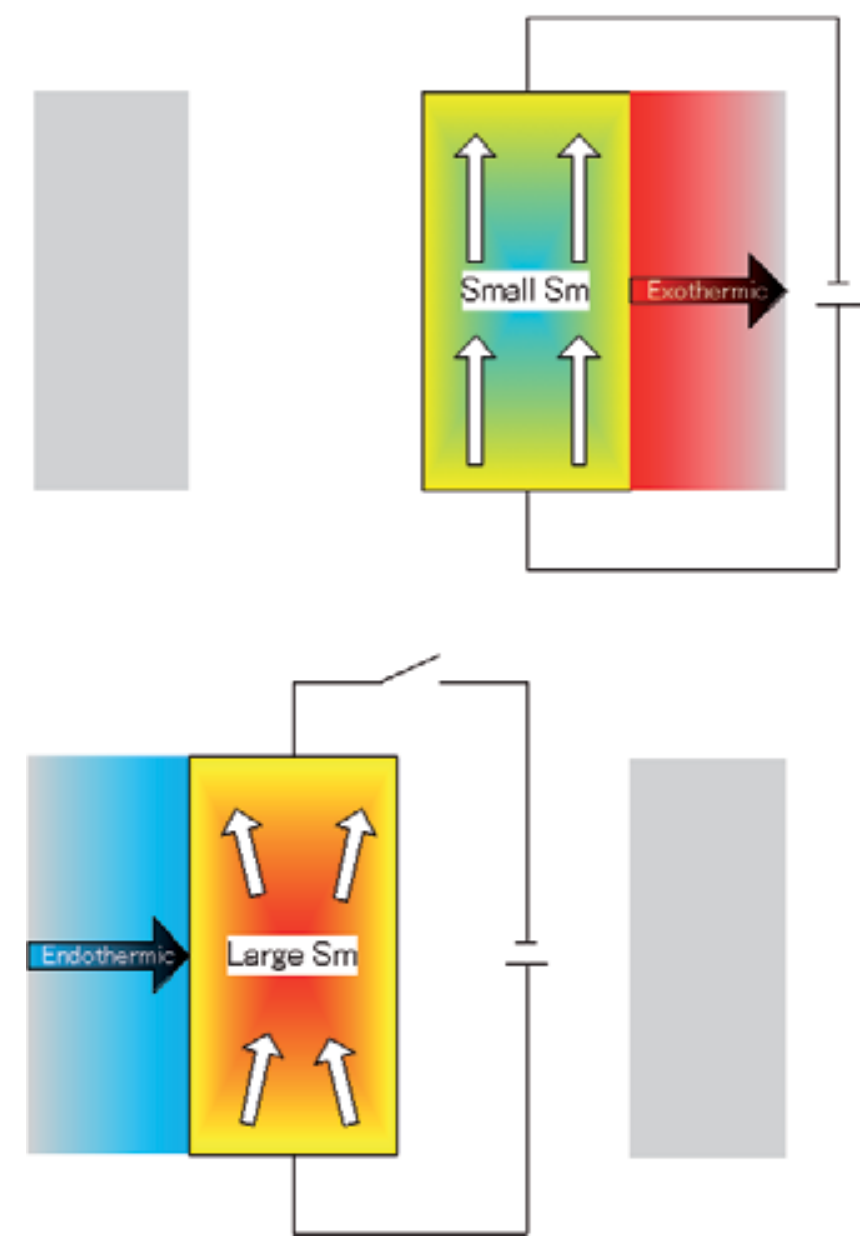

Figure 3. The operation mechanism of the ECE cooler.

electric field (P-E) hysteresis loops of the samples at various temperatures were measured using a combination of a programmable signal generator and a charge amplifier (POEL 101). The samples were cut into 3-4 mm squares, and their temperatures were changed by immersing them in a heated or a cooled oil bath [21,22]. Strain-electric field (s-E) hysteresis loops of the samples at room temperature were measured using a combination of a programmable signal generator and a strain gauge. Triangular waves of $0.1 \mathrm{~Hz}$ with $30 \mathrm{kV} / \mathrm{cm}$ were applied to the samples in $\mathrm{P}-\mathrm{E}$ and s-E measurements. The sample temperatures during the application of triangular waves of $0.1 \mathrm{~Hz}$ with $30 \mathrm{kV} / \mathrm{cm}$ field were measured using a platinum thermometer. The sample temperatures changed periodically in accordance with the external field. The polarization reversals of the samples were monitored on the basis of signals from the charge amplifier (POEL 101). By synchronization of electric field to sample temperature, temperatureelectric field (T-E) hysteresis loops were obtained. 


\section{Results and discussion}

\subsection{Microstructure}

Figure 4 shows SEM micrographs of the surface of the PLZT(7/65/35) and PLZT(9.1/65/35) ceramics sintered at $1225^{\circ} \mathrm{C}$. Densely packed microstructures of both ceramics are observed. In the sintering temperature range between $1225^{\circ} \mathrm{C}$ and $1275^{\circ} \mathrm{C}$, the grain growth was not remarkable for these samples; however, the surface roughening were observed in the ceramics sintered at $1275^{\circ} \mathrm{C}$, suggesting the lead evaporation loss from the samples. Figure 5 shows SEM micrographs of the surface of the $\mathrm{BaTiO}_{3}$ ceramics sintered at $1300^{\circ} \mathrm{C}, 1350^{\circ} \mathrm{C}$, and $1400^{\circ} \mathrm{C}$. The surface of the $\mathrm{BaTiO}_{3}$ ceramics sintered at $1300^{\circ} \mathrm{C}$ consists of the small grains of $1-2 \mu \mathrm{m}$. The melted grains are observed in the $\mathrm{BaTiO}_{3}$ ceramics sintered at $1350^{\circ} \mathrm{C}$, and large grains at 50 $200 \mu \mathrm{m}$ grains were observed in the $\mathrm{BaTiO}_{3}$ ceramics sintered at $1400^{\circ} \mathrm{C}$. This suggests the abrupt grain growth happened in the sintering temperature above $1350^{\circ} \mathrm{C}$.

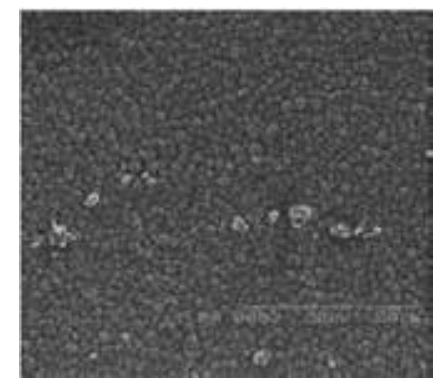

PLZT (7/65/35)

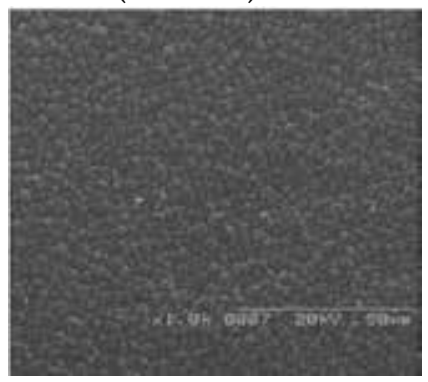

PLZT(9.1/65/35)

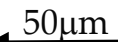

Figure 4. SEM micrographs of the surface of the PLZT(7/65/35) and PLZT(9.1/65/35) ceramics sintered at $1225^{\circ} \mathrm{C}$.

\subsection{Electrical properties}

Figure 6 shows the P-E hysteresis loops at $10^{\circ} \mathrm{C}, 27^{\circ} \mathrm{C}$, and $100^{\circ} \mathrm{C}$, s-E hysteresis loops at room temperature, and the T-E hysteresis loops of the PLZT(7/65/35) and PLZT(9.1/65/35) ceramics 


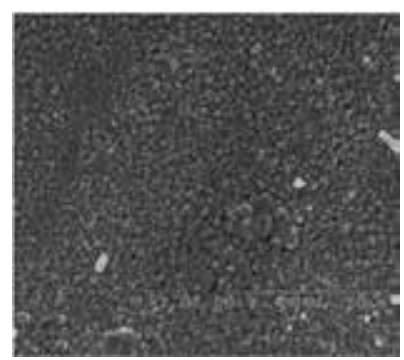

BT $1300^{\circ} \mathrm{C}$

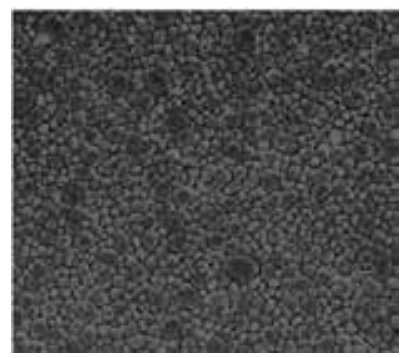

\section{BT $1350^{\circ} \mathrm{C}$}

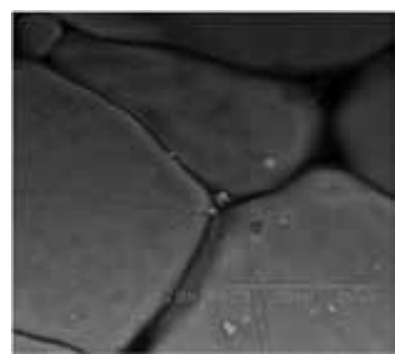

BT $1400^{\circ} \mathrm{C}$

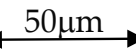

Figure 5. SEM micrographs of the surface of the $\mathrm{BaTiO}_{3}$ ceramics sintered at $1300^{\circ} \mathrm{C}, 1350^{\circ} \mathrm{C}$, and $1400^{\circ} \mathrm{C}$.

sintered at $1225^{\circ} \mathrm{C}$. Those of the $\mathrm{BaTiO}_{3}$ ceramics sintered at $1300^{\circ} \mathrm{C}, 1350^{\circ} \mathrm{C}$, and $1400^{\circ} \mathrm{C}$ are shown in Fig. 7. The electrical properties of these ceramics are summarized in Table 1 . The change to "soft" ferroelectrics with La content increase yields the increase in dielectric constant, the decrease in remanent polarization (Pr) and coercive force $(\mathrm{Ec})$, the slanted and slim P-E hysteresis loops, and the parabolic s-E loops in the PLZT(9.1/65/35) ceramics, compared with the PLZT(7/65/35) ceramics. In the case of $\mathrm{BaTiO}_{3}$ ceramics, ferroelectricity increases with the grain growth accompanying the higher sintering temperature. The increase in $\operatorname{Pr}$ and $\mathrm{d}_{33}$, the more distinct shrink around Ec in s-E loops with sintering temperature would be due to the increase of ferroelectricity. The low Ec in the $\mathrm{BaTiO}_{3}$ sintered at $1300^{\circ} \mathrm{C}$ is probably due to the 
slim P-E loop in weaker ferroelectricity and the low Ec in the $\mathrm{BaTiO}_{3}$ sintered at $1400^{\circ} \mathrm{C}$ is due to the high domain mobility in large grain ceramics. The higher dielectric constant in the $\mathrm{BaTiO}_{3}$ sintered at $1300^{\circ} \mathrm{C}$ compared with those in the $\mathrm{BaTiO}_{3}$ sintered at $1350^{\circ} \mathrm{C}$ and $1400^{\circ} \mathrm{C}$ is characteristic of $\mathrm{BaTiO}_{3}$ ceramics, and the similar results that $\mathrm{BaTiO}_{3}$ with grains with at around $1 \mu \mathrm{m}$ size have been reported thus far [23-25].

\begin{tabular}{lllll}
\hline & \multicolumn{2}{l}{ Dielectric constant $\operatorname{Pr}\left(\mu \mathrm{C} / \mathbf{c m}^{2}\right)$} & Ec $(\mathbf{k V} / \mathbf{c m})$ & $\mathbf{d}_{33}(\mathrm{pC} / \mathrm{N})$ \\
\hline PLZT(7/65/35) & 2464 & 15.5 & 6.9 & 490 \\
\hline PLZT(9.1/65/35) & 5564 & 2.4 & 2.3 & 37 \\
\hline BT sintered at $1300^{\circ} \mathrm{C}$ & 3927 & 4.7 & 3.3 & 97 \\
\hline BT sintered at $1350^{\circ} \mathrm{C}$ & 1966 & 7.1 & 4.5 & 126 \\
\hline BT sintered at $1400^{\circ} \mathrm{C}$ & 1591 & 7.2 & 3.2 & 137 \\
\hline
\end{tabular}

Table 1. Electrical properties of PLZT and $\mathrm{BaTiO}_{3}$ ceramics

\subsection{Indirect estimation}

The $\mathrm{dP} / \mathrm{dT}$ between $10^{\circ} \mathrm{C}$ and $100^{\circ} \mathrm{C}$ for the $\mathrm{PLZT}$ and $\mathrm{BaTiO}_{3}$ ceramics were calculated using $\mathrm{P}$-E hysteresis loops. Estimated $\Delta \mathrm{T}$ for from Equation (1) for these ceramics are shown in Table 2. Among the ceramics, PLZT(9.1/65/35), which contains relaxor behavior by introducing Lanthanum substitution, estimated the largest temperature change. Among the $\mathrm{BaTiO}_{3}$ ceramics, the $\mathrm{BaTiO}_{3}$ sintered at $1400^{\circ} \mathrm{C}$ with large grains and accompanying strong ferroelectricity estimated the largest temperature change.

\begin{tabular}{llll}
\hline Samples & $\mathrm{dP} / \mathrm{dT}\left(\mu \mathrm{Ccm}^{-2} \mathrm{~K}^{-1}\right)$ & Estimated $\Delta \mathrm{T}(\mathrm{K})$ & Measured $\Delta \mathrm{T}(\mathrm{K})$ \\
\hline PLZT $(7 / 65 / 35)$ & -0.031 & 0.35 & 0.07 \\
\hline PLZT $(9.1 / 65 / 35)$ & -0.051 & 0.58 & 0.26 \\
\hline BT sintered at $1300^{\circ} \mathrm{C}$ & -0.030 & 0.29 & 0.12 \\
\hline BT sintered at $1350^{\circ} \mathrm{C}$ & -0.026 & 0.25 & 0.08 \\
\hline BT sintered at $1400^{\circ} \mathrm{C}$ & -0.037 & 0.36 & 0.29 \\
\hline
\end{tabular}

Table 2. Electrocaloric properties of PLZT and $\mathrm{BaTiO}_{3}$ ceramics

\subsection{Direct measurement}

Figures 6 and 7 contain s-E loops and T-E loops of the PLZT and $\mathrm{BaTiO}_{3}$ ceramics. The similar shapes between s-E loops and T-E loops are observed in these samples. The similar results were reported by J. Wang et al. and our previous report. Field-induced displacement derives from the change in the polarization, and the appearance of similar loops is reasonable. The 


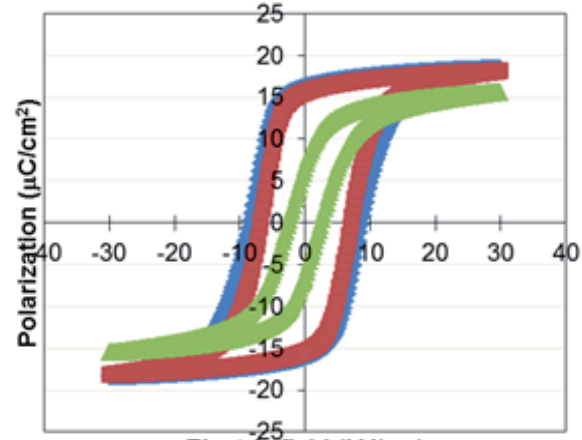

Electric field $(\mathrm{kV} / \mathrm{cm})$

$\bullet 10 \mathrm{C}=27 \mathrm{C} \triangle 100 \mathrm{C}$

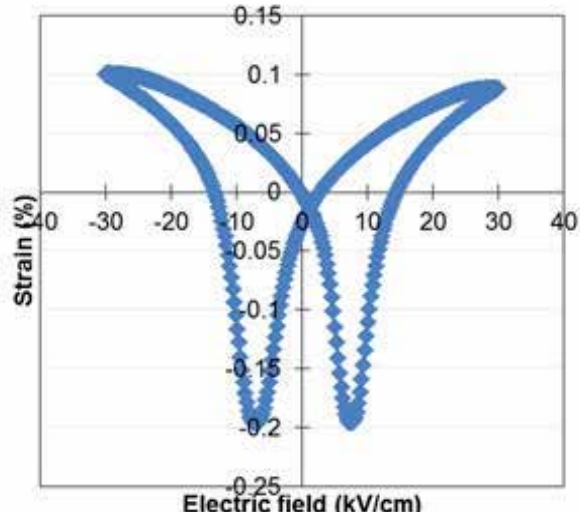

Electric field $(\mathrm{kV} / \mathrm{cm})$

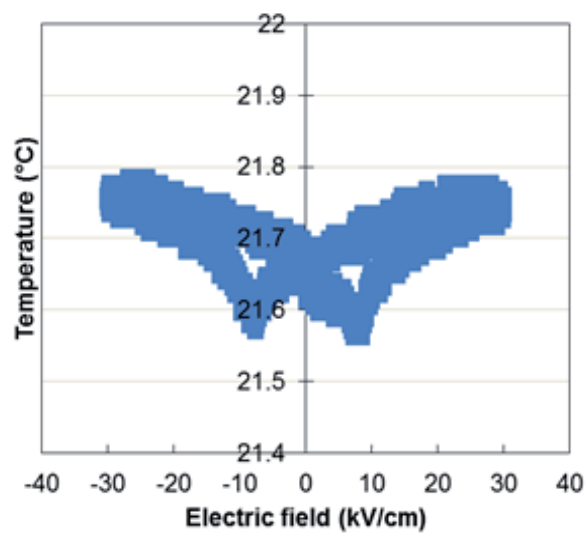

(a) PLZT(7/65/35) ceramics

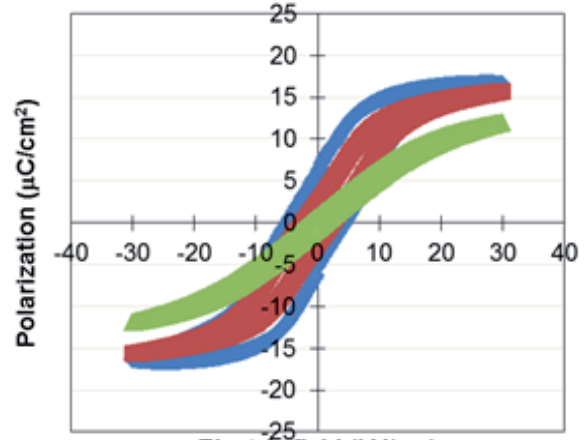

Electric field $(\mathrm{kV} / \mathrm{cm})$

$\rightarrow 10 \mathrm{C}=27 \mathrm{C} \triangle 100 \mathrm{C}$
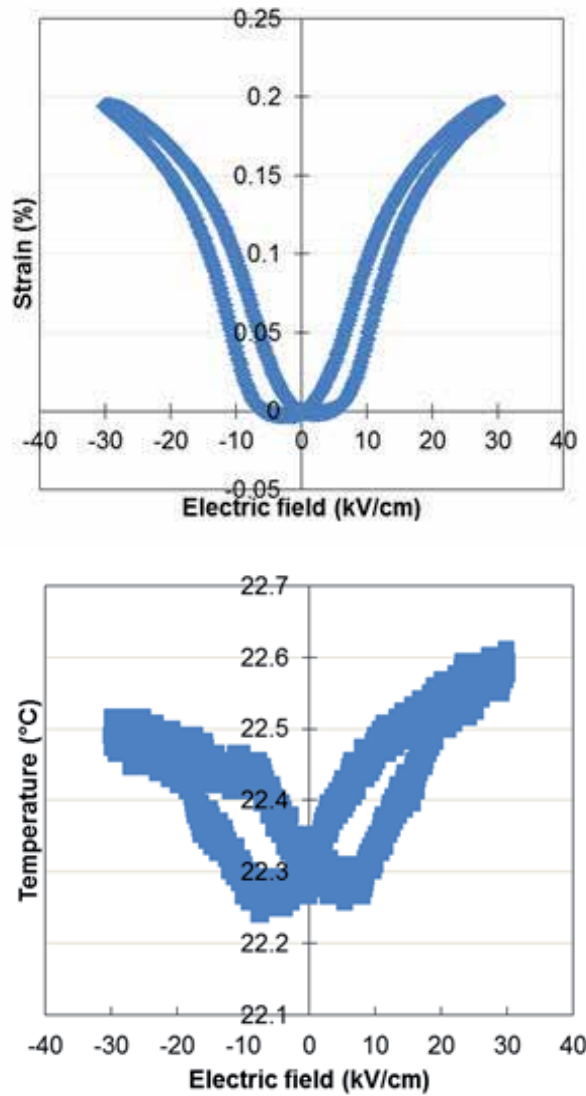

(b) PLZT(9.1/65/35) ceramics

Figure 6. Polarization-electric field (P-E) loops (above), strain-electric field (s-E) loop (middle), and temperature-electric field (T-E) loop (below) of the PLZT(7/65/35) and PLZT(9.1/65/35) ceramics sintered at $1225^{\circ} \mathrm{C}$. 

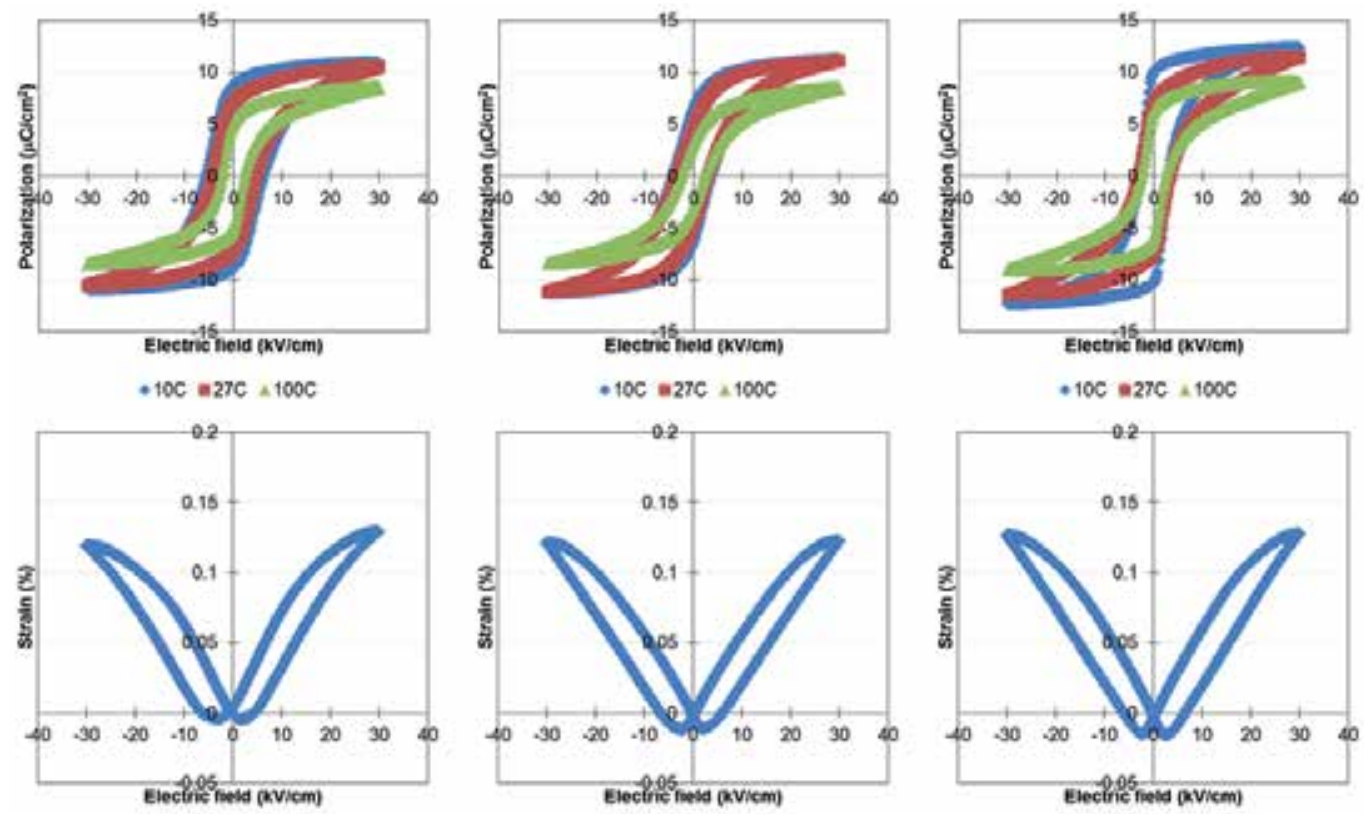

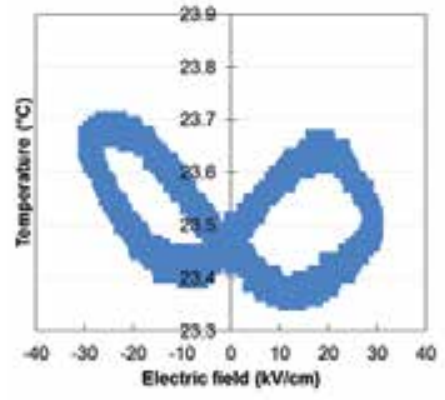

(a) BT ceramics $1300^{\circ} \mathrm{C}$

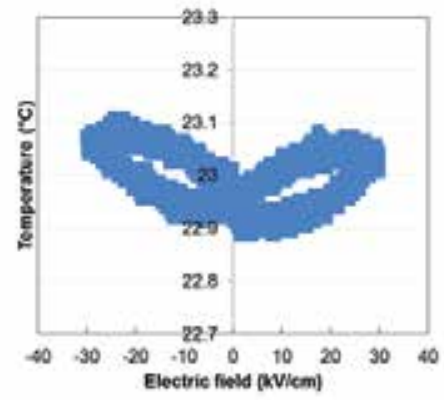

(b) BT ceramics $1350^{\circ} \mathrm{C}$

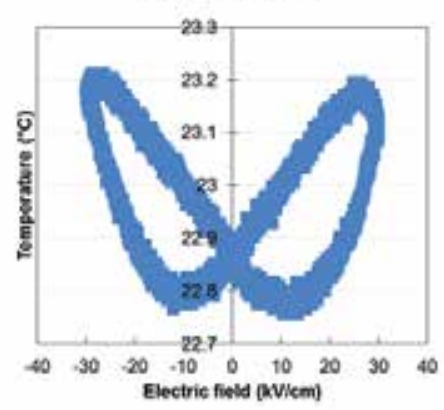

(c) BT ceramics $1400^{\circ} \mathrm{C}$

Figure 7. Polarization-electric field (P-E) loops (above), strain-electric field (s-E) loop (middle), and temperature-electric field (T-E) loop (below) of the $\mathrm{BaTiO}_{3}$ ceramics sintered at $1300^{\circ} \mathrm{C}, 1350^{\circ} \mathrm{C}$, and $1400^{\circ} \mathrm{C}$.

temperature change $\Delta \mathrm{T}$ of the samples was calculated from the slope beginning with maximum field and ending at the zero field. The temperature change, $\Delta \mathrm{T}$, in PLZT(9.1/65/35) ceramics induced by bipolar switching field of $30 \mathrm{kV} / \mathrm{cm}$ was $0.26 \mathrm{~K}$, and that in the $\mathrm{BaTiO}_{3}$ sintered at $1400{ }^{\circ} \mathrm{C}$ by bipolar switching field of $30 \mathrm{kV} / \mathrm{cm}$ was $0.29 \mathrm{~K}$. The round T-E and s-E shapes around polarization switching observed in the loop from PLZT(9.1/65/35) attributes characteristic of relaxor ferroelectric materials. The decreasing transition temperature and increasing the polarization movements in relaxor ferroelectrics provide larger temperature change.

The direct measurement shows smaller values, compared with the estimation, generally. The reasons are unknown at present; heat dissipation may play a role in real systems. Although quantitative consistency is not obtained, it is safe to say that the materials with large $\mathrm{dP} / \mathrm{dT}$ provided large temperature change generally. 


\section{Conclusion}

The electrocaloric properties of $(\mathrm{Pb}, \mathrm{La})(\mathrm{Zr}, \mathrm{Ti}) \mathrm{O}_{3}(\mathrm{PLZT})$ and $\mathrm{BaTiO}_{3}$ ceramics were investigated by the indirect estimation and direct measurement of temperature-electric field (T-E) hysteresis loops. The measured T-E loops showed a similar shape to strain-electric field (s-E) loops. This suggests the ECE of these materials are mainly governed by the change of their polarization. The extrinsic contribution from the multi-domain behavior to ECE is limited. The adiabatic temperature change $\Delta \mathrm{T}$ due to electrocaloric effects was estimated from the polarization change of these samples. $\Delta \mathrm{Ts}$ of 0.58 and $0.36 \mathrm{~K}$ were estimated for the $(\mathrm{Pb}, \mathrm{La})$ $(\mathrm{Zr}, \mathrm{Ti}) \mathrm{O}_{3}(\mathrm{PLZT})(9.1 / 65 / 35)$ ceramics and $\mathrm{BaTiO}_{3}$ ceramics sintered at $1400^{\circ} \mathrm{C}$, respectively. The measured temperature changes, $\Delta \mathrm{Ts}$, in these samples upon the release of the electric field from $30 \mathrm{kV} / \mathrm{cm}$ to zero were 0.26 and $0.29 \mathrm{~K}$, respectively.

\section{Acknowledgements}

This study is partly supported by grant from KAKENHI Grant Number. 26420684, GRENE (Green Network of Excellence) project from The Ministry of Education, Culture, Sports, Science and Technology, Japan, and Kato Science Foundation.

\section{Author details}

Hiroshi Maiwa* $^{*}$

Address all correspondence to: maiwa@mate.shonan-it.ac.jp

Department of Materials and Human Environmental Sciences, Shonan Institute of Technology, Fujisawa, Kanagawa, Japan

\section{References}

[1] Correia T and Zhang Q editors: Electrocaloric materials, Springer, 2014. p.1-12. DOI: 10.1007/978-3-642-40264-7

[2] Lines ME and Glass AM: Principles and applications of ferroelectrics and related materials, Clarendon press, Oxford, 1977; 148-150

[3] Moya X, Kar-Narayan S, Mathur ND: Caloric materials near ferroic phase transitions. Nat. Mater., 2014;13:439-450. DOI: 10.1038/nmat3951 
[4] Valant M: Electrocaloric materials for future solid-state refrigeration technologies. Prog. Mater. Sci., 2012;57: 980-1009. DOI: 10.1016/j.pmatsci.2012.02.001

[5] Kobeko P and Kurtschatov J: Dielectriche Eigenshaften der Seignettesalykristalle. Zeit. Phys.,.1930;66:192

[6] Mischenko AS, Zhang Q, Scott JF, Whatmore RW and Mathur ND: Giant electrocaloric effect in thin-film $\mathrm{PbZr}_{0.95} \mathrm{Ti}_{0.05} \mathrm{O}_{3}$.Science, 2006;311: 1270-1271. DOI: 10.1126/ science.1123811

[7] Tuttle BA and Payne DA: The effects of microstructure on the electrocaloric properties of $\mathrm{Pb}(\mathrm{Zr}, \mathrm{Sn}, \mathrm{Ti}) \mathrm{O}_{3}$ ceramics, Ferroelectr., 1981;37: 603-606. DOI: 10.1080/ 00150198108223496

[8] Chukka R, Cheah JW, Chen Z, Yang P, Shannigrahi S, Wang J, Chen L: Enhanced cooling capacities od ferroelectric materials at morphotropic phase boundary. Appl. Phys. Lett.,2011;98:242902. DOI: 10.1063/1.3595344

[9] Zhang R, Peng D, Xiao D, Wang Y, Zhu J, Yu P, Zhang W: Preparation and Characterization of (1-x) $\mathrm{Pb}\left(\mathrm{Mg}_{1 / 3} \mathrm{Nb}_{2 / 3}\right) \mathrm{O}_{3}-\mathrm{xPbTiO}_{3}$ electrocaloric ceramics. Crys. Res. Technol.,1998;33: $\quad$ 827-832. $\quad$ DOI: $\quad$ 10.1002/(SICI)1521-4079(1998)33:5<827::AIDCRAT827>3.0.CO;2-H

[10] Shebanovs L, Borman K, Lawless WN, Kalvane A: Electrocaloric effect in some perovskite ferroelectric ceramics and multilayer capacitor. Ferroelectr., 2002;273: 137142. DOI: $10.1080 / 00150190211761$

[11] Mischenko AS, Zhang Q, Whatmore RW, Mathur ND: Giant electrocaloric effect in the thin film relaxor ferroelectric $0.9 \mathrm{PbMg}_{1 / 3} \mathrm{Nb}_{2 / 3} \mathrm{O}_{3}-0.1 \mathrm{PbTiO}_{3}$ near room temperature. Appl. Phys. Lett, 2006;89: 242912. DOI: 10.1063/1.2405889

[12] Lin GC, Xiong XM, Zhang JX, Wei Q: Latent heat study of phase transition in $\mathrm{Ba} 0_{.73} \mathrm{Sr}_{0.27} \mathrm{TiO}_{3}$ induced by electric field. J. Therm. Anal. Calor, 2005;81:41-44. DOI: 10.1007/s10973-005-6369-5

[13] Kar-Narayan S and Mathur ND: Direct and indirect electrocalorc measurements using multilayer capacitor. J Phys. D: Appl. Phys, 2010;43: 032002. DOI: 10.1088/0022-3727/43/3/032002

[14] Chen H, Ren TL, Wu XM, Yang Y, Liu LT: Giant electrocaloric effect in lead-free film of strontium bismuth tantalite. Appl. Phys. Lett, 2009;94:182902. DOI: $10.1063 / 1.3123817$

[15] Neese B, Chu B, Lu SG, Wang Y, Furman E, Zhang QM: Large electrocaloric effect in ferroelectric polymers near room temperature, Science, 2008; 321: 821-823. DOI: 10.1126/science. 1159655 
[16] Lu SG, Rožič B, Zhang QM, Kutnjal Z, Pirc R, Lin M, Li X, Gorny L: Comparison of directly and indirectly measured electrocaloric effect in relaxor ferroelectric polymer. Appl. Phys. Lett. 2010; 97: 202901. DOI: 10.1063/1.3514255

[17] Lu SG, Rožič B, Zhang QM, Kutnjal Z, Neese B: Enhanced electrocaloric effect in ferroelectric poly(vinylidene-fluoride/trifluoroethylene) 55/45 mol\% copolymer at ferroelectric-paraelectric transition. Appl. Phys. Lett, 2011; 98: 122906. DOI: $10.1063 / 1.3569953$

[18] Weisman GG, IEEE Trans. Electron Devices, 1969; ED-16: 588

[19] Wang J, Yang T, Wei K, and Yao X: Temperature-electric field hysteresis loop of electrocaloric effect in ferroelectricity - Direct measurement and analysis of electrocaloric effect. I. Appl. Phys. Lett. 2013;102: 152907. DOI: 10.1063/1.4801997

[20] Maiwa H: Characterization of electrocaloric properties by indirect estimation and direct measurement of temperature-electric field hysteresis loops. Jpn. J. Appl. Phys. 2015;54: 10NB08. DOI: 10.7567/JJAP.54.10NB08

[21] Maiwa H: Pyroelectric and electrocaloric properties of PZT- and BT-based ceramics. Ferroelectr., 2013;450: 84-92. DOI: 10.1080/00150193.2013.838497

[22] Maiwa H, Jia TT, and Kimura H: Energy harvesting using PLZT and lead-free ceramics and their piezoelectric properties on the nano scales. Ferroelectr., 2015;475: 71-81. DOI: $10.1080 / 00150193.2015 .995518$

[23] Kinoshita K, Yamaji A: Grain-size effects on dielectric properties in barium titanate ceramics. J. Appl. Phys., 1976;47: 371-373. DOI: 10.1063/1.322330

[24] Arlt G, Hennings D, De With G: Dielectric properties of fine-grained barium titanate ceramics. J. Appl. Phys., 1985;58: 1619-1925. DOI: 10.1063/1.336051

[25] Maiwa H: Advances in ceramics - Electric and magnetic ceramics, bioceramics, ceramics and environment. InTech, 2011; p.3-22. 



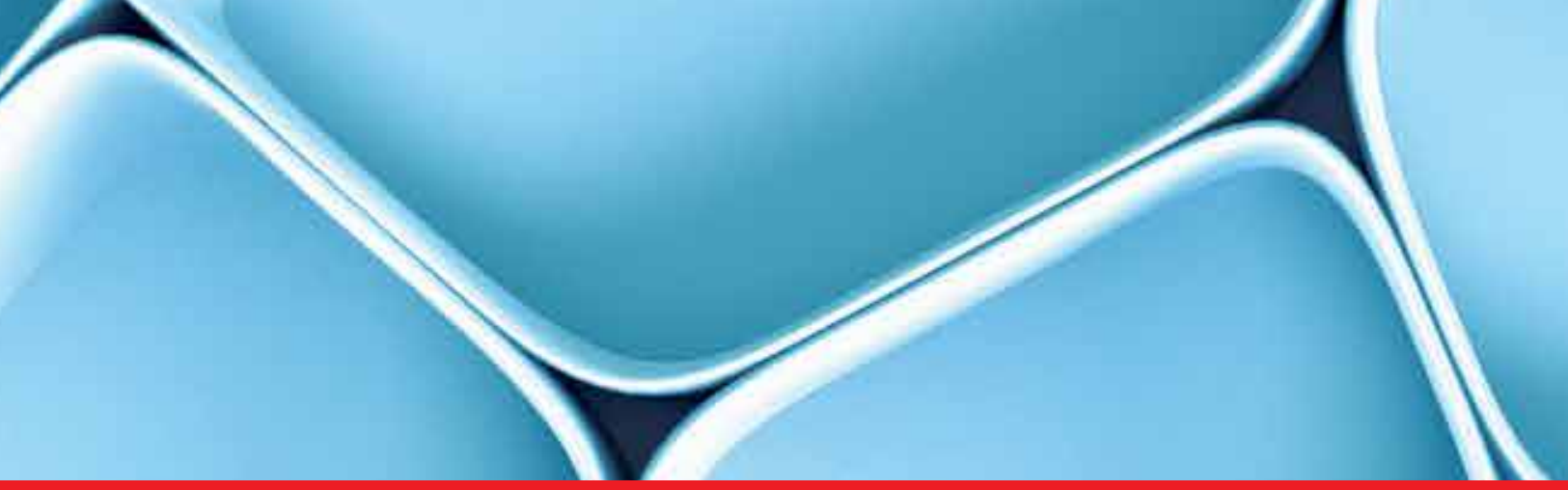

\section{Edited by Adel Mohamed}

Ceramic oxides typically have a combination of properties that make them attractive for many applications compared with other materials. This book attempts to compile, unify, and present a recent development for the production techniques, such as electrochemical, foaming, and microwave sintering, of rare earth ceramic oxide materials. This book presents leading-edge research in this field from around the world. Although there is no formal partition of the book, the chapters cover several preparation methods for ceramic oxides, especially for coating and electrical applications. In addition, a fabrication foaming technique for porous ceramics with tailored microstructure along with distinctive properties is provided. The information provided in this book is very useful for a board of scientists and engineers from both academia and industry.

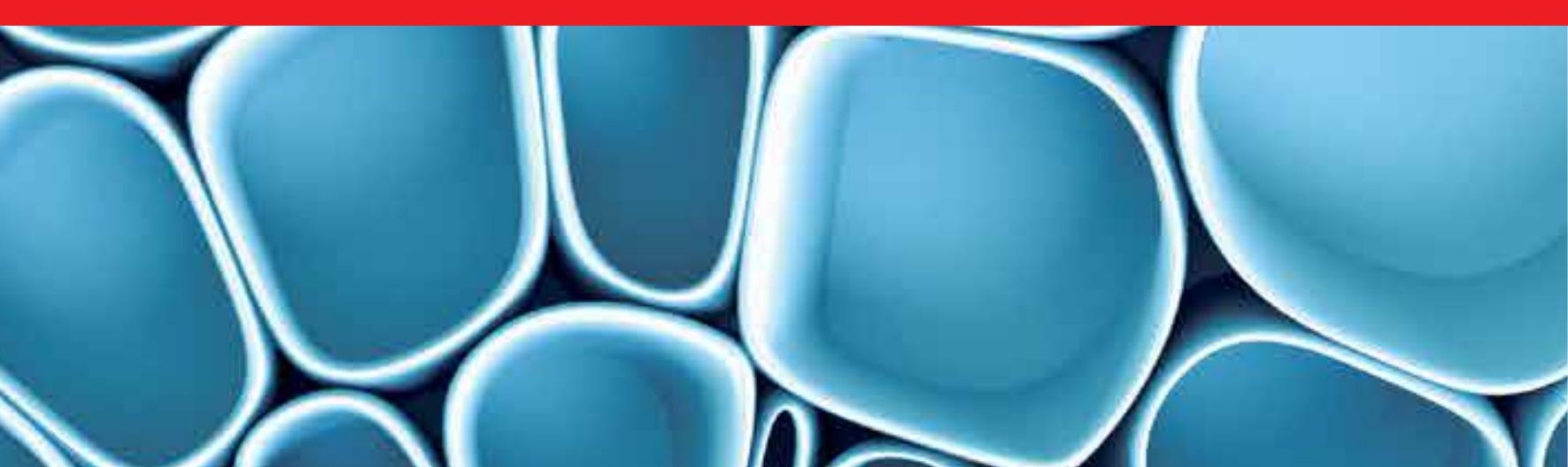

